STERGIOS PERICLES TSILOUFAS

ESTUDO DA FRATURA DÚCTIL EM CHAPAS DE AÇO MÉDIO CARBONO SOB A ÓTICA DA TEORIA DA MECÂNICA DO DANO 
STERGIOS PERICLES TSILOUFAS

\section{ESTUDO DA FRATURA DÚCTIL EM CHAPAS DE AÇO MÉDIO CARBONO SOB A ÓTICA DA TEORIA DA MECÂNICA DO DANO}

Dissertação apresentada à Escola Politécnica da Universidade de São Paulo para obtenção do título de Mestre em Ciências 


\title{
ESTUDO DA FRATURA DÚCTIL EM CHAPAS DE AÇO MÉDIO CARBONO SOB A ÓTICA DA TEORIA DA MECÂNICA DO DANO
}

\author{
Dissertação apresentada à Escola Politécnica da \\ Universidade de São Paulo para obtenção do tí- \\ tulo de Mestre em Ciências \\ Área de Concentração: Eng. Metalúrgica e \\ de Materiais
}

Orientador: Prof. Dr. Ronald Lesley Plaut 
Este exemplar foi revisado e alterado em relação à versão original, sob responsabilidade única do autor e com a anuência de seu orientador.

São Paulo, 13 de novembro de 2012

Stergios Pericles Tsiloufas

Ronald Lesley Plaut

\section{FICHA CATALOGRÁFICA}

\section{Tsiloufas, Stergios Pericles}

Estudo da fratura dúctil em chapas de aço médio carbono sob a ótica da mecânica do dano / S.P. Tsiloufas. - ed. rev. - São Paulo, 2012.

$163 \mathrm{p}$.

Dissertação (Mestrado) - Escola Politécnica da Universidade de São Paulo. Departamento de Engenharia Metalúrgica e de Materiais.

1. Mecânica do dano 2. Conformação mecânica 3. Ensaios mecânicos 4. Método dos elementos finitos 5. Materiais metalicos I. Universidade de São Paulo. Escola Politécnica. Departamento de Engenharia Metalúrgica e de Materiais II. t. 
Dedico este trabalho ao meu avô, Stergios, imigrante, autodidata e inspirador da terceira geração de engenheiros da família. 


\section{AGRADECIMENTOS}

Agradeço à família, sempre. Agradeço a Pericles, meu pai, engenheiro e exemplo como homem; a Idalina, minha mãe, pelo apoio e orientação nas decisões que tomei; meus irmãos Georgios e Thalles, a melhor companhia que alguém poderia ter no cotidiano agitado de São Paulo; Marcela, sempre atenciosa e carinhosa, me trazendo de volta ao mundo real; aos avós Stergios, Loris e Ana, deseducadores na medida certa, e ao restante de minha enorme família, pelo suporte, atenção e acolhimento, seja na capital, seja no interior.

Ao Prof. Dr. Ronald Lesley Plaut, sempre disponível e atencioso na orientação no trabalho, ágil na revisão dos textos e instigador de um trabalho que honre as tradições desta Escola.

Aos meus colegas: Bruno Carmo, Alessandro Lima, Iago Barbeiro, Pedro Lavinas, Ádson de Paula, Rodrigo Provasi, Rafael Nemoto, Rafael Gioria, Reinaldo Orselli, Eduardo Malta, Alfredo Gay Neto, Fernanda Takafuji, Ivan Korkischko, Fabiano Imada, Guilherme Franzini, André Bonatto, Gustavo Assi, Sérgio Pellegrini, Renato Neves e Amin Assad, responsáveis por tornar o ambiente de trabalho um ambiente de amizade e, por que não, de descontração.

Ao amigo e companheiro de caronas César Monzú Freire, pelo auxílio com a rotina de reconhecimento de imagens e, principalmente, pelas incontáveis discussões teóricas em meio ao trânsito caótico de São Paulo,

Quanto à parte técnica do trabalho, agradeço à Brasmetal Waelzholz, por gentilmente ceder as chapas metálicas que serviram como matéria prima para o estudo. Atenção especial a Daniel Augusto Ferro e Francisco Clayton de Oliveira Silva, por dispor de seu tempo para ajuda com micrografias e ensaios. À Rafael Celeghini Santiago e Caio Cesar Fukumori Brasilino, do Grupo de Mecânica dos Sólidos e Impacto em Estruturas, pelo auxílio nos ensaios de tração para caracterização dos materiais. Ao fórum online "Eng. Tips" e todos os colaboradores, sempre dispostos a auxiliar programadores inexperientes perdidos com os segredos dos Abaqus.

À Escola Politécnica em geral; professores, funcionários e colegas. Responsáveis pela minha formação acadêmica e humanística durante estes 7 anos e meio ininterruptos de convivência. O sonho de tantos se torna realidade para mim, e espero retribuir para a sociedade os frutos que ela semeou investindo no autor deste trabalho. 
"É tarefa da ciência reduzir as verdades profundas a trivialidades."

Niels Bohr (1949) 


\section{RESUMO}

Este trabalho busca avaliar a ductilidade de ligas metálicas utilizando como ferramenta a teoria da mecânica do dano proposta por Kachanov e desenvolvida por Lemaitre, a qual é apresentada desde as hipóteses básicas até as equações que modelam a deterioração de um material em regime de fratura dúctil. Como o enfoque do trabalho é a predição de trincas em processos de conformação mecânica, em especial estampagem de chapas, o mecanismo de formação destes defeitos é revisado, buscando na literatura o entendimento de como os parâmetros microestruturais influenciam na fratura dúctil.

Ensaios de tração foram efetuados em corpos de prova retirados de chapas de aço SAE 1050 em duas condições microestruturais, cementita esferoidizada em matriz ferrítica e ferritaperlita, e em duas direções em relação à laminação da chapa original, paralelo e transversal. A evolução do dano foi medida de maneira indireta por meio da variação do módulo elástico e as propriedades mecânicas necessárias para utilização do modelo de Lemaitre foram calculadas.

Por meio de difração de raios X, efetuamos o estudo da evolução da textura cristalográfica, apresentado na forma de figuras de distribuição de orientação e análise da intensidade das principais fibras encontradas em aços laminados a quente. Não foi observada influência significativa do tipo de microestrutura e da direção de deformação na evolução da textura.

Por fim, o modelo de evolução de dano de Lemaitre foi transformado em um algoritmo numérico e implementado no código comercial Abaqus, em sua versão explícita, por meio do uso da subrotina VUMAT. Resultados foram obtidos e comparados com os experimentos, validando a aplicação do modelo.

A evolução do dano para o aço SAE 1050 também foi comparada com resultados para outros aços ao manganês encontrados na literatura. Relações empíricas entre o teor de carbono e parâmetros como a deformação limite para início do dano, resistência à evolução do dano e dano máximo suportado foram desenvolvidas e apresentadas, com o intuito de funcionar como guias gerais para cálculo sem a necessidade de uma bateria de ensaios dedicados, facilitando a utilização da teoria da mecânica do dano em condições industriais.

Palavras-chave: Mecânica do dano, conformação mecânica, ensaios mecânicos, método dos elementos finitos, materiais metálicos 


\section{ABSTRACT}

The aim of the present work is to evaluate the ductility of metallic alloys employing the theory of damage mechanics as suggested by Kachanov and developed by Lemaitre, which is presented since its basic hypothesis until the equation that model the material deterioration under a regime of ductile fracture. As the focus of the work is the fracture prediction during mechanical working processes (mainly sheet metal stamping), the mechanism of formation of these defects is revised, based upon literature data, aiming at the understanding of how the material microstuctural parameters influence ductile fracture.

Tensile tests have been performed on samples obtained from SAE 1050 steel sheets for two microstructural conditions namely spheroidized cementite and regular ferrite-perlite for two rolling directions (rolling and transverse directions). In those tests, damage evolution has been measured indirectly through the materials variation in the Young modulus with strain, obtaining the mechanical properties, needed to be used in the calculation of Lemaitre's model.

Through X-ray diffraction measurements, the crystallographic texture evolution, presented in the form of orientation distribution functions and the associated fiber intensities observed for both microstuctural conditions, has been evaluated. No major influence has been observed in this texture evolution, for the tested conditions.

Finally, the Lemaitre damage evolution model has been transformed into a numerical algorithm and implemented in the Abaqus commercial code, in its explicit form, through the VUMAT sub-routine. Results have been obtained and compared with the experimental values, validating the suggested model.

Damage evolution for the SAE 1050 steel has been also compared with results from literature for other C-Mn steels. Empirical relationships between $\mathrm{C}$ level and damage parameters such as limit strain for damage initiation, resistance to damage evolution and maximum allowable damage, have been developed and presented, envisaging their application as general guidelines, without requiring a sequence of dedicated tests, making easier the usage of damage mechanics under industrial conditions.

Keywords: Continuum damage mechanics, mechanical conformation, mechanical testing, finite element method, metallic material 


\section{LISTA DE FIGURAS}

Figura - 1.1 Macroestruturas típicas de peças fabricadas por fundição, usinagem e conformação. Adaptado de Jeswiet et al. (2008).

Figura - 1.2 Evolução do número típico de peças em diversos produtos manufaturados após a revolução industrial. Adaptado de Jeswiet et al. (2008).

Figura - 2.1 Componentes de uma tensão atuando no ponto O. Adaptado de Timoshenko e Goodier (1951).

Figura - 2.2 Variação da deformação na fratura com a relação de triaxialidade do estado de tensões (BAO; WIERZBICKI, 2004).

Figura - 2.3 Caminhos de deformação para diversos tipos de carregamento no estado planar de tensões, caracterizados pela relação de triaxialidade $\eta=\sigma_{H} / \sigma_{e q}$. Adap-

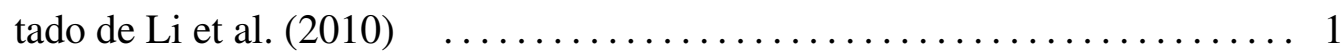

Figura - 2.4 Área danificada em uma seção do elemento volumétrico. $\ldots \ldots \ldots \ldots \ldots 11$

Figura - 2.5 Mudança do módulo de elasticidade equivalente no ensaio de tração do cobre 99,9\% (LEMAITRE, 1984).

Figura - 2.6 Esquema ilustrativo do local geométrico da tensão de escoamento no espaço das tensões principais para um caso de tensão plana, mostrando os efeitos do encruamento isotrópico e cinemático.

Figura - 2.7 Evolução do dano no ensaio de tração a do cobre 99,9\% (LEMAITRE, 1984).

Figura - 3.1 Micrografia eletrônica da superfície de fratura de um corpo de prova de ensaio de tenacidade ilustrando o coalescimento dos vazios, formando os chamados dimples. (GARRISON JR.; MOODY, 1987)

Figura - 3.2 Curva tensão-deformação de engenharia retirada de um ensaio de tração genérico e principais propriedades medidas.

Figura - 4.1 Micrografia das ligas 1050 utilizadas nos ensaios de tração. Aumento de 1000 vezes. Ataque utilizado é nital a 3\%. (a) Material esferoidizado. (b) Material laminado a quente.

Figura - 4.2 Evolução do dano medido diretamente pela fração de vazios para ligas de aço 
esferoidizadas. Adaptado de Le Roy et al. (1981).

Figura - 4.3 Variação do módulo de elasticidade para as ligas SAE 1020 e SAE 1045. Adaptado de Celentano, Tapia e Chaboche (2004) e Celentano e Chaboche (2007).

Figura - 4.4 Gravador eletroquímico, líquido de neutralização e líquido de gravação utilizados na marcação eletroquímica.

Figura - 4.5 Círculos marcados por gravação eletroquímica no corpo de prova.

Figura - 4.6 Equipamento utilizado nos ensaios de tração. (a) Vista geral da máquina universal de ensaios. (b) Detalhe do extensômetro montado no corpo de prova.

Figura - 4.7 Curvas tensão de engenharia versus deformação de engenharia. (a) CP1- $0^{\circ}$. (b) $\mathrm{CP} 2-0^{\circ}$. (c) $\mathrm{CP} 3-0^{\circ}$. (d) $\mathrm{CP} 4-0^{\circ}$. (e) $\mathrm{CP} 2-90^{\circ}$. (f) $\mathrm{CP} 4-90^{\circ}$. 46

Figura - 4.8 Detalhe da curva tensão de engenharia versus deformação de engenharia, mostrando a histerese no ciclo de carregamento/descarregamento. Material: aço SAE 1050 esferoidizado.

Figura - 4.9 Diferença no módulo elástico medido no carregamento e descarregamento. Material: aço SAE 1050 laminado a quente, ensaio de tração na direção de laminação da chapa $\left(\mathrm{CP} 4-0^{\circ}\right)$.

Figura - 4.10 Evolução do módulo de elasticidade do material com a deformação em um ensaio de tração. (a) $\mathrm{CP} 1-0^{\circ}$. (b) $\mathrm{CP} 2-0^{\circ}$. (c) $\mathrm{CP} 3-0^{\circ}$. (d) $\mathrm{CP} 4-0^{\circ}$. (e) $\mathrm{CP} 2-$ $90^{\circ}$. (f) $\mathrm{CP} 4-90^{\circ}$.

Figura - 4.11 Decaimento não linear do módulo de elasticidade em baixas deformações plásticas para ligas de aço (MORESTIN; BOIVIN, 1996).

Figura - 4.12 Comparação da evolução do módulo de elasticidade com a deformação para o ferro puro (BENITO et al., 2005) e os aços SAE 1020 laminado a quente (CELENTANO; CHABOCHE, 2007), SAE 1045 laminado a quente (CELENTANO; TAPIA; CHABOCHE, 2004) e SAE 1050 laminado a quente e esferoidizado (presente trabalho).

Figura - 4.13 Curva tensão real versus deformação plástica real. Dados experimentais e equação de Ludwig ajustada. (a) $\mathrm{CP} 1-0^{\circ}$. (b) $\mathrm{CP} 2-0^{\circ}$. (c) $\mathrm{CP} 3-0^{\circ}$. (d) $\mathrm{CP} 4-$ $0^{\circ}$. (e) $\mathrm{CP} 2-90^{\circ}$. (f) $\mathrm{CP} 4-90^{\circ}$.

Figura - 4.14 Evolução do dano com a deformação real. Aço SAE 1050. (a) Esferoidizado, $0^{\circ}$. (b) Esferoidizado, $90^{\circ}$. (c) Laminado a quente, $0^{\circ}$. (d) Laminado a quente $90^{\circ}$. 
Figura - 4.15 Fotografia utilizada para identificação dos círculos.

Figura - 4.16 Círculos identificados por meio da rotina computacional e seus respectivos raios na região não deformada do corpo de prova. $\ldots \ldots \ldots \ldots \ldots \ldots$

Figura - 4.17 Elipses identificadas pela rotina de análise de imagens. $\ldots \ldots \ldots \ldots \ldots 64$

Figura - 4.18 Deformação longitudinal em função da posição no ensaio de tração. $\quad \ldots \ldots 65$

Figura - 4.19 Deformação longitudinal em função da deformação transversal no ensaio de

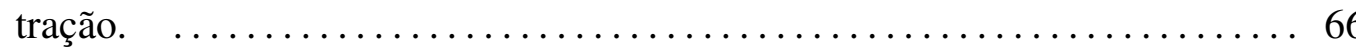

Figura - 4.20 Esboço de critérios para determinação de instabilidade e localização durante a fratura de chapas. Direções 1, 2 e 3 são, respectivamente, longitudinal, transversal e normal ao plano da chapa. (a) Critério de Stören e Rice (1975). (b) Critério de Bressan e Williams (1983).

Figura - 4.21 Caminhos de deformação para diversos tipos de carregamento no estado planar de tensões, caracterizados pela relação de triaxialidade $\eta=\sigma_{H} / \sigma_{e q}$. Adap-

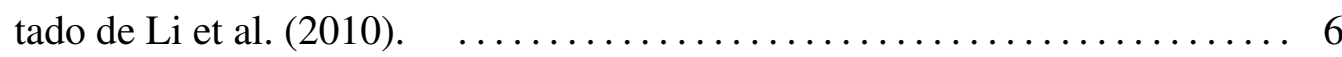

Figura - 4.22 Corpos de prova fraturados. Material esferoidizado, $0^{\circ}$. (a), (b) Vista frontal.

Figura - 4.23 Corpos de prova fraturados. Material laminado a quente, $0^{\circ}$. (a), (b) Vista

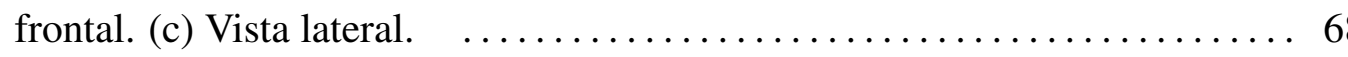

Figura - 5.1 Ângulos de Euler utilizados para compor uma função de distribuição de orientação (FDO). ........................................ 72

Figura - 5.2 FDO para uma amostra de aço SAE 1050 laminado a quente (PLAUT et al., 2009).

Figura - 5.3 FDO para uma amostra de aço médio carbono laminado a quente mostrando o aspecto das fibras $\gamma$ e $\alpha$ no diagrama. Adaptado de Storojeva et al. (2004).

Figura - 5.4 Figuras de distribuição de orientação para o aço SAE 1050 esferoidizado. (a) Amostra não deformada. (b) Amostra deformada a $0^{\circ}$. (c) Amostra deformada a $90^{\circ}$.

Figura - 5.5 Figuras de distribuição de orientação para o aço SAE 1050 laminado a quente. (a) Amostra não deformada. (b) Amostra deformada a $0^{\circ}$. (c) Amostra deformada a $90^{\circ}$.

Figura - 5.6 Evolução das fibras (a) $\gamma$, (b) $\gamma^{\prime}$ e (c) $\alpha$ para o aço SAE 1050 esferoidizado 
quando deformado nas direções de laminação $\left(0^{\circ}\right)$ e transversal $\left(90^{\circ}\right) . \quad \ldots \quad 78$

Figura - 5.7 Evolução das fibras (a) $\gamma$, (b) $\gamma^{\prime}$ e (c) $\alpha$ para o aço SAE 1050 laminado a quente quando deformado nas direções de laminação $\left(0^{\circ}\right)$ e transversal $\left(90^{\circ}\right) . \quad \ldots \quad 79$

Figura - 5.8 Posição dos picos de intensidade correspondentes às fibras $\gamma^{\prime}$, em vermelho, e $\alpha$, em azul.

Figura - 6.1 Evolução da fratura para um ensaio de tração de corpo de prova com furo. (a) Simulações. (b) Experimentos. (ABOUTALEBI; FARZIN; POURSINA, 2010). $\quad$. 81

Figura - 6.2 Fratura num ensaio de estampagem profunda. (a) Simulação. (b) Experimento. (KHELIFA; OUDJENE; KENNANE, 2007).

Figura - 6.3 Evolução da força no punção em função do deslocamento do mesmo em ensaio de compressão axial de um tubo de aço SAE 1020. (CELENTANO; CHABOCHE, 2007).

Figura - 6.4 Contornos da variável de dano no quarto estágio do forjamento do "duplo cálice". (a) Matrizes com geometrias originais. (b) Matrizes com geometrias modificadas (BEHRENS; JUST, 2002).

Figura - 6.5 Fluxograma da subrotina VUMAT para cálculo do dano com solver explícito. Ver mais detalhes no Apêndice D.

Figura - 6.6 Dimensões do corpo de prova utilizado nas simulações numéricas. Espessura é de $1,0 \mathrm{~mm}$.

Figura - 6.7 Curva tensão-deformação real para o aço SAE 1050 na direção de laminação.

(a) Liga esferoidizada. (b) Liga laminada a quente.

Figura - 6.8 Contornos de deformação longitudinal para a simulação corpo de prova laminado a quente no momento da fratura.

Figura - 6.9 Deformações ao longo da linha de simetria do corpo de prova no momento da fratura. (a) Caminho de deformações longitudinais e transversais. (b) Distribuição das deformações longitudinais em função da posição e comparação com resultados experimentais.

Figura - 6.10 Contornos real para o aço SAE 1050 esferoidizado. (a) Deformação longitudinal. (b) Dano. (c) Tensão verdadeira. (d) Tensão aparente.

Figura - 6.11 Contornos real para o aço SAE 1050 laminado a quente. (a) Deformação longitudinal. (b) Dano. (c) Tensão verdadeira. (d) Tensão aparente. . ..... 92

Figura - 6.12 Curva de evolução do dano para o aço SAE 1050 na direção de laminação. (a) Liga esferoidizada. (b) Liga laminada a quente. 
Figura - 6.13 Curva de evolução do fator de triaxialidade para o aço SAE 1050 na direção de laminação nas condições esferoidizado e laminado a quente.

Figura - 6.14 Contornos da variável de dano para o aço SAE 1050 esferoidizado. (a) Início da simulação. (b) $75 \%$. (c) $90 \%$. (d) $95 \%$ (e) $99 \%$. (f) $100 \%$. (g) Corpo de prova experimental.

Figura - 6.15 Contornos de deformação longitudinal para o aço SAE 1050 esferoidizado. (a) Início da simulação. (b) $75 \%$. (c) $90 \%$. (d) $95 \%$ (e) $99 \%$. (f) $100 \%$. . 97

Figura - 6.16 Contornos da variável de dano para o aço SAE 1050 laminado a quente. (a) Início da simulação. (b) $75 \%$. (c) $90 \%$. (d) $95 \%$ (e) 99\% (f) 100\%. (g) Corpo

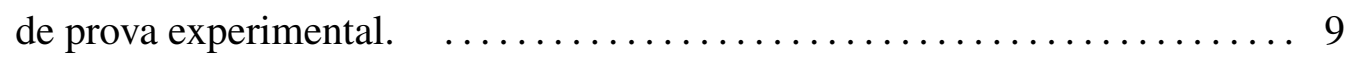

Figura - 6.17 Contornos de deformação longitudinal para o aço SAE 1050 laminado a quente. (a) Início da simulação. (b) $75 \%$. (c) $90 \%$. (d) $95 \%$ (e) $99 \%$. (f) $100 \%$.

Figura - 6.18 Curva de evolução do dano para aços carbono da série 10XX.

Figura - 6.19 Evolução do dano medido diretamente pela fração de vazios para ligas de aço esferoidizadas. Adaptado de Le Roy et al. (1981).

Figura - 6.20 Variação dos parâmetros de evolução do dano com o nível de carbono em aços da série SAE 10XX. (a) Deformação limite para surgimento do dano. (b) Parâmetro de resistência ao dano.

Figura - F.1 Importando modelo IGES.

Figura - F.2 Criação da malha.

Figura - F.3 Definição do modelo de material - variáveis definidas pelo usuário.

Figura - F.4 Definição do modelo de material - propriedades mecânicas.

Figura - F.5 Definição da montagem.

Figura - F.6 Definição da seção - tipo de elemento.

Figura - F.7 Definição da seção - associar material ao modelo.

Figura - F.8 Definição dos resultados a serem salvos.

Figura - F.9 Definição do step. 139

Figura - F.10 Definição da condição de contorno na garra esquerda. 140

Figura - F.11 Definição da condição de contorno na garra direita. 
Figura - F.12 Definição do deslocamento imposto à garra direita. $\quad \ldots \ldots \ldots \ldots \ldots \ldots \ldots 2$

Figura - F.13 Definição do job, com indicação do uso da subrotina VUMAT. ......... 143

Figura - F.14 Submetendo o caso para simulação. $\quad \ldots \ldots \ldots \ldots \ldots \ldots \ldots \ldots \ldots \ldots \ldots \ldots \ldots \ldots$ 


\section{LISTA DE TABELAS}

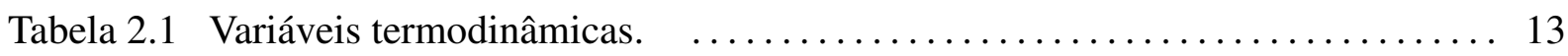

Tabela 2.2 Qualidade dos métodos de medição de dano. Adaptado de Racha (2008). . . 21

Tabela 3.1 Modos de falha em processos de conformação. (ASM HANDBOOK, 1996 25

Tabela 3.2 Critérios macroscópicos para fratura dúctil. $\quad \ldots \ldots \ldots \ldots \ldots \ldots \ldots \ldots \ldots$

Tabela 4.1 Dano crítico em ensaio de tração quasi-estático segundo diferentes técnicas de

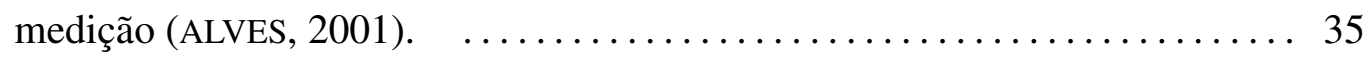

Tabela 4.2 Composição química do aço SAE 1050 (em porcentagem mássica). ...... 37

Tabela 4.3 Classificação dos corpos de prova. $\quad \ldots \ldots \ldots \ldots \ldots \ldots \ldots \ldots \ldots \ldots \ldots \ldots \ldots \ldots \ldots \ldots \ldots$

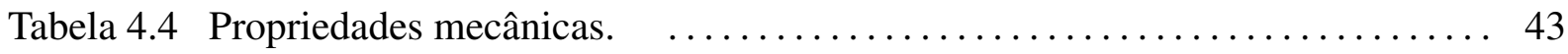

Tabela 4.5 Propriedades mecânicas das ligas SAE 1050 e 1055 segundo norma NBR 6662

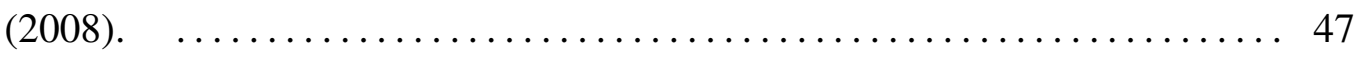

Tabela 4.6 Equações constitutivas do comportamento plástico (GRONOSTAJSKI, 2000). 54

Tabela 4.7 Propriedades do comportamento plástico. $\ldots \ldots \ldots \ldots \ldots \ldots \ldots \ldots \ldots . \ldots$

Tabela 4.8 Propriedades de evolução do dano, aço SAE $1050 . \quad \ldots \ldots \ldots \ldots \ldots \ldots \ldots \ldots 1$

Tabela 4.9 Propriedades mecânicas do aço SAE 1050 à temperatura ambiente. ...... 61

Tabela 4.10 Propriedades mecânicas de diversos materiais à temperatura ambiente. . . . 62

Tabela 4.11 Coeficientes da equação de Hollomon, aço SAE $1050 . \quad \ldots \ldots \ldots \ldots \ldots \ldots \ldots 66$

Tabela 4.12 Deformações críticas para fratura e ângulos da banda de ruptura. Comparação entre resultados analíticos e experimentais. ................. 69

Tabela 5.1 Orientações importantes na fibra $\gamma^{\prime}$. $\ldots \ldots \ldots \ldots \ldots \ldots \ldots \ldots \ldots \ldots \ldots \ldots \ldots \ldots \ldots \ldots \ldots \ldots$

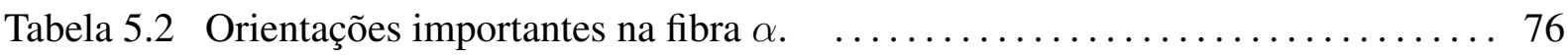

Tabela 6.1 Constantes da regressão exponencial das propriedades de evolução do dano com o nível de carbono dos aços da série SAE 10XX. $\ldots \ldots \ldots \ldots \ldots . \ldots 100$

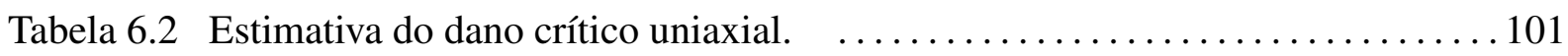




\section{LISTA DE SÍMBOLOS}

A Tensor de quarta ordem da elasticidade

$A_{0}, \tilde{A}, A_{d} \quad$ Área total, efetiva e de defeitos de uma superfície de um elemento sólido

D Variável contínua do dano

$D_{c} \quad$ Dano crítico

$D_{1 c} \quad$ Dano crítico no estado de tensões uniaxial

E Módulo elástico

$\tilde{E} \quad$ Módulo elástico efetivo

e Deformação de engenharia

I Tensor identidade

K Coeficiente de resistência plástica

$l \quad$ Comprimento útil do corpo de prova

$n \quad$ Coeficiente de encruamento

p Deformação plástica acumulada

$p_{D} \quad$ Deformação plástica acumulada limite para surgimento do dano

$R \quad$ Tensão de encruamento isotrópico

$r \quad$ Deformação plástica acumulada no dano

r Vetor posição de um ponto em um sólido

$R_{v} \quad$ Fator de triaxialidade

S Parâmetro de resistência ao dano

$s \quad$ Entropia

$s_{u} \quad$ Limite de resistência de engenharia

$s_{f} \quad$ Tensão de engenharia na fratura

T Temperatura

$\mathbf{u} \quad$ Vetor deslocamento de um ponto em um sólido 


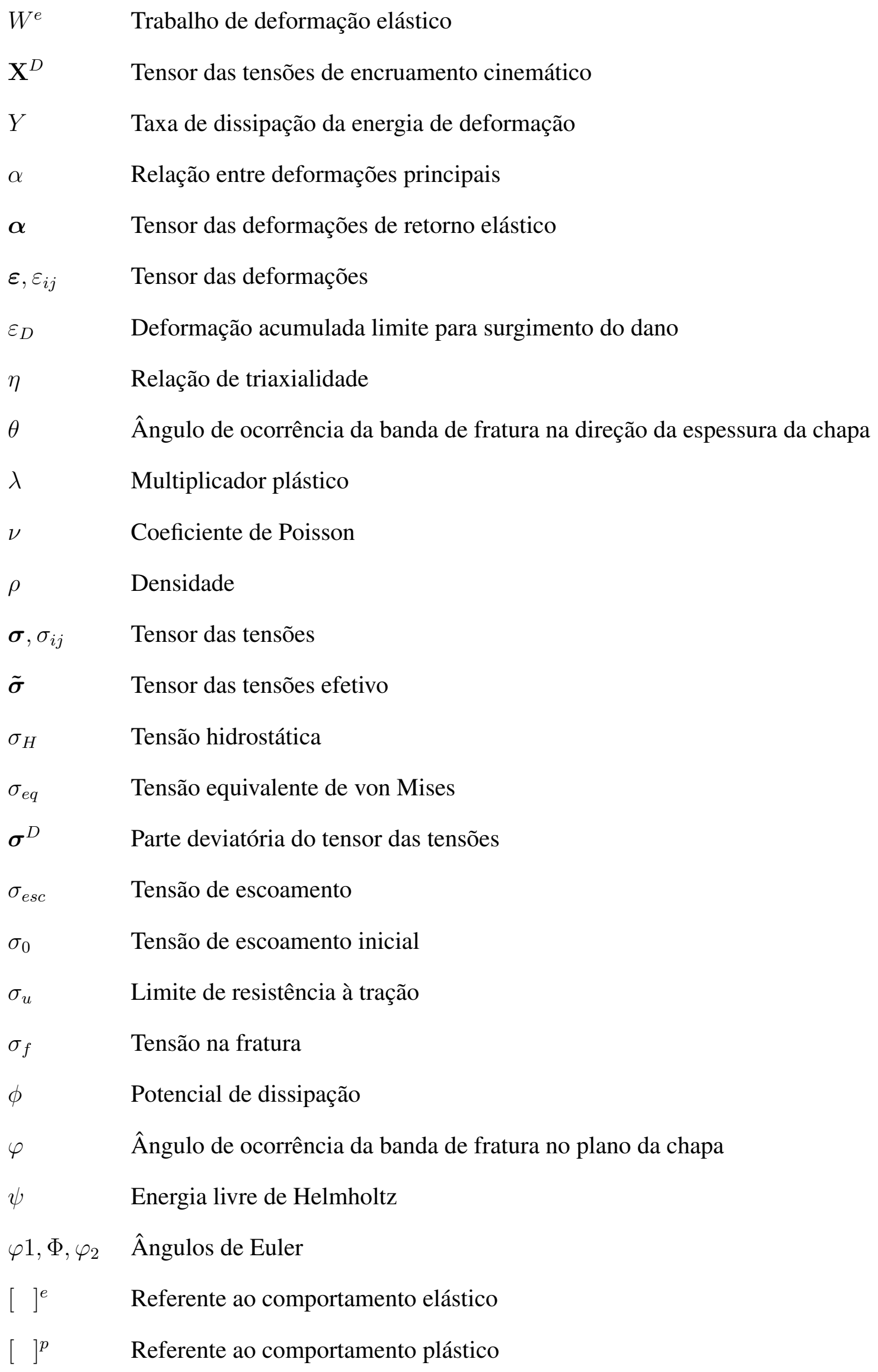


[ ] $]_{1,2,3}$ Referente às direções principais do tensor

[]$_{x, y, z} \quad$ Referente às direções $(x, y, z)$ 


\section{SUMÁRIO}

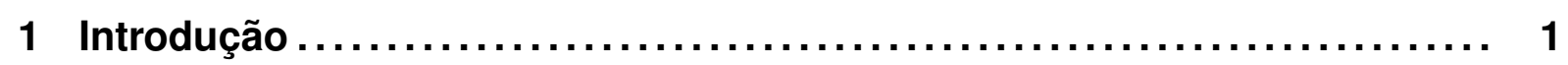

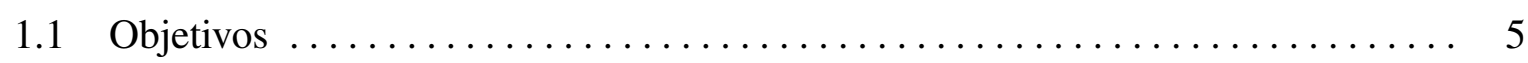

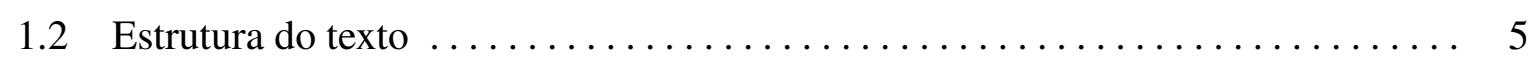

2 Fundamentos da mecânica do dano ............................ 6

2.1 Revisão de conceitos da mecânica dos sólidos ................. 6

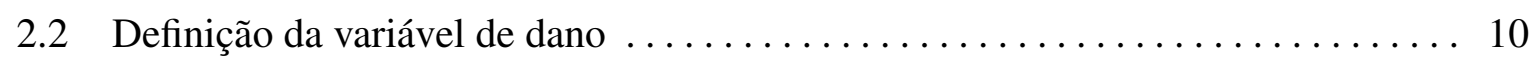

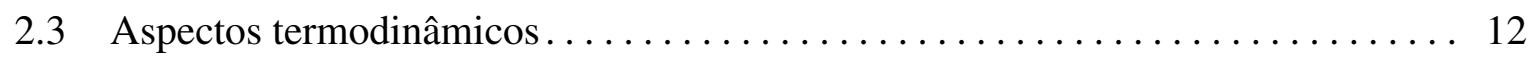

2.4 Modelos de evolução do dano para grandes deformações plásticas . . . . . . . . 17

2.5 Caracterização de um material no contexto da mecânica do dano . . . . . . . . 20

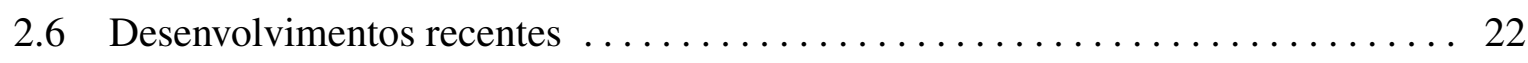

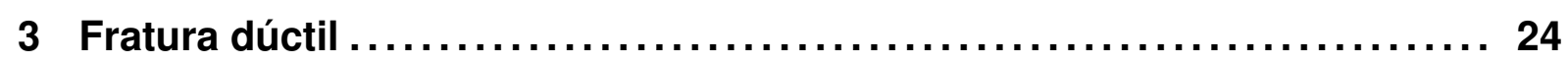

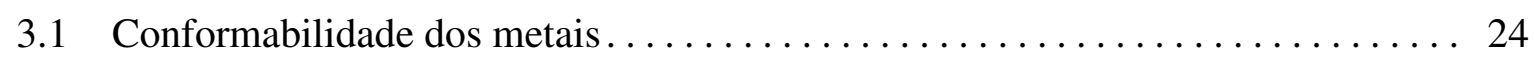

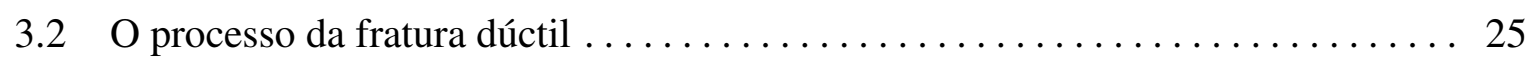

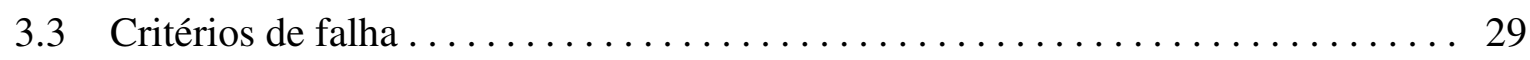

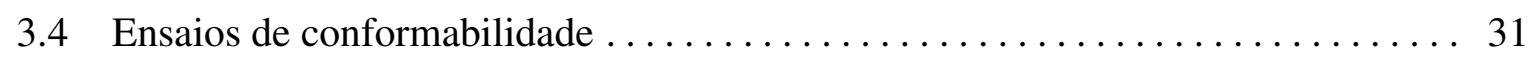

3.5 Resumo do capítulo.............................. 34

4 Ensaios mecânicos para caracterização dos materiais............... 35

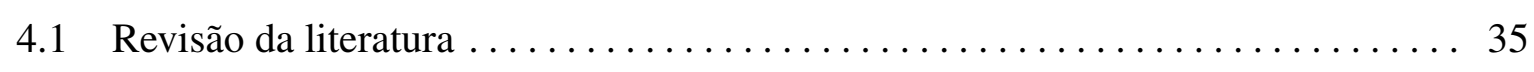

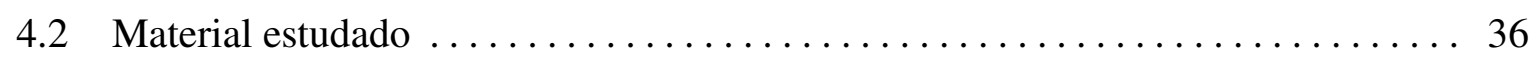

4.3 Metodologia .................................. 40 


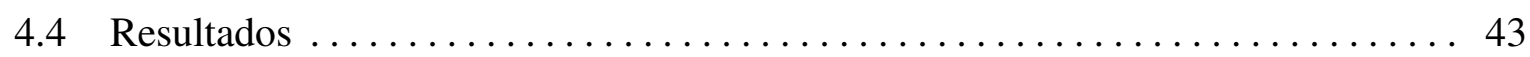

4.4.1 Propriedades mecânicas $\ldots \ldots \ldots \ldots \ldots \ldots \ldots \ldots \ldots \ldots \ldots \ldots \ldots \ldots \ldots \ldots \ldots \ldots$

4.4 .2 Evolução do dano $\ldots \ldots \ldots \ldots \ldots \ldots \ldots \ldots \ldots \ldots \ldots \ldots \ldots$

4.4.3 Localização das deformações $\ldots \ldots \ldots \ldots \ldots \ldots \ldots \ldots \ldots \ldots \ldots \ldots \ldots \ldots \ldots \ldots$

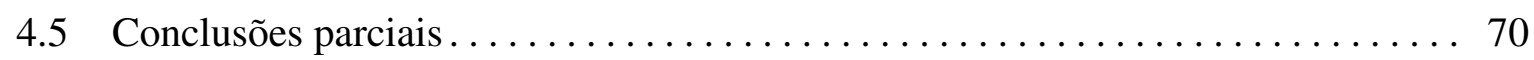

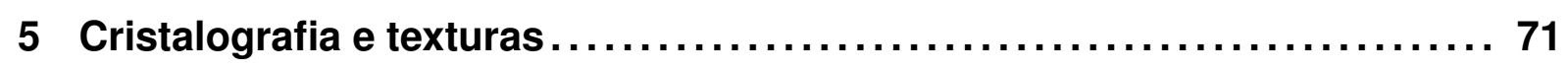

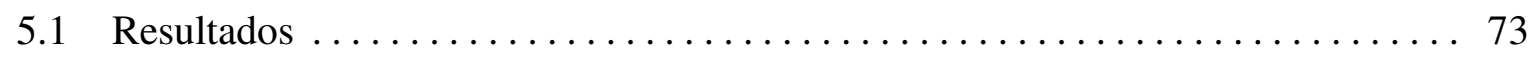

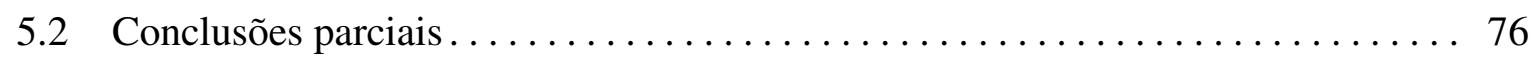

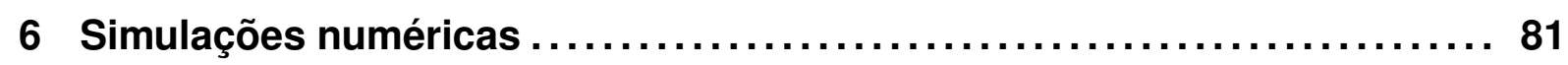

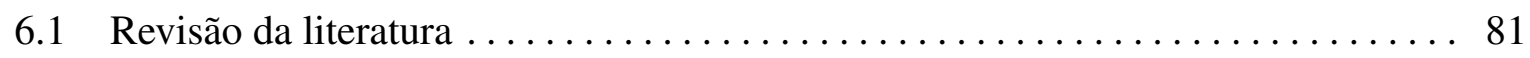

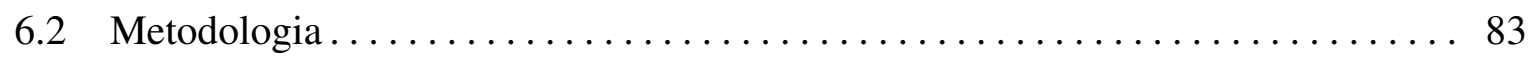

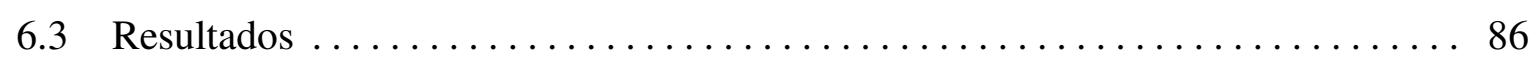

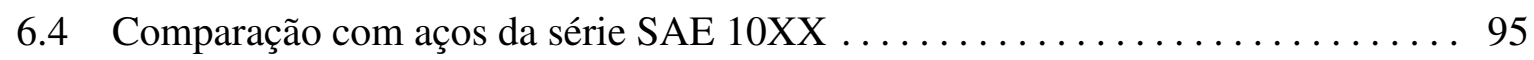

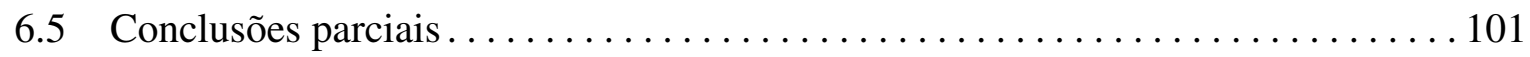

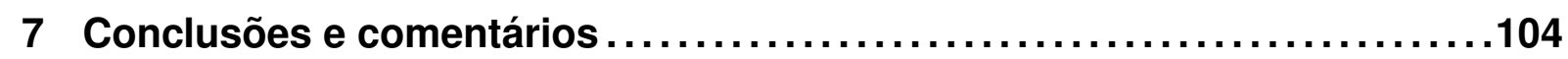

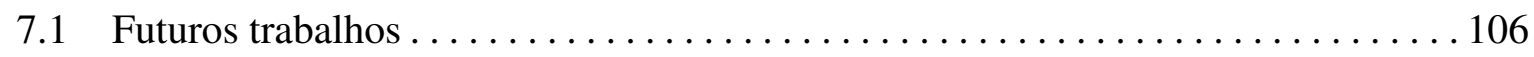

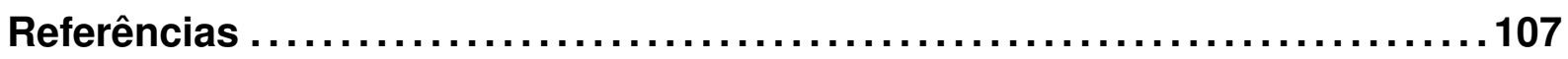

Apêndice A - Contração tensorial de segunda ordem ..................113

Apêndice B - Dedução da expressão da taxa de dissipação da energia de deformação ..............................................

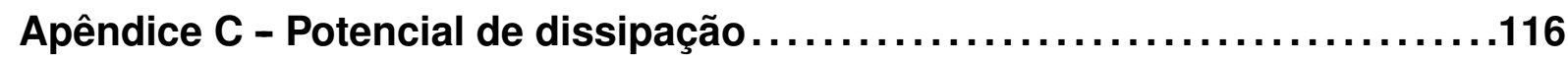

Apêndice D - Formulação acoplada das equações de evolução do dano pelo método dos elementos finitos. ................................118 
D.1 Algoritmo numérico

Apêndice E - Subrotina VUMAT para cálculo da evolução do dano utilizando

o Abaqus/Explicit .122

Apêndice F - Manual para uso da subrotina VUMAT no Abaqus/Explicit . . . . . 130 


\section{INTRODUÇÃO}

Os processos de conformação mecânica de metais são utilizados na confecção de utensílios domésticos, agrícolas, decorativos ou bélicos desde a antiguidade. A partir da segunda metade do século XIX tais processos deixaram de ser tratados como arte e passaram a ser estudados cientificamente. Somente na era digital a conformação perdeu sua importância estratégica e se tornou uma commodity a ser comercializada globalmente (STANDRING, 2010).

Existem diversas maneiras de dar a um ou mais objetos metálicos a forma desejada. Pode ser adicionando material - como na soldagem -, removendo material - o que caracteriza os diversos processos de usinagem -, ou pela conformação propriamente dita, em que o volume final da peça pode ser considerado semelhante ao da matéria prima. Dentre os processos de conformação, que podem ocorrer a frio, a morno ou a quente, alguns dos mais conhecidos são: laminação de barras e chapas, estampagem de chapas, extrusão de perfis, trefilação de perfis e fios, forjamento em matriz fechada ou aberta.

Os processos de conformação são largamente utilizados na indústria pelas boas propriedades mecânicas conferidas às peças e pela flexibilidade em termos de geometrias possíveis de serem fabricadas, além da facilidade de produção em larga escala. Tais propriedades mecânicas das peças conformadas têm relação com o fibramento que acompanha a geometria da peça, tornando propriedades como resistência à fadiga, por exemplo, anisotrópicos. Por isso, um bom projetista deve se preocupar para que a direção dos esforços principais na peça coincida com a direção do fibramento, maximizando a resistência mecânica. Peças fundidas apresentam estruturas globulares provenientes da solidificação e as peças usinadas tem o fibramento em uma única direção, fruto de operações de laminação anteriores, que acaba sendo quebrado durante o processo de corte. O fibramento terminando concorrentemente com a superfície da peça causa locais que podem nuclear trincas ou pontos de corrosão. A Fig. 1.1 ilustra essas macroestruturas.

A evolução dos projetos faz com que o número médio de peças, por máquina, e a complexidade das mesmas, venha sofrendo um aumento exponencial. Por exemplo, de acordo 


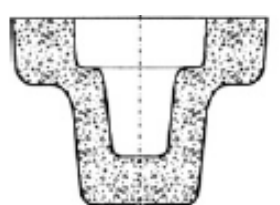

Fundido

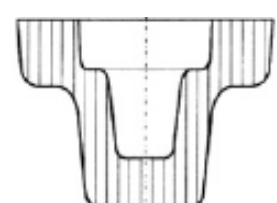

Usinado

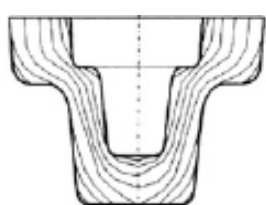

Conformado

Figura 1.1: Macroestruturas típicas de peças fabricadas por fundição, usinagem e conformação. Adaptado de Jeswiet et al. (2008).

com a Fig. 1.2, os primeiros automóveis fabricados no início do século XX apresentavam da ordem de centenas de peças, enquanto que este número, para os modelos atuais, já chega a quinze mil peças. Em outras indústrias, como na aeronáutica, o número de componentes médio pode chegar até a casa dos milhões (JESWIET et al., 2008).

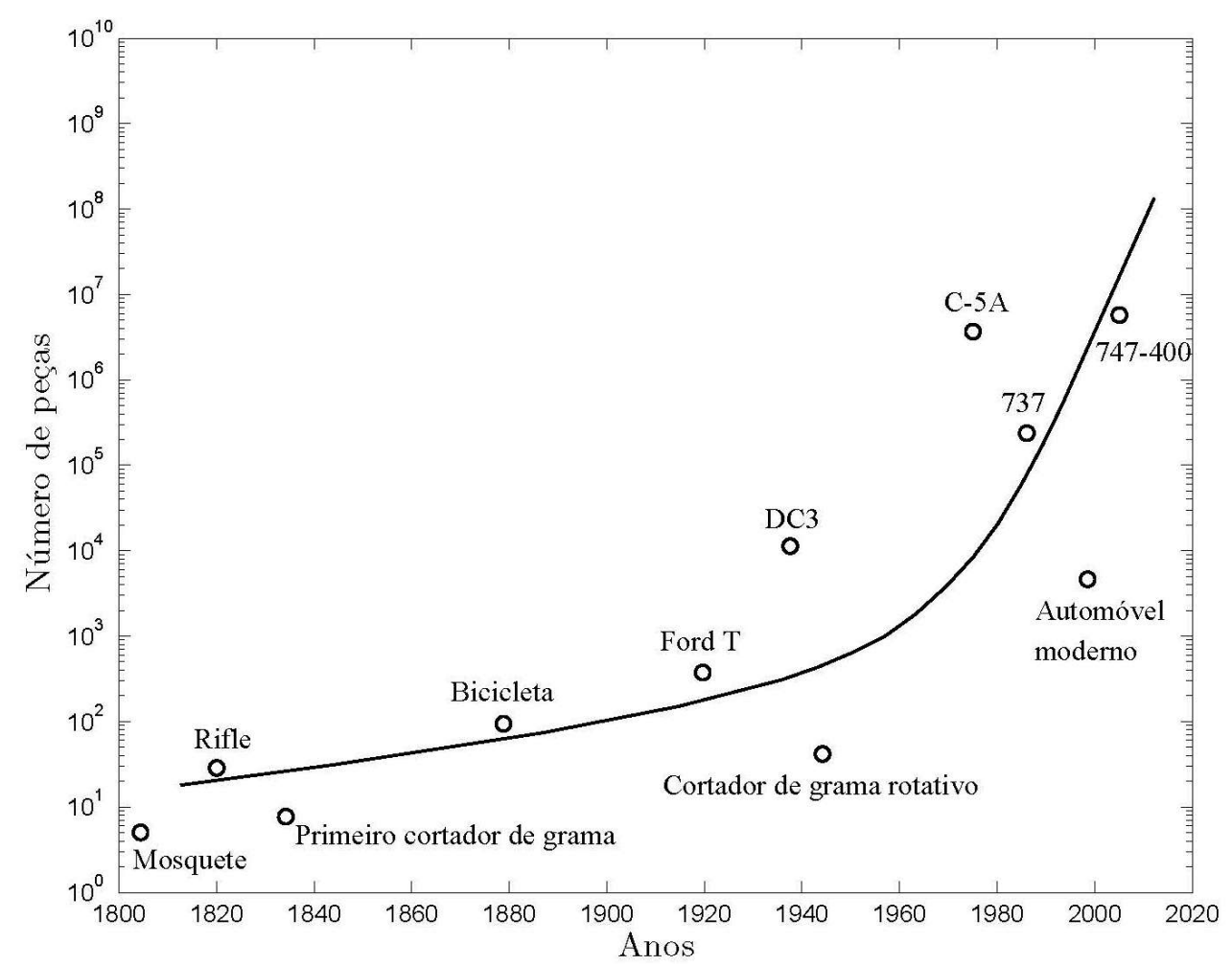

Figura 1.2: Evolução do número típico de peças em diversos produtos manufaturados após a revolução industrial. Adaptado de Jeswiet et al. (2008).

Da mesma maneira que os produtos fabricados, o próprio processo de fabricação deve constantemente evoluir para atender aos requisitos cada vez mais restritos, em termos de precisão dimensional e propriedades mecânicas, impostos pelo mercado. Deste modo, novos processos, como hidroconformação e tixoforjamento, vêm ganhando espaço nas indústrias mundiais, fazendo com que processos tradicionais de conformação, para se manterem competitivos, busquem novas soluções com respeito aos seguintes fatores (DOEGE; BOHNSACK, 2000): 
- diminuição do número de etapas de conformação;

- melhoria das propriedades mecânicas por meio da otimização do fluxo de material;

- aproximação da peça conformada à peça final, diminuindo operações de acabamento (near-net shaping).

Para atingir essas metas, diversos cuidados com respeito ao processo devem ser tomados, tais como:

- garantir que o aquecimento da peça seja uniforme e repetitivo no caso de trabalho a quente;

- minimizar as vibrações e desalinhamentos da máquina de conformação;

- controlar o tempo de transferência da peça entre as etapas do processo;

- controlar as dimensões da matéria prima;

- controlar a composição química e a microestrutura da matéria prima;

- manter a temperatura das ferramentas constante;

- garantir a geometria das ferramentas por um grande número de peças;

- garantir ausência de trincas e outros defeitos na peça conformada;

- controle do resfriamento pós-conformação, visando obter melhores microestruturas e propriedades mecânicas.

Embora todas as medidas listadas acima sejam importantes, o objetivo deste trabalho está em estudar uma metodologia de previsão do surgimento de defeitos mecânicos em operações de conformação. Segundo Garrison Jr. e Moody (1987), trincas são o resultado do coalescimento de microvazios nucleados no interior do material que crescem dependendo do estado de tensão ao qual estão submetidos, e este fenômeno tem sido estudado ao longo do anos por alguns ramos da mecânica dos sólidos.

A teoria da mecânica da fratura clássica, desenvolvida por Griffith (1920) e Irwin (1948), lida com a propagação de uma trinca pré-existente em um material, detalhando os caminhos que este defeito tende a seguir no interior de um meio contínuo até um ponto crítico em que a falha torna-se instável e o material se parte. Contudo, tal abordagem não consegue identificar o ponto de surgimento de uma trinca a partir de um meio perfeitamente coeso. 
Outros modelos, semi-empíricos, se preocupam apenas com o ponto em que a trinca atinge um tamanho visível a olho nu, correlacionando variáveis integrais, como os trabalhos realizados para a deformação plástica ou pela máxima tensão de tração, com o momento que o material sofre a falha. Tais modelos são de utilização simples, mas tem como desvantagem a não consideração de aspectos microestruturais inerentes a cada material, sendo necessário calibrar os valores para cada condição de carregamento. Os modelos de Cockroft e Latham (1968) e Oyane et al. (1980) se enquadram nesta categoria.

Neste contexto, a mecânica do dano (continuum damage mechanics, ou CDM), desenvolvida por Lemaitre e Chaboche a partir da definição de Kachanov (1958), trata o dano como uma propriedade de estado termodinâmica, que leva em conta a perda da capacidade do material em resistir a um esforço aplicado devido ao surgimento de microvazios no interior de um meio contínuo. A evolução desta variável pode ser modelada numericamente até o ponto em que tais microcavidades atingem um tamanho crítico que promove a perda de coesão macroscópica do material.

A teoria da mecânica do dano, desenvolvida a partir da década de 70, tem ramificações para diversos modos de falha do material. Na literatura existem trabalhos que aplicam com sucesso modelos para a evolução do dano para condição de fadiga, fluência e fratura frágil (CHABOCHE, 1987). Contudo, o enfoque que será dado neste trabalho diz respeito aos modelos criados para a fratura dúctil de materiais metálicos, isto é, falhas acompanhadas por grandes deformações plásticas em carregamentos não-cíclicos, que correspondem à maior parte dos problemas encontrados durante o processo de fabricação por conformação mecânica. Algumas propriedades inerentes ao material devem ser definidas para caracterizar o quão resistente este material é ao surgimento de um microdefeito e o quão rápido se dá o crescimento deste, qual é o valor crítico de deterioração e como este dano e o estado de tensões ao qual o sólido está submetido se afetam mutuamente.

A grande referência dentre os testes para avaliação de propriedades mecânicas é o ensaio de tração, de modo que não é surpresa a utilização deste ensaio para a caracterização de um material também com respeito à mecânica do dano, por meio da metodologia criada por Lemaitre. Assim, com um único ensaio de tração, consegue-se obter os parâmetros necessários para calibrar um modelo de falha generalista, que pode ser aplicado em outras condições de carregamento que não tensão uniaxial.

Tal metodologia tende a ser vista com bons olhos pela indústria, visto que o equipamento para ensaios de tração já está presente em diversas plantas e o custo de operação deste teste não é aumentado quando se avalia a evolução do dano em paralelo com as propriedades 
mecânicas tradicionais, como módulo de Young, tensão de escoamento e limite de resistência.

\subsection{Objetivos}

Tendo em vista este contexto, a motivação desta dissertação de mestrado é avaliar uma metodologia para avaliação da conformabilidade de uma liga metálica usando a mecânica do dano.

O material de estudo será a liga de aço SAE 1050 submetida ao tratamento térmico de esferoidização, que garante aumento na ductilidade do material, justificando sua recente utilização em processos de estampagem em escala industrial. A meta é, usando a teoria da mecânica do dano, prever corretamente a formação de trincas em ensaios de tração. Comparação com a liga SAE 1050 laminada a quente será efetuada. As equações da mecânica do dano serão acopladas ao modelo constitutivo clássico do material, elasto-plasticidade isotrópica, e simulações serão efetuadas utilizando o método dos elementos finitos. Comparação entre simulação e ensaios responderá o quão viável é o modelo. Uma comparação entre a evolução do dano para os materiais estudados e outros materiais encontrados na literatura também será efetuada.

\subsection{Estrutura do texto}

O trabalho está organizado conforme a seguinte estrutura. No Cap. 2 apresentamos os fundamentos da mecânica do dano, com maior ênfase no modelo proposto por Lemaitre. A conformabilidade dos metais e o fenômeno físico da fratura dúctil são assunto do Cap. 3. O Cap. 4 discute a metodologia empregada para a caracterização das propriedades mecânicas relacionadas à evolução do dano em materiais metálicos e os resultados destes ensaios. Uma análise da evolução da textura do material é apresentada no Cap. 5. No Cap. 6 apresentamos um algoritmo numérico de acoplamento entre dano e plasticidade, e os resultados obtidos por meio de simulações computacionais, além de comparação com resultados experimentais. Conclusões e comentários finais do texto estão no Cap. 7. 


\section{FUNDAMENTOS DA MECÂNICA DO DANO}

Este capítulo se propõe a apresentar com detalhes a teoria da mecânica do dano, desde a definição da variável representativa do dano até as equações que modelam a evolução deste parâmetro. Neste trabalho foi utilizada a metodologia descrita em Lemaitre (1996).

A próxima seção apresenta uma breve revisão de conceitos da mecânica dos sólidos que serão necessários posteriormente.

\subsection{Revisão de conceitos da mecânica dos sólidos}

A mecânica dos sólidos lida com o comportamento de corpos sólidos sujeitos a diversos tipos de carregamento. Os conceitos mais fundamentais neste ramo da mecânica aplicada são tensão e deformação (GERE, 2003).

Sob ação de forças externas, qualquer corpo sólido se deforma, mesmo que de maneira mínima. Para representar matematicamente essa deformação, devemos definir o vetor posição de um ponto neste sólido $\mathbf{r}$, dado pelas coordenadas $\left(x_{1}, x_{2}, x_{3}\right)$ deste ponto em algum sistema de coordenadas fixo. O vetor deslocamento $\mathbf{u}$ é definido como a variação do vetor posição quando este ponto se desloca no espaço, ou seja $\mathbf{u}=\Delta \mathbf{r}=\mathbf{r}^{\prime}-\mathbf{r}$.

Vamos considerar dois pontos infinitesimalmente próximos, com vetor posição relativa entre eles igual a $\mathbf{r}=\left(\mathrm{d} x_{1}, \mathrm{~d} x_{2}, \mathrm{~d} x_{3}\right)$, ou, em notação de índices, $\mathbf{r}=\mathrm{d} x_{i}$. Se o corpo for deformado, a posição relativa entre esses pontos deve variar, de modo que $\mathbf{r}^{\prime}=\mathrm{d} x_{i}^{\prime}=\mathrm{d} x_{i}+\mathrm{d} u_{i}$. Sabemos que as distâncias entre os pontos antes e depois da deformação podem ser representadas como $\mathrm{d} l=\sqrt{\left(\mathrm{d} x_{i}\right)^{2}}$ e $\mathrm{d} l^{\prime}=\sqrt{\left(\mathrm{d} x_{i}^{\prime}\right)^{2}}$, respectivamente. Assim, podemos escrever:

$$
\mathrm{d} l^{\prime 2}=\left(\mathrm{d} x_{i}^{\prime}\right)^{2}=\left(\mathrm{d} x_{i}+\mathrm{d} u_{i}\right)^{2}=\mathrm{d} l^{2}+2 \mathrm{~d} x_{i} \mathrm{~d} u_{i}+\left(\mathrm{d} u_{i}\right)^{2}
$$

Substituindo $\mathrm{d} u_{i}=\left(\partial u_{i} / \partial x_{j}\right) \mathrm{d} x_{j}$, e mantendo a notação de índices, temos:

$$
\mathrm{d} l^{\prime 2}-\mathrm{d} l^{2}=2 \frac{\partial u_{i}}{\partial x_{j}} \mathrm{~d} x_{i} \mathrm{~d} x_{j}+\frac{\partial u_{i}}{\partial x_{j}} \frac{\partial u_{i}}{\partial x_{k}} \mathrm{~d} x_{j} \mathrm{~d} x_{k}
$$


Como no primeiro termo do lado direito da equação a soma é efetuada sobre os índices $i$ e $j$, podemos escrever que $\left(\partial u_{i} / \partial x_{j}\right) \mathrm{d} x_{i} \mathrm{~d} x_{j}=\left(\partial u_{j} / \partial x_{i}\right) \mathrm{d} x_{i} \mathrm{~d} x_{j}$. No segundo termo, podemos trocar os índices $i$ e $k$. Assim, obtemos, como mostrado em Landau e Lifshitz (1964):

$$
\mathrm{d} l^{\prime 2}-\mathrm{d} l^{2}=2\left[\frac{1}{2}\left(\frac{\partial u_{i}}{\partial x_{j}}+\frac{\partial u_{j}}{\partial x_{i}}+\frac{\partial u_{k}}{\partial x_{j}} \frac{\partial u_{k}}{\partial x_{i}}\right)\right] \mathrm{d} x_{i} \mathrm{~d} x_{j}
$$

Definimos o tensor das deformações $\varepsilon$, ou $\varepsilon_{i j}$, como:

$$
\varepsilon_{i j}=\frac{1}{2}\left(\frac{\partial u_{i}}{\partial x_{j}}+\frac{\partial u_{j}}{\partial x_{i}}+\frac{\partial u_{k}}{\partial x_{i}} \frac{\partial u_{k}}{\partial x_{j}}\right)
$$

que representa a mudança de tamanho de um elemento volumétrico infinitesimal quando o corpo é deformado. Este tensor tem por propriedade a simetria, ou seja, $\varepsilon_{i j}=\varepsilon_{j i}$. Tratando de pequenas deformações, o vetor deslocamento geralmente será pequeno (LANDAU; LIFSHITZ, 1964), de modo que o último termo pode ser desprezado frente aos demais. Assim, obtemos a expressão clássica do tensor das deformações:

$$
\varepsilon_{i j}=\frac{1}{2}\left(\frac{\partial u_{i}}{\partial x_{j}}+\frac{\partial u_{j}}{\partial x_{i}}\right)
$$

Sempre que houver deformação, o corpo sólido sairá do seu estado de equilíbrio natural e forças internas surgirão entre regiões deste corpo, buscando retomar a condição de equilíbrio. A força total que age em uma porção do corpo é definida como a força por unidade de volume $\mathbf{F}^{\prime}$ integrada ao longo do volume, ou seja $\int \mathbf{F}^{\prime} \mathrm{d} V$. Como, pela terceira lei de Newton, as forças interiores a essa porção do corpo estudado devem se cancelar, a força total atuante pode ser calculada considerando somente as forças que atuam na superfície exterior, exercidas pelas outras regiões do sólido. Ou seja, para cada uma das três direções $(i, j, k)$, deve haver uma resultante calculada por meio de uma integral ao longo da superfície externa deste pedaço de sólido (LANDAU; LIFSHITZ, 1964).

Aplicando o teorema de Gauss ao nosso problema, temos que a integral volumétrica, tendo como domínio o volume $V$ enclausurado pela superfície fechada $S$, de uma quantidade vetorial $\mathbf{F}^{\prime}$ pode ser transformada na integral ao longo da superfície $S$ se o vetor for o divergente de um tensor de segunda ordem $\boldsymbol{\sigma}$, de acordo com a seguinte equação:

$$
\int_{V} \mathbf{F}^{\prime} \mathrm{d} V=\int_{V} \nabla \cdot \boldsymbol{\sigma} \mathrm{d} V=\oint_{S} \boldsymbol{\sigma} \cdot \mathbf{n} \mathrm{d} S
$$

onde $\mathbf{n}$ é o vetor unitário normal ao elemento de área infinitesimal $\mathrm{d} S$ e a quantidade $\boldsymbol{\sigma} \cdot \mathbf{n} \mathrm{d} S$ é a resultante de força sobre este elemento de área.

O tensor de segunda ordem $\sigma$ é chamado de tensor das tensões, e seus componentes $\sigma_{i j}$ 
representam a quantidade de força na direção $i$ por unidade de área atuando sobre a superfície de normal $j$ para cada elemento volumétrico infinitesimal do sólido. Também pode ser deduzido que o tensor é simétrico, ou seja $\sigma_{i j}=\sigma_{j i}$ (LANDAU; LIFSHITZ, 1964). As componentes $\sigma_{i i}$ são ditas tensões normais, enquanto que as componentes cruzadas $\sigma_{i j}$, usualmente também representadas como $\tau_{i j}$ são nomeadas tensões de cisalhamento. Tais componentes são ilustradas na Fig. 2.1 para um sistema de coordenadas $(x, y, z)$ arbitrário.

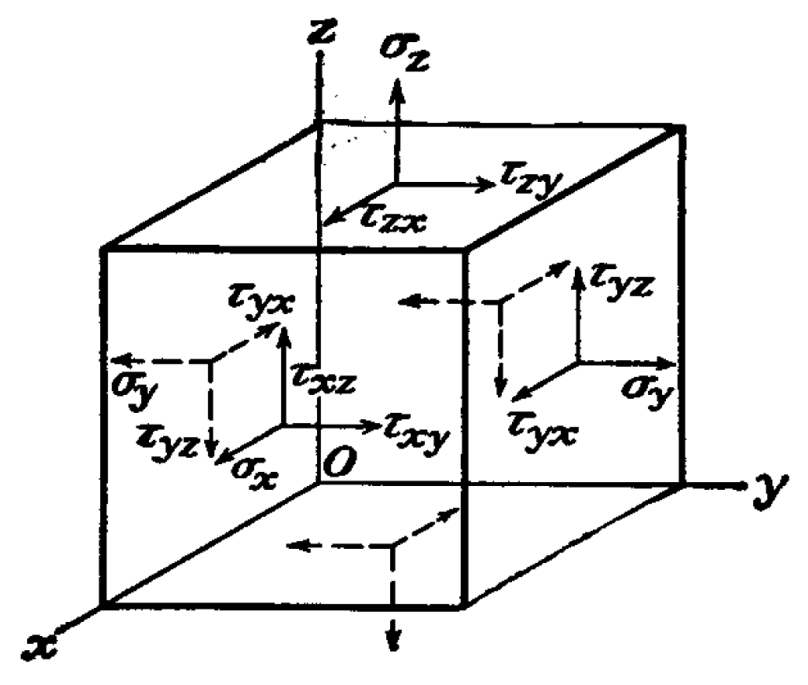

Figura 2.1: Componentes de uma tensão atuando no ponto O. Adaptado de Timoshenko e Goodier (1951).

A lei de Hooke mostra a relação entre as tensões e deformações no regime elástico, isto é, aquele em que as deformações são reversíveis uma vez que o carregamento externo é retirado (TIMOSHENKO; GOODIER, 1951). A lei de Hooke num regime de tensão unidimensional é o seguinte conjunto de relações lineares:

$$
\begin{gathered}
\varepsilon_{x}=\frac{1}{E} \sigma_{x} \\
\varepsilon_{y}=\varepsilon_{z}=\frac{-\nu}{E} \sigma_{x}
\end{gathered}
$$

onde $E$ é o módulo de elasticidade e $\nu$ é o coeficiente de Poisson, os quais, neste trabalho, serão assumidos como constantes isotrópicas características do material.

Considerando um carregamento genérico, teremos os seguintes tensores de segunda ordem:

$$
\boldsymbol{\sigma}=\left[\begin{array}{ccc}
\sigma_{x} & \tau_{x y} & \tau_{x z} \\
\tau_{x y} & \sigma_{y} & \tau_{y z} \\
\tau_{y z} & \tau_{y z} & \sigma_{z}
\end{array}\right] \quad \text { e } \quad \boldsymbol{\varepsilon}=\left[\begin{array}{ccc}
\varepsilon_{x} & \gamma_{x y} & \gamma_{x z} \\
\gamma_{x y} & \varepsilon_{y} & \gamma_{y z} \\
\gamma_{y z} & \gamma_{y z} & \varepsilon_{z}
\end{array}\right]
$$

das tensões e deformações, respectivamente. Deste modo, a lei de Hook em forma tensorial 
pode ser escrita como:

$$
\boldsymbol{\sigma}=\mathbf{A}: \varepsilon
$$

onde A é o tensor de quarta ordem da elasticidade que, dada a simetria dos tensores $\sigma$ e $\varepsilon$, apresenta 27 coeficientes elásticos independentes, e o símbolo ":" indica uma dupla contração tensorial (ver Apêndice A). Maiores detalhes sobre álgebra tensorial e a derivação da lei de Hooke nesta notação podem ser obtidos em Malvern (1969).

Para qualquer carregamento pode-se escolher um sistema de coordenadas preferencial no qual o tensor das tensões acaba sendo reduzido apenas aos termos da sua diagonal principal:

$$
\boldsymbol{\sigma}=\left[\begin{array}{ccc}
\sigma_{1} & 0 & 0 \\
0 & \sigma_{2} & 0 \\
0 & 0 & \sigma_{3}
\end{array}\right]
$$

onde $\sigma_{1}>\sigma_{2}>\sigma_{3}$ são denominadas as tensões principais (TIMOSHENKO; GOODIER, 1951).

Aqui cabe apresentar algumas quantidades que serão importantes no decorrer do texto. A partir do traço do tensor das tensões, define-se na Eq. (2.12) a chamada tensão hidrostática $\sigma_{H}$, a qual pode ser entendida como uma tensão média aplicada de maneira isotrópica em um dado elemento representativo de volume.

$$
\sigma_{H}=\frac{\sigma_{x}+\sigma_{y}+\sigma_{z}}{3}=\frac{\sigma_{1}+\sigma_{2}+\sigma_{3}}{3}
$$

Outro parâmetro importante é a tensão de von Mises $\sigma_{e q}$, definida como uma tensão equivalente a partir da qual o material muda do regime elástico para o regime plástico utilizandose o critério da máxima energia de distorção (JONES, 2009). Tal quantidade tem relação com a parte deviatória do tensor das tensões, e pode ser definida como:

$$
\sigma_{e q}=\sqrt{\frac{\left(\sigma_{x}-\sigma_{y}\right)^{2}+\left(\sigma_{y}-\sigma_{z}\right)^{2}+\left(\sigma_{z}-\sigma_{x}\right)^{2}+\tau_{x y}^{2}+\tau_{y z}^{2}+\tau_{z x}^{2}}{2}}=\sqrt{\frac{3}{2} \boldsymbol{\sigma}^{D}: \boldsymbol{\sigma}^{D}}
$$

onde $\boldsymbol{\sigma}^{D}=\boldsymbol{\sigma}-\sigma_{H} \mathbf{I}$ é a parte deviatória do tensor das tensões e I é a matriz identidade de ordem 3. Em relação às tensões principais:

$$
\sigma_{e q}=\sqrt{\frac{\left(\sigma_{1}-\sigma_{2}\right)^{2}+\left(\sigma_{2}-\sigma_{3}\right)^{2}+\left(\sigma_{3}-\sigma_{1}\right)^{2}}{2}}
$$

A relação $\eta=\left(\sigma_{H} / \sigma_{e q}\right)$, a qual será recorrente neste texto, é importante pois quantifica o nível de triaxialidade do estado de tensões em um elemento volumétrico. O valor desta relação pode variar entre $-1 / 3$, no caso de compressão uniaxial, nos quais as maiores deformações plásticas na falha podem ser encontradas, até tender ao infinito, no caso de um material sujeito a 


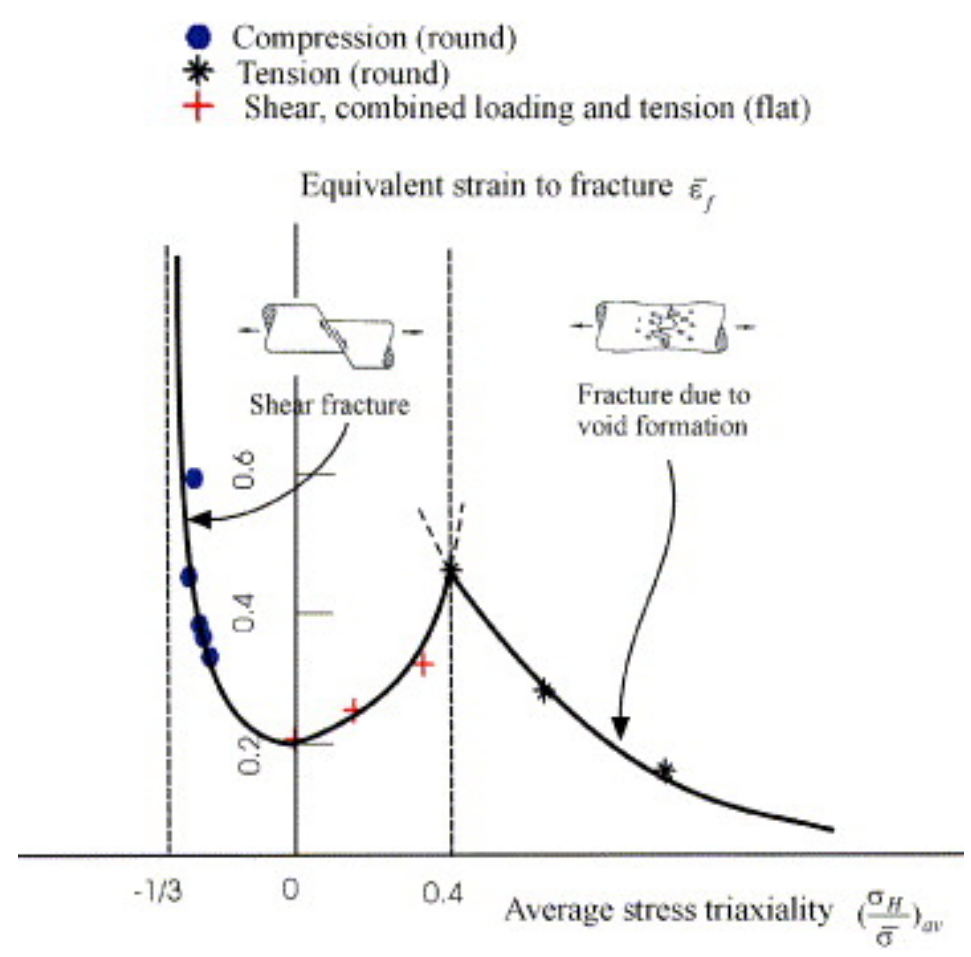

Figura 2.2: Variação da deformação na fratura com a relação de triaxialidade do estado de tensões (BAO; WIERZBICKI, 2004).

um carregamento predominantemente hidrostático, que torna o material sujeito a fratura frágil, caso haja uma pequena componente de cisalhamento atuando em conjunto. A Fig. 2.2 mostra, para uma liga de alumínio AA 2024, como varia a deformação máxima na fratura com a triaxialidade do estado de tensões.

Uma outra maneira de evidenciar a influência dá relação de triaxialidade é por meio dos caminhos de deformação em diversos modos de carregamento diferentes, como mostrado na Fig. 2.3, adaptada de Li et al. (2010). Cada valor de $\eta$ descrevendo um estado planar de tensões também define uma relação única entre a deformação principal $\varepsilon_{1}$ e a deformação secundária $\varepsilon_{2}$. Medir essas deformações, portanto, é uma maneira de estimar o valor da relação de triaxialidade em um modo de carregamento combinado.

Após esta breve revisão acerca de alguns conceitos da mecânica dos sólidos, podemos prosseguir para a derivação da teoria da mecânica do dano, como apresentado por Lemaitre (1996).

\subsection{Definição da variável de dano}

Primeiramente, é necessário definir uma variável que represente o dano de um material. Kachanov (1958) foi o pioneiro a apresentar uma definição contínua para o dano em um meio sólido. 


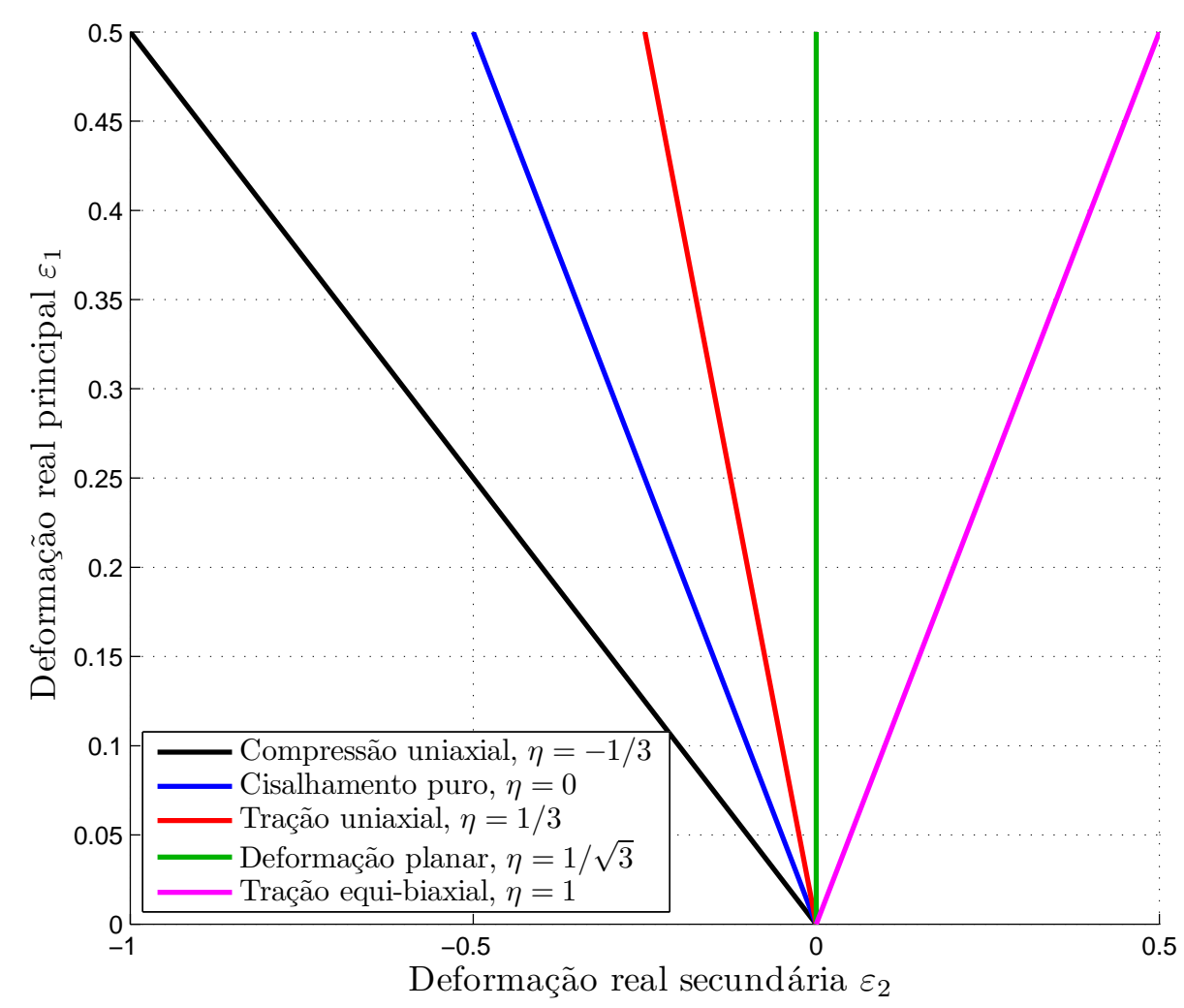

Figura 2.3: Caminhos de deformação para diversos tipos de carregamento no estado planar de tensões, caracterizados pela relação de triaxialidade $\eta=\sigma_{H} / \sigma_{e q}$. Adaptado de Li et al. (2010)

Considerando um elemento de volume grande o suficiente para conter diversos defeitos mas pequeno o bastante para ser tratado como um ponto material pela mecânica dos meios contínuos, vamos denominar $A_{0}$ a área da superfície de uma dada seção transversal desse elemento. Por hipótese, assumiremos que o dano é isotrópico, ou seja, tomando seções com diferentes orientações, as trincas e cavidades são igualmente distribuídas. A intersecção desses defeitos internos com a seção $A_{0}$ determinam uma área de vazios igual a $A_{d}$, como mostrado na Fig. 2.4.

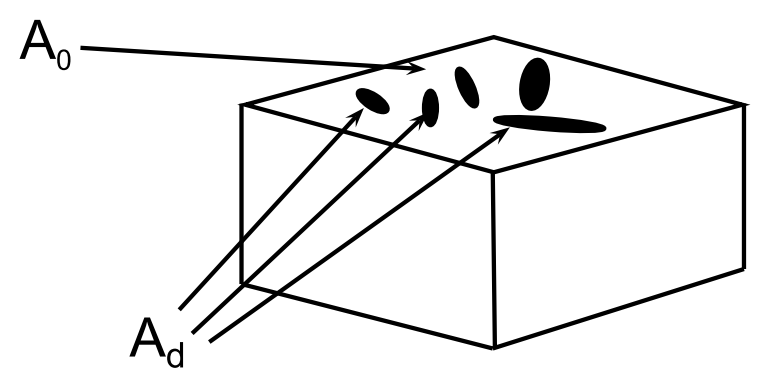

Figura 2.4: Área danificada em uma seção do elemento volumétrico.

As descontinuidades acabam por diminuir a seção resistente efetiva $\tilde{A}=A_{0}-A_{d}$. Por 
definição, a variável de dano $D$ é escrita como:

$$
D=\frac{A_{0}-\tilde{A}}{A_{0}}=\frac{A_{d}}{A_{0}}
$$

Nota-se que $D=0$ corresponde ao estado não danificado do material, enquanto que $D=D_{c}$ corresponde ao valor crítico de dano que leva à ruptura do material. Para metais, este valor varia entre 0,2 e 0,8 (LEMAITRE, 1984). Uma consequência do dano em materiais é a alteração do campo de tensões atuante, visto que a área da seção transversal resistente diminui. Para o caso de tensão unidimensional, temos:

$$
\tilde{\sigma}=\frac{F}{\tilde{A}}=\frac{F}{A_{0}\left(1-\frac{A_{d}}{A_{0}}\right)}=\frac{\sigma}{1-D}
$$

onde $F$ é a força atuante, $\sigma$ é a tensão usual a que o material estaria submetido e $\tilde{\sigma}$ é a tensão real no material danificado. Essa idéia pode ser expandida para o tensor completo de tensões $\sigma$ :

$$
\tilde{\boldsymbol{\sigma}}=\frac{\boldsymbol{\sigma}}{1-D}
$$

Uma das hipóteses importantes a se assumir é a de que o dano no material influencia o campo de deformações apenas por meio de mudanças no campo de tensões atuante. Por exemplo, a deformação elástica $\varepsilon^{e}$, no caso unidimensional, pode ser escrita como:

$$
\varepsilon^{e}=\frac{\tilde{\sigma}}{E}=\frac{\sigma}{E(1-D)}=\frac{\sigma}{\tilde{E}}
$$

onde $E$ é o módulo de Young, também conhecido como módulo elástico, de rigidez ou de elasticidade, do material não danificado e $\tilde{E}=E(1-D)$ pode ser entendido como o módulo elástico efetivo do material danificado. A Fig. 2.5 (LEMAITRE, 1984) mostra como este módulo de elasticidade efetivo varia durante o ensaio de tração de um corpo de prova de cobre com 99,9\% de pureza. Em diversos pontos do ensaio a carga sobre o corpo de prova foi retirada e reaplicada, de modo que o retorno elástico do material fosse medido, dando uma medida de $\tilde{E}$. Essa é uma maneira indireta de medição do dano no material.

\subsection{Aspectos termodinâmicos}

As equações de evolução da variável de dano são baseadas em princípios da termodinâmica irreversível (CHABOCHE, 1988a). Algumas variáveis devem ser introduzidas, como a deformação 


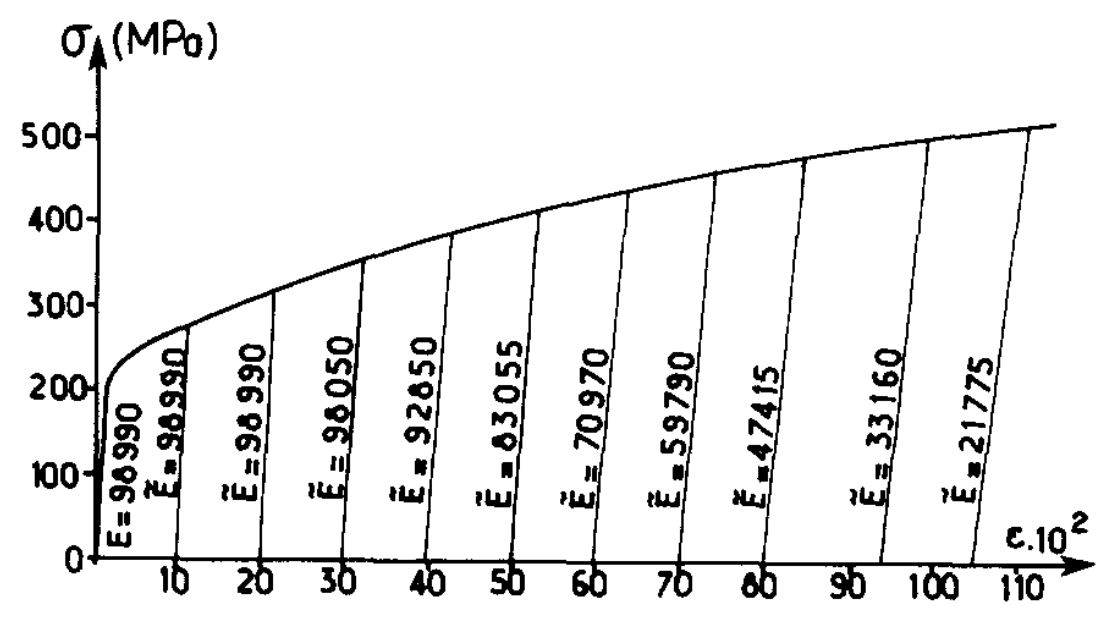

Figura 2.5: Mudança do módulo de elasticidade equivalente no ensaio de tração do cobre 99,9\% (LEMAITRE, 1984).

plástica acumulada $p$, definida por meio de sua derivada:

$$
\dot{p}=\sqrt{\frac{2}{3} \dot{\boldsymbol{\varepsilon}}^{p}: \dot{\boldsymbol{\varepsilon}}^{p}}
$$

onde $\varepsilon^{p}$ é o tensor das deformações plásticas $\varepsilon^{p}=\varepsilon-\varepsilon^{e}$. A lista destas variáveis está apresentada na Tab. 2.1.

Tabela 2.1: Variáveis termodinâmicas.

\begin{tabular}{ccc}
\hline Variáveis observadas & Variáveis internas & Variáveis associadas \\
\hline $\begin{array}{c}\text { Tensor das deformações } \\
\text { elásticas } \varepsilon^{e}\end{array}$ & - & Tensor das tensões $\boldsymbol{\sigma}$ \\
\hline Temperatura $T$ & - & Entropia $s$ \\
\hline- & $\begin{array}{c}\text { Deformação plástica } \\
\text { acumulada no dano } r\end{array}$ & $\begin{array}{c}\text { Variável de encruamento } \\
\text { isotrópico } R\end{array}$ \\
\hline- & $\begin{array}{c}\text { Tensor das deformações de } \\
\text { retorno elástico } \boldsymbol{\alpha}\end{array}$ & $\begin{array}{c}\text { Tensor de encruamento } \\
\text { cinético } \mathbf{X}^{D}\end{array}$ \\
\hline- & Dano $D$ & $\begin{array}{c}\text { Taxa de dissipação da } \\
\text { energia de deformação } Y\end{array}$ \\
\hline
\end{tabular}

A Fig. 2.6 mostra como se comporta o local geométrico do escoamento plástico, segundo o critério de von Mises, antes e após o encruamento no espaço das tensões principais para um estado de tensão plana $\left(\sigma_{3}=0\right)$, mostrando os efeitos de $R$ e $\mathbf{X}^{D}$ na superfície de escoamento. O encruamento isotrópico aumenta a superfície de escoamento e está relacionado com o aumento de resistência do material enquanto que o encruamento cinético desloca a posição central desta superfície e está relacionado com o retorno elástico do material. Notar que $\sigma_{e s c}$ é a tensão de escoamento original do material e que um estado de tensões interno à superfície de 
escoamento encontra-se em regime elástico, enquanto que um estado de tensões externo a esta superfície está em regime plástico.
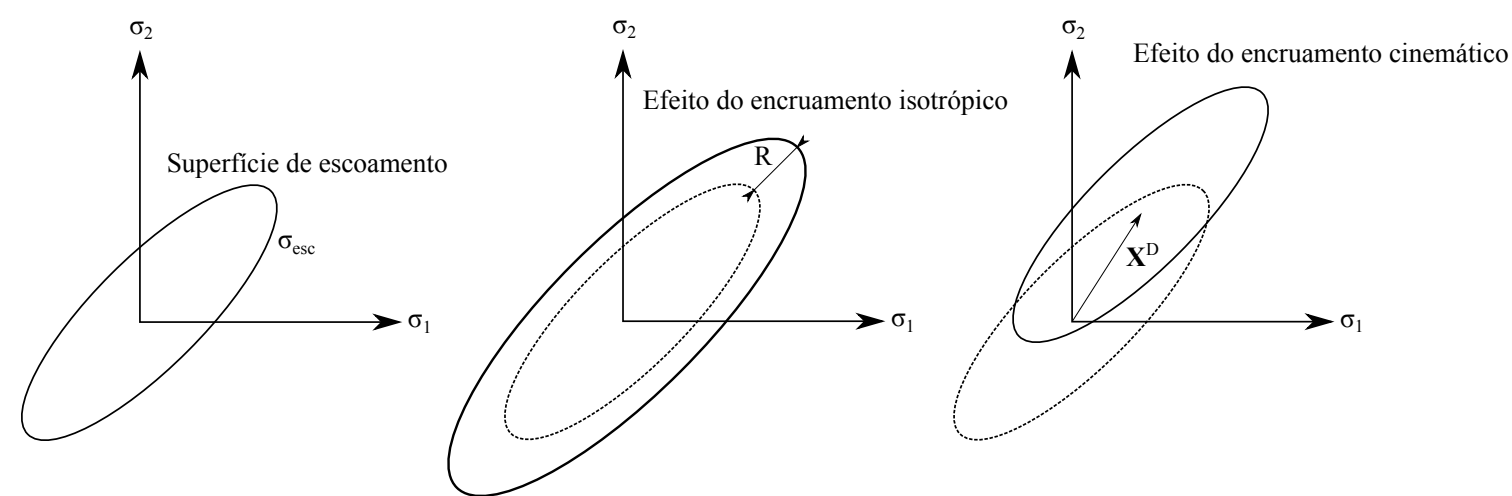

Figura 2.6: Esquema ilustrativo do local geométrico da tensão de escoamento no espaço das tensões principais para um caso de tensão plana, mostrando os efeitos do encruamento isotrópico e cinemático.

As variáveis associadas estão relacionadas às variáveis internas ou observáveis por meio de um potencial termodinâmico, neste caso escolhido como a energia específica livre de Helmholtz $\psi=\psi^{e}\left(\varepsilon^{e}, T, D\right)+\psi^{p}(T, p)$ :

$$
\begin{gathered}
\boldsymbol{\sigma}=\rho \frac{\partial \psi}{\partial \boldsymbol{\varepsilon}^{e}} \\
s=-\rho \frac{\partial \psi}{\partial T} \\
R=\rho \frac{\partial \psi}{\partial r} \\
\mathbf{X}^{D}=\rho \frac{\partial \psi}{\partial \boldsymbol{\alpha}} \\
Y=\rho \frac{\partial \psi}{\partial D}
\end{gathered}
$$

onde $\rho$ é a densidade do material, considerada constante.

Uma expressão analítica para $\psi$ deve seguir as seguintes hipóteses (LEMAITRE, 1996):

- elasticidade linear e isotrópica;

- nenhum acoplamento entre elasticidade e plasticidade e entre dano e plasticidade;

- princípio de equivalência de tensões $\tilde{\boldsymbol{\sigma}}(1-D)=\boldsymbol{\sigma}$;

- não há efeito dinâmico na plasticidade - encruamento não depende da taxa de deformação;

- saturação do encruamento isotrópico para altas deformações plásticas; 
- processo isotérmico.

Assim, define-se a energia livre de Helmholtz como sendo:

$$
\psi=\frac{1}{\rho}\left\{\frac{1}{2} \mathbf{A}: \varepsilon^{e}: \varepsilon^{e}(1-D)+R_{\infty}\left[r+\frac{1}{b} \exp (-b r)\right]\right\}
$$

onde A é o tensor de quarta ordem da rigidez e $R_{\infty}$ e $b$ são parâmetros do material que descrevem o encruamento. As hipóteses listadas anteriormente são satisfeitas por esta expressão.

Nota-se que o dano está associado apenas à parte elástica, ou seja, à perda de rigidez do material durante a deformação. Inclusive, conseguimos recuperar a expressão $\tilde{\boldsymbol{\sigma}}=\mathbf{A}: \boldsymbol{\varepsilon}^{e}$, que é a lei de elasticidade para o caso geral:

$$
\boldsymbol{\sigma}=\rho \frac{\partial \psi}{\partial \varepsilon^{e}}=\mathbf{A}: \varepsilon^{e}(1-D) \Longleftrightarrow \tilde{\boldsymbol{\sigma}}=\mathbf{A}: \boldsymbol{\varepsilon}^{e}
$$

O encruamento é dado por:

$$
R=\rho \frac{\partial \psi}{\partial r}=R_{\infty}[1-\exp (-b r)]
$$

o que satisfaz as condições de encruamento isotrópico com saturação para grandes deformações plásticas.

A variável associada $Y$ pode ser escrita como:

$$
Y=\rho \frac{\partial \psi}{\partial D}=-\frac{1}{2} \mathbf{A}: \varepsilon^{e}: \varepsilon^{e}
$$

Definindo-se o trabalho de deformação elástico $W^{e}$ por meio de $\mathrm{d} W^{e}=\boldsymbol{\sigma}$ : $\mathrm{d} \varepsilon^{e}$, Lemaitre (1996) mostra que:

$$
\begin{gathered}
W^{e}=\int \boldsymbol{\sigma}: \mathrm{d} \boldsymbol{\varepsilon}^{e}=\int \mathbf{A}: \boldsymbol{\varepsilon}^{e}(1-D): \mathrm{d} \boldsymbol{\varepsilon}^{e}=\frac{1}{2} \mathbf{A}: \boldsymbol{\varepsilon}^{e}: \boldsymbol{\varepsilon}^{e}(1-D) \\
-Y=\frac{W^{e}}{1-D}
\end{gathered}
$$

$Y$ também pode ser escrito como a variação do trabalho de deformação elástica correspondente a uma variação do dano para tensão e temperatura constantes $(\mathrm{d} \sigma=0)$. Começando com a lei de elasticidade:

$$
\begin{gathered}
\mathrm{d} \boldsymbol{\sigma}=\mathbf{A}:\left[(1-D) \mathrm{d} \boldsymbol{\varepsilon}^{e}-\boldsymbol{\varepsilon}^{e} \mathrm{~d} D\right]=0 \\
\mathrm{~d} \boldsymbol{\varepsilon}^{e}=\boldsymbol{\varepsilon}^{e} \frac{\mathrm{d} D}{1-D}
\end{gathered}
$$




$$
\begin{gathered}
\left.\mathrm{d} W^{e}\right|_{\boldsymbol{\sigma}, T=\text { constantes }}=\boldsymbol{\sigma}: \mathrm{d} \boldsymbol{\varepsilon}^{e}=\boldsymbol{\sigma}: \boldsymbol{\varepsilon}^{e} \frac{\mathrm{d} D}{1-D}=\mathbf{A}: \boldsymbol{\varepsilon}^{e}(1-D): \boldsymbol{\varepsilon}^{e} \frac{\mathrm{d} D}{1-D} \\
\left.\frac{\mathrm{d} W^{e}}{\mathrm{~d} D}\right|_{\boldsymbol{\sigma}, T=\text { constantes }}=\mathbf{A}: \boldsymbol{\varepsilon}^{e}: \boldsymbol{\varepsilon}^{e} \\
-Y=\left.\frac{1}{2} \frac{\mathrm{d} W^{e}}{\mathrm{~d} D}\right|_{\boldsymbol{\sigma}, T=\text { constantes }}
\end{gathered}
$$

relação que explica a definição de $Y$ como a taxa de dissipação do trabalho de deformação elástica. Essa é a energia perdida pela perda de rigidez do elemento volumétrico devido ao dano.

Lemaitre (1996) também mostra que $Y$ pode ser escrito como função da tensão hidrostática $\sigma_{H}$ e da tensão equivalente de Von Mises $\sigma_{e q}($ ver Apêndice B):

$$
-Y=\frac{\sigma_{e q}^{2}}{2 E(1-D)^{2}}\left[\frac{2}{3}(1+\nu)+3(1-2 \nu)\left(\frac{\sigma_{H}}{\sigma_{e q}}\right)^{2}\right]
$$

Podemos definir o termo $R_{v}$ como sendo o fator de triaxialidade. Quanto maior este termo, mais o comportamento do material se assemelha a um comportamento frágil.

$$
R_{v}=\frac{2}{3}(1+\nu)+3(1-2 \nu)\left(\frac{\sigma_{H}}{\sigma_{e q}}\right)^{2}
$$

A Segunda Lei da Termodinâmica enuncia que a dissipação de energia no interior do material deve ser positiva. Deste modo, a seguinte relação deve ser satisfeita (CHABOCHE, 1988a):

$$
\boldsymbol{\sigma}: \dot{\boldsymbol{\varepsilon}}^{p}-R \dot{r}-Y \dot{D} \geq 0
$$

Lemaitre (1996) assume que a dissipação devido à deformação plástica pode ser negligenciada, de tal forma que é suficiente afirmar que:

$$
-Y \dot{D} \geq 0
$$

de onde conclui-se que $\dot{D} \geq 0$, pois $-Y$ é uma função quadrática, ou seja, positiva.

Vamos assumir um potencial de dissipação $\phi$, função das variáveis de estado e de suas variáveis associadas. Este potencial, por hipótese está desacoplado do potencial de dissipação da deformação plástica (LEMAITRE, 1996). Podemos assumir que as equações cinéticas, em particular do dano, são derivadas a partir deste potencial. Por exemplo:

$$
\dot{D}=-\dot{\lambda} \frac{\partial \phi}{\partial Y}
$$


onde $\dot{\lambda}$ é fator multiplicativo escalar e positivo. Ver o Apêndice C para mais detalhes.

Este formalismo permite a derivação de diversos modelos, os quais dependem de uma escolha particular para a expressão analítica da função $\phi$. Os modelos devem descrever a evolução do dano para um tipo de solicitação, que pode ser fadiga mecânica, fluência, grandes deformações plásticas, e comprovados por experimentos. Neste trabalho nos preocupamos com os modelos desenvolvidos para as condições de fratura dúctil.

\subsection{Modelos de evolução do dano para grandes defor- mações plásticas}

O modelo mais simples existente para a evolução do dano na chamada fratura dúctil, aquela que envolve grandes deformações plásticas, é o desenvolvido por Lemaitre (1985). Neste modelo, Lemaitre mostrou que (ver Apêndice C):

$$
\dot{\lambda}=\dot{p}(1-D)
$$

de modo que a equação de evolução torna-se:

$$
\dot{D}=-\frac{\partial \phi}{\partial Y} \dot{p}(1-D)
$$

Como resultado do experimento mostrado na Fig. 2.5, a Fig. 2.7 foi montada e mostra como o dano evolui durante o ensaio de tração de uma corpo de prova de cobre com 99,9\% de pureza. A medida do dano foi feita de maneira indireta, por meio da variação do módulo de elasticidade aparente.

$$
D=1-\frac{\tilde{E}}{E}
$$

Nota-se que o dano é constantemente zero até um valor crítico de deformação. O dano aumenta linearmente com a deformação plástica. Lemaitre (1996) comenta sobre as seguintes observações experimentais:

- A evolução do dano $\dot{D}$ é proporcional ao incremento de deformação plástica acumulada.

$$
\dot{D} \sim-Y \dot{p} \Longleftrightarrow \phi \sim(-Y)^{2}
$$

- Deve haver um parâmetro de resistência ao dano, característico de cada material, o qual denominaremos pelo símbolo $S$. A evolução do dano deve ser inversamente proporcional 


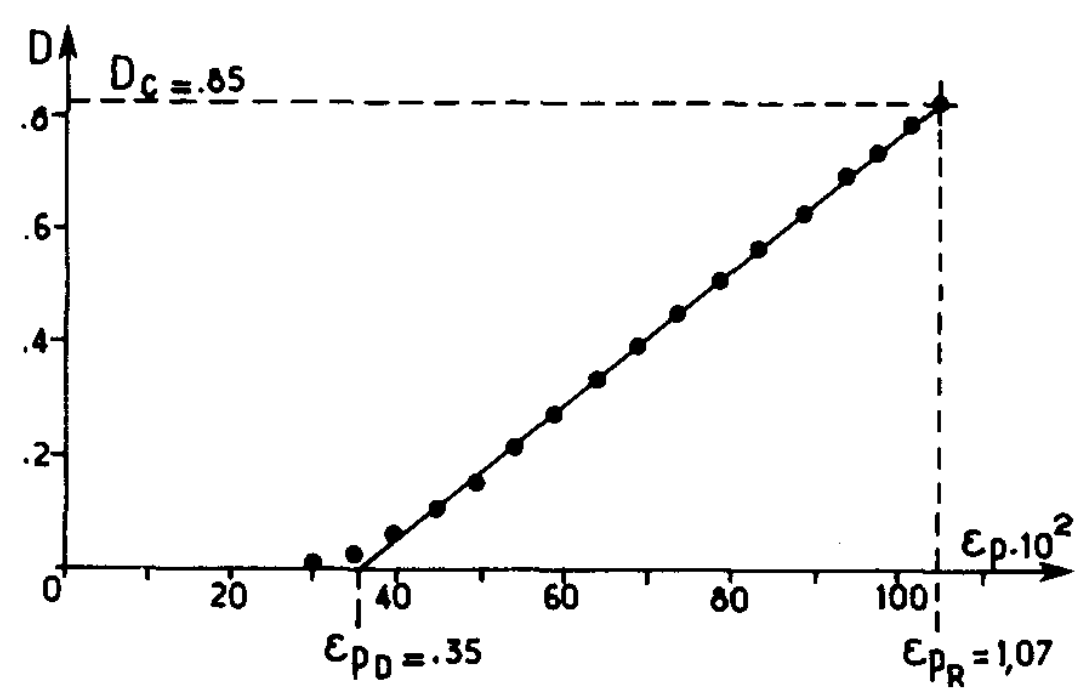

Figura 2.7: Evolução do dano no ensaio de tração a do cobre 99,9\% (LEMAITRE, 1984).

a este parâmetro.

$$
\dot{D} \sim \frac{-Y}{S} \dot{p} \Longleftrightarrow \phi \sim \frac{(-Y)^{2}}{S}
$$

- Caso $Y$ e $\dot{p}$ permaneçam constantes, não há relato experimental de que a taxa de evolução do dano diminua. Assim, devemos adicionar um fator $(1-D)$ ao denominador, para cancelar com o fator $(1-D)$ no numerador proveniente de $\dot{\lambda}=\dot{p}(1-D)$.

$$
\dot{D} \sim \frac{-Y}{S(1-D)} \dot{p} \Longleftrightarrow \phi \sim \frac{(-Y)^{2}}{S(1-D)}
$$

- A evolução do dano só a partir de um valor de deformação plástica acumulada crítico $p=p_{D}$.

Uma escolha do potencial $\phi$ que seja compatível com tais observações experimentais é:

$$
\phi=\frac{(-Y)^{2}}{2 S(1-D)} \mathrm{H}\left(p-p_{D}\right)
$$

onde $S$ é o parâmetro de resistência do dano do material e $\mathrm{H}\left(p-p_{D}\right)$ é uma função degrau:

$$
\mathrm{H}\left(p-p_{D}\right)= \begin{cases}1 & \text { se } p \geq p_{D} \\ 0 & \text { se } p<p_{D}\end{cases}
$$

Deste modo, a equação que rege a evolução do dano é:

$$
\dot{D}=\frac{-Y}{S} \dot{p} \mathrm{H}\left(p-p_{D}\right)=\frac{\sigma_{e q}^{2} R_{v} \dot{p}}{2 E S(1-D)^{2}} \mathrm{H}\left(p-p_{D}\right)
$$


Se considerarmos um carregamento monotônico e que o nível de deformação elástica é desprezível frente às deformações totais $\left(\varepsilon \approx \varepsilon^{p}\right)$, podemos assumir que $p \approx \varepsilon$. Deste modo, a partir do momento que a a deformação plástica acumulada ultrapassa o valor limite $p_{D}$, temos que:

$$
\mathrm{d} D=\frac{\sigma_{e q}^{2} R_{v}}{2 E S(1-D)^{2}} \mathrm{~d} \varepsilon
$$

Esta equação modela o crescimento da variável de dano até esta atingir o valor crítico $D=D_{c}$, que implica na falha do material. O valor crítico $D_{c}$ é calculado assumindo que a quantidade de energia dissipada no crescimento da variável de dano é constante no momento da fratura (LEMAITRE, 1996). Deste modo temos:

$$
\int_{0}^{D_{c}}(-Y) \mathrm{d} D=\int_{0}^{D_{c}} \frac{\sigma_{e q}^{2} R_{v}}{2 E S(1-D)^{2}} \mathrm{~d} D=\text { constante na fratura }
$$

Além disso, Lemaitre (1996) também mostra que no estágio de instabilidade logo antes da fratura se iniciar, o valor da taxa de dissipação da energia de deformação permanece praticamente constante.

Do ensaio de tração uniaxial, podemos aproximar que $\sigma_{e q}$ é igual a $\sigma_{f}$, que é a tensão na fratura do corpo de prova, $R_{v} \approx 1$ e $D=D_{1 c}$, tomado como sendo o dano crítico para um carregamento uniaxial. Aqui vamos ressaltar que na região da estricção o estado de tensões não é uniaxial, e que a aproximação $R_{v} \approx 1$ pode não ser válida. Tal fato será verificado quando da aplicação do modelo nas simulações numéricas. Assim:

$$
-Y=\frac{\sigma_{f}^{2}}{2 E\left(1-D_{1 c}\right)^{2}}
$$

Porém, a seguinte aproximação pode ser efetuada. Na fratura em condição de carregamento uniaxial, a máxima tensão suportada pelo material é a tensão última $\sigma_{u}$. Logo, podemos aproximar a tensão efetiva à qual o material está submetido $\sigma_{f} /\left(1-D_{1 c}\right)$ por esta tensão última, visto que a tensão deve ter um valor finito mesmo na mais crítica condição, de modo que:

$$
-Y=\frac{\sigma_{u}^{2}}{2 E}
$$

e, portanto:

$$
\int_{0}^{D_{c}}(-Y) \mathrm{d} D=\frac{\sigma_{u}^{2}}{2 E} D_{1 c}
$$

Em uma condição de carregamento tridimensional genérica:

$$
\int_{0}^{D_{c}}(-Y) \mathrm{d} D=(-Y) D_{c}=\frac{\sigma_{e q}^{2} R_{v}}{2 E(1-D)^{2}} D_{c}
$$


Igualando os dois valores, chegamos à conclusão que:

$$
D_{c}=\frac{D_{1 c}}{R_{v}}\left[\frac{\sigma_{u}}{\sigma_{e q}}(1-D)\right]^{2}
$$

Deste modo o modelo para avaliação do dano no processo de fratura dúctil está completo. Resta, no entanto, mostrar como podem ser determinados experimentalmente os parâmetros do material para que possamos confrontar os resultados.

\subsection{Caracterização de um material no contexto da me- cânica do dano}

Dentro do contexto da mecânica do dano, um material tem quatro parâmetros que o caracterizam, além dos parâmetros clássicos da teoria da plasticidade, sendo eles:

- valor de dano crítico na condição de tensão uniaxial $D_{1 c}$;

- limite de resistência à tração $\sigma_{u}$;

- deformação plástica acumulada limite para surgimento do dano $p_{D}$;

- resistência ao dano $S$.

Em primeiro lugar, é necessário definir uma maneira de se medir o dano experimentalmente de modo a validar o modelo. Diversas maneiras diretas e indiretas de medição do dano são propostas na literatura, as quais foram compiladas por Racha (2008) na Tab. 2.2.

A maneira direta de se medir a variável de dano em um material é por meio da fração de vazios, avaliada por meio de micrografias. Para metais, um aumento de 1000 vezes é suficiente para a determinação precisa de vazios (LEMAITRE, 1996). Esta medida, no entanto, é local e como o dano normalmente não é isotrópico em um material, podemos estar olhando para uma região não danificada, ou danificada demais, em relação ao restante do material.

As maneiras indiretas mais comuns de medição do dano são a medição pela variação do módulo de elasticidade e pela micro-dureza, como demonstrado por Lemaitre (1996). A medição pelo módulo de elasticidade mostra um valor de dano médio, porém exige máquinas de ensaio de tração bem precisas de modo a capturar com exatidão a variação sensível nesta propriedade mecânica. A medida pela micro-dureza é local e conta com a vantagem de ser não-destrutiva. Maiores detalhes acerca das técnicas experimentais para medição do dano em materiais metálicos serão apresentadas na Sec. 4.1. 
Tabela 2.2: Qualidade dos métodos de medição de dano. Adaptado de Racha (2008).

\begin{tabular}{cc}
\hline Método & Variável de dano \\
\hline Micrografia & $D=\frac{\delta \tilde{A}}{\delta A_{0}}$ \\
Variação de densidade & $D=\left(1-\frac{\tilde{\rho}}{\rho}\right)^{\frac{2}{3}}$ \\
Módulo de elasticidade & $D=1-\frac{\tilde{E}}{E}$ \\
Micro-dureza & $D=1-\frac{H}{H^{*}}$ \\
Resistência elétrica & $D=1-\frac{V}{\tilde{V}}$ \\
\hline
\end{tabular}

Isto posto, o primeiro parâmetro para caracterização do material, que é o dano na fratura em condição de carregamento uniaxial $D_{1 c}$, pode ser avaliado experimentalmente. Caso nenhuma das maneiras listadas por Racha (2008) seja possível ou suficientemente precisa, podemos utilizar a aproximação apresentada na seção anterior acerca da tensão máxima que um ponto do material pode suportar e deduzir a seguinte relação:

$$
D_{1 c}=1-\frac{s_{f}}{s_{u}}
$$

onde $s_{f}$ é a tensão de engenharia na fratura e $s_{u}$ é o limite de resistência à tração de engenharia.

A deformação plástica acumulada crítica para o início da danificação do material $\left(p_{D}\right)$ também pode ser obtida do ensaio de tração. Nesta condição de carregamento uniaxial e monotônico, $p_{D}$ pode ser tomado como sendo o valor de deformação plástica no qual se inicia o dano, normalmente coincidente com o valor da deformação no ponto de tensão máxima, que marca o início do empescoçamento do material. Alves (2001) afirma que este parâmetro varia pouco com o estado de tensões aplicado ao corpo de prova.

O último parâmetro a ser avaliado é a resistência ao dano $S$ do material. Da Eq. (2.45), temos que:

$$
\frac{\mathrm{d} D}{\mathrm{~d} \varepsilon}=\frac{\sigma_{e q}^{2} R_{v}}{2 E S(1-D)^{2}}
$$


Em condição uniaxial, $R_{v}=1$ e $\sigma_{e q}=\sigma$. Levantando-se uma curva de dano versus deformação, como da Fig. 2.7, podemos estimar o valor de $\mathrm{d} D / \mathrm{d} \varepsilon$, de modo que:

$$
S=\frac{\sigma^{2}}{2 E(1-D)^{2}(\mathrm{~d} D / \mathrm{d} \varepsilon)}
$$

Deste modo, por meio de um ensaio de tração com sucessivos carregamentos e descarregamentos, de modo a capturar como o módulo de elasticidade efetivo varia com a deformação aplicada, podemos levantar um gráfico $D \times \varepsilon$, como o mostrado na Fig. 2.7, e assim obter todos os parâmetros necessários para a utilização do modelo de Lemaitre.

\subsection{Desenvolvimentos recentes}

O modelo apresentado é aquele desenvolvido para a fratura dúctil de metais por Lemaitre e Chaboche (ver Lemaitre (1984), Lemaitre (1985), Chaboche (1988a), Chaboche (1988b), Lemaitre (1996)). Este modelo tem como hipóteses: isotropia dos defeitos internos e uma evolução linear do dano com a deformação plástica em um regime uniaxial de tensões, o que nem sempre pode ser tomado como verdadeiro, mas serve como ponto de partida para a criação de modelos mais elaborados que levem em conta efeitos que foram descartados.

Por exemplo, Chow e Wang (1987) desenvolvem um modelo considerando um dano anisotrópico, o que acaba substituindo uma variável de dano por um tensor de dano $\mathrm{D}$ que correlaciona o tensor das tensões nominais $\boldsymbol{\sigma}$ com o tensor das tensões efetivo do material danificado $\tilde{\boldsymbol{\sigma}}$. O modelo por ele proposto foi verificado experimentalmente para a liga de alumínio AA 2024 por meio de ensaios de tração e da verificação do aparecimento de um coeficiente de Poisson efetivo $\tilde{\nu}$, relacionado com esta variação do dano conforme a direção tomada.

Baseado em uma diferente escolha da função potencial de dissipação $\phi$, modelos diferentes podem ser derivados, inclusive para outros modos de falha, como fluência, fratura frágil ou fadiga, os quais, no entanto, não são o enfoque deste trabalho. Voltando os modelos de fratura dúctil, alguns exemplos são o modelo de Tai e Yang (1987), que considera que a evolução do dano tem relação com o próprio nível de dano existente, prevendo um crescimento exponencial de D. O modelo de Tie-Jun (TIE-JUN, 1992a) (TIE-JUN, 1992b) consegue recuperar o modelo linear de Lemaitre, mas também prevê uma evolução parabólica, assim como o modelo proposto por Chandrakanth e Pandey (1995), dependendo do valor de um parâmetro de calibração proposto pelos autores.

Modelos não lineares mais complexos também existem. Bonora (1997) leva em conta 
que a evolução do dano em cada instante depende do dano acumulado até o momento e na diferença entre o dano crítico $D_{c}$ e o dano no instante considerado. Deste modo, quanto mais próximo da falha está o material, mais rapidamente o dano crescerá, gerando um modelo não linear. Um outro modelo não linear, com ainda mais parâmetros, foi proposto por Thakkar e Pandey (2007), cujo trabalho também inclui uma revisão sobre todos estes modelos aqui citados.

Thakkar e Pandey (2007) ainda afirmam que modelos lineares ou parabólicos conseguem capturar de maneira satisfatória a evolução do dano para uma ampla classe de metais, tendo como uma das exceções o alumínio. Mesmo assim, o modelo linear foi utilizado por Behrens et al. (2010) com sucesso para predição do dano em ligas de alumínio no ensaio de recalque a frio, conseguindo inclusive capturar o efeito de uma tensão hidrostática de compressão atrasando o surgimento de trincas. Para ligas de aço, o modelo linear foi aplicado por Celentano e Chaboche (2007) para um ensaio de esmagamento das paredes de tubos e conseguiu predizer o local de surgimento dos defeitos, porém com um valor de dano crítico menor do que o esperado.

Mesmo conhecendo estes modelos mais elaborados, no presente trabalho utilizaremos o modelo de linear de Lemaitre (1996), que é mais simples e exige menos parâmetros de calibração. Isto torna a compreensão do fenômeno um pouco mais fácil, embora talvez um ou outro aspecto não consiga ser perfeitamente modelado. Trabalhos futuros podem buscar a calibração destes outros modelos e comparação com os resultados do presente trabalho. 


\section{FRATURA DÚCTIL}

Neste capítulo, o enfoque está em discutir a fundo como se dá o processo de fratura dúctil em materiais metálicos, e quais são os parâmetros do material que controlam tal fenômeno. Em primeiro lugar, vamos apresentar o conceito de conformabilidade.

\subsection{Conformabilidade dos metais}

Durante qualquer processo de conformação mecânica, a matéria prima é sujeita a elevados níveis de deformação plástica, visto que a intenção é dar uma nova forma à peça em questão. A deformação plástica é a maneira que o material encontra de acomodar as discordâncias gastando o mínimo de energia. No entanto, conforme o material vai se deformando, o número de discordâncias vai aumentando e o campos de tensões que estas exercem acabam sendo suficientemente fortes para desagregar o material em pequenas regiões, formando micro-vazios. A evolução destes micro-vazios acaba por formar micro-trincas que levam à falha macroscópica do material.

No volume 14 do ASM Handbook a conformabilidade é definida como sendo a propriedade que se refere à facilidade com que um metal pode ser conformado por meio de deformação plástica, sendo que durante os processos industriais de conformação, o mecanismo que rege a falha dos materiais é a fratura dúctil. A Tab. 3.1 mostra os principais defeitos observados.

A conformabilidade não pode ser considerada uma propriedade inerente a um certo material, pois condições externas, tais como temperatura, estado de tensões ou lubrificação, levam a mudanças significativas no modo de falha ou na deformação verdadeira máxima antes da fratura. Um exemplo clássico é a imposição de uma tensão hidrostática de compressão, que tende a fechar micro-trincas ou dificultar seu crescimento, levando a um aumento na conformabilidade. A microestrutura do material também exerce influência significativa, visto que os micro-vazios se formam preferencialmente em regiões de interface, como contornos de grão, precipitados incoerentes ou contornos de fase, locais estes que são naturais concentradores de 
Tabela 3.1: Modos de falha em processos de conformação. (ASM HANDBOOK, 1996

\begin{tabular}{c|cc}
\hline $\begin{array}{c}\text { Regime de } \\
\text { temperatura }\end{array}$ & Defeitos na estrutura fundida & $\begin{array}{c}\text { Defeitos na estrutura } \\
\text { trabalhada ou recristalizada }\end{array}$ \\
\hline Trabalho a frio & $-(1)$ & $\begin{array}{c}\text { Trincas na superfície livre, } \\
\text { bandas de cisalhamento nas } \\
\text { zonas mortas, trincas internas } \\
\text { (center bursts })\end{array}$ \\
\hline Trabalho a morno & $-(1)$ & $\begin{array}{c}\text { Trincas de ponto triplo, trincas } \\
\text { no contorno de grão }\end{array}$ \\
\hline Trabalho a quente & $\begin{array}{c}\text { Trincas internas (center bursts), } \\
\text { trincas de ponto triplo, } \\
\text { fragilidade devido a impurezas } \\
\text { do fundido }\end{array}$ & $\begin{array}{c}\text { Bandas de cisalhamento, trincas } \\
\text { de ponto triplo }\end{array}$ \\
\hline
\end{tabular}

${ }^{(1)}$ São raros os trabalhos a frio e a morno em estruturas brutas de fundição.

tensão.

Como tais micro-vazios se formam e como eles crescem até a formação de uma trinca é o tema da próxima seção.

\subsection{O processo da fratura dúctil}

A definição aceita diz que "a fratura dúctil é um modo de falha de um material no qual vazios, sejam preexistentes ou formado durante a deformação, crescem até coalescerem, formando um caminho contínuo de fratura" (GARRISON JR.; MOODY, 1987). No século passado, Henry (1855) analisou o rompimento de barras de ferro e chumbo em tração e observou a formação de um vazio interno na região da fratura. Este foi um dos primeiros registros de estudos da fratura dúctil de um metal. A sugestão de Henry é que uma barra metálica nunca deve ser deformada apenas por uma força de tração na direção de seu eixo sem uma força de compressão transversal, ou as fibras que compõem a barra seriam separadas, levando à sua fratura. Basicamente ele verificou experimentalmente a formação da estricção na fratura dúctil, e acaba sugerindo que mesmo em carregamentos compressivos, a falha do material se daria por um "empescoçamento interno das fibras metálicas".

Tipper (1949) sugeriu pela primeira vez que a fratura dúctil em metais se dá pelo crescimento de vazios que se originam da perda de coesão de inclusões não metálicas, normalmente mais duras e frágeis, com a matriz metálica. Como consequência, a superfície de uma fratura dúctil nunca será lisa, mas sim composta pelos vazios que deram origem à trinca, como mos- 
trado na Fig. 3.1. Trabalhos experimentais posteriores acabaram confirmando essa afirmação, porém existem casos em que outras regiões que não partículas de uma segunda fase agem como nucleadores de vazios como, por exemplo, nas ligas de titânio $\alpha$ - $\beta$, onde os vazios são nucleados e crescem em uma das fases (na fase $\alpha$ para temperatura ambiente ou na fase $\beta$ para trabalho a quente), o que possibilita controlar a ductilidade dessas ligas por meio do controle do tamanho e distribuição das fases (SEMIATIN et al., 1999). Também já foi sugerido que os micro-vazios se formam por condensação de lacunas atômicas (WILSDORF, 1983), embora pouca evidência experimental neste sentido tenha sido encontrada.

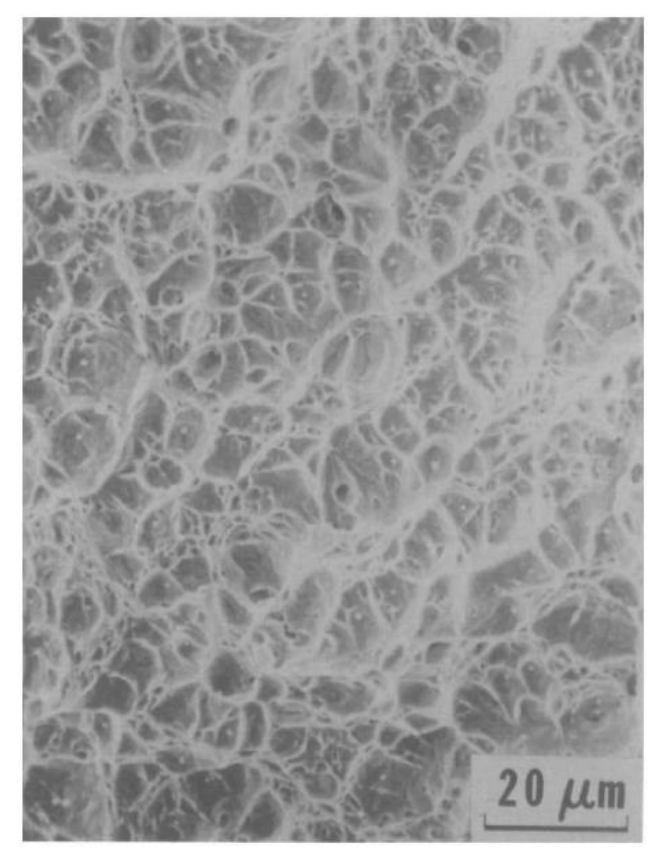

Figura 3.1: Micrografia eletrônica da superfície de fratura de um corpo de prova de ensaio de tenacidade ilustrando o coalescimento dos vazios, formando os chamados dimples. (GARRISON JR.; MOODY, 1987)

O grande nível de deformação plástica local nos dimples sugere que a fratura dúctil seja caracterizada por alta absorção de energia antes da falha, o que não pode ser tomado como uma verdade absoluta. A energia absorvida na formação de uma superfície de fratura dúctil está vinculada não só com a resiliência do material, mas também com o modo do carregamento externo (tração, compressão ou torção). Deste modo, um mesmo material pode falhar por fratura dúctil absorvendo diferentes quantidades de energia, dependendo do ensaio mecânico ao qual foi submetido (GARRISON JR.; MOODY, 1987).

O processo de fratura dúctil pode ser dividido em três estágios: nucleação, crescimento e coalescimento de vazios. Evidências experimentais sugerem que os vazios se nucleiam mais facilmente ao redor das inclusões de maior tamanho (GURLAND, 1972), o que sugere que a diminuição do tamanho médio das partículas de segunda fase deve aumentar a deformação crítica 
de nucleação. Gurland também concluiu que a nucleação se dá pela fratura destas inclusões, as quais em seu trabalho eram cementita esferoidizada em um aço ferramenta, nos estágios iniciais da deformação, gerando perda de coesão com a matriz metálica. French e Weinrich (1974) estudaram o efeito do estado de tensões na nucleação de vazios em um aço SAE 1050 esferoidizado, e concluíram que tensões hidrostáticas compressivas ajudam a retardar a nucleação de vazios até um certo valor crítico de pressão. Aumentar a tensão hidrostática além deste valor gera poucos benefícios, o que indica que não só tensões, mas deformações também devem ser levadas em conta em modelos de fratura dúctil.

O mecanismo de crescimento dos vazios e propagação de uma trinca dúctil é analisado por Schwalbe (1977) no contexto da microestrutura do material. O autor discute o efeito da matriz e das inclusões na resistência macroscópica do material e propõe que uma maneira de se melhorar as propriedades mecânicas de um material com respeito a fratura dúctil seria o refinamento dos precipitados. Partículas menores necessitam de deformações plásticas maiores para fraturarem, dificultando a perda de coesão com a matriz. Outro modo de se melhorar o material seria aumentar a distância entre esses precipitados, dificultado o coalescimento das micro-cavidades.

Por outro lado, uma abordagem contínua do processo de crescimento de vazios pode ser desenvolvida, como os modelos listados a seguir, todos eles modelando o micro-cavidades isoladas. O modelo de McClintock (1968) para vazios cilíndricos de grande relação comprimentodiâmetro em uma matriz que isenta de encruamento foi o pioneiro nesta linha de pesquisa, contudo subestima o crescimento das cavidades. Tal erro está associado com a hipótese de uma geometria dos vazios que não condiz com a realidade, embora o modelo sugira corretamente que a taxa de crescimento cresce com a relação de triaxialidade $\sigma_{H} / \sigma_{e q}$, isto é, a relação entre a tensão hidrostática e a tensão equivalente de von Mises, que indica o quão longe do estado uniaxial de tensões é o carregamento em cada elemento (detalhes mostrados no Cap. 2). O modelo de Rice e Tracey (1969) trata o crescimento de vazios esféricos, que são mais realistas do que os vazios cilíndricos, e apresenta melhores resultados, porém funciona apenas para pequenas deformações, o que inviabiliza sua aplicação nos processos de conformação industriais. Vale notar que na época em que foram desenvolvidos estes modelos, a capacidade computacional era praticamente nula, e modelos complexos que levassem em conta a interferência entre vazios seria de aplicação prática restrita.

A coalescência dos vazios já foi definida como o momento da falha do material em si, porém hoje é considerada um estágio distinto do processo de fratura dúctil. As grandes dificuldades no modelamento dessa fase encontram-se em determinar uma equação que defina 
o escoamento de uma matriz metálica com vazios internos e em como tratar a localização de deformações. Gurson (1977) propôs um modelo de plasticidade de materiais porosos no qual a matriz se plastifica mais facilmente conforme o nível de vazios em seu interior aumenta. $\mathrm{O}$ modelo é amplamente utilizado na literatura, embora Thompson (1987) discuta sua validade baseado em observações experimentais. Thompson também sugere que a localização das tensões sucede o coalescimento dos vazios, enquanto o trabalho de Garrison Jr. e Moody (1987) discute o mecanismo coalescimento por folhas de cavidades (void sheet), no qual a localização de deformações devido a duas cavidades maiores é responsável pela formação de microcavidades em um caminho reto entre as duas cavidades maiores.

Thompson (1987) afirma que o esforço maior no campo de pesquisa da fratura dúctil seria a criação de modelos estocásticos que considerem não valores singulares para parâmetros como tamanho, distribuição ou formato de inclusões, mas sim distribuições estatísticas. A partir da década de 1990, tais modelos começaram a evoluir, muito em função do aumento da capacidade computacional, possibilitando modelos numéricos mais complexos.

Por exemplo, Tvegaard e Hutchinson (2002), por meio de simulações, analisam dois modelos de crescimento de vazios diferentes baseados na função de plasticidade de meios porosos de Gurson, sendo que um considera o crescimento de cada vazio isoladamente com interação apenas no coalescimento enquanto que o segundo considera a interação entre múltiplos vazios em todas as fases da fratura. Os autores concluem que ambos os modelos são válidos, dependendo da fração inicial de vazios presente no material $f_{0}$. Trabalhos ainda mais recentes, como o de Tian et al. (2010), começam a estudar numericamente efeitos tridimensionais, avaliando inclusive o surgimento de vazios na direção transversal à direção de propagação da trinca, expandindo o modelo de coalescimento por folhas de cavidades.

Desta análise da literatura, podemos tirar três conclusões qualitativas:

- o processo de fratura dúctil se dá pelo crescimento de vazios em um mecanismo governado pela deformação plástica localizada;

- partículas de segunda fase são os principais nucleadores dos vazios, sendo que quanto maior a partícula, mais fácil a nucleação;

- quanto maior a condição de triaxialidade das tensões, mais rápido se dá a fratura dúctil.

Os ensaios utilizados para a verificação experimental da ductilidade são listados na Sec. 3.4. Na próxima seção, apresentamos alguns critérios macroscópicos de falha de um material por fratura dúctil. 


\subsection{Critérios de falha}

Embora seja um conceito bastante antigo, ainda hoje não existe uma maneira plenamente aceita de quantificar a conformabilidade. Alguns autores propõem critérios macroscópicos que, embora não sejam considerados leis fundamentais do material, conseguem descrever de maneira satisfatória quando uma dada peça em certos estados de tensões específicos falhará. Talvez o critério mais conhecido seja o publicado por Cockroft e Latham (1968). Neste trabalho, os autores partem do princípio que a formação de trincas na conformação de metais está associada às tensões locais de tração, mesmo em processos predominantemente compressivos, como forjamento.

A análise primordial que Cockroft e Latham efetuam é na região de estricção formada pelo corpo de prova cilíndrico durante o ensaio de tração. Eles concluem que a tensão na região da fratura pode ser decomposta em duas parcelas: uma componente efetiva que é constante em todo o pescoço e uma componente hidrostática que varia de um valor nulo na periferia até um valor máximo no centro do corpo de prova. Como a tensão efetiva não é influenciada pelo formato do pescoço, ela não pode fazer parte do critério de falha, visto que existem evidências experimentais que comprovam a influência da geometria da região de estricção. Deste modo, deve ser o trabalho da componente hidrostática que contribui para a fratura. Daí é derivado o critério básico de falha de Cockroft e Latham:

$$
C=\int_{0}^{\varepsilon_{f}} \sigma_{1} \mathrm{~d} \varepsilon
$$

onde $\sigma_{1}$ é a máxima tensão de tração, $\varepsilon$ é a deformação efetiva e $\varepsilon_{f}$ é a deformação no instante da fratura. $\mathrm{O}$ critério de Cockroft e Latham tem uma desvantagem por não considerar todo o estado de tensões ao qual o material está submetido.

Oyane et al. (1980) apresentaram um critério de falha diferente, baseado em equações de plasticidade para materiais porosos. Por hipótese, os autores assumem que após o início da fratura, que se dá com uma deformação $\varepsilon_{f}$, o material, mesmo que livre de poros, segue o comportamento de materiais porosos. Isso leva ao seguinte critério:

$$
C=\int_{0}^{\varepsilon_{f}}\left(1+\frac{\sigma_{H}}{A \sigma_{e q}}\right) \mathrm{d} \varepsilon
$$

onde $A$ é uma constante do material, $\sigma_{H}$ é a tensão hidrostática (igual a 1/3 do traço do tensor das tensões) e $\sigma_{e q}$ é a tensão equivalente de von Mises. Os autores testaram o critério por meio de um experimento de recalque a frio de cilindro e a comparação entre os valores calculados e medidos de redução máxima na altura se mostrou muito próxima. Nenhuma menção a 
conformação a quente é feita no trabalho.

Diversos outros critérios existem. A Tab. 3.2 mostra alguns dos mais utilizados. Certos critérios, como o de Freudenthal (1950), que integra o trabalho da tensão equivalente de von Mises $\sigma_{e q}$, são bastante contestados. Hoje, acredita-se que nem todo trabalho plástico é responsável pelo crescimento dos vazios internos do material. Além disso, sabe-se experimentalmente que o estado de tensões influencia muito na falha do material, o que não é contabilizado por este critério. O critério de Rice e Tracey (1969) baseia-se em na teoria da plasticidade dos meios contínuos aplicada a um material incompressível com um vazio perfeitamente esférico sujeito a uma tensão de tração ao longe e com taxa de deformação constante.

É interessante notar como a relação $\sigma_{H} / \sigma_{e q}$ aparece repetidamente. Quanto mais distante de 1 for a relação $\sigma_{H} / \sigma_{e q}$, maior será a condição de triaxialidade das tensões. Lemaitre (1996) afirma que alta triaxialidade leva o material a um comportamento mais próximo do frágil, facilitando o surgimento e propagação de trincas.

Tabela 3.2: Critérios macroscópicos para fratura dúctil.

\begin{tabular}{|c|c|c|}
\hline Critério & Equação & Referência \\
\hline $\begin{array}{l}\text { Máxima tensão } \\
\text { principal }\end{array}$ & $C=\int_{0}^{\varepsilon_{f}} \sigma_{1} \mathrm{~d} \varepsilon$ & $\begin{array}{c}\text { Cockroft e } \\
\text { Latham (1968) }\end{array}$ \\
\hline $\begin{array}{l}\text { Plasticidade de } \\
\text { meios porosos }\end{array}$ & $C=\int_{0}^{\varepsilon_{f}}\left(1+\frac{\sigma_{H}}{A \sigma_{e q}}\right) \mathrm{d} \varepsilon$ & $\begin{array}{l}\text { Oyane et al. } \\
\quad(1980)\end{array}$ \\
\hline $\begin{array}{l}\text { Trabalho plástico } \\
\text { total }\end{array}$ & $C=\int_{0}^{\varepsilon_{f}} \sigma_{e q} \mathrm{~d} \varepsilon$ & $\begin{array}{l}\text { Freudenthal } \\
\quad(1950)\end{array}$ \\
\hline $\begin{array}{l}\text { Crescimento de } \\
\text { vazios esféricos }\end{array}$ & $C=\int_{0}^{\varepsilon_{f}}\left(\frac{3 \sigma_{H}}{2 \sigma_{e q}}\right) \mathrm{d} \varepsilon$ & $\begin{array}{l}\text { Rice e Tracey } \\
\text { (1969) }\end{array}$ \\
\hline $\begin{array}{c}\text { Tensão } \\
\text { hidrostática }\end{array}$ & $C=\int_{0}^{\varepsilon_{f}} \frac{1}{1-A \sigma_{H}} \mathrm{~d} \varepsilon$ & $\begin{array}{l}\text { Norris Jr. et al. } \\
\quad(1977)\end{array}$ \\
\hline $\begin{array}{l}\text { Fator de } \\
\text { triaxialidade }\end{array}$ & $C=\int_{0}^{\varepsilon_{f}}\left[\frac{2}{3}(1+\nu)+3(1-2 \nu)\left(\frac{\sigma_{H}}{\sigma_{e q}}\right)^{2}\right] \mathrm{d} \varepsilon$ & $\begin{array}{l}\text { Tai e Yang } \\
\quad(1987)\end{array}$ \\
\hline $\begin{array}{l}\text { Trabalho } \\
\text { dissipado pelo } \\
\text { dano }\end{array}$ & $C=\int_{0}^{D_{c}}(-Y) \mathrm{d} D$ & Lemaitre (1996) \\
\hline
\end{tabular}


Todas as abordagens listadas na Tab. 3.2 tomam como hipótese que alguma propriedade, normalmente relacionada com a energia dissipada na fratura dúctil, é constante na fratura. Contudo, a abordagem da mecânica do dano desenvolvida por Lemaitre, e apresentada no Cap. 2, busca entender quando o dano se inicia no material virgem e, partir daí, como ele se desenvolve até o momento da falha. Buscar detalhar a evolução desta variável é o grande diferencial deste modelo. Além disso, no modelo de Lemaitre, o dano modifica o estado de tensões do material, acoplando as duas análises.

Todos os critérios favorecem o surgimento de trincas em regiões com maiores tensões de tração, sendo os propostos por Oyane e por Cockroft e Latham os mais utilizados. Há indicações na literatura que qualquer modelo pode ser utilizado, desde que devidamente calibrado. Neste trabalho buscaremos avaliar o método da mecânica do dano de Lemaitre e se sua aplicabilidade é de fato, como afirma o autor, universal.

A seguir serão descritos ensaios de conformabilidade normalmente utilizados para verificar a ductilidade de ligas metálicas.

\subsection{Ensaios de conformabilidade}

Diversos ensaios foram desenvolvidos para a avaliação da conformabilidade de um material, cada qual representando um estado de tensões e de temperaturas típicos de um determinado

processo, industrial ou não, de conformação mecânica. Uma revisão completa encontra-se no ASM Handbook, volume 14.

Os ensaios podem ser separados em três grandes categorias: ensaios de torção, ensaios de compressão e ensaios de tração. Em ensaios de torção, a deformação é causada puramente por cisalhamento, o que possibilita que o material atinja grandes deformações na fratura, devido à não formação de pescoços. Embora o estado de tensões no corpo de prova deste tipo de ensaio seja parecido com aquele dos processos de conformação, as deformações neste objeto são muito mais elevadas do que as presentes num processo industrial devido à massiva reorientação do material, o que causa uma certa perda de representatividade do ensaio. De certo modo, isso acaba sendo uma vantagem em outro aspecto, pois permite a obtenção das curvas de tensão de escoamento-deformação para valores de deformação muito altas, como as do forjamento a quente, o que seria impossível por meio de outros ensaios. Outra desvantagem do ensaio de torção é a heterogeneidade de deformações ao longo do raio, o que implica em uma escolha arbitrária de um ponto da seção transversal para padronização.

Já os ensaios de compressão, também conhecidos como ensaios de recalque, são os 
mais utilizados para avaliação da conformabilidade volumétrica. Várias geometrias de corpos de prova foram desenvolvidas, sendo a mais comum a de formato cilíndrico. Os níveis de deformação no ensaio são semelhantes aos dos processos industriais de conformação volumétrica, assim como o estado de tensões.

Ensaios de tração são úteis para a caracterização de propriedades mecânicas devido ao melhor controle do estado de tensões no corpo de prova (pelo menos no início do ensaio), mas não caracterizam nenhum processo de conformação, em sua maioria compressivos. Além disso, a formação do pescoço, região que concentra tensões e deformações em um estado triaxial complexo, impossibilita a quantificação precisa da deformação na fratura no caso de ensaios em barras cilíndricas.

Uma vantagem dos ensaios de tração sobre os demais é a grande disseminação deste tipo de ensaio no meio industrial, de modo que uma metodologia desenvolvida baseando-se neste tipo de ensaio seria mais facilmente utilizada dentro das fábricas, exigindo menos investimento em máquinas e sensores. O ensaio de tração é regido, no Brasil, pela norma NBR 6152 (1992), que define os tamanhos padronizados dos corpos de prova, métodos de medição das tensões e deformações e faixas de velocidade de conformação permitidas.

Genericamente, os ensaios de tração fornecem como resultado a curva de tensão de engenharia $s$ em função da deformação de engenharia $e$ imposta ao material, como mostrada na Fig. 3.2. Essas propriedades são definidas da seguinte maneira:

$$
s=\frac{F}{A_{0}} \quad \text { e } \quad e=\frac{L-L_{0}}{L_{0}}
$$

onde $F$ é a força medida no ensaio, $L$ é a dimensão do corpo de prova em cada instante, $A_{0}$ é a área da seção transversal inicial e $L_{0}$ é o comprimento inicial do corpo de prova.

Primeiramente, a tensão cresce de maneira linear com a deformação, caracterizando o chamado regime elástico, no qual toda deformação imposta pode ser restituída caso o carregamento externo seja retirado. Após isso, acontece o chamado regime plástico, no qual as deformações são irreversíveis e a tensão cresce de maneira não linear. A partir de um certo momento, a tensão de engenharia atinge um valor máximo e começa a cair, caracterizando o início da estricção, ou "empescoçamento", do corpo de prova. A partir deste estágio, a seção do material começa a diminuir devido aos elevados valores de deformação longitudinal e logo a espécime se rompe.

As propriedades mecânicas obtidas são as seguintes:

- módulo de elasticidade, ou módulo de Young $(E)$ : definida como a inclinação da curva 


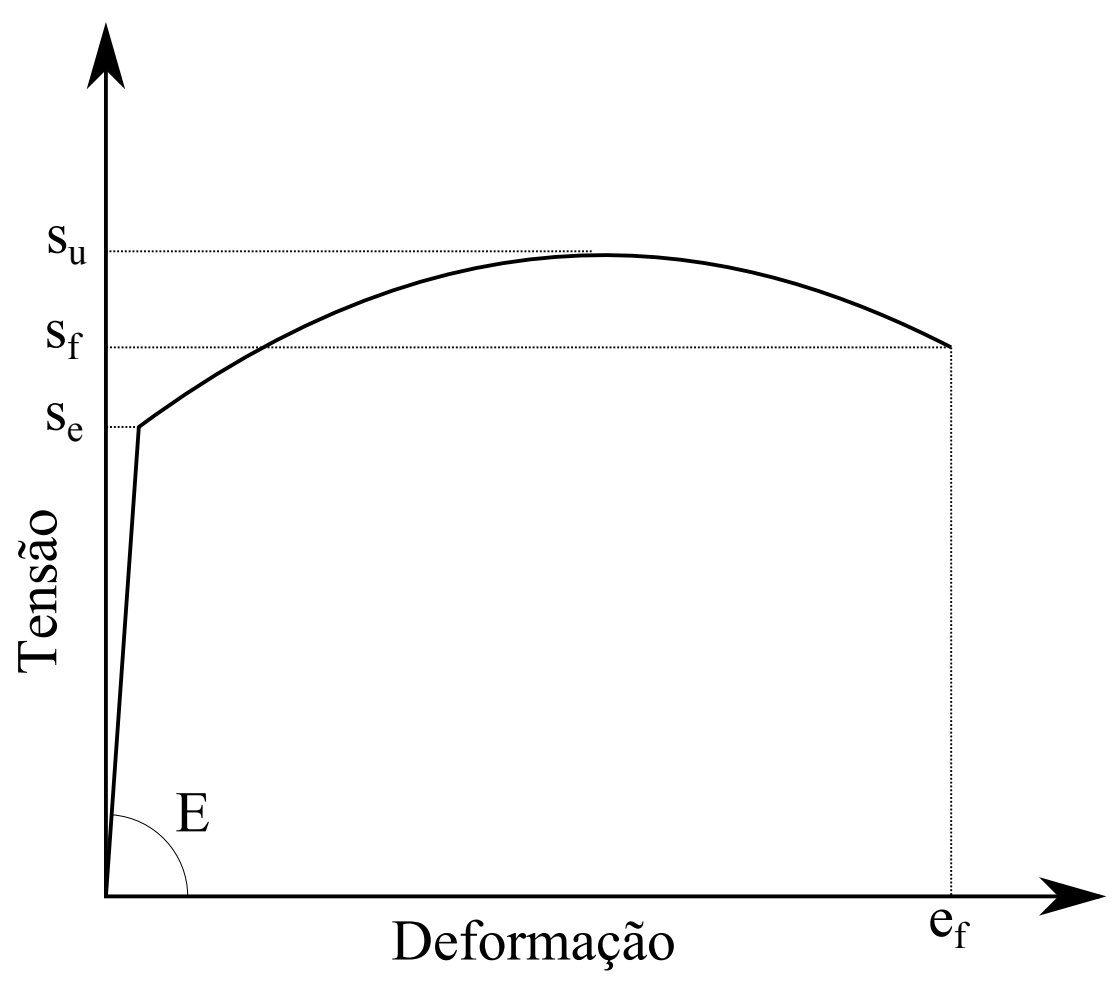

Figura 3.2: Curva tensão-deformação de engenharia retirada de um ensaio de tração genérico e principais propriedades medidas.

no regime elástico;

- tensão de escoamento $\left(s_{e}\right)$ : definida como a tensão a partir da qual o material começa a apresentar regime plástico;

- limite de resistência, ou tensão última $\left(s_{u}\right)$ : definida como a máxima tensão de engenharia admitida pelo material;

- limite de fratura $\left(s_{f}\right)$ : definida como a tensão na fratura da espécime;

- deformação máxima, ou deformação de fratura $\left(e_{f}\right)$ : deformação de engenharia no momento da fratura.

As propriedades mecânicas de tensão e deformação de engenharia devem ser transformadas para seus valores reais, de tensão $\sigma$ e deformação $\varepsilon$, a partir das seguintes relações:

$$
\begin{gathered}
\varepsilon=\ln (1+e) \\
\sigma=s(1+e)
\end{gathered}
$$

Neste trabalho, utilizaremos os ensaios de tração em corpos de prova planos para determinação das propriedades mecânicas relacionadas à evolução do dano. Um maior detalhamento 
da metodologia empregada será mostrado no Cap. 4.

\subsection{Resumo do capítulo}

A ductilidade de um material não é propriedade intrínseca do mesmo, dependendo de uma conjunção de fatores como: estado de tensões ao qual está submetido, nível e tamanho de partículas de segunda fase, histórico de processamento do material, orientação do carregamento imposto em relação ao material e velocidade de deformação, entre outros. Assim, um critério de falhas baseado na fratura dúctil deve ser capaz de levar em conta estes fatores de algum modo.

Lemaitre (1996) afirma que a teoria da mecânica do dano é capaz de prever, baseandose em informações provenientes de um ensaio de conformabilidade, como se dará a evolução dos microvazios, representados pela variável de dano $D$, em qualquer tipo de carregamento mecânico.

Neste trabalho efetuaremos ensaios mecânicos de tração para ligas de aço médio carbono em diferentes condições de microestrutura para determinar as propriedades mecânicas que dizem respeito à evolução do dano e testar o modelo de Lemaitre por meio de simulações numéricas utilizando o método dos elementos finitos.

Os ensaios de caracterização das ligas é assunto do Cap. 4. 


\section{ENSAIOS MECÂNICOS PARA CARACTERIZAÇÃO DOS MATERIAIS}

Como mostrado na Sec. 2.5, os quatro parâmetros que descrevem o comportamento do material no contexto da mecânica do dano podem ser obtidos num ensaio de tração. Neste capítulo abordaremos detalhes dos ensaios e apresentaremos resultados.

\subsection{Revisão da literatura}

Aqui apresentaremos algumas discussões levantadas numa breve revisão bibliográfica sobre a caracterização do dano em materiais dúcteis. Lemaitre (1996) afirma que o dano pode ser medido por diferentes técnicas experimentais, o que foi explorado no trabalho de Alves (2001), no qual o autor mediu o dano em aço carbono por diversos métodos diferentes e encontrou diferenças no valor de dano crítico em um ensaio de tração quasi-estático. Os resultados encontram-se na Tab. 4.1.

Tabela 4.1: Dano crítico em ensaio de tração quasi-estático segundo diferentes técnicas de medição (ALVES, 2001).

\begin{tabular}{cc}
\hline Método & Dano crítico \\
\hline Fração de vazios (medida local) & 0,0075 \\
Módulo de elasticidade (medida média) & 0,45 \\
Micro-dureza (medida local) & 0,041 \\
Resistência elétrica (medida média) & 0,20 \\
\hline
\end{tabular}

O autor afirma que o dano crítico é dependente da técnica de medição utilizada, e portanto não é um parâmetro constante do material. Assim, deve-se especificar claramente qual a definição de dano adotada.

No tocante à medição por variação do módulo de elasticidade, Alves chama a atenção para o problema da localização de deformações na região da estricção durante os estágios finais do ensaio de tração, que leva o estado de tensões deixar de ser uniaxial e uniforme. Deste 
modo, o autor aconselha a utilização de um fator de correção, como o apresentado em Alves, Yu e Jones (2000), com o intuito de melhorar a determinação do valor de dano crítico. A medida do módulo de elasticidade corrigido $E_{c}$, por este fator de correção, é dada por:

$$
E_{c}=\frac{F}{A_{0} \varepsilon \exp \left(-\varepsilon^{p}\right)}
$$

onde $F$ é a força no ensaio de tração, $A_{0}$ é a área inicial da seção transversal do corpo de prova, $\varepsilon$ é a deformação total e $\varepsilon^{p}$ é a parcela plástica desta deformação. Nos resultados que serão apresentados neste trabalho tal correção foi utilizada.

Racha (2008) usou a variação do módulo de elasticidade para caracterizar a evolução do dano em quatro ligas de alumínio, sendo elas AA 7075-T6, AA 6061-T651, AA 2024-851 e AA 2024-O. O autor efetua ensaios em barras lisas e barras com entalhe para avaliar o efeito de um estado triaxial de tensões imposto na região de fratura. $\mathrm{O}$ autor justifica o uso da técnica de medição da variação do módulo de elasticidade por meio de ensaio de tração com sucessivos carregamentos e descarregamentos listando as seguintes vantagens:

- esta técnica produz resultados mais precisos numa escala macroscópica do que qualquer outra técnica experimental;

- os parâmetros da mecânica do dano assim obtidos são dependentes do material, não da geometria;

- os parâmetros podem ser utilizados para modelos de fratura dúctil em diferentes tipos de carregamento.

A terceira afirmação é relevante para o presente trabalho, visto que buscamos aplicar os modelos de mecânica do dano para prever falhas em materiais sujeitos a carregamentos predominantemente planares, e não uniaxiais, utilizando um ensaio de tração para caracterização de parâmetros de material. Com suporte no trabalho de Racha (2008), utilizaremos, portanto, a variação do módulo de elasticidade para determinar o dano no material.

\subsection{Material estudado}

Aços carbono, em especial na forma de chapas, são os produtos metálicos produzidos em maior quantidade no mundo. Economicamente, o segmento de chapas planas é dominado pelos aço de baixo teor de carbono, isto é, até $0,3 \%$ em porcentagem mássica, devido à maior conformabilidade presente nestas ligas. No entanto, devido ao baixo teor de carbono, tais ligas não podem 
receber tratamento térmico posterior, o que limita a gama de propriedades mecânicas que se pode conferir a tais materiais (PLAUT et al., 2009).

Neste trabalho buscaremos avaliar o aço SAE 1050 esferoidizado, cuja composição química é mostrada na Tab. 4.2. Aços carbonos apresentam geralmente em sua microestrutura uma combinação entre ferrita, fase metálica cristalina cúbica de corpo centrado e também conhecida como ferro- $\alpha$, e carbonetos de diversas morfologias. A quantidade relativa, morfologia e distribuição destas fases são refletidas nas propriedades mecânicas do material.

Tabela 4.2: Composição química do aço SAE 1050 (em porcentagem mássica).

\begin{tabular}{ccccc}
\hline $\mathrm{C}$ & $\mathrm{Mn}$ & $\mathrm{P}$ (máx.) & $\mathrm{S}$ (máx.) & $\mathrm{Fe}$ \\
\hline $0,48-0,55$ & $0,60-0,90$ & 0,040 & 0,050 & restante \\
\hline
\end{tabular}

Os aços médio carbono, como o SAE 1050, não conseguem ser levados até grandes deformações plásticas, o que é um limitante no que diz respeito ao seu uso industrial. Uma das maneiras de contornar este problema é ajustar a morfologia da a cementita presente na perlita, transformando-a, por coalescimento, em estruturas globulares de carbonetos em uma matriz ferrítica, no processo conhecido como esferoidização ou coalescimento.

O potencial termodinâmico desta reação é a redução da energia superficial, visto que a perlita apresenta estrutura lamelar, que tem superfície externa maior do que a estrutura globular. Tal microestrutura é obtida por meio de tratamento térmico de recozimento ou deformação massiva a morno (STOROJEVA et al., 2004).

Segundo o volume 4 do ASM Handbook , aços são submetidos ao processo de esferoidização para melhorar sua conformabilidade a frio e usinabilidade. Os carbonetos globulares são mais difíceis de serem fraturados do que carbonetos em formato lamelar, o que aumenta a ductilidade do material. Deste modo, propriedades mecânicas como limite de escoamento, tensão máxima de tração e alongamento na fratura devem ser menores que aquelas de um aço normalizado ou temperado e revenido. De fato, dentre as microestruturas conhecidas do aço, a esferoidizada é aquela correspondente aos menores níveis de dureza e resistência mecânica da liga. Desta maneira, justificamos o estudo deste aço pela tendência de apresentar uma fratura dúctil pronunciada, o que deve facilitar a aplicação do modelo de Lemaitre, que tem por hipótese um comportamento de fratura puramente dúctil do material.

Para comparação, também efetuaremos ensaios com a liga de aço SAE 1050 laminada a quente, ou seja, com composição de ferrita e perlita tradicional. A Fig. 4.1 mostra as micrografias efetuadas nos corpos de prova antes do ensaio de tração. 
Para uma avaliação metalográfica dos corpos de prova antes do ensaio de tração, estes passaram por um processo padrão de polimento com lixas finas e acabamento com silica coloidal de $0,25 \mu \mathrm{m}$. O ataque utilizado foi nital a 3\%. A Fig. 4.1 mostra o resultado da microscopia ótica para as duas ligas estudadas.

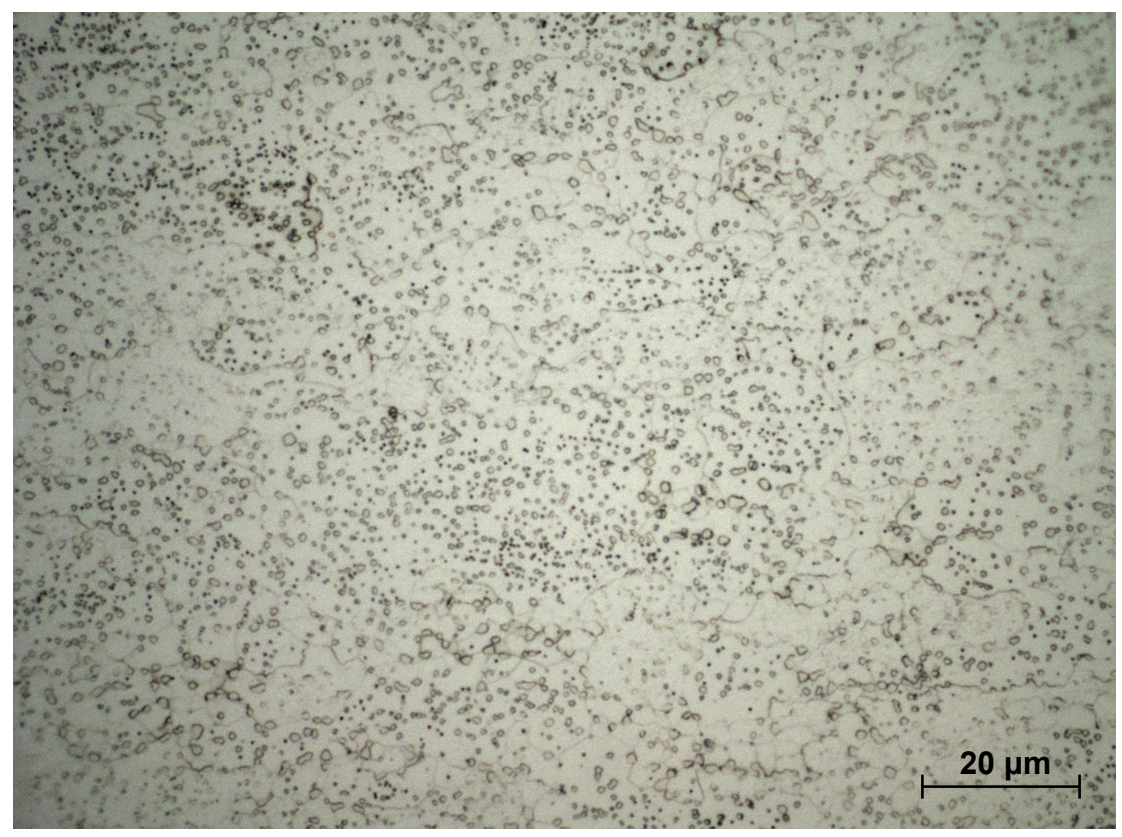

(a)

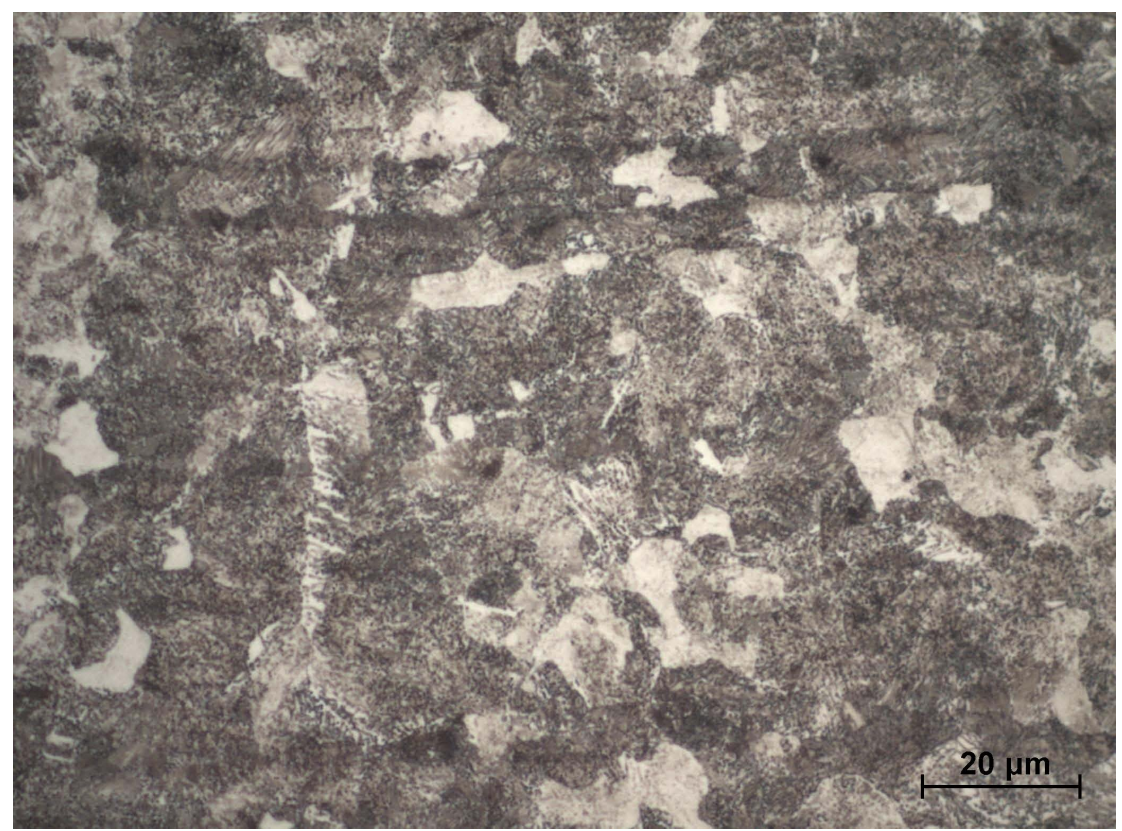

(b)

Figura 4.1: Micrografia das ligas 1050 utilizadas nos ensaios de tração. Aumento de 1000 vezes. Ataque utilizado é nital a 3\%. (a) Material esferoidizado. (b) Material laminado a quente.

Nota-se que, analisando a Fig. 4.1(a), que foi atingido o grau completo de esferoidização da cementita, o que deve dar ao material menores valores de resistência mecânica. Já o 
material laminado a quente, como visto na Fig. 4.1(b), apresenta microestrutura composta por perlita-ferrita, como esperado.

Existem na literatura poucos trabalhos lidando com a evolução da variável contínua do dano em ligas de aço esferoidizadas. Em um deles, Le Roy et al. (1981) mostram detalhadamente como a fração de vazios cresce em um ensaio de tração quasi-estático de corpos de prova cilíndricos. As medidas foram efetuadas por meio de microscopia eletrônica de varredura e os resultados são apresentados na Fig. 4.2. Devido a composição similar, resultados para as ligas 1045 e 1050 esferoidizadas devem ser semelhantes, e passíveis de comparação.

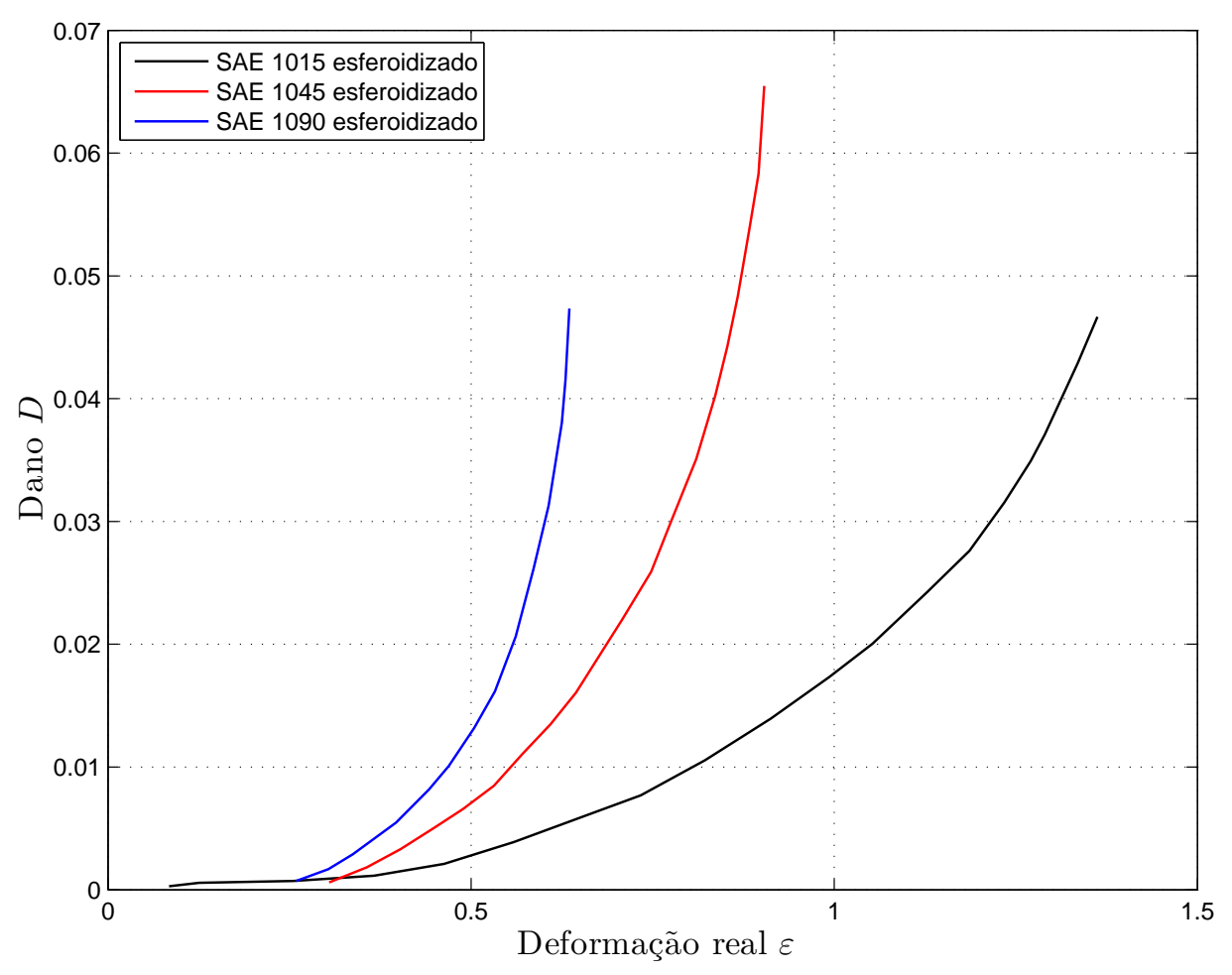

Figura 4.2: Evolução do dano medido diretamente pela fração de vazios para ligas de aço esferoidizadas. Adaptado de Le Roy et al. (1981).

Celentano, Tapia e Chaboche (2004) efetuaram uma caracterização das propriedades de evolução do dano para a liga SAE 1045 laminada a quente semelhante à proposta no presente trabalho, ou seja, por meio da medida da variação do módulo de elasticidade em ensaio de tração. O módulo elástico medido pelos autores, para dez diferentes amostras, é mostrado na Fig. 4.3, em que podemos notar claramente a alta dispersão dos resultados experimentais, a qual será discutida posteriormente neste trabalho. Na figura também estão expostos os resultados para a liga SAE 1020, do trabalho de Celentano e Chaboche (2007).

Vale ressaltar novamente, que as medidas de dano por métodos diferentes não podem ser comparadas devido à própria natureza das medições, ou seja, algumas delas medem efeitos 


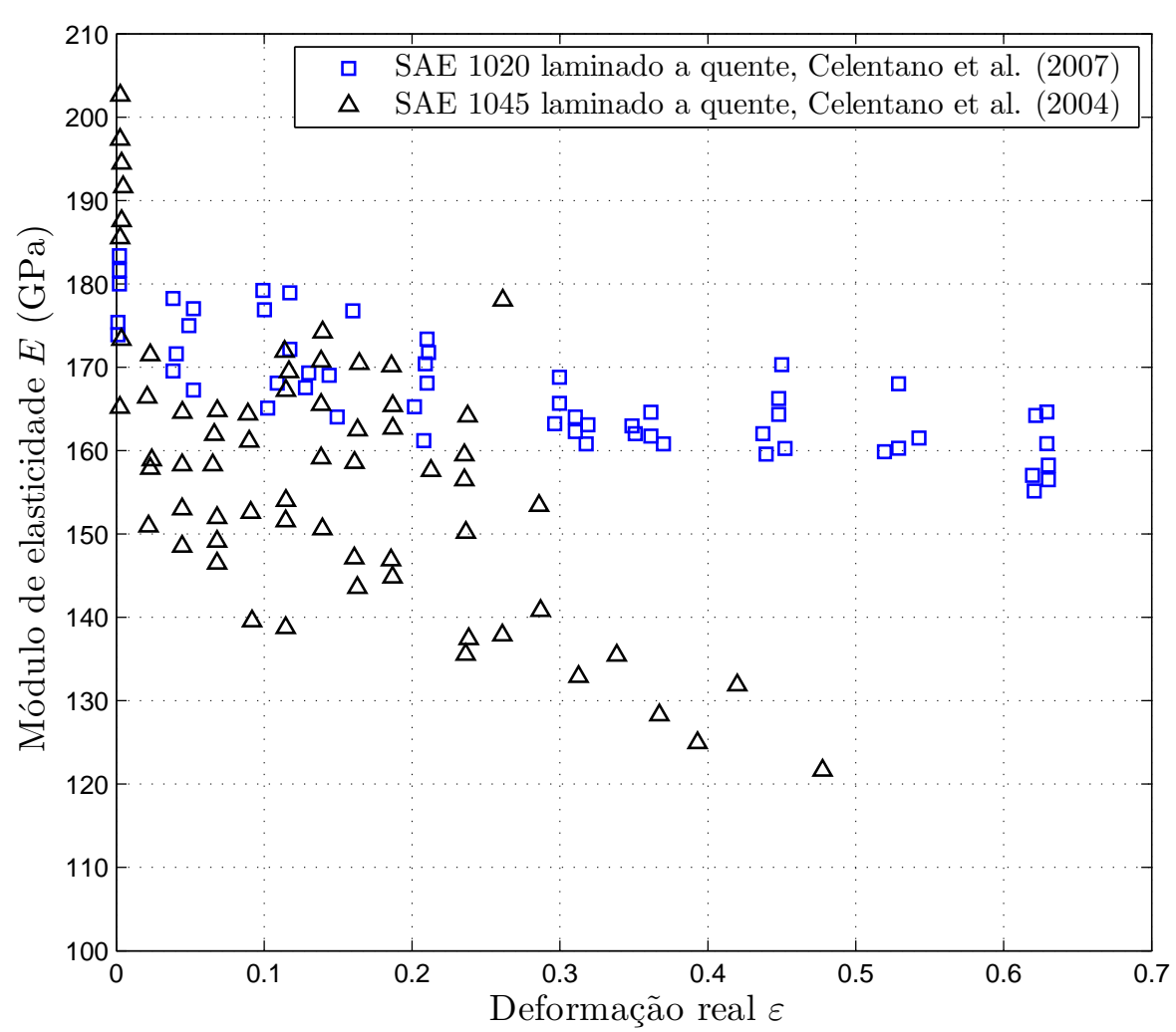

Figura 4.3: Variação do módulo de elasticidade para as ligas SAE 1020 e SAE 1045. Adaptado de Celentano, Tapia e Chaboche (2004) e Celentano e Chaboche (2007).

globais, outras locais. Isto é, a medida do dano por meio da variação do módulo de elasticidade não pode ser comparada à medida do dano pela medição direta da fração de vazios do material.

A seguir apresentamos a metodologia utilizada nos ensaios de tração efetuados para o presente trabalho.

\subsection{Metodologia}

Os corpos de prova, tanto laminados a quente quanto esferoidizados, utilizados neste trabalho são retirados de chapas gentilmente cedidas pela Brasmetal Waelholz. O material esferoidizado foi previamente laminado a frio com redução de espessura de $50 \%$ e depois recozido a uma temperatura de $700{ }^{\circ} \mathrm{C}$ em um forno industrial com atmosfera com $100 \%$ de $\mathrm{H}_{2}$ por 23 minutos. Tais chapas foram cortadas com jato de água e posteriormente lixadas na região da seção de teste. Esta seção transversal tem 12,5 mm de largura e espessura variando com o tipo de corpo de prova, de acordo com a Tab. 4.3. O comprimento útil é de $75 \mathrm{~mm}$. Três corpos de prova de cada tipo foram levados ao ensaio. 
Tabela 4.3: Classificação dos corpos de prova.

\begin{tabular}{cccc}
\hline Denominação & Material & Espessura & Direção \\
\hline $\mathrm{CP} 1-0^{\circ}$ & 1050 esferoidizado & $1,0 \mathrm{~mm}$ & Longitudinal \\
$\mathrm{CP} 2-0^{\circ}$ & 1050 esferoidizado & $1,4 \mathrm{~mm}$ & Longitudinal \\
$\mathrm{CP} 2-90^{\circ}$ & 1050 esferoidizado & $1,4 \mathrm{~mm}$ & Transversal \\
$\mathrm{CP} 3-0^{\circ}$ & 1050 esferoidizado & $1,5 \mathrm{~mm}$ & Longitudinal \\
$\mathrm{CP} 4-0^{\circ}$ & 1050 laminado a quente & $2,0 \mathrm{~mm}$ & Longitudinal \\
$\mathrm{CP} 4-90^{\circ}$ & 1050 laminado a quente & $2,0 \mathrm{~mm}$ & Transversal \\
\hline
\end{tabular}

Notar que "Longitudinal" e "Transversal" são relativos à direção de laminação da chapa que originou os corpos de prova. O restante das medidas dos corpos de prova é definido pela norma NBR 6152 (1992).

Uma máscara de círculos foi desenhada por gravação eletroquímica nos corpos de prova para posterior aferição da deformação local em vários pontos após o ensaio de tração. Os círculos, com 2 milímetros de diâmetro, foram gravados utilizando o marcador eletroquímico Tecnigrav MSM RB-200, gentilmente disponibilizado pela Brasmetal Waelzholz, que pode ser visto na Fig. 4.4. A Fig. 4.5 mostra os círculos marcados em um dos corpos de prova.

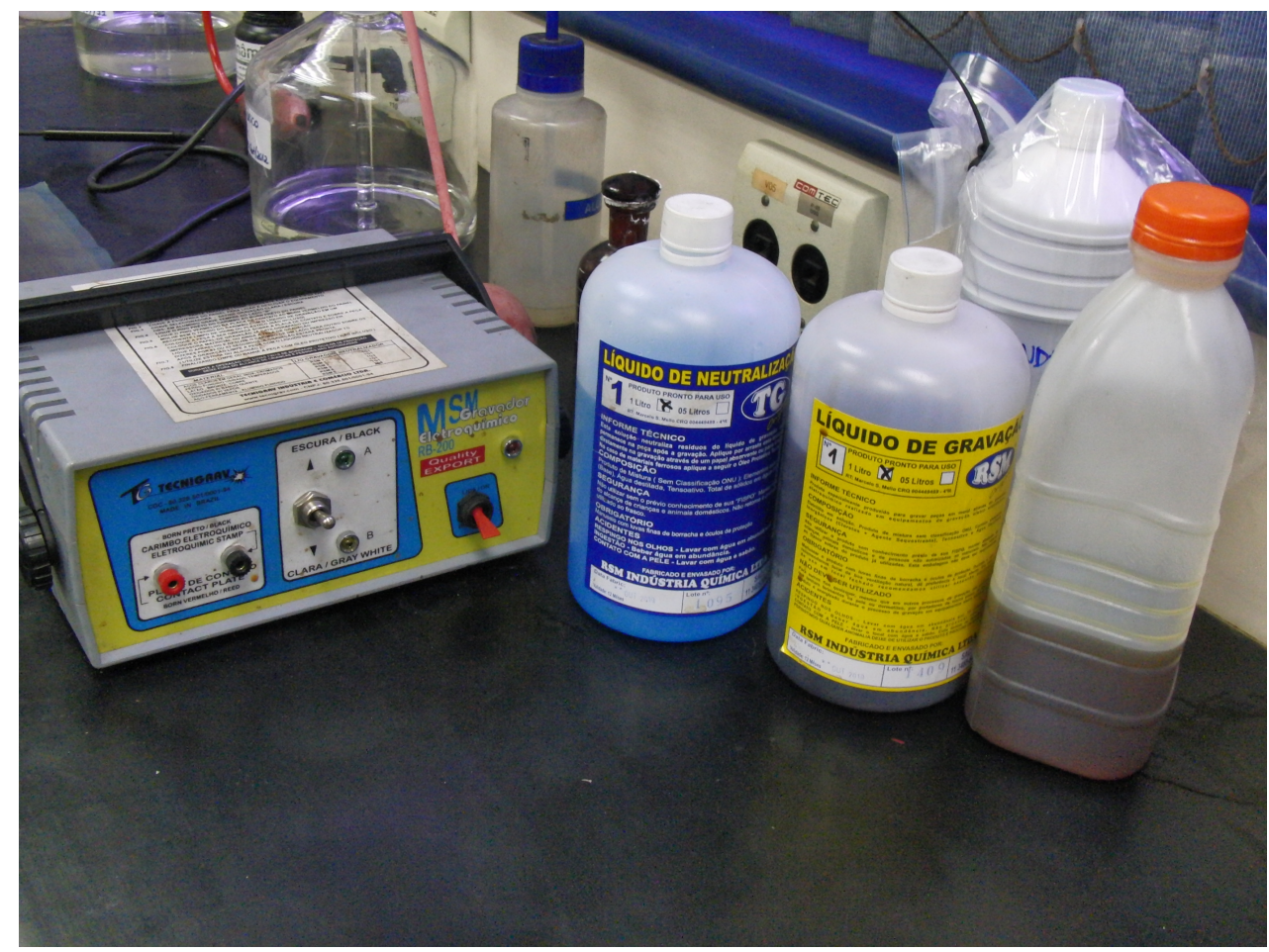

Figura 4.4: Gravador eletroquímico, líquido de neutralização e líquido de gravação utilizados na marcação eletroquímica.

Os ensaios foram efetuados no Grupo de Mecânica dos Sólidos e Impacto em Estru- 


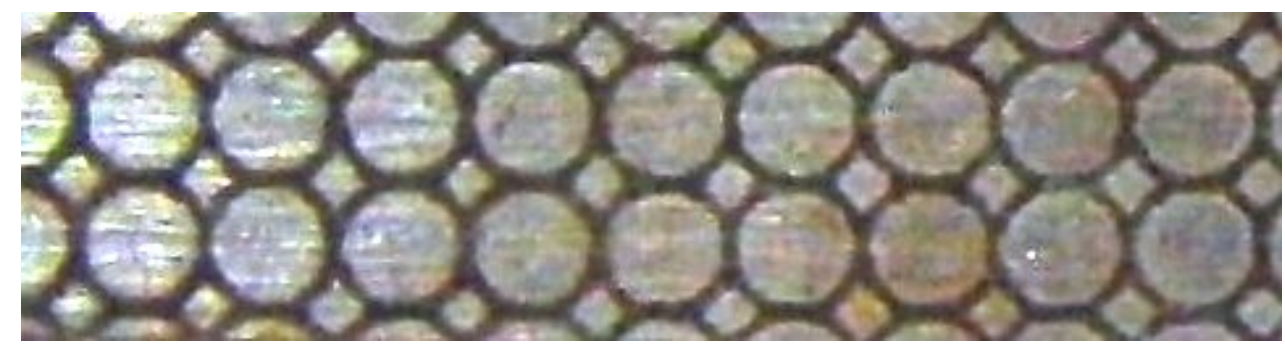

Figura 4.5: Círculos marcados por gravação eletroquímica no corpo de prova.

turas (GMSIE), do Departamento de Engenharia Mecatrônica e Sistemas Mecânicos (PMR) da Escola Politécnica da Universidade de São Paulo (EPUSP), em uma máquina de ensaios universal Instron, modelo 3369, com capacidade máxima igual a $50 \mathrm{kN}$. As forças do ensaio são medidas pela célula de carga da própria máquina, e as deformações são medidas por meio de um extensômetro do tipo clip gage, de comprimento inicial $50 \mathrm{~mm}$. A taxa de amostragem é de 5 Hz. O aparato experimental é mostrado na Fig. 4.6.

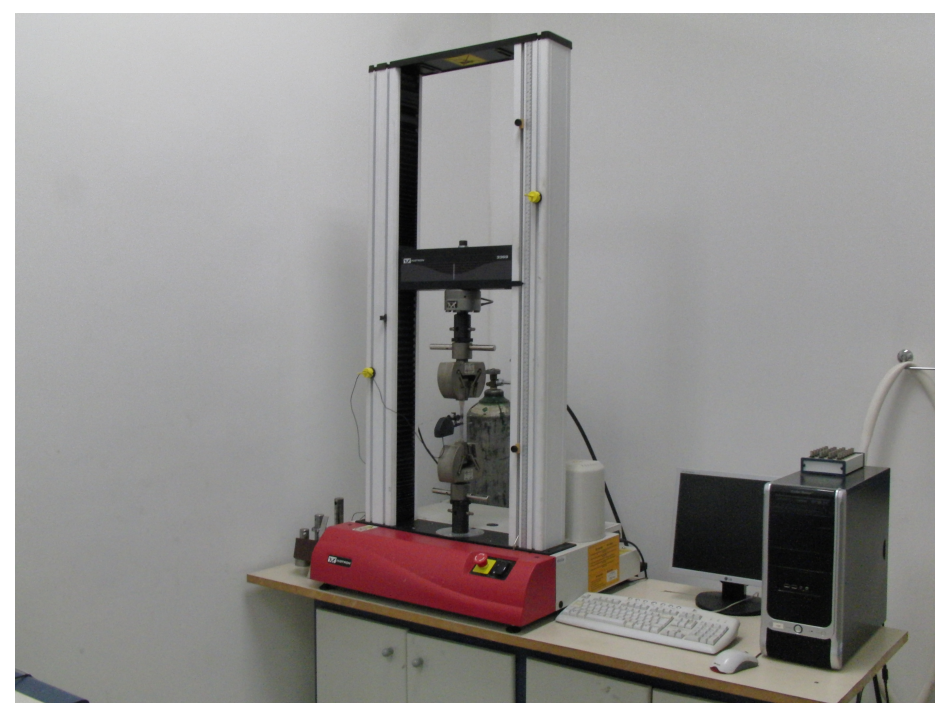

(a)

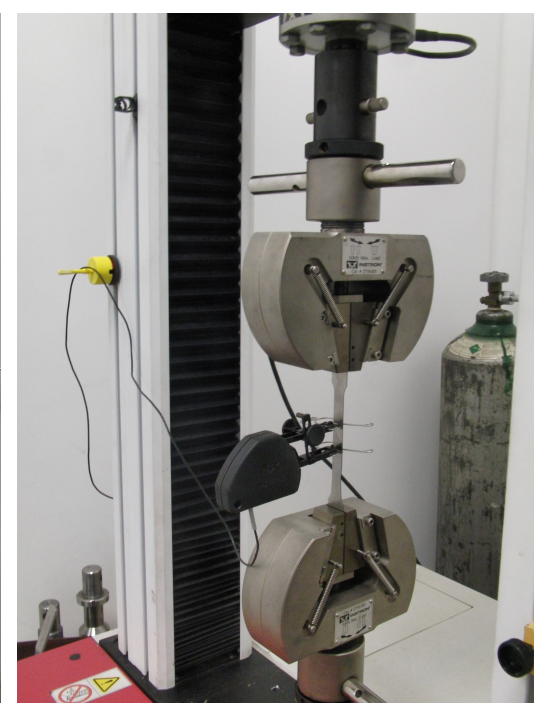

(b)

Figura 4.6: Equipamento utilizado nos ensaios de tração. (a) Vista geral da máquina universal de ensaios. (b) Detalhe do extensômetro montado no corpo de prova.

O procedimento adotado nos ensaios foi o seguinte. O deslocamento do cabeçote da máquina de ensaio universal se move com velocidade constante de $2 \mathrm{~mm} / \mathrm{min}$ tanto no carregamento quanto no descarregamento. Cada ciclo de carregamento vai até um deslocamento de $1 \mathrm{~mm}$ do cabeçote, e o descarregamento vai até a força atingir o valor de $50 \mathrm{~N}$.

Os resultados obtidos são a força medida na célula de carga do máquina em função da deformação no clip gage, os quais podem ser tratados e transformados em valores de tensões e deformações de engenharia e reais, como mostrado na Sec. 3.4. 


\subsection{Resultados}

\subsubsection{Propriedades mecânicas}

Os corpos de prova foram ensaiados até a fratura e os resultados, no formato de gráficos de tensão de engenharia em função da deformação de engenharia, são expostos na Fig. 4.7. Das curvas de tensão-deformação, as seguintes propriedades mecânicas, apresentadas na Tab. 4.4 com os valores médios e desvios padrões medidos para cada conjunto de três amostras, podem ser retiradas:

- limite de escoamento $\left(s_{e}\right)$ : tensão a partir da qual o material deixa de ter comportamento elástico;

- limite de resitência $\left(s_{u}\right)$ : tensão de engenharia máxima no material;

- deformação na fratura $\left(e_{f}\right)$ : deformação de engenharia na fratura.

Tabela 4.4: Propriedades mecânicas.

\begin{tabular}{ccccccc}
\hline Propriedade & $\mathrm{CP1-0^{ \circ }}$ & $\mathrm{CP} 2-0^{\circ}$ & $\mathrm{CP} 2-90^{\circ}$ & $\mathrm{CP} 3-0^{\circ}$ & $\mathrm{CP} 4-0^{\circ}$ & $\mathrm{CP}^{\circ}-90^{\circ}$ \\
\hline $\begin{array}{c}\text { Limite de } \\
\text { escoamento } s_{e} \\
(\mathrm{MPa})\end{array}$ & $310 \pm 8$ & $318 \pm 5$ & $352 \pm 4$ & $304 \pm 3$ & $558 \pm 3$ & $574 \pm 9$ \\
\hline $\begin{array}{c}\text { Limite de resistência } \\
s_{u}(\mathrm{MPa})\end{array}$ & $482 \pm 3$ & $469 \pm 2$ & $484 \pm 1$ & $465 \pm 3$ & $912 \pm 10$ & $880 \pm 11$ \\
\hline $\begin{array}{c}\text { Deformação na } \\
\text { fratura } e_{f}(\%)\end{array}$ & $38.0 \pm 0.7$ & $41.6 \pm 1.7$ & $38.4 \pm 0.9$ & $43.2 \pm 0.6$ & $25.1 \pm 2.9$ & $15.9 \pm 7.6$ \\
\hline
\end{tabular}

O material apresenta propriedades consistentes com a literatura. A norma NBR 6662 (2008) define que as ligas de aço SAE 1050 e 1055 devem apresentar as propriedades descritas na Tab. 4.5, dependendo da classe, ou seja, condição de fabricação e tratamento térmico. Os corpos de prova CP1, CP2 e CP3 devem ser comparados com os materiais da classe Coalescido, enquanto os corpos de prova do tipo $\mathrm{CP} 4$ devem ser comparados com os materiais Parcialmente encruados. Notar que a amostra 3 do corpo de prova do tipo CP4-90 ${ }^{\circ}$ sofreu uma fratura prematura, devido a um defeito proveniente do processo de usinagem do mesmo, e será desconsiderada das análises futuras.

Pode-se notar, na Fig. 4.8, que o material apresenta uma histerese nos ciclos de carregamento e descarregamento. As medidas de módulo de elasticidade, que caracterização a 


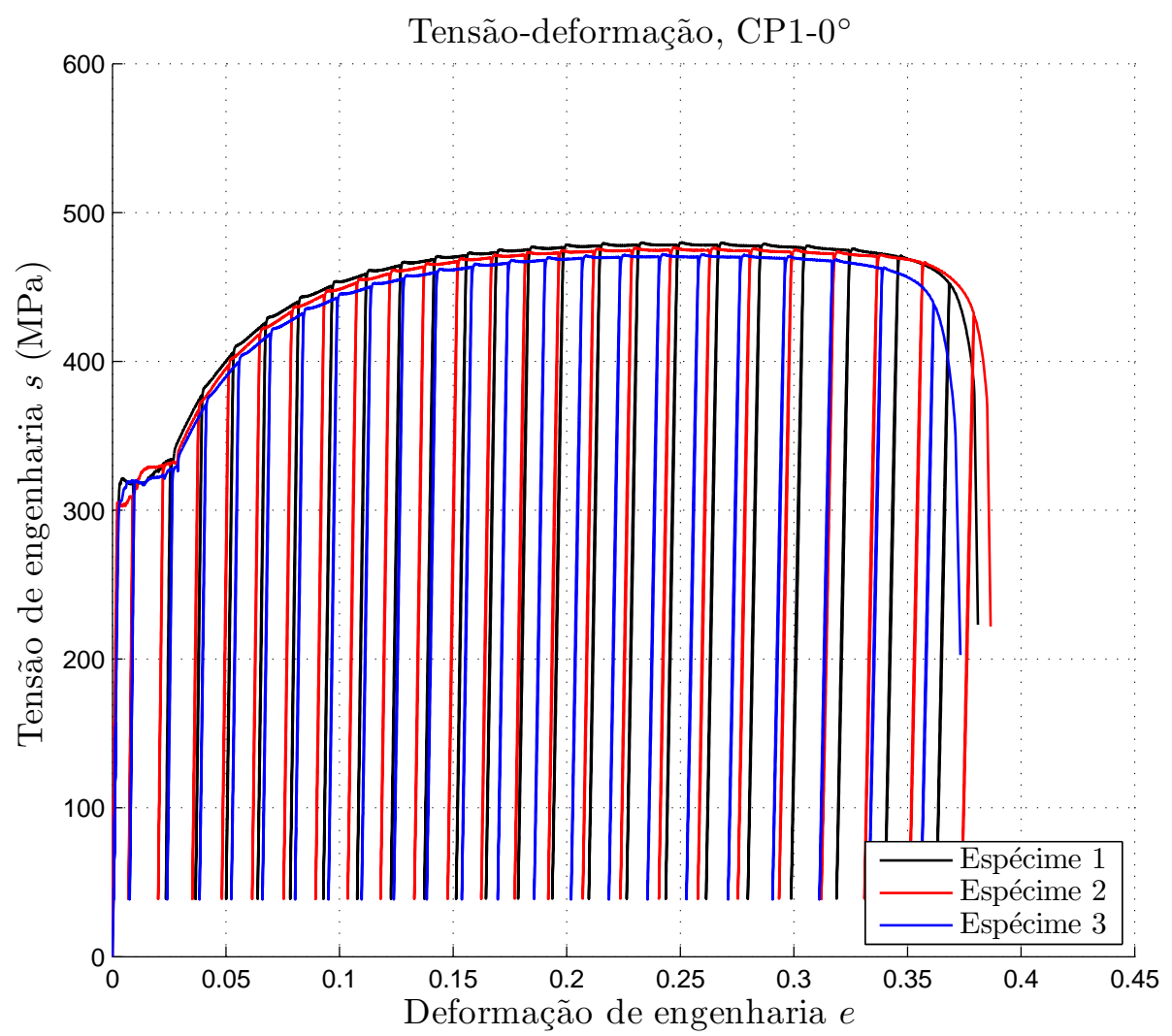

(a)

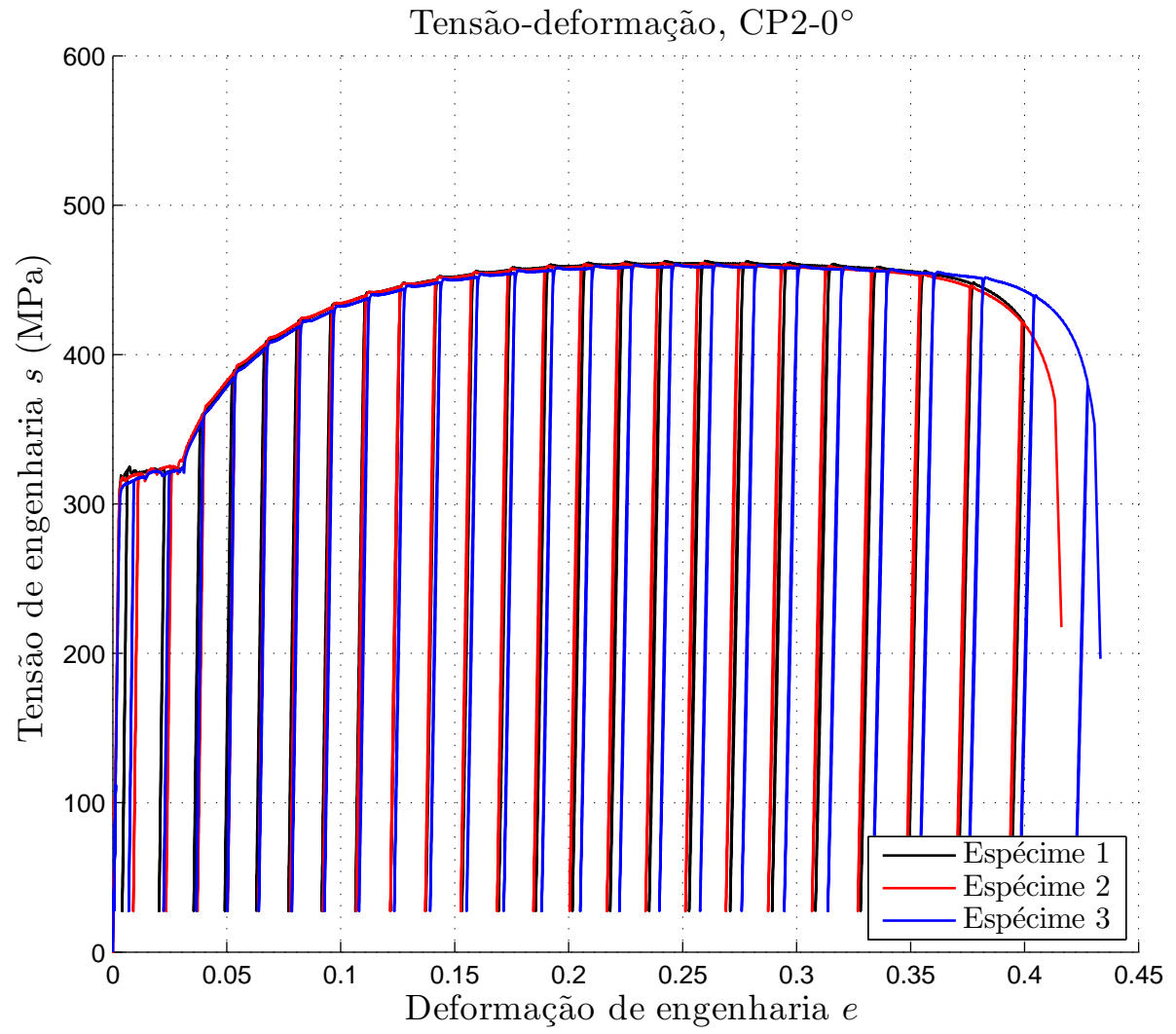

(b) 


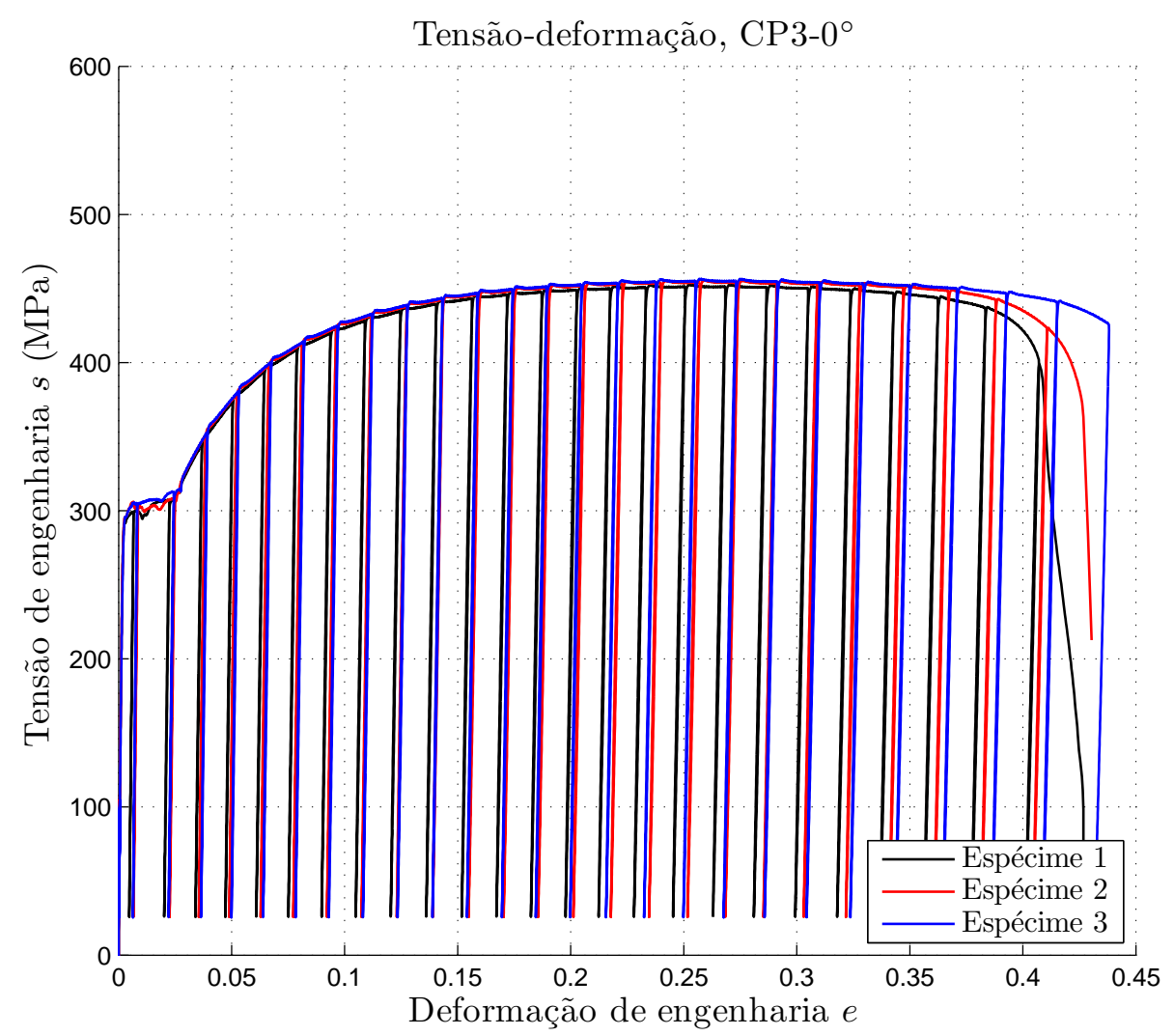

(c)

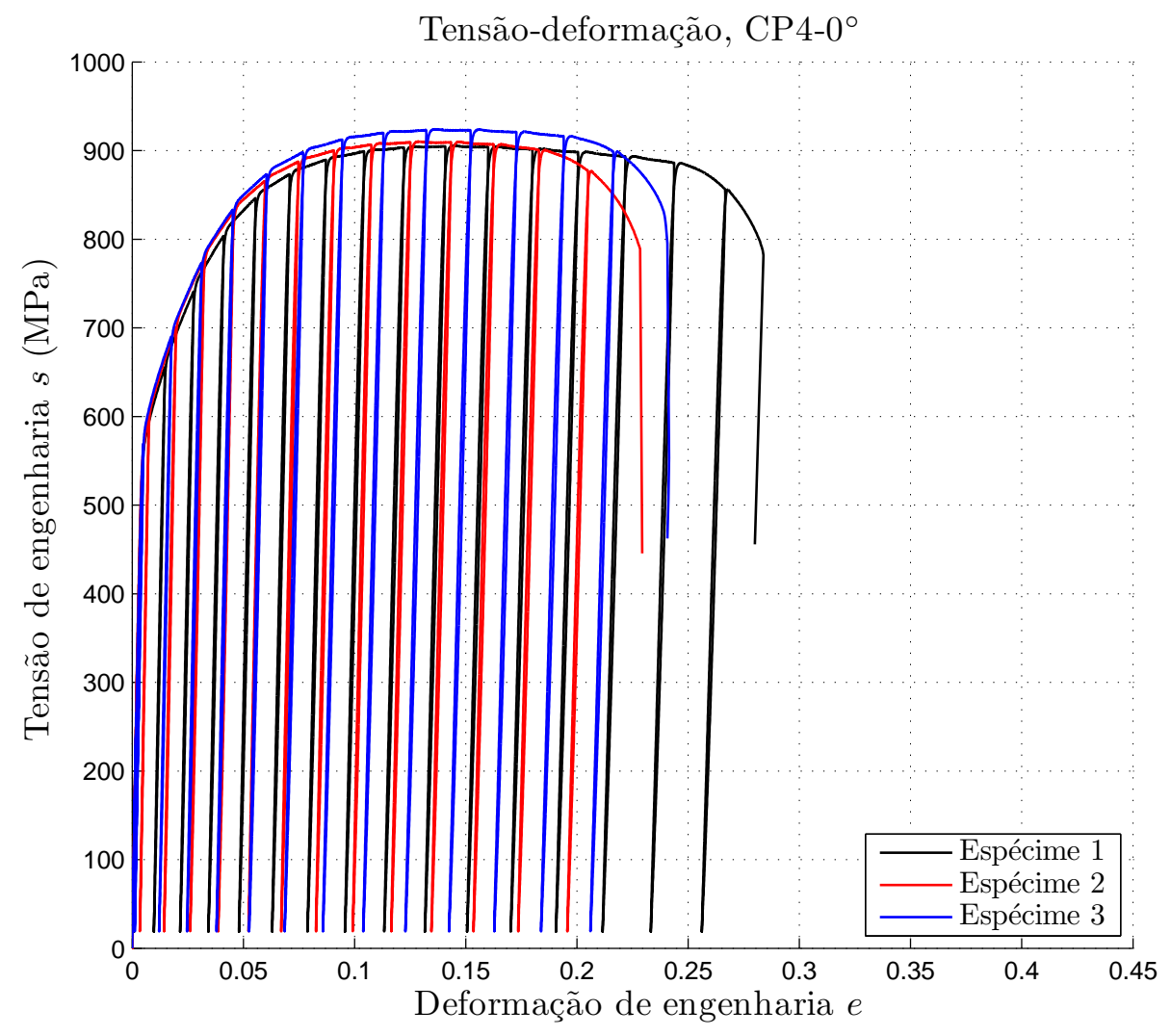

(d) 


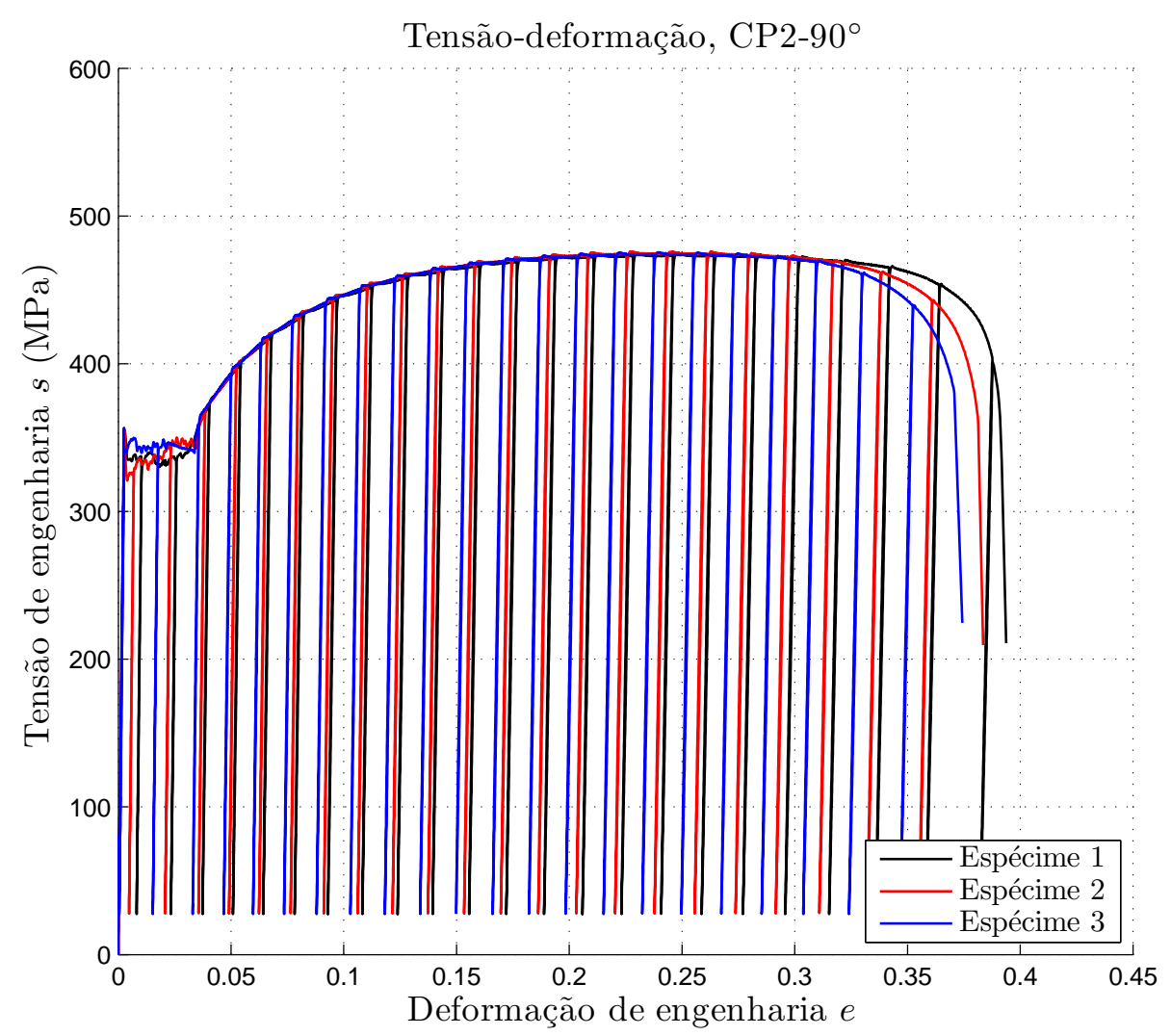

(e)

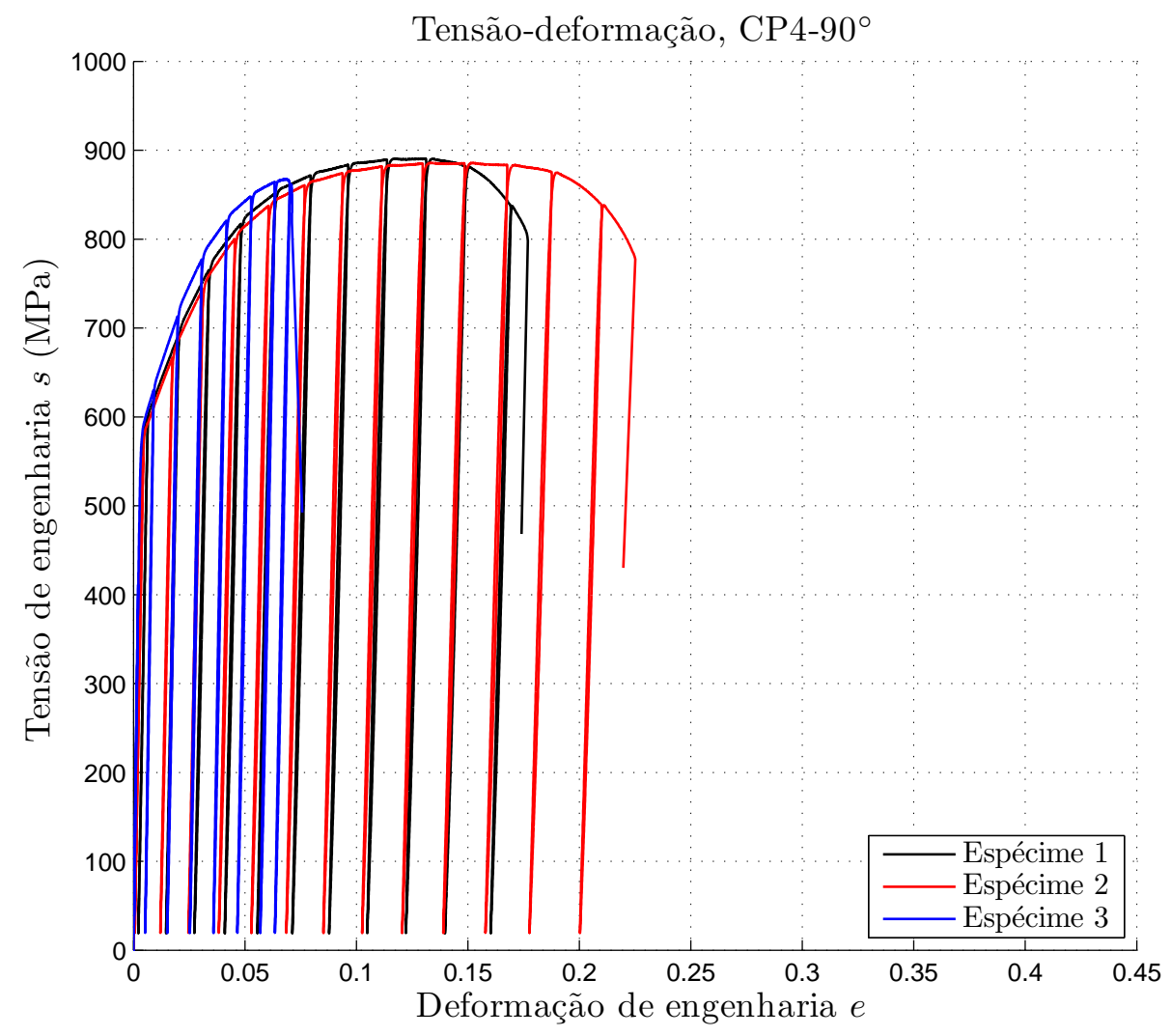

(f)

Figura 4.7: Curvas tensão de engenharia versus deformação de engenharia. (a) CP1- $0^{\circ}$. (b) $\mathrm{CP} 2-0^{\circ}$. (c) $\mathrm{CP} 3-0^{\circ}$. (d) $\mathrm{CP} 4-0^{\circ}$. (e) $\mathrm{CP} 2-90^{\circ}$. (f) $\mathrm{CP} 4-90^{\circ}$. 
Tabela 4.5: Propriedades mecânicas das ligas SAE 1050 e 1055 segundo norma NBR 6662 (2008).

\begin{tabular}{|c|c|c|c|}
\hline \multirow[b]{2}{*}{ Classe do material } & \multicolumn{2}{|c|}{ Dureza } & \multirow{2}{*}{$s_{u}$ máximo (MPa) } \\
\hline & HRB & HRC & \\
\hline Coalescido & 80 & - & 490 \\
\hline Coalescido e levemente laminado & 83 & - & 520 \\
\hline Recozimento simples & 85 & - & 540 \\
\hline Recozimento simples e levemente laminado & 88 & - & 580 \\
\hline Parcialmente encruado & - & 24 & 920 \\
\hline
\end{tabular}

evolução do dano no material, serão tomadas apenas no descarregamento, isto é, na rampa de descida da curva, seguindo orientação de Lemaitre (1996). O autor explica que no descarregamento há menor influência de efeitos não lineares devido ao escorregamento das discordâncias do que no carregamento, visto que o material já parte de uma condição deformada. Durante o carregamento, as discordâncias ainda não se acomodaram e, portanto, apresentam maior mobilidade. Como resultado, o material tem um comportamento menos rígido do que o esperado, como é ilustrado na Fig. 4.9.

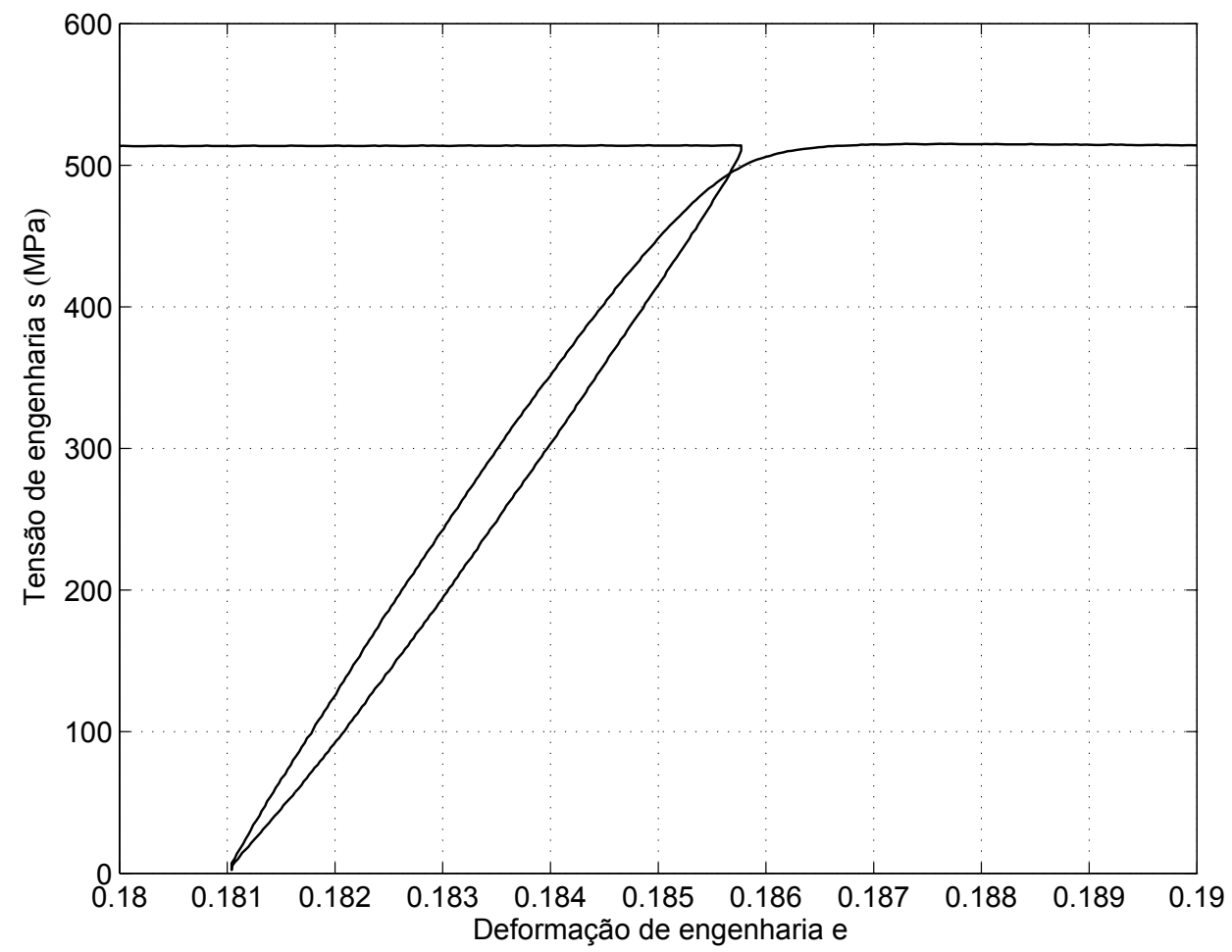

Figura 4.8: Detalhe da curva tensão de engenharia versus deformação de engenharia, mostrando a histerese no ciclo de carregamento/descarregamento. Material: aço SAE 1050 esferoidizado. 


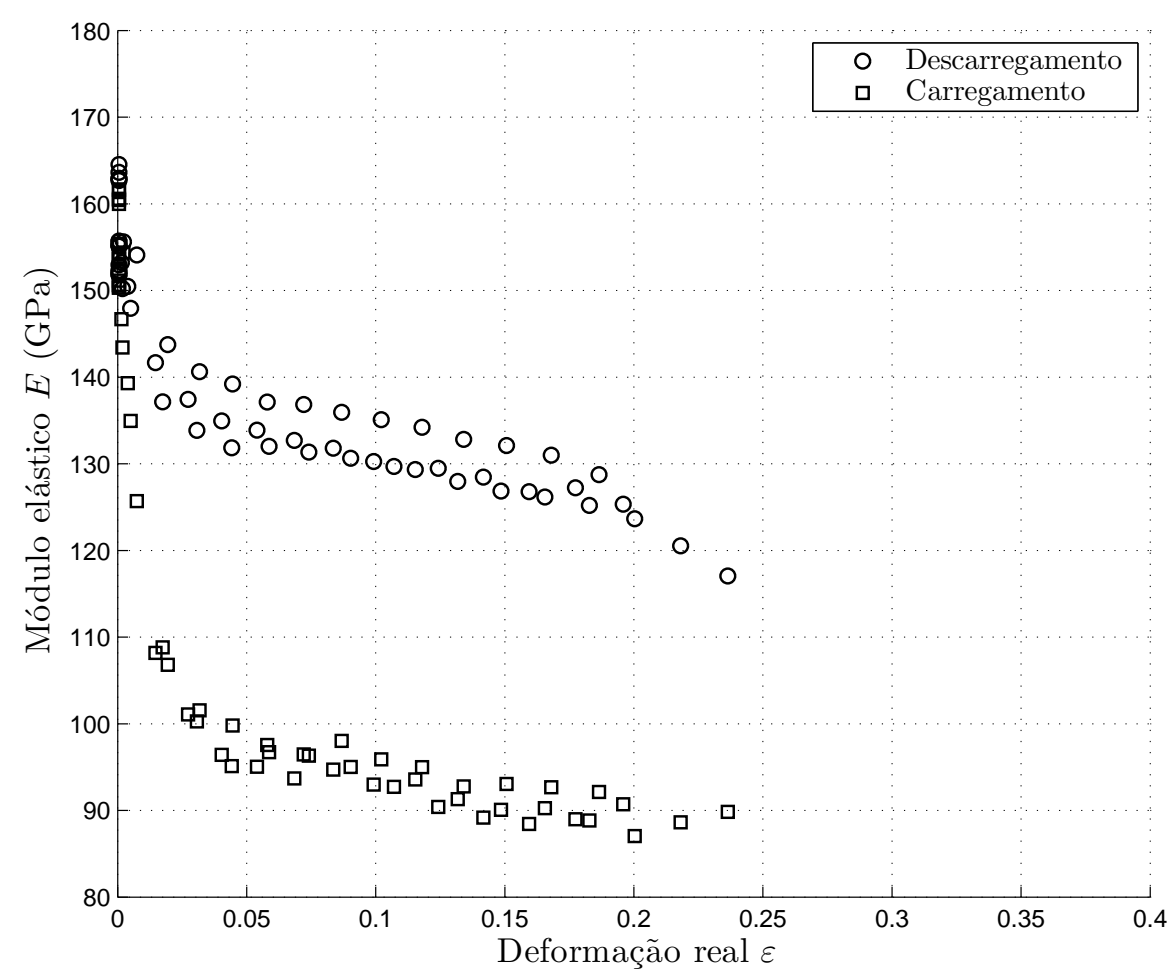

Figura 4.9: Diferença no módulo elástico medido no carregamento e descarregamento. Material: aço SAE 1050 laminado a quente, ensaio de tração na direção de laminação da chapa $\left(\mathrm{CP} 4-0^{\circ}\right)$.

A Fig. 4.10 mostra como o módulo de elasticidade vai decaindo com o aumento da deformação imposta, evidenciando a perda de rigidez do material. Tais valores foram obtidos por meio de uma interpolação linear dos dados na rampa de descida da curva tensão versus deformação de engenharia e com a aplicação da correção descrita por Alves, Yu e Jones (2000).

$$
E=\frac{F}{A_{0} \varepsilon \exp \left(-\varepsilon^{p}\right)}
$$

O modelo de Lemaitre propõe que o módulo de elasticidade permanece constante até uma certa deformação crítica e, após este limite, decai de maneira linear com a deformação, o que não é o caso dos presentes resultados. Para os materiais estudados, há um decréscimo da ordem de $20 \%$ no módulo de elasticidade antes para valores de deformação de engenharia da ordem de $5 \%$, e após isso a rigidez cai em uma taxa constante.

No trabalho de Morestin e Boivin (1996), a evolução do módulo de elasticidade para duas ligas de aço - DIN 17100 St33 e SAE 1035 - é avaliada em baixas deformações plásticas, e resultados semelhantes aos do presente trabalho são encontrados. Os autores afirmam que a diminuição da rigidez dos aços pode chegar a mais que $10 \%$ após cerca de $5 \%$ de deformação plástica, como mostrado na Fig. 4.11, embora o mecanismo por trás dessa queda não linear não 


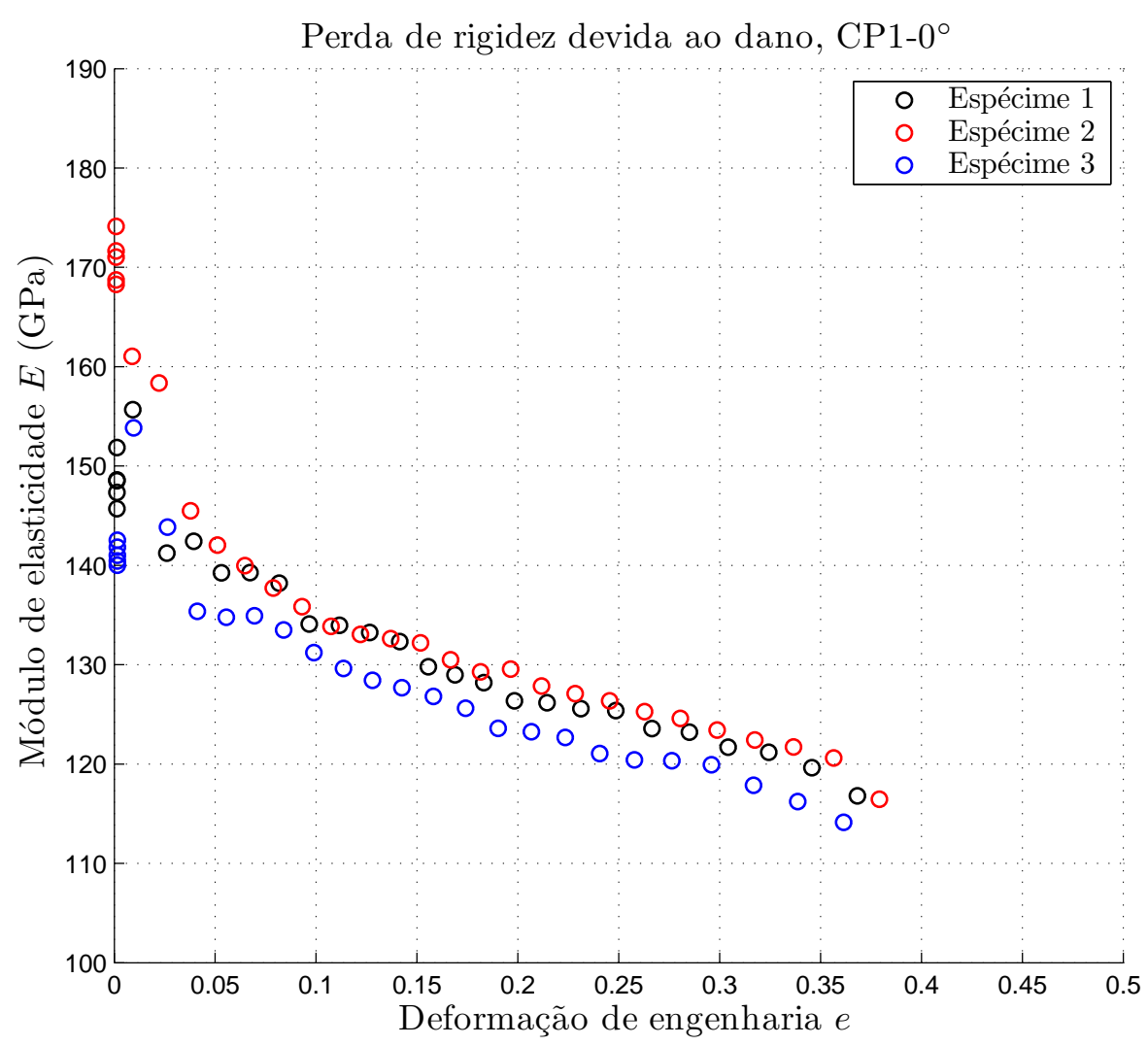

(a)

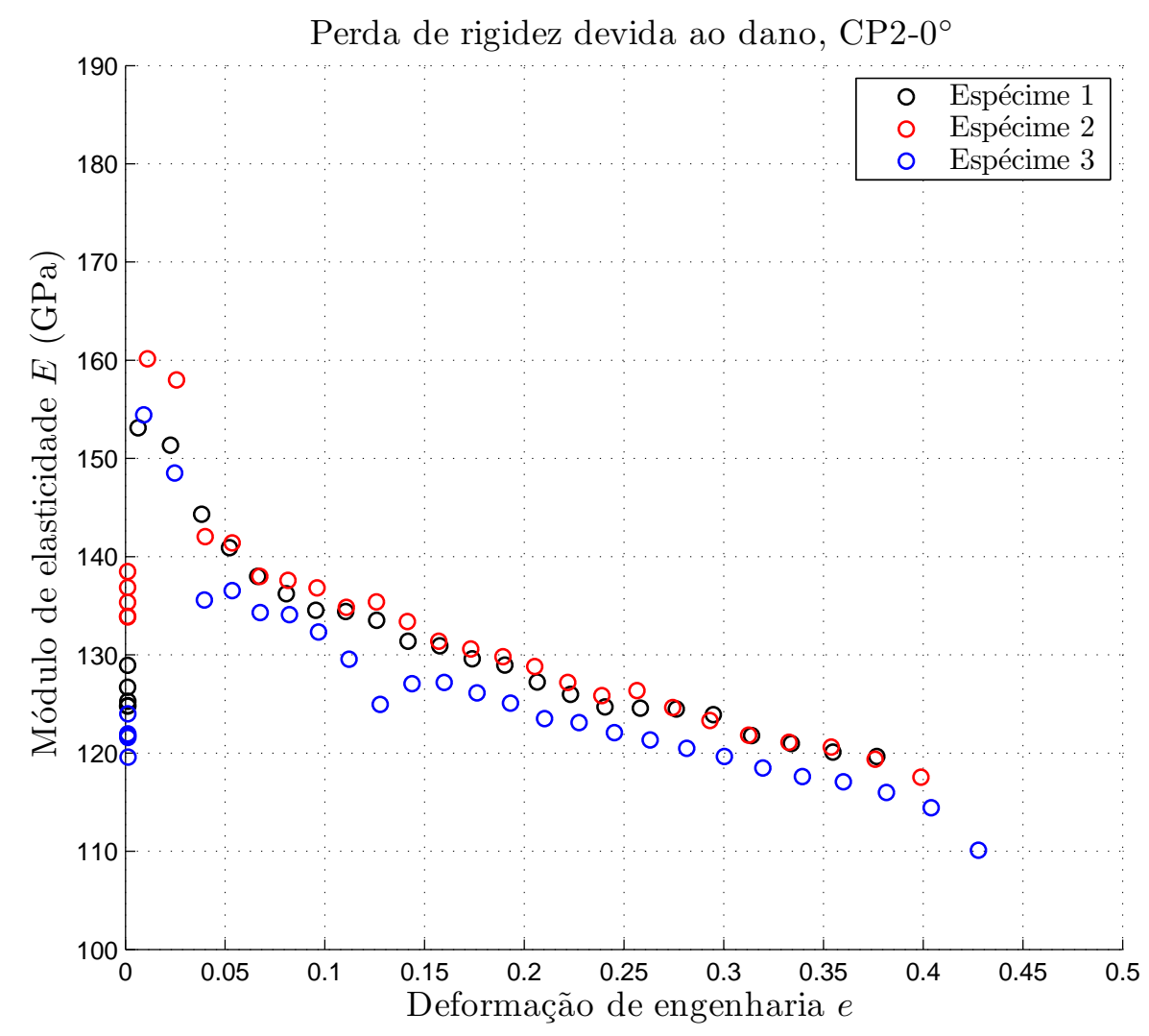

(b) 


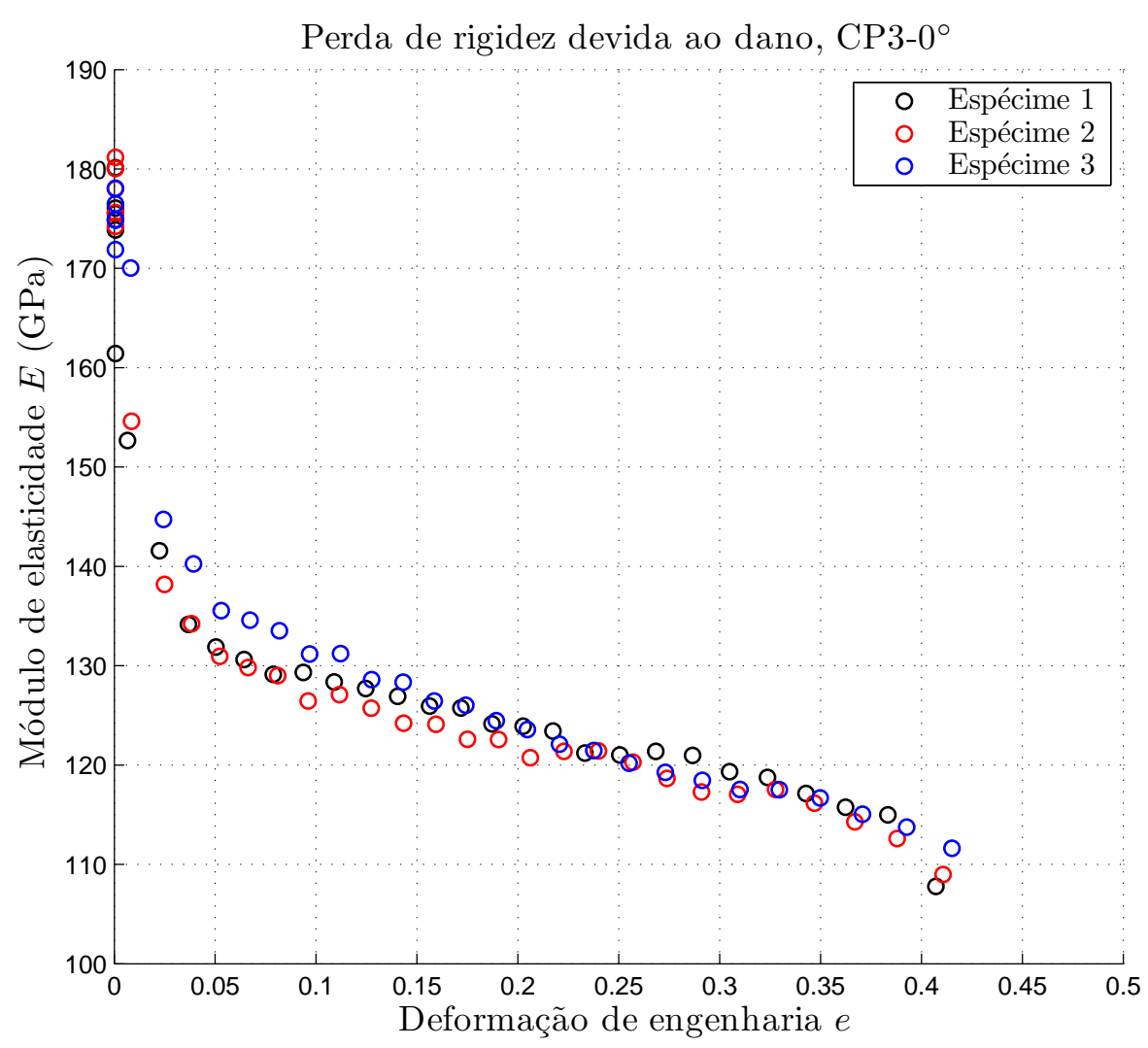

(c)

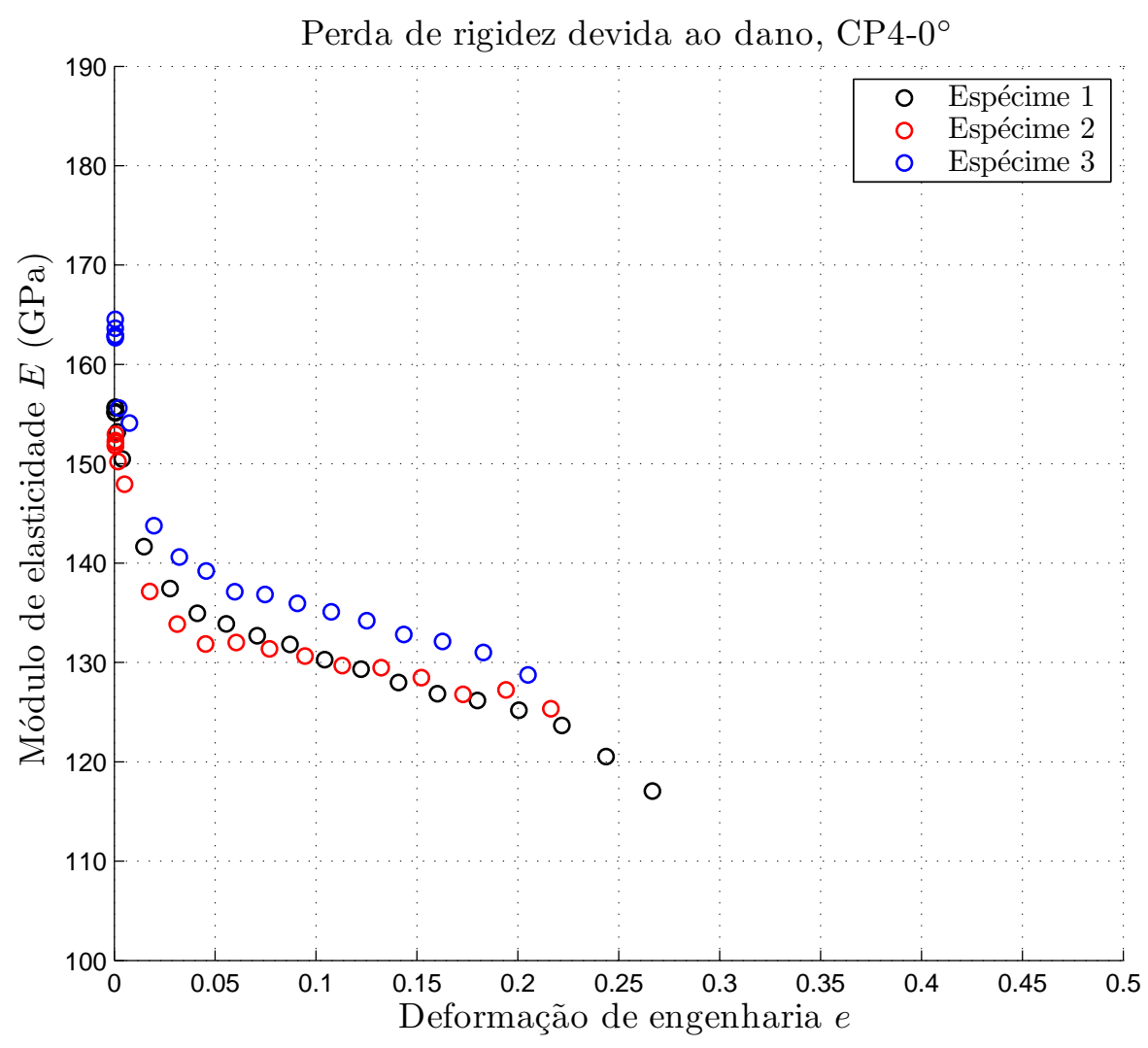

(d) 


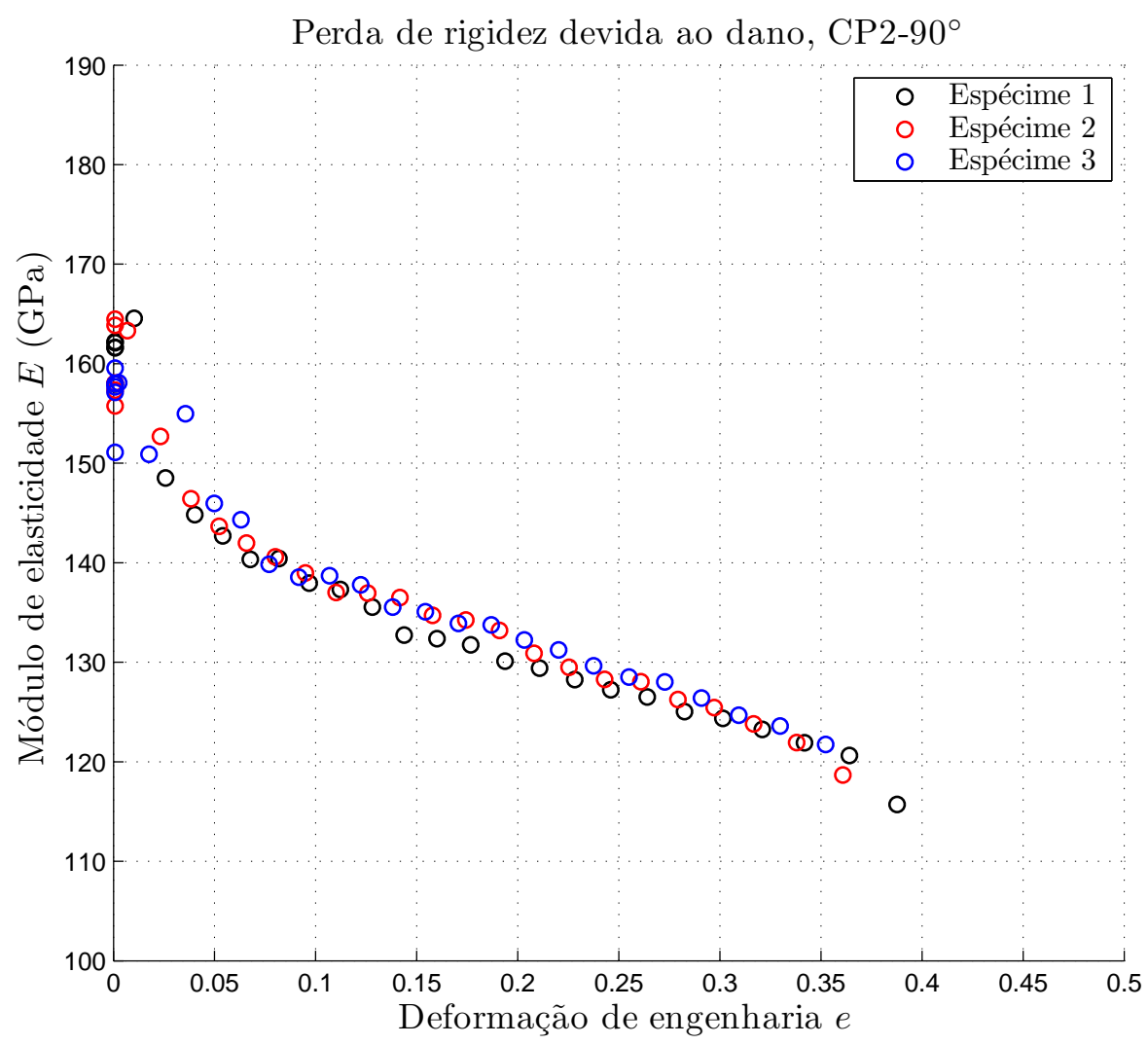

(e)

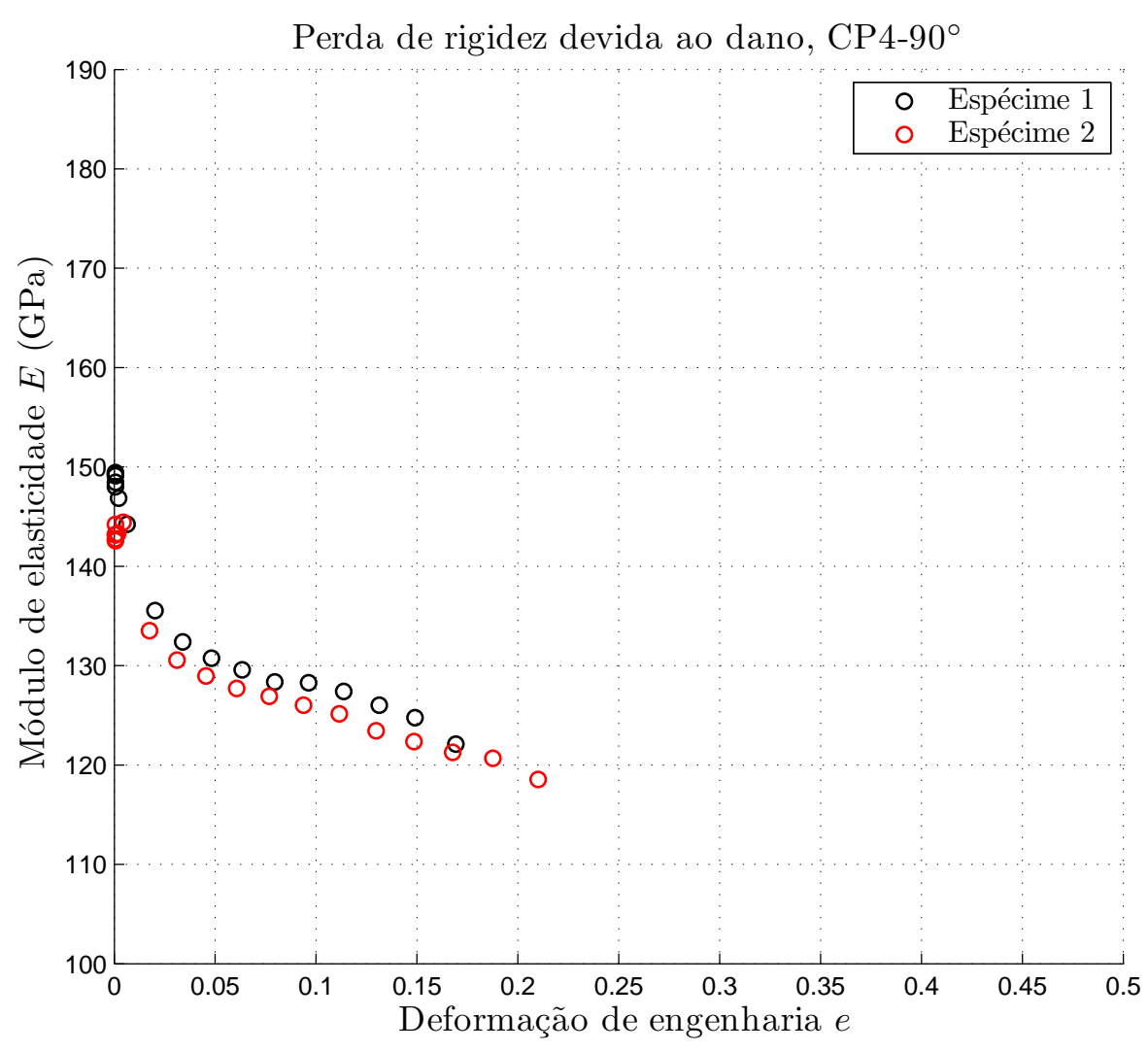

(f)

Figura 4.10: Evolução do módulo de elasticidade do material com a deformação em um ensaio de tração. (a) $\mathrm{CP} 1-0^{\circ}$. (b) $\mathrm{CP} 2-0^{\circ}$. (c) $\mathrm{CP} 3-0^{\circ}$. (d) $\mathrm{CP} 4-0^{\circ}$. (e) $\mathrm{CP} 2-90^{\circ}$. (f) $\mathrm{CP} 4-90^{\circ}$. 
seja discutido. O trabalho de Benito et al. (2005) efetua uma análise das discordâncias por meio de microscopia eletrônica de tunelamento e atribui essa queda inicial da rigidez ao aumento da densidade de discordâncias durante a deformação plástica. Em um primeiro momento, novas discordâncias são criadas, o que possibilita maior possibilidade de deslizamento de planos cristalinos, aumentando a deformação no material e diminuindo a rigidez. No entanto, quando a densidade de discordâncias atinge um valor crítico, elas começam a se aglomerar em células, que atuam como barreiras à movimentação de novas discordâncias, e o fenômeno cessa, estabilizando o valor da rigidez. Os autores também notam que este é um fenômeno reversível com o tempo.

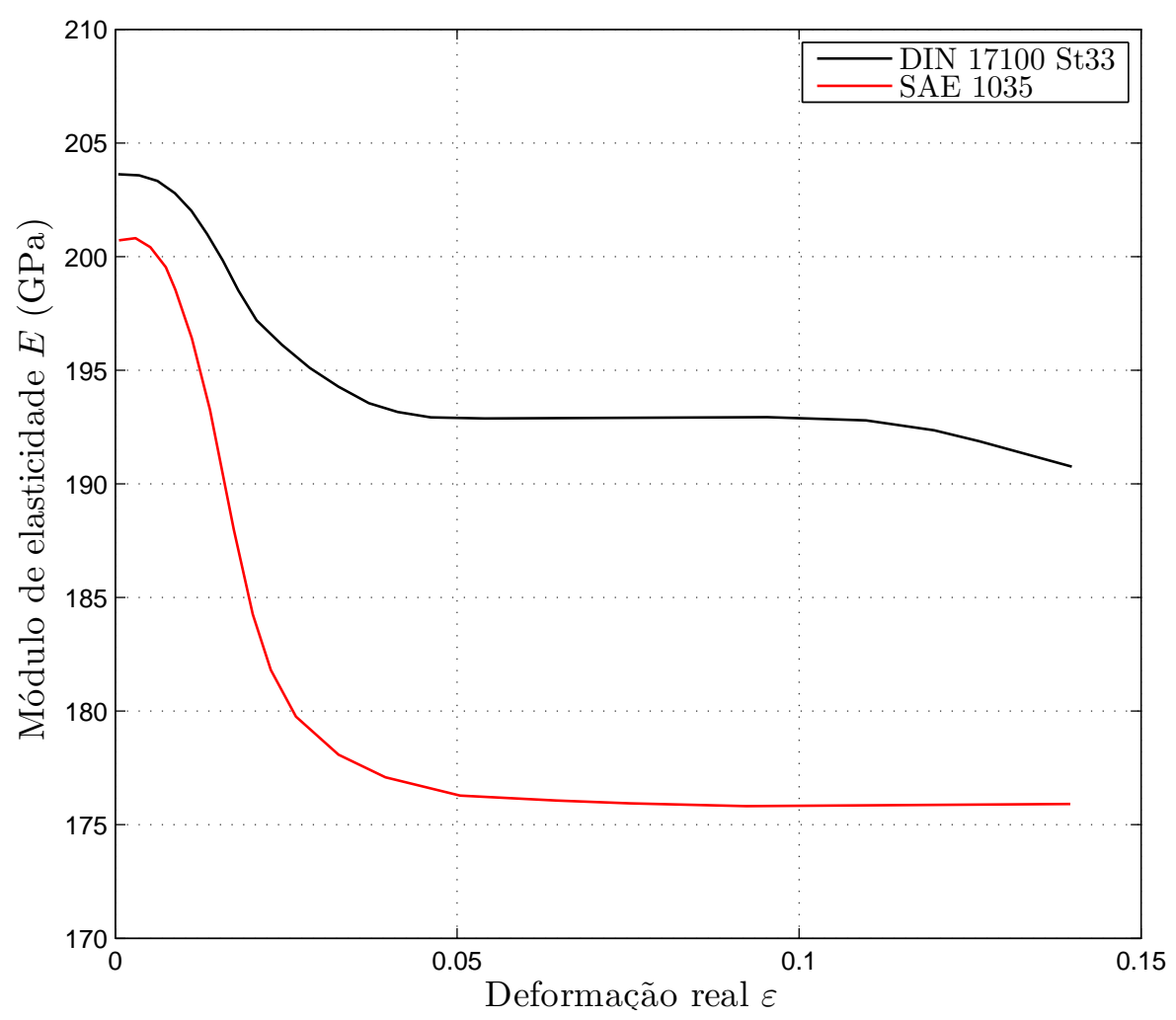

Figura 4.11: Decaimento não linear do módulo de elasticidade em baixas deformações plásticas para ligas de aço (MORESTIN; BOIVIN, 1996).

Assim como no trabalho de Celentano e Chaboche (2007), qualquer variação do módulo de Young anterior ao momento em que o decréscimo é linear com a deformação, será desconsiderado, pois não é causado pelo fenômeno irreversível do dano. Os valores de módulo de elasticidade inicial mostrados na Tab. 4.4, portanto, serão tomados como aqueles para o início da deformação plástica, que estão após o efeito não linear de queda do valor de $E$.

Na Fig. 4.12 mostramos uma compilação de nossos resultados com o ensaio de tração efetuado na direção de laminação, e os resultados obtidos por Celentano, Tapia e Chaboche 
(2004) para a liga SAE 1045 laminada a quente e os resultados de Celentano e Chaboche (2007) para a liga SAE 1020. Além de ficar claro que a medida do módulo de elasticidade apresenta uma dispersão considerável, nota-se que há uma tendência do módulo de elasticidade diminuir conforme o aumento do nível de carbono nas ligas, fato corroborado pelo resultado, também apresentado na figura, de Benito et al. (2005) para ferro puro. O tratamento de esferoidização interfere menos taxa de decréscimo da rigidez do material e mais no valor crítico do módulo de rigidez mínimo. Para o cálculo do dano, isso terá influência no valor de dano crítico $D_{1 c}$ do que no parâmetro de resistência $S$, como será mostrado posteriormente.

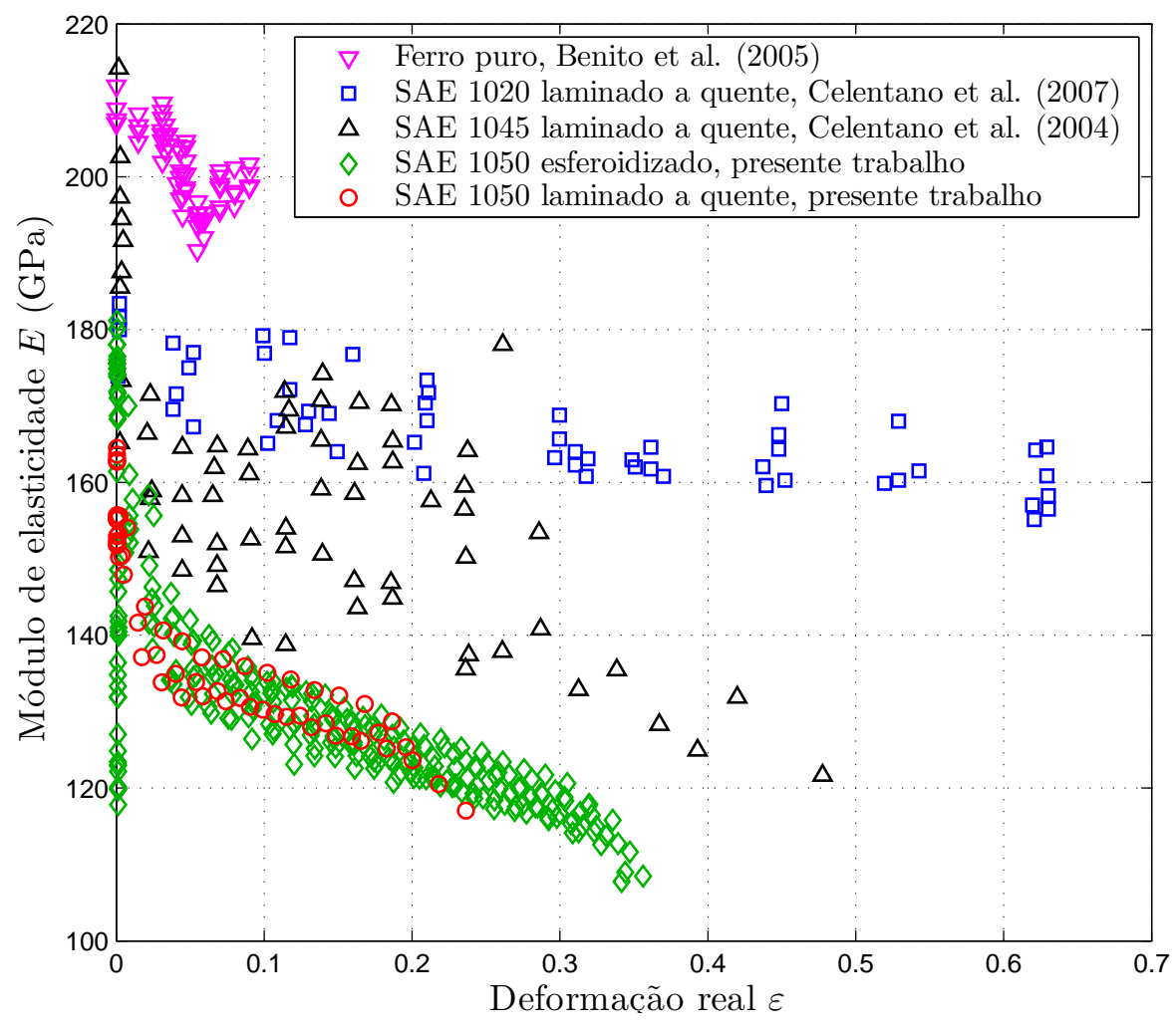

Figura 4.12: Comparação da evolução do módulo de elasticidade com a deformação para o ferro puro (BENITO et al., 2005) e os aços SAE 1020 laminado a quente (CELENTANO; CHABOCHE, 2007), SAE 1045 laminado a quente (CELENTANO; TAPIA; CHABOCHE, 2004) e SAE 1050 laminado a quente e esferoidizado (presente trabalho).

Mesmo não obtendo, neste trabalho, resultados para estas outras ligas, podemos estimar, a partir da Fig. 4.12, como se dá a perda de rigidez para as ligas de aço-carbono da série SAE 10XX e, portanto, a evolução do dano.

Com relação às propriedades mecânicas, fica faltando apenas a determinação das propriedades plásticas do material. Para isso devemos utilizar a curva de tensão verdadeira $\sigma$ versus deformação verdadeira $\varepsilon$ do material. Uma equação que descreva o comportamento plástico do material será necessária para a utilização de um modelo de elementos finitos posteriormente. A 
Tab. 4.6, adaptada do trabalho de Gronostajski (2000) lista as principais equações constitutivas disponíveis na literatura para deformação em temperatura ambiente e desconsiderando efeitos da taxa de deformação.

Tabela 4.6: Equações constitutivas do comportamento plástico (GRONOSTAJSKI, 2000).

\begin{tabular}{cc}
\hline Equação & Referência \\
\hline$\sigma=K\left(\varepsilon^{p}\right)^{n}$ & Hollomon (1945) \\
$\sigma=\sigma_{0}+K\left(\varepsilon^{p}\right)^{n}$ & Ludwik (1909) \\
$\sigma=K\left(\varepsilon^{p}+\varepsilon_{0}^{p}\right)^{n}$ & Swift (1952) \\
$\sigma=\sigma_{0}+K\left(\varepsilon^{p}+\varepsilon_{0}^{p}\right)^{n}$ & Hartley et al. (1978) \\
$\sigma=\sigma_{0}+K \ln \varepsilon^{p}$ & Samanta (1968) \\
$\sigma=\sigma_{s}-\left(\sigma_{s}-\sigma_{0}\right) \exp \left(-n \varepsilon^{p}\right)$ & Voce (1948) \\
$\sigma=\sigma_{0}+\left(\sigma_{m}-\sigma_{0}\right)\left[1-\exp \left(-n \varepsilon^{p}\right)\right]^{n}$ & Sah, Richardson e Sellars (1969) \\
$\sigma=K\left(\varepsilon^{p}\right)^{n} \exp \left(n_{1} \varepsilon^{p}\right)$ & Voce (1948) \\
\hline
\end{tabular}

Neste trabalho usaremos a equação de Ludwik:

$$
\sigma=\sigma_{0}+K\left(\varepsilon^{p}\right)^{n}
$$

onde $\sigma_{0}$ é a tensão de escoamento inicial $\varepsilon^{p}$ é a parcela plástica da deformação, $K$ é o coeficiente de resistência plástica do material e $n$ é o coeficiente de encruamento. Para a determinação destes parâmetros, levantamos alguns pontos experimentais de tensão e deformação reais dos corpos de prova e, por mínimos quadrados, aproximamos os coeficientes de Ludwik. Os dados experimentais e a curva de ajuste são mostradas na Fig. 4.13 para todos os tipos de corpos de prova ensaiados.

As curvas ajustadas têm os seguintes coeficientes, mostrados na Tab. 4.7 com os valores médios e desvio padrão. Notar que $\varepsilon_{e s c}$ corresponde ao valor de deformação a partir do qual a equação é válida. Para os corpos de prova laminados a quente, a transição entre o regime elástico e plástico não apresentou um patamar de escoamento, o que facilita a modelagem. Ou seja, há uma reta modelando o regime elástico e e equação de Ludwik modela o regime plástico. Para os corpos de prova esferoidizados, este patamar existe, o que indica que o material não passou por uma laminação de acabamento no processo de fabricação. Assim, além da reta modelando o regime elástico e a parte plástica modelada pela equação de Ludwik, a faixa de transição é representada por uma reta horizontal, no valor da tensão de escoamento inicial $\sigma_{0}$ do material.

Assim, temos todos os parâmetros necessários para a implementação de um modelo elasto-plástico do material com dano acoplado. Este modelo será testado por meio de simulações em elementos finitos. Todas as propriedades mecânicas são compiladas na Tab. 4.9. 


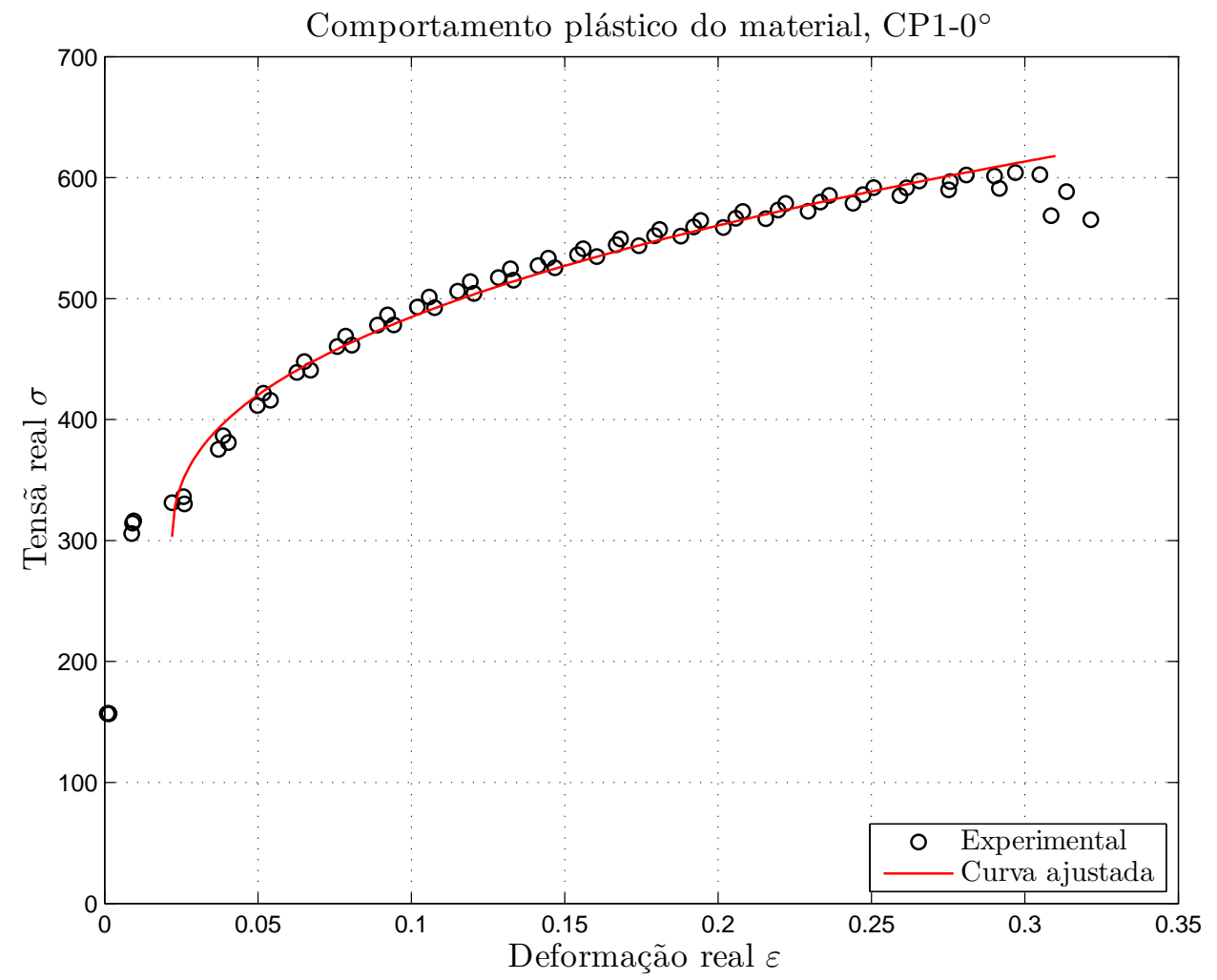

(a)

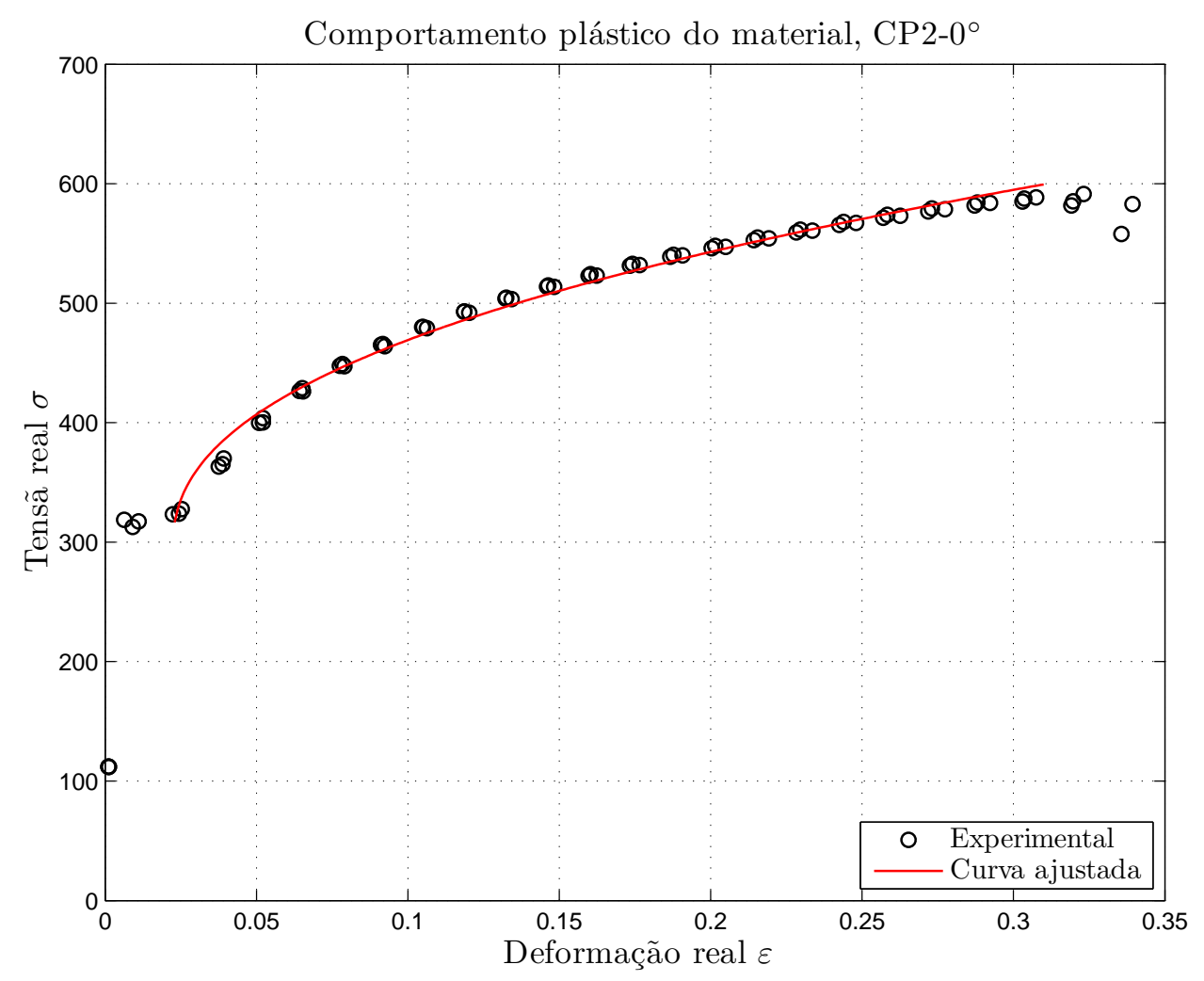

(b) 


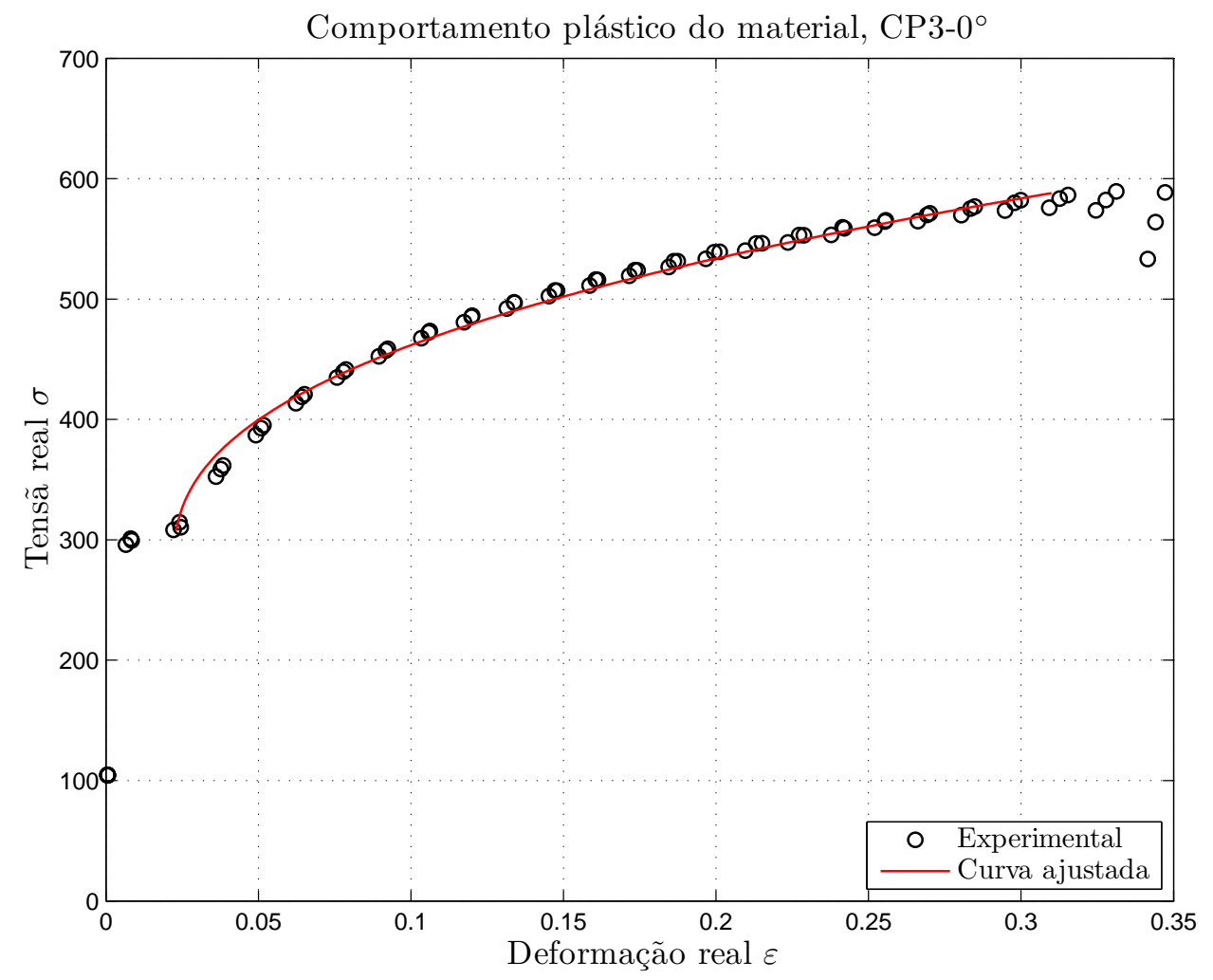

(c)

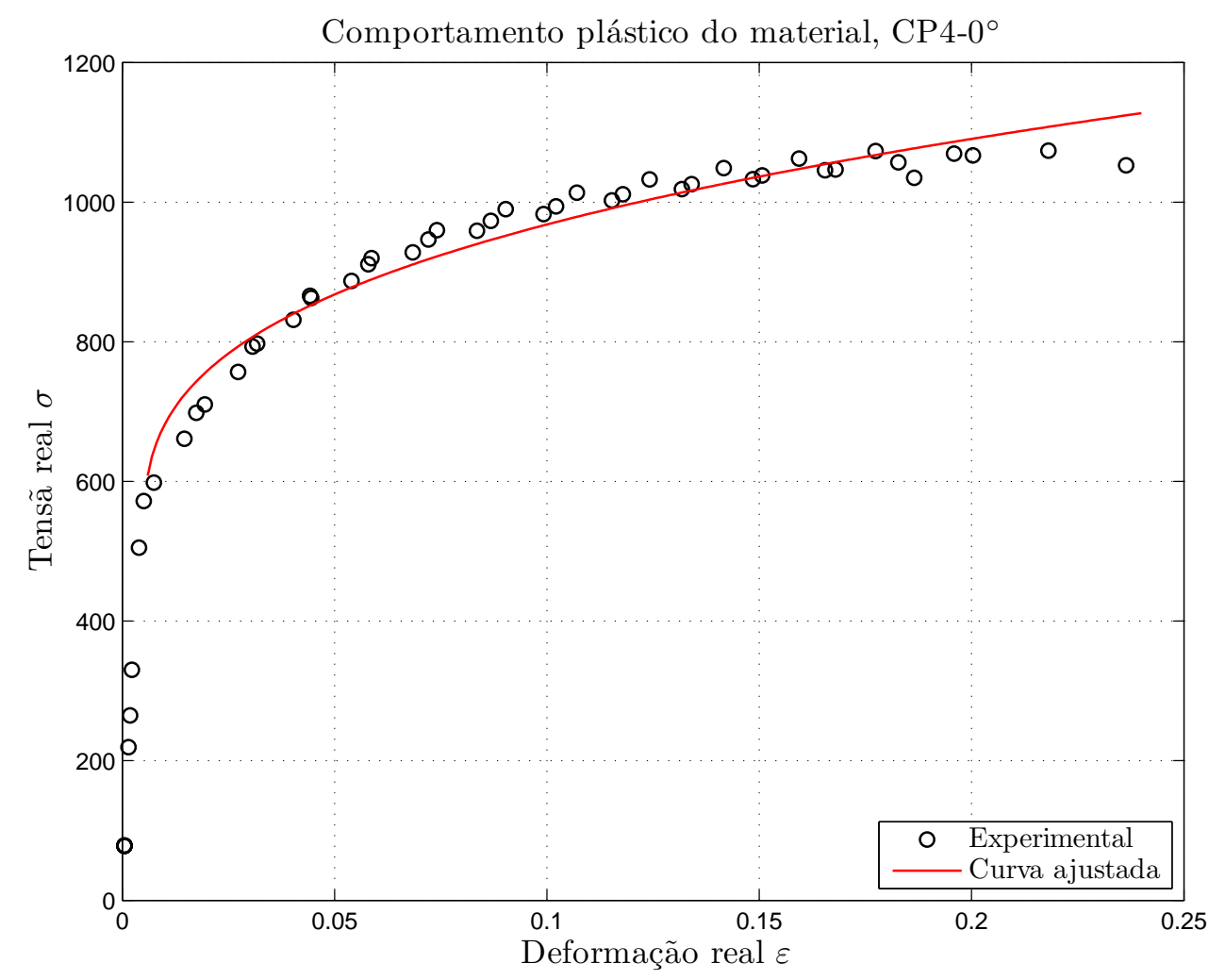

(d) 


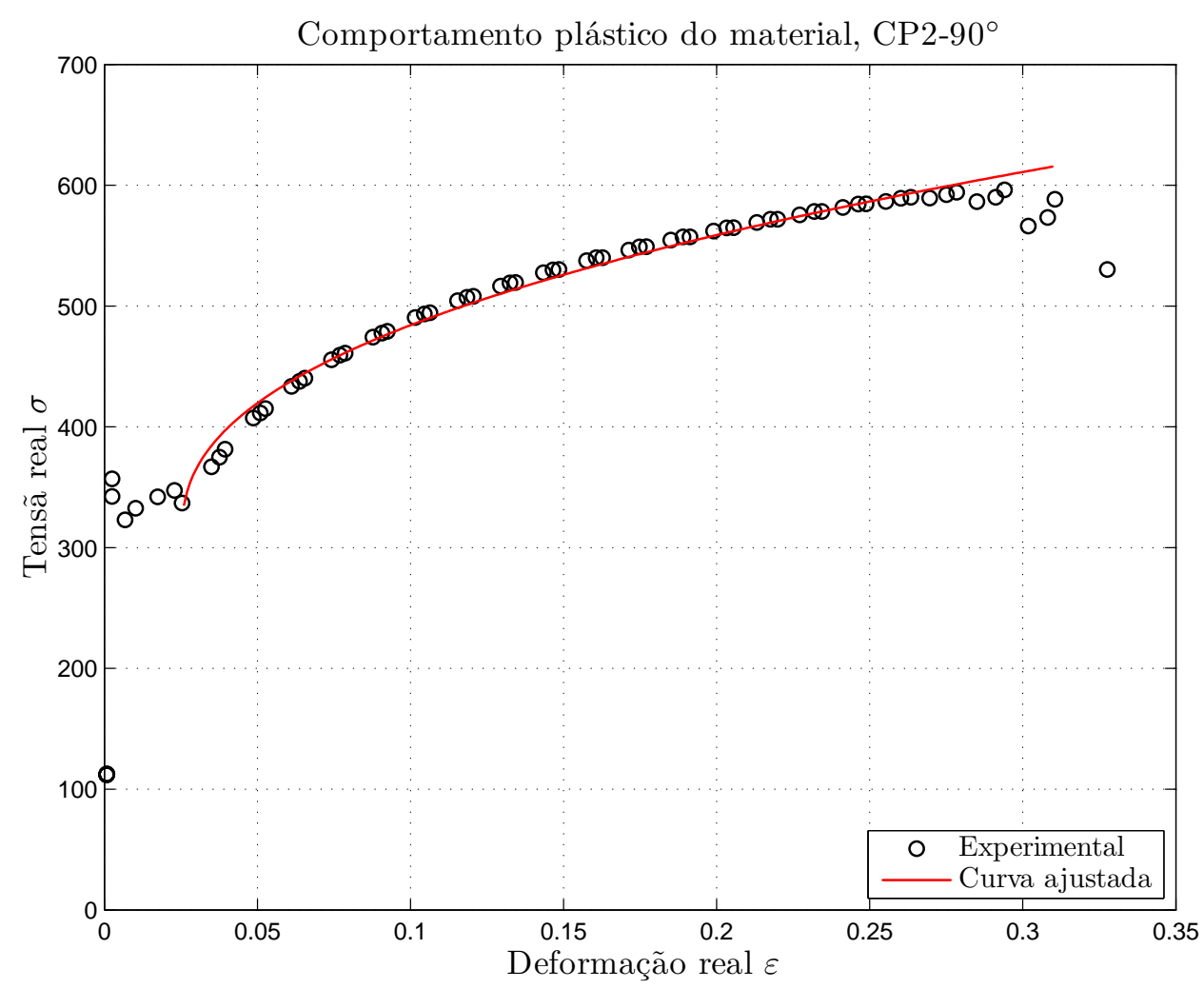

(e)

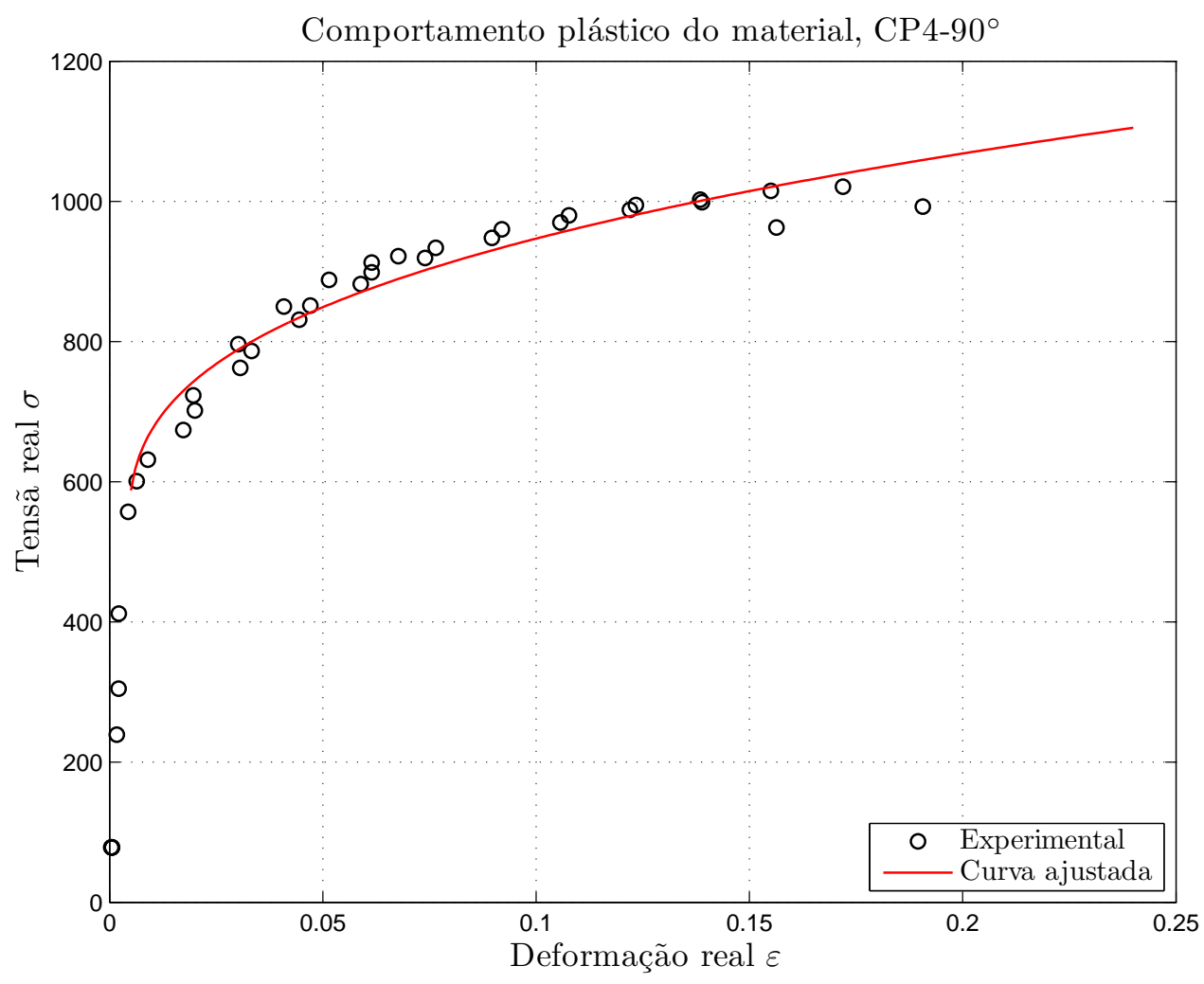

(f)

Figura 4.13: Curva tensão real versus deformação plástica real. Dados experimentais e equação de Ludwig ajustada. (a) $\mathrm{CP} 1-0^{\circ}$. (b) $\mathrm{CP} 2-0^{\circ}$. (c) $\mathrm{CP} 3-0^{\circ}$. (d) $\mathrm{CP} 4-0^{\circ}$. (e) $\mathrm{CP} 2-90^{\circ}$. (f) $\mathrm{CP} 4-90^{\circ}$. 
Tabela 4.7: Propriedades do comportamento plástico.

\begin{tabular}{c|cccc}
\hline Corpo de prova & $\boldsymbol{\sigma}_{\mathbf{0}}(\mathbf{M P a})$ & $\boldsymbol{K}(\mathbf{M P a})$ & $\boldsymbol{n}(-)$ & $\boldsymbol{\varepsilon}_{\boldsymbol{e s c}}(\boldsymbol{\%})$ \\
\hline $\mathrm{CP} 1-0^{\circ}$ & $297 \pm 16$ & $535 \pm 16$ & $0.41 \pm 0.04$ & $2.2 \pm 0.2$ \\
$\mathrm{CP} 2-0^{\circ}$ & $294 \pm 13$ & $518 \pm 15$ & $0.42 \pm 0.03$ & $2.2 \pm 0.2$ \\
$\mathrm{CP} 2-90^{\circ}$ & $312 \pm 14$ & $517 \pm 18$ & $0.43 \pm 0.04$ & $2.5 \pm 0.2$ \\
$\mathrm{CP} 3-0^{\circ}$ & $278 \pm 13$ & $511 \pm 13$ & $0.40 \pm 0.03$ & $2.2 \pm 0.2$ \\
$\mathrm{CP} 4-0^{\circ}$ & $506 \pm 66$ & $998 \pm 77$ & $0.33 \pm 0.07$ & $0.5 \pm 0.1$ \\
$\mathrm{CP} 4-90^{\circ}$ & $508 \pm 66$ & $978 \pm 106$ & $0.34 \pm 0.08$ & $0.4 \pm 0.1$ \\
\hline
\end{tabular}

\subsubsection{Evolução do dano}

O dano foi medido por meio da equação $D=1-\tilde{E} / E$, com $E$ sendo o módulo de elasticidade inicial do material e $\tilde{E}$ o módulo em cada operação de descarregamento.

O módulo de elasticidade inicial foi tomado aquele do início do comportamento plásticos, de modo a evitar a região não linear para baixas deformações. A partir de agora, os resultados dos corpos de prova $\mathrm{CP} 1-0^{\circ}, \mathrm{CP} 2-0^{\circ}$ e $\mathrm{CP} 3-0^{\circ}$ serão colocados juntos, sob a denominação SAE 1050 esferoidizado na direção de laminação. A evolução do dano com a deformação para todos os corpos de prova é mostrada na Fig. 4.14.

Da análise da Fig. 4.14, alguns pontos devem ser notados. A evolução do dano pôde ser aproximada por uma reta, com os valores de $R^{2}$ mostrados nas figuras, o que permitiu calcular a taxa de evolução do dano com a deformação $\mathrm{d} D / \mathrm{d} \varepsilon$, que será necessária para caracterizar o material seguindo o modelo de Lemaitre (1996). Próximo à fratura, há um crescimento acelerado do dano com a deformação, o que não é apreciado pelo modelo de teórico. Tais pontos foram desconsiderados para o cálculo da reta aproximada.

Podemos calcular o valor do parâmetro $S$, que indica a resistência ao dano do material, em diversos pontos da curva por meio da equação Eq. (2.54), reproduzida a seguir. Os resultados se encontram na Tab. 4.8, assim como os valores adotados para dano crítico unidimensional $D_{1 c}$ e deformação limite para início do dano $\varepsilon_{D}$. Os valores de dano crítico foram tomados como os últimos medidos antes do crescimento não linear próximo à fratura. Já o valor da deformação plástica de início do dano foi tomada como a deformação de escoamento do material, a partir da qual o módulo de elasticidade tem um decaimento em taxa linear, pela teoria de Lemaitre, é desconsiderado o surgimento de dano no regime elástico de um material metálico.

$$
S=\frac{\sigma^{2}}{2 E(1-D)^{2}(\mathrm{~d} D / \mathrm{d} \varepsilon)}
$$


Evlolução do dano, Esferoidizado, $0^{\circ}$

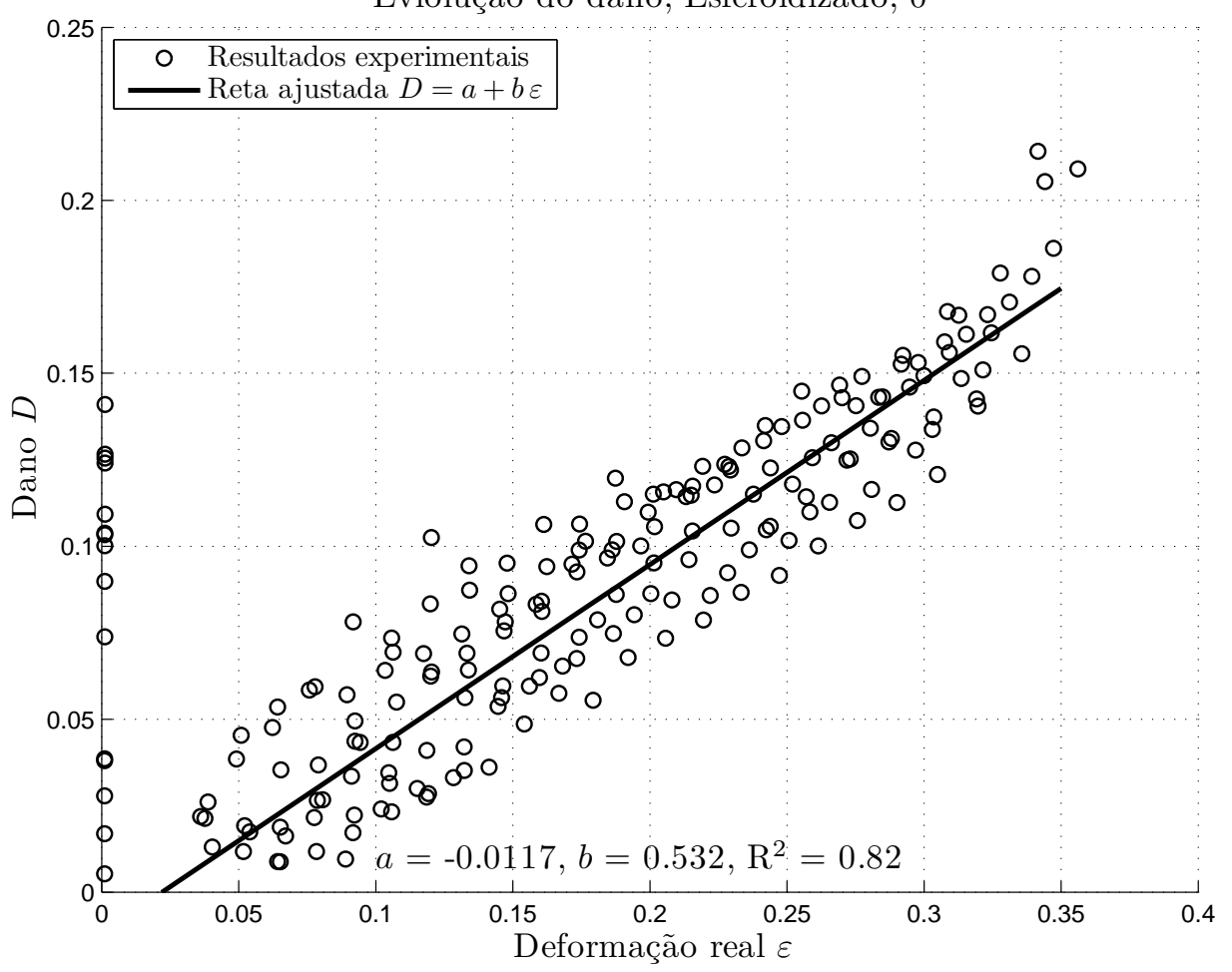

(a)

Evlolução do dano, Esferoidizado, 90

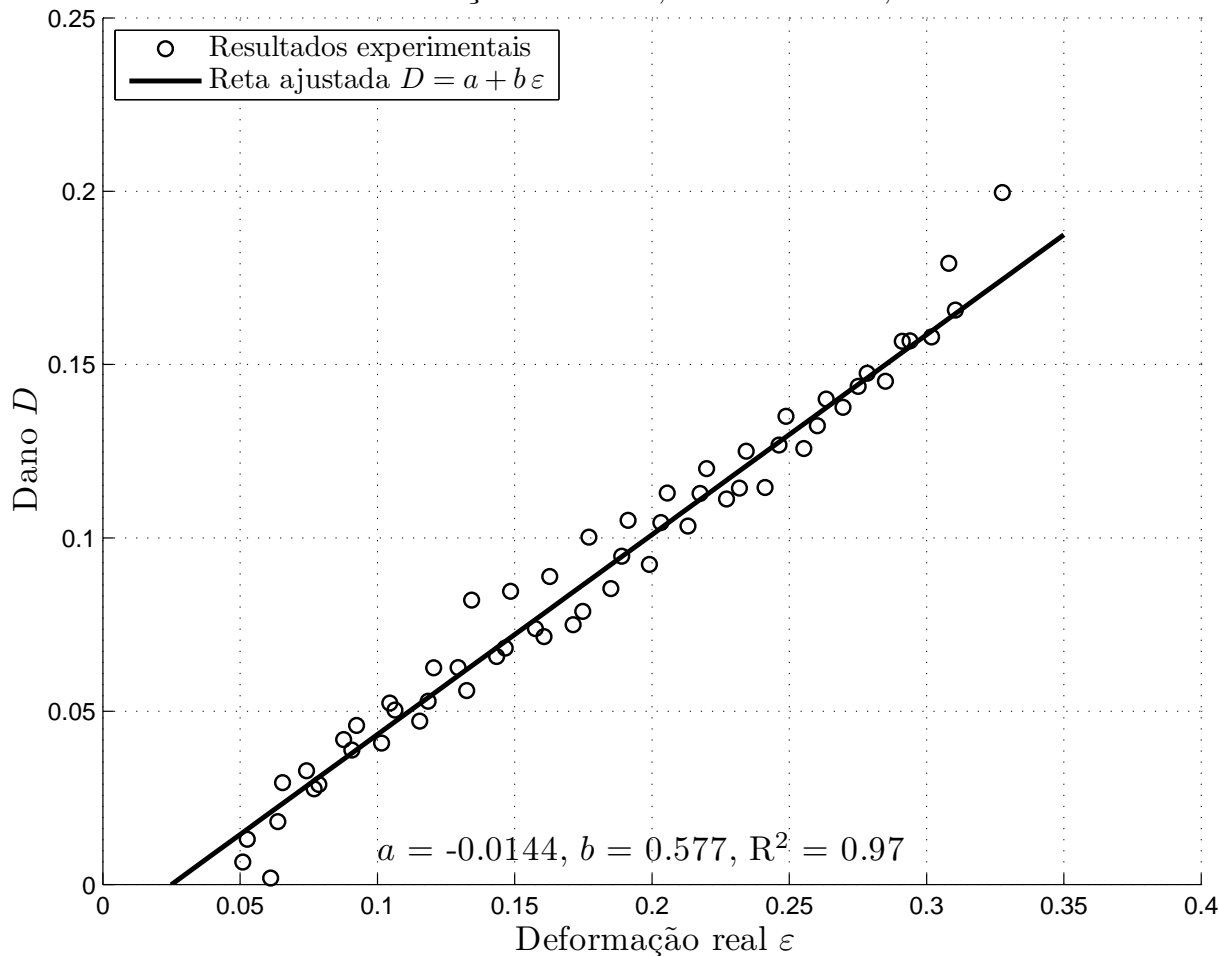

(b) 
Evlolução do dano, Laminado a quente, $0^{\circ}$

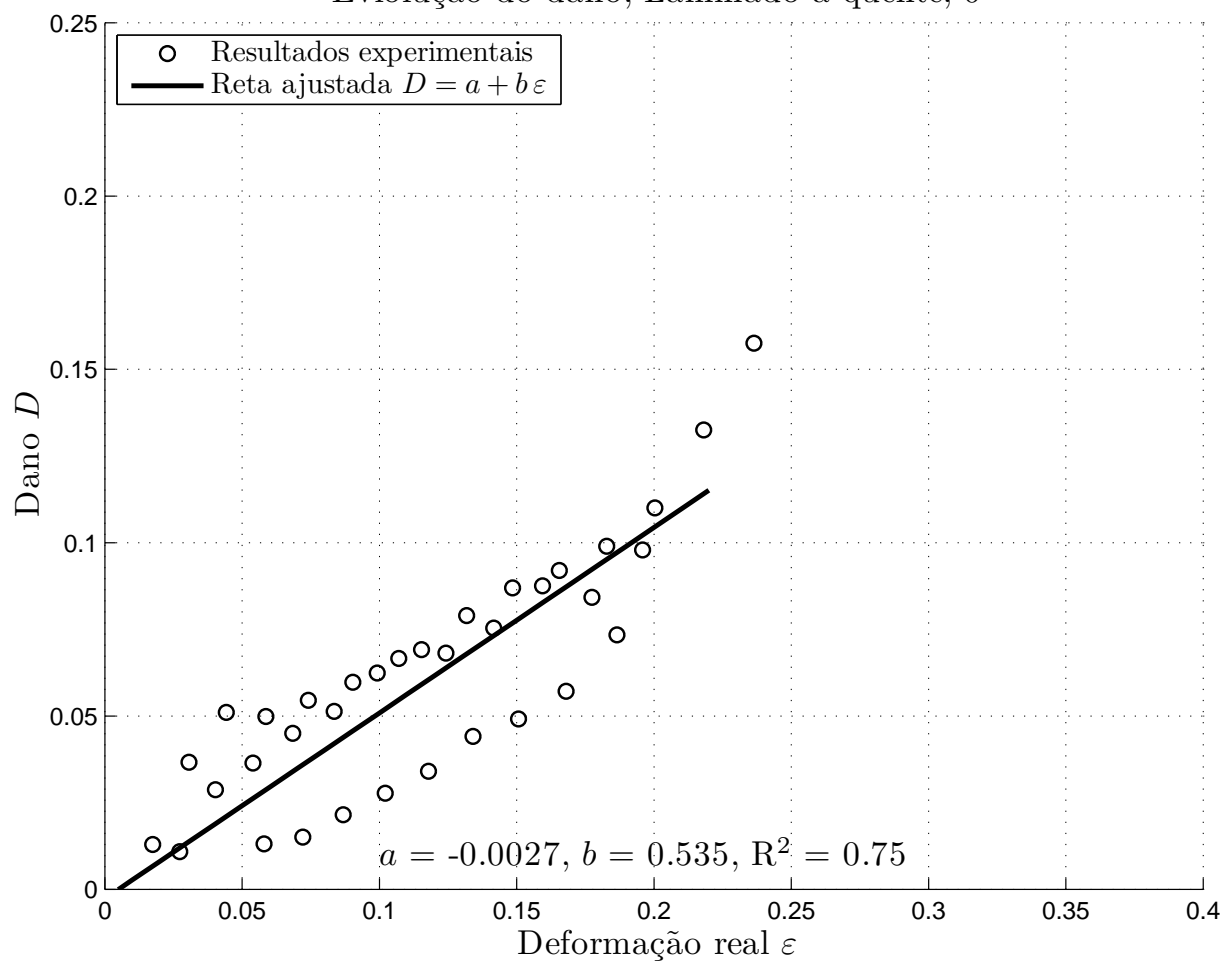

(c)

Evlolução do dano, Laminado a quente, $90^{\circ}$

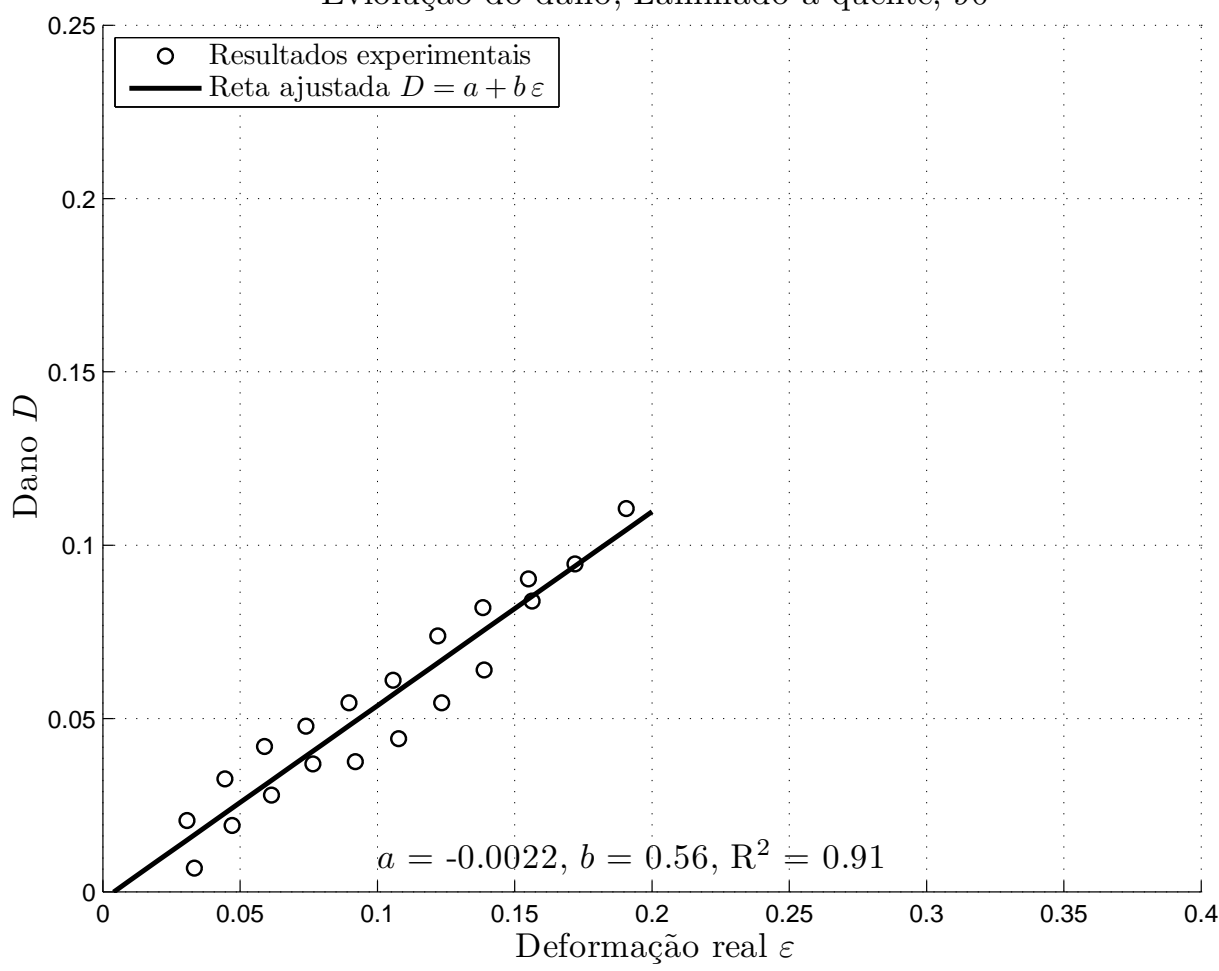

(d)

Figura 4.14: Evolução do dano com a deformação real. Aço SAE 1050. (a) Esferoidizado, $0^{\circ}$. (b) Esferoidizado, $90^{\circ}$. (c) Laminado a quente, $0^{\circ}$. (d) Laminado a quente $90^{\circ}$. 
Tabela 4.8: Propriedades de evolução do dano, aço SAE 1050.

\begin{tabular}{cccc}
\hline Corpo de prova & $\boldsymbol{S}(\mathrm{MPa})$ & $\boldsymbol{D}_{\mathbf{1 c}}(-)$ & $\boldsymbol{\varepsilon}_{\boldsymbol{D}}(\%)$ \\
\hline Esferoidizado, $0^{\circ}$ & 1,97 & 0,19 & 2,2 \\
Esferoidizado, 90 & 1,80 & 0,18 & 2,5 \\
Laminado a quente, $0^{\circ}$ & 4,79 & 0,13 & 0,5 \\
Laminado a quente, $90^{\circ}$ & 4,06 & 0,11 & 0,4 \\
\hline
\end{tabular}

A Tab. 4.9 compila todas as propriedades mecânicas (elásticas, plásticas e de dano) para a liga de aço 1050 estudada em quatro diferentes condições: laminada a quente (L) e esferoidizada $(\mathrm{E})$, na direção de laminação $\left(0^{\circ}\right)$ e transversal à direção de laminação $\left(90^{\circ}\right)$. Tais parâmetros serão utilizados como dados de entrada nas simulações numéricas efetuadas posteriormente.

Tabela 4.9: Propriedades mecânicas do aço SAE 1050 à temperatura ambiente.

\begin{tabular}{cccccccccc}
\hline \multicolumn{10}{c}{ Propriedades } \\
\hline & $E$ & $\nu^{(1)}$ & $\sigma_{\text {esc }}$ & $\sigma_{u}$ & $K$ & $n$ & $S$ & $\varepsilon_{D}$ & $D_{1 c}$ \\
$\mathrm{E}-0^{\circ}$ & $138 \mathrm{GPa}$ & 0,3 & $290 \mathrm{MPa}$ & $595 \mathrm{MPa}$ & $520 \mathrm{MPa}$ & 0,41 & $2,0 \mathrm{MPa}$ & 0,022 & 0,19 \\
$\mathrm{E}-90^{\circ}$ & $142 \mathrm{GPa}$ & 0,3 & $312 \mathrm{MPa}$ & $602 \mathrm{MPa}$ & $517 \mathrm{MPa}$ & 0,42 & $1,8 \mathrm{MPa}$ & 0,025 & 0,18 \\
$\mathrm{~L}^{\circ}$ & $139 \mathrm{GPa}$ & 0,3 & $506 \mathrm{MPa}$ & $1073 \mathrm{MPa}$ & $998 \mathrm{MPa}$ & 0,33 & $4,8 \mathrm{MPa}$ & 0,005 & 0,13 \\
$\mathrm{~L}^{\circ} 90^{\circ}$ & $133 \mathrm{GPa}$ & 0,3 & $508 \mathrm{MPa}$ & $1021 \mathrm{MPa}$ & $978 \mathrm{MPa}$ & 0,34 & $4,1 \mathrm{MPa}$ & 0,004 & 0,11 \\
\hline
\end{tabular}

${ }^{(1)} \mathrm{O}$ valor do coeficiente de Poisson foi retirado da literatura. Nenhum ensaio de determinação foi efetuado.

A título de comparação, apresentamos na Tab. 4.10 propriedades de alguns materiais, levantados por diversos trabalhos (LEMAITRE, 1996) (ABOUTALEBI; FARZIN; POURSINA, 2010) (VAZ JR.; DE SANTI JR.; DE SOUZA NETO, 2010) (NIAZI et al., 2012) (DESMORAT; CANTOURNET, 2008) (MASHAYEKHI et al., 2007). O ponto que chama mais atenção é o baxo valor de deformação crítica para início da evolução do dano encontrado para ambos os materiais. Isso indica que a perda de coesão da cementita esferoidizada com a matriz ferrítica ocorre inclusive para pequenos valores de deformação. O valor do dano crítico, como esperado, foi maior para o material esferoidizado. Ou seja, sua maior ductilidade também é refletida pelo fato de conseguir aceitar maiores valores de dano antes da falha completa. O parâmetro de resistência ao dano $S$ para o material esferoidizado é cerca da metade do material com microestrutura ferrita-perlita. Contudo, ao analisar as inclinações das retas da Fig. 4.14, notamos que a diferença não chega a ser de $10 \%$. Isso indica que para haver algum tipo de efeito significativo na taxa de evolução do dano, o parâmetro $S$ precisa variar ordens de grandeza. 
Tabela 4.10: Propriedades mecânicas de diversos materiais à temperatura ambiente.

\begin{tabular}{|c|c|c|c|c|c|c|c|}
\hline \multirow{2}{*}{ Material } & \multicolumn{2}{|c|}{ Parâmetros elásticos } & \multicolumn{2}{|c|}{ Parâmetros plásticos } & \multicolumn{3}{|c|}{ Dano } \\
\hline & $E(\mathrm{GPa})$ & $\nu$ & $\sigma_{e s c}(\mathrm{MPa})$ & $\sigma_{u}(\mathrm{MPa})$ & $S(\mathrm{MPa})$ & $\varepsilon_{D}$ & $D_{1 c}$ \\
\hline $\begin{array}{c}\text { SAE } 1050 \\
\text { esferoidizado, } \\
0^{\circ}\end{array}$ & 138 & 0,30 & 290 & 595 & 2,0 & 0,022 & 0,19 \\
\hline $\begin{array}{c}S A E 1050 \\
\text { esferoidizado, } \\
90^{\circ}\end{array}$ & 142 & 0,30 & 312 & 602 & 1,8 & 0,025 & 0,18 \\
\hline $\begin{array}{c}\text { SAE } 1050 \\
\text { laminado a } \\
\text { quente, } 0^{\circ}\end{array}$ & 139 & 0,30 & 506 & 1073 & 4,8 & 0,005 & 0,13 \\
\hline $\begin{array}{c}\text { SAE } 1050 \\
\text { laminado a } \\
\text { quente, } 90^{\circ}\end{array}$ & 133 & 0,30 & 508 & 1021 & 4,1 & 0,004 & 0,11 \\
\hline $\begin{array}{c}\text { Aço SAE } \\
1010^{(1)}\end{array}$ & 190 & 0,28 & 320 & 700 & 2,4 & 0,44 & 0,20 \\
\hline $\begin{array}{c}\text { Aço inox } \\
\text { AISI } 316^{(1)}\end{array}$ & 200 & 0,30 & 260 & 700 & 7,0 & 0,10 & 0,15 \\
\hline $\begin{array}{l}\text { Cobre comer- } \\
\text { cialmente } \\
\text { puro }^{(1)}\end{array}$ & 100 & 0,33 & 190 & 300 & 0,40 & 0,35 & 0,85 \\
\hline $\begin{array}{c}\text { Liga de } \\
\text { alumínio AA } \\
2024^{(1)}\end{array}$ & 72 & 0,32 & 300 & 500 & 1,7 & 0,030 & 0,23 \\
\hline $\begin{array}{c}\text { Aço DIN } \\
1623 \mathrm{St}_{14}{ }^{(2)}\end{array}$ & 180 & - & 159 & 283 & 2,5 & 0 & 0,43 \\
\hline $\begin{array}{l}\text { Aço baixo } \\
\text { carbono }^{(3)}\end{array}$ & 200 & 0,3 & 275 & 600 & 0,1 & 0 & 0,80 \\
\hline $\begin{array}{c}\text { Aço } \\
\text { dual-phase } \\
\mathrm{DP}^{2} 00^{(4)}\end{array}$ & 210 & - & 350 & 620 & 1,4 & 0,18 & 0,18 \\
\hline 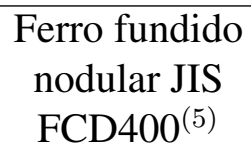 & 200 & 0,3 & 300 & 470 & 0,45 & 0 & 0,14 \\
\hline $\begin{array}{l}\text { Dispersoid } \\
\text { steel } \\
\text { SOLDUR } \\
355^{(5)}\end{array}$ & 200 & 0,3 & 300 & 475 & 0,34 & 0,025 & 0,30 \\
\hline $\begin{array}{c}\text { Aço ASTM } \\
533-B 1^{(6)}\end{array}$ & 200 & 0,3 & 430 & 600 & 2,8 & 0,04 & 0,43 \\
\hline $\begin{array}{c}\text { Aço SAE } \\
5115^{(7)}\end{array}$ & 200 & 0,3 & - & 505 & 0,48 & 0,17 & 0,23 \\
\hline
\end{tabular}

${ }^{(1)}$ Lemaitre (1996), ${ }^{(2)}$ Aboutalebi, Farzin e Poursina (2010), ${ }^{(3)}$ Vaz Jr., de Santi Jr. e de Souza Neto (2010), ${ }^{(4)}$ Niazi et al. (2012), ${ }^{(5)}$ Desmorat e Cantournet (2008), ${ }^{(6)}$ Mashayekhi et al. (2007), ${ }^{(7)}$ Behrens e Just (2005) 


\subsubsection{Localização das deformações}

Sabe-se que a localização da deformação ocorre quando qualquer material dúctil é submetido a deformações plásticas elevadas (RICE, 1976). As deformações, que podem ser definidas por um gradiente constante num estágio anterior do fenômeno, começam a crescer de maneira acentuada apenas em uma pequena região do corpo, levando à fratura dúctil naquele local.

De modo a medir o grau de localização da deformação nos corpos de prova ensaiados, os círculos gravados por marcação eletroquímica, ver Fig. 4.5, são analisados após o ensaio e suas novas dimensões são comparadas com o raio original, possibilitando a medida local das deformações longitudinais e transversais reais.

Para medir a variação dos círculos usou-se uma rotina programada em MatLab para identificação e processamento de fotografias dos corpos de prova após o ensaio de tração, como a ilustrada na Fig. 4.15.

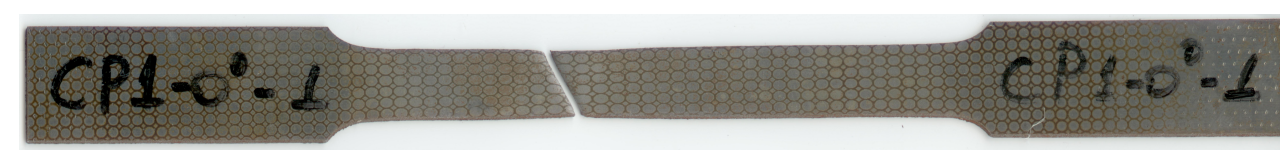

Figura 4.15: Fotografia utilizada para identificação dos círculos.

Por meio do contraste entre as regiões mais escuras, marcadas eletroquimicamente, com a cor natural do metal, pode-se identificar os pixels que estão contidos dentro dos círculos, e suas posições. Assim, podemos identificar o raio dessas entidades geométricas.

Em primeiro lugar, é feita uma medida de calibração, ou seja, analisamos uma região do corpo de prova que não foi deformada, de modo a fazer a correlação entre número de pixels e tamanho real do círculo ( $2 \mathrm{~mm}$ ), como é mostrado na Fig. 4.16. O raio é tomado como a média dos raios medidos.

Após esta calibração, a mesma técnica é aplicada para a região deformada. Nota-se que os círculos se transformam em elipses, cujos semi-eixos são calculados pela rotina. A medida das deformações longitudinais $\varepsilon_{1}$ e transversais $\varepsilon_{2}$ é dada por:

$$
\begin{aligned}
\varepsilon_{1} & =\ln \left(\frac{a}{r}\right) \\
\varepsilon_{2} & =\ln \left(\frac{b}{r}\right)
\end{aligned}
$$

onde $a, b$ e $r$ são, respectivamente, o semi-eixo maior da elipse, o semi-eixo menor da elipse e o raio original dos círculos, todos medidos em pixels. A Fig. 4.17 mostra as elipses da região deformada identificadas pela rotina. 


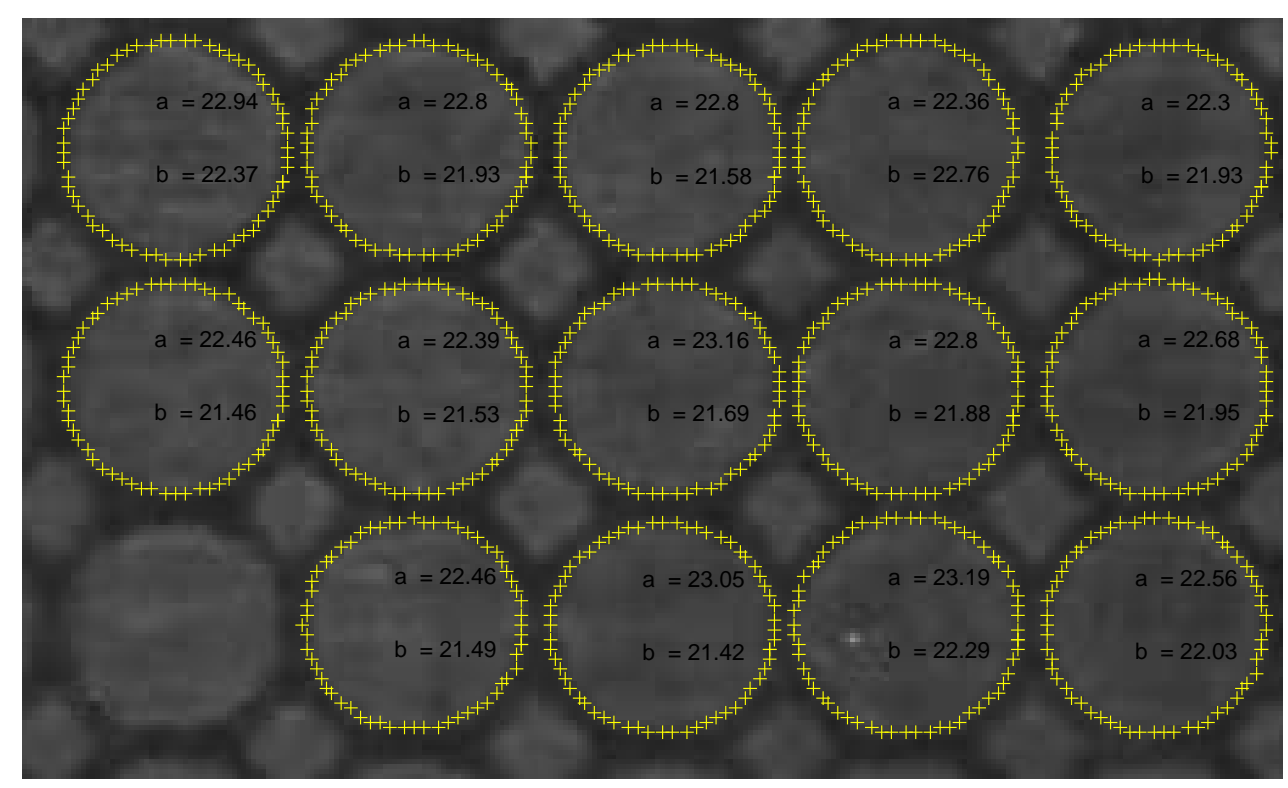

Figura 4.16: Círculos identificados por meio da rotina computacional e seus respectivos raios na região não deformada do corpo de prova.

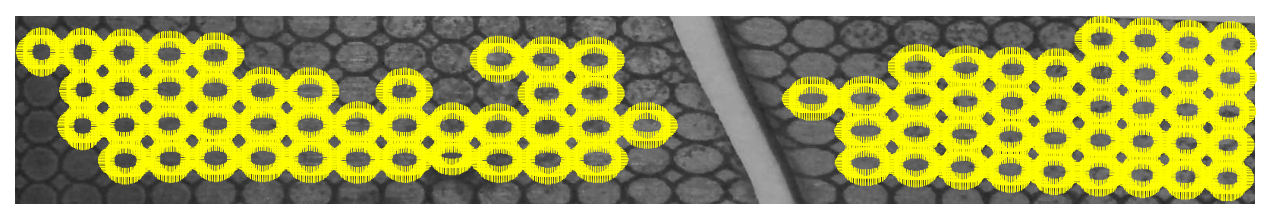

Figura 4.17: Elipses identificadas pela rotina de análise de imagens.

Podemos plotar as deformações longitudinais de cada uma das elipses em função da posição no corpo de prova, como mostrado na Fig. 4.18. É possível perceber que as deformações ao longo do corpo de prova tendem a permanecer em um patamar, se elevando apenas próximo à fratura, evidenciando a localização. Tais resultados serão comparados posteriormente com as simulações numéricas, servindo como critério de validação do modelo em elementos finitos.

Já a Fig. 4.19 mostra o caminho de deformação do material no ensaio de tração, ou seja, como a deformação longitudinal evolui em função da deformação transversal. A linha contínua representa o resultado analítico do caminho de deformações para o estado de tensões de tração uniaxial perfeito, dado pela equação $\varepsilon_{1}=-2 \varepsilon_{2}$ (BANABIC et al., 2000).

Embora seja útil para estimar ordens de grandeza, o método de medição de deformações por meio dá máscara de círculos aqui utilizado não se mostrou muito preciso, visto que seriam necessários círculos menores para obter uma medida mais correta da deformação em cada ponto ao longo do corpo de prova. Outras dificuldades do método são garantir a qualidade 


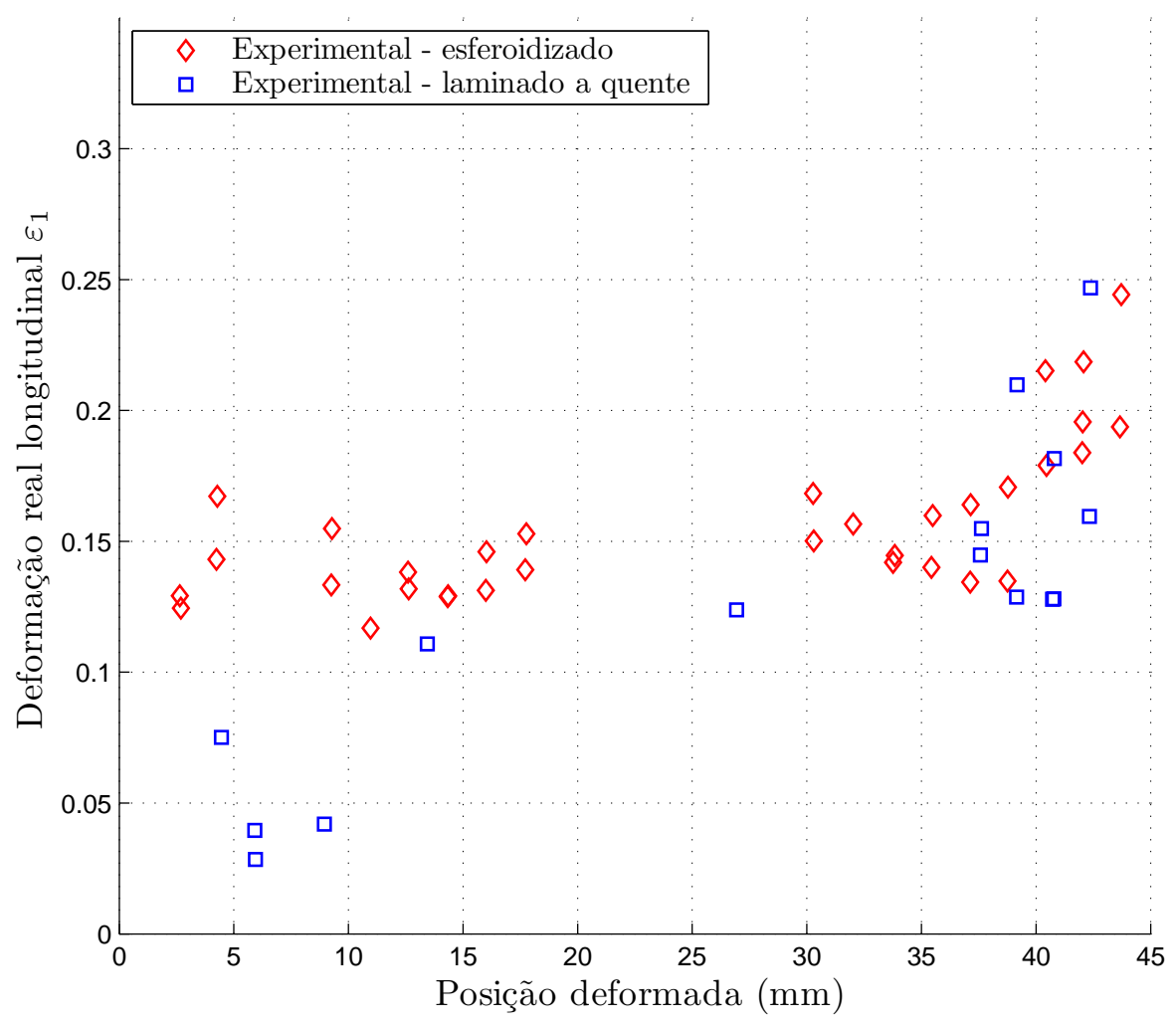

Figura 4.18: Deformação longitudinal em função da posição no ensaio de tração.

da marcação eletroquímica e a resolução das fotografias utilizadas, pois problemas de nitidez vão levar a maiores imprecisões nas medições. Buscando minimizar tais problemas, Volk e Hora (2011) apresentam uma metologia baseada nos mesmos princípios de reconhecimento de imagens, porém amparada por um equipamento de captura de imagens de alta resolução dedicado e acoplado às máquinas de ensaio, possibilitando capturar a evolução das deformações em vários pontos ao longo do tempo. Futuros trabalhos podem se beneficiar desta nova tecnologia.

Alguns modelos analíticos utilizam essas informações de deformações $\varepsilon_{1}$ e $\varepsilon_{2}$ como dados de entrada para predição da deformação crítica na fratura e previsão da localização das deformações em chapas, como apresentado por Li et al. (2010). O modelo de Hill (1952), posteriormente expandido por Stören e Rice (1975), assume que a instabilidade que leva a localização se dá na direção em que a deformação é nula no plano da chapa. O modelo de Bressan e Williams (1983), ao contrário, descreve a localização se iniciando na direção da espessura da chapa. A Fig. 4.20 esquematiza os dois modelos.

Os parâmetros de entrada destes modelos são a relação entre deformações $\alpha=\mathrm{d} \varepsilon_{2} / \mathrm{d} \varepsilon_{1}$ e o coeficiente de encruamento $n$ da equação de Hollomon (1945), $\sigma_{e s c}=K\left(\varepsilon^{p}\right)^{n}$. Por hipóteses, assumimos o ensaio de tração como sendo perfeitamente uniaxial, de modo que $\alpha=-1 / 2$, 


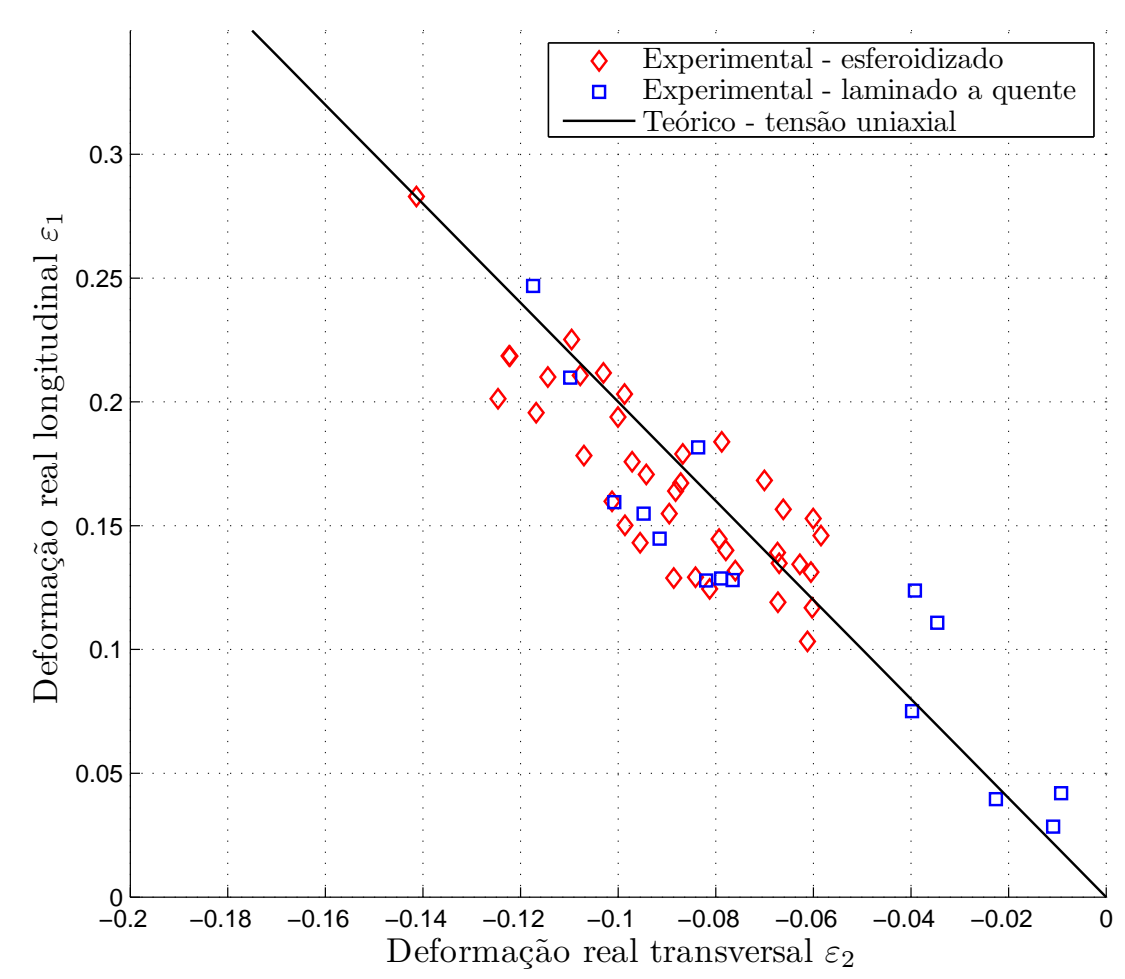

Figura 4.19: Deformação longitudinal em função da deformação transversal no ensaio de tração.

de acordo com a Fig. 4.21.

Os coeficientes da equação de Hollomon para a liga SAE 1050 esferoidizada e laminada a quente, ambas deformadas na direção de laminação original, foram calculados ajustandose a curva aos dados de tensão real e deformação real mostrados na Fig. 4.13. Os resultados estão na Tab. 4.11.

Tabela 4.11: Coeficientes da equação de Hollomon, aço SAE 1050.

\begin{tabular}{ccc}
\hline Corpo de prova & $\boldsymbol{K}(\mathrm{MPa})$ & $\boldsymbol{n}(-)$ \\
\hline Esferoidizado, $0^{\circ}$ & 731 & 0,157 \\
Laminado a quente, $0^{\circ}$ & 1307 & 0,124 \\
\hline
\end{tabular}

As Figs. 4.22 e 4.23 mostram como se deram as fraturas nos corpos de prova esferoidizado e laminado a quente, respectivamente. Pode-se perceber que fratura dos corpos de prova esferoidizados seguem o mesmo padrão do modelo de Stören e Rice (1975), com a localização se formando no plano da chapa. O ângulo de ocorrência da instabilidade que leva à formação da banda de ruptura, definido na Fig. 4.20, foi de aproximadamente $\varphi=25^{\circ}$. Já para a fratura do corpo de prova laminado a quente, que tem localização concentrada no sentido da espessura da chapa, seguindo o modelo de Bressan e Williams (1983), o ângulo de instabilidade $\theta$ encontrado 


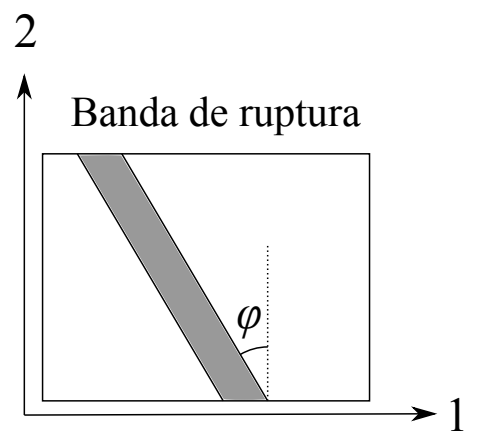

(a)
3

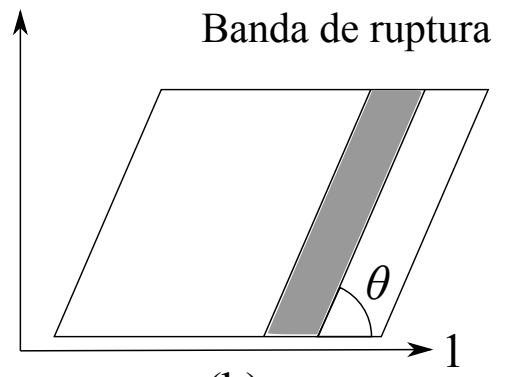

(b)

Figura 4.20: Esboço de critérios para determinação de instabilidade e localização durante a fratura de chapas. Direções 1, 2 e 3 são, respectivamente, longitudinal, transversal e normal ao plano da chapa. (a) Critério de Stören e Rice (1975). (b) Critério de Bressan e Williams (1983).

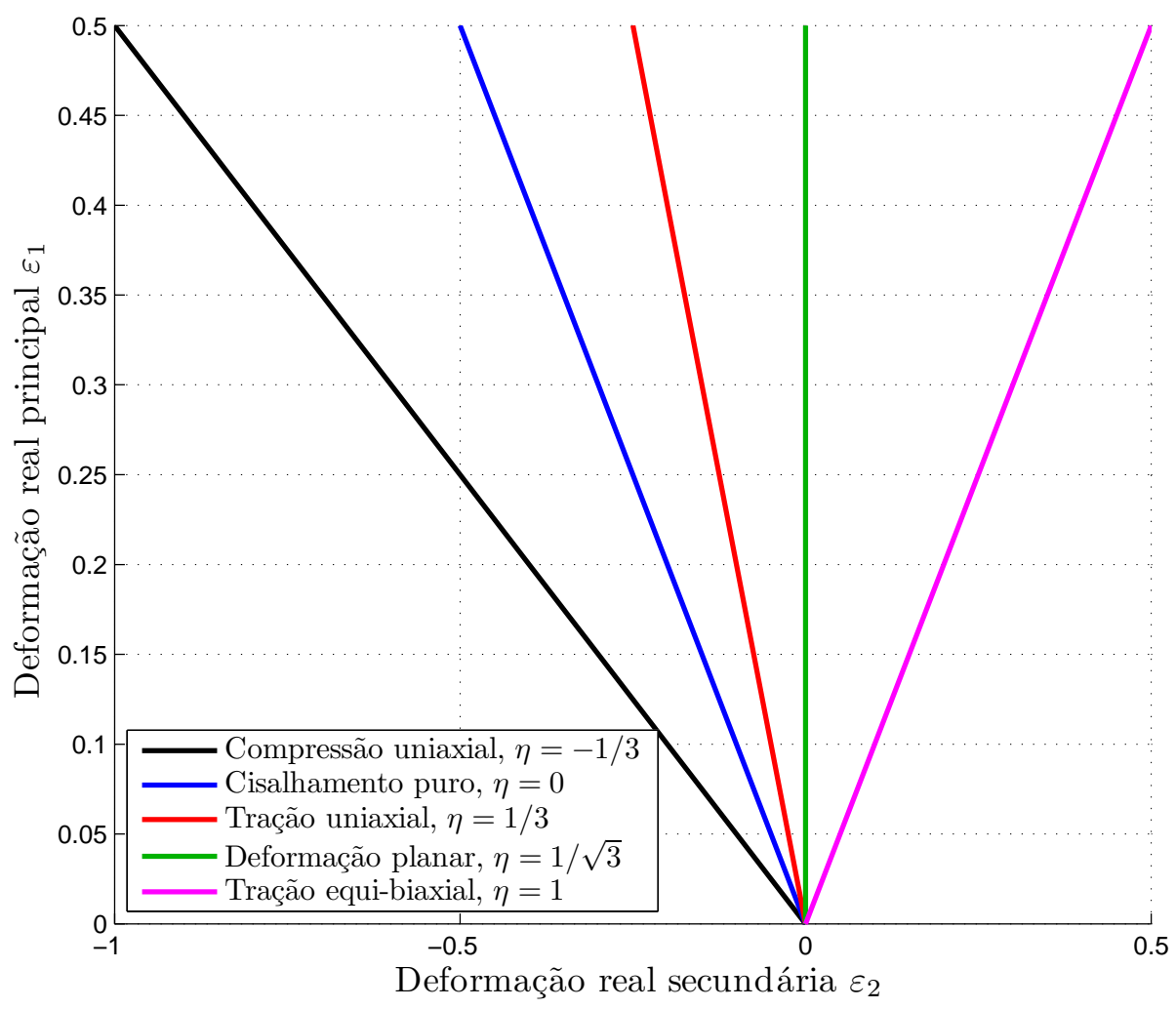

Figura 4.21: Caminhos de deformação para diversos tipos de carregamento no estado planar de tensões, caracterizados pela relação de triaxialidade $\eta=\sigma_{H} / \sigma_{e q}$. Adaptado de Li et al. (2010).

foi de cerca de $40^{\circ}$. Essa variação no modo como se dá a fratura pode estar relacionada tanto à microestrutura do material como também com a espessura das chapas, visto que os materiais laminados a quente ensaiados tinham espessura maior: $2,0 \mathrm{~mm}$ contra 1,0-1,5 $\mathrm{mm}$ dos materiais esferoidizados. A seguir mostramos os valores de deformações críticas e ângulos da banda de ruptura estimados por estes modelos. 


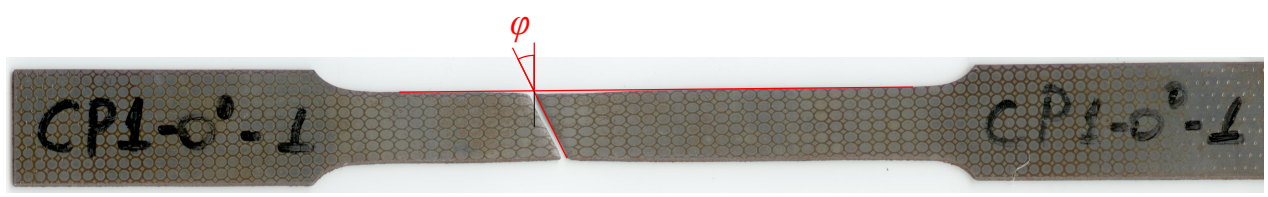

(a)

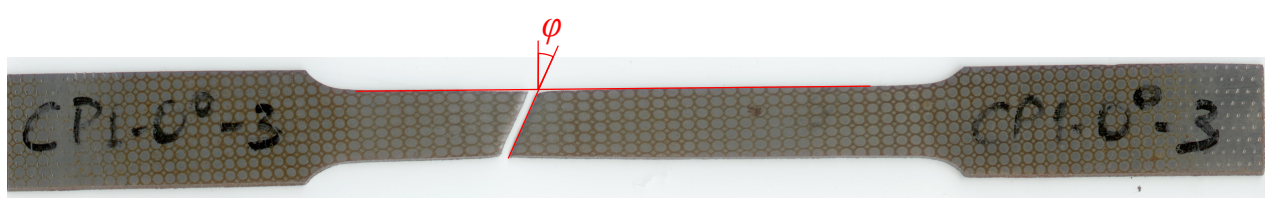

(b)

Figura 4.22: Corpos de prova fraturados. Material esferoidizado, $0^{\circ}$. (a), (b) Vista frontal.

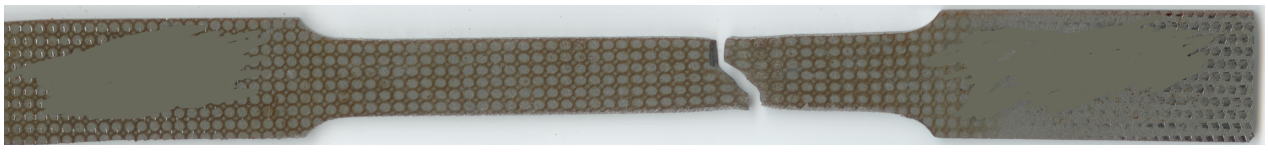

(a)

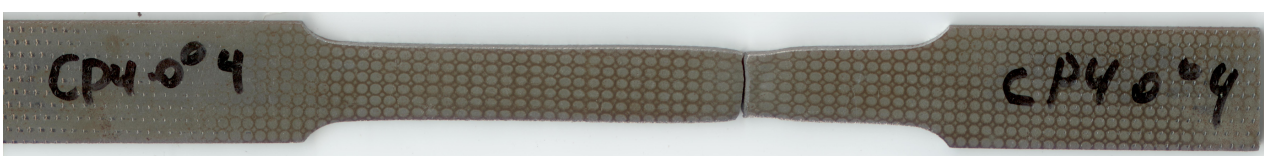

(b)

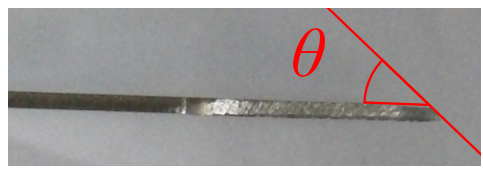

(c)

Figura 4.23: Corpos de prova fraturados. Material laminado a quente, $0^{\circ}$. (a), (b) Vista frontal. (c) Vista lateral. 
Tabela 4.12: Deformações críticas para fratura e ângulos da banda de ruptura. Comparação entre resultados analíticos e experimentais.

\begin{tabular}{ccccccccc}
\hline & $\alpha$ & $n$ & $\left(\varepsilon_{1}^{f}\right)_{\text {anal. }}$ & $\left(\varepsilon_{1}^{f}\right)_{\text {exp. }}$ & $\varphi_{\text {anal. }}$ & $\varphi_{\text {exp. }}$ & $\theta_{\text {anal. }}$ & $\theta_{\text {exp. }}$ \\
\hline E-0 $^{\circ}$ & $-0,5$ & 0,157 & 0,314 & 0,33 & $26,5^{\circ}$ & $\approx 25^{\circ}$ & - & - \\
LQ-0 $^{\circ}$ & $-0,5$ & 0,124 & 0,248 & 0,25 & - & - & $35,2^{\circ}$ & $\approx 40^{\circ}$ \\
\hline
\end{tabular}

A deformação crítica para fratura, segundo ambos os modelos, é calculada por:

$$
\varepsilon_{1}^{f}=\frac{n}{1+\alpha}
$$

enquanto que o ângulo de instabilidade $\varphi$, do modelo de Hill (1952) e Stören e Rice (1975) é definido como:

$$
\varphi=\tan ^{-1}(-\alpha)
$$

e o ângulo $\theta$, do modelo de Bressan e Williams (1983), pode ser obtido como:

$$
\theta=\frac{1}{2} \cos ^{-1}\left(-\frac{\alpha}{2+\alpha}\right)
$$

Na Tab. 4.12, mostramos os resultados estimados pelos modelos analíticos e comparamos com os medidos experimentalmente. É possível perceber que a deformação na fratura é muito bem estimada, com erro máximo de $5 \%$ para o caso do material esferoidizado. O ângulo da banda de ruptura na direção da espessura da chapa, para o caso do material laminado a quente, apresentou um erro da ordem de $12 \%$, enquanto que o ângulo da banda de ruptura no plano da chapa calculado para o material esferoidizado apresentou um erro de $6 \%$.

Podemos concluir que os modelos analíticos, pelo menos para este caso, no qual o estado de tensões do material é governado por um único modo de carregamento - tensão uniaxial -, funcionam bem na previsão da fratura do material. Logo, os parâmetros mecânicos que governam o processo de localização de deformações e, portanto, de fratura dúctil do material, são o estado de tensões, o comportamento plástico do material e a espessura, visto que as chapas mais espessas, 2,0 mm para o caso laminado a quente, apresentaram uma banda de ruptura mais bem definida no sentido da espessura da chapa. Já nas chapas mais finas do material esferoidizado, entre 1,0 e 1,5 mm, este tipo de comportamento é mais difícil de ocorrer e a fratura acontece predominantemente no próprio plano da chapa. Contudo, como exposto por Banabic et al. (2010), estes modelos sofrem de limitações, pois não podem ser aplicados independentemente do caminho de deformações ou visando analisar variações de parâmetros de processo, como velocidade de deformação ou temperatura do material. 


\subsection{Conclusões parciais}

Este capítulo tratou da caracterização das propriedades mecânicas do aço SAE 1050 nas condições esferoidizado e laminado a quente, se baseando em uma metodologia que pode ser seguida para outros materiais metálicos. Mostramos que nem toda perda de rigidez do material pode ser associada ao dano, visto que nos primeiros estágios da deformação há uma queda não linear do módulo elástico que, segundo a literatura, pode sofrer um processo de recuperação.

Nenhuma variação significativa, tanto nas propriedades mecânicas quanto nas propriedades de evolução do dano, foi encontrada ao variar a direção de deformação em relação à direção original de laminação das chapas, indicando um comportamento isotrópico dos materiais estudados. No próximo capítulo, tal característica será investigada por meio da análise da evolução da textura por meio de difração de raios X.

Por fim, modelos analíticos de previsão da fratura foram analisados e os resultados estimados foram comparados com os experimentais, mostrando que em condições de carregamento não complexos, isto é, quando um estado de tensões único é dominante, tais modelos funcionam bem, prevendo a deformação crítica da fratura e o ângulo de formação da ruptura com boa precisão. O comportamento plástico do material, a espessura da chapa e o estado de tensões atuante parecem ser os parâmetros mecânicos principais que governam o processo de fratura dúctil neste caso.

As propriedades mecânicas encontradas serão utilizadas para alimentar uma simulação numérica da teoria do mesmo ensaio de tração, com a evolução do dano caracterizada pelo modelo de Lemaitre. 


\section{CRISTALOGRAFIA E TEXTURAS}

É de conhecimento geral que os materiais metálicos apresentam uma estrutura atômica cristalina, ou seja, os átomos estão posicionados em um arranjo que se repete por longas distâncias atômicas (CALLISTER JR., 2002). Cada um destes cristais dá origem a um grão diferente, cada qual com uma orientação no espaço diferente das demais.

A conformabilidade de chapas metálicas depende fortemente da anisotropia do material, a qual está diretamente ligada a como os grãos estão orientados no espaço (PLAUT et al., 2009). Posto isto, é importante avaliar de alguma maneira como a propensão a uma determinada orientação cristalina, também conhecida como textura, influencia nas propriedades mecânicas de um material.

Sabe-se que materiais policristalinos com orientação de grãos totalmente aleatória, isto é, sem textura cristalográfica, são pouco encontrados industrialmente, visto que qualquer operação de processamento de uma liga metálica, seja fundição, extrusão, laminação ou forjamento, imprime, em maior ou menor grau, algum tipo de orientação preferencial aos grãos (SOUZA, 2012). Este tipo de orientação, chamada de textura de deformação, ocorre pela rotação do reticulado cristalino de modo a favorecer o escorregamento de determinados planos cristalinos e permitir maiores deformações plásticas no material metálico (PADILHA; SICILIANO JR., 2005).

A presença de certas texturas geralmente indica que um material se deformará mais facilmente com menor chance de se romper. Em chapas metálicas, a textura é analisada pela orientação dos grãos em relação ao plano da superfície da chapa, tendo a direção de laminação como referência. Uma das maneiras de representar a textura é por meio das funções de distribuição de orientação (FDO), baseada nos ângulos de Euler.

Para materiais com estrutura cristalina cúbica define-se dois sistemas de coordenadas: o primeiro, fixo em relação à chapa, composto pela direção de laminação (DL), pela direção transversal (DT) e pela direção normal ao plano da chapa (DN), enquanto que o segundo, $(x, y, z)$, é fixo em um cubo arbitrário cujas normais inicialmente estão alinhadas com o sistema (DL,DT,DN). Por meio de três rotações conseguimos obter qualquer orientação possível 
do cubo. $\mathrm{O}$ ângulo $\varphi_{1}$ é tomado a partir de uma rotação ao redor da direção $\mathrm{DN}$, o ângulo $\Phi$ em relação ao eixo $x$, e o ângulo $\varphi_{2}$ em relação ao eixo $z$, como mostrado na Fig. 5.1.
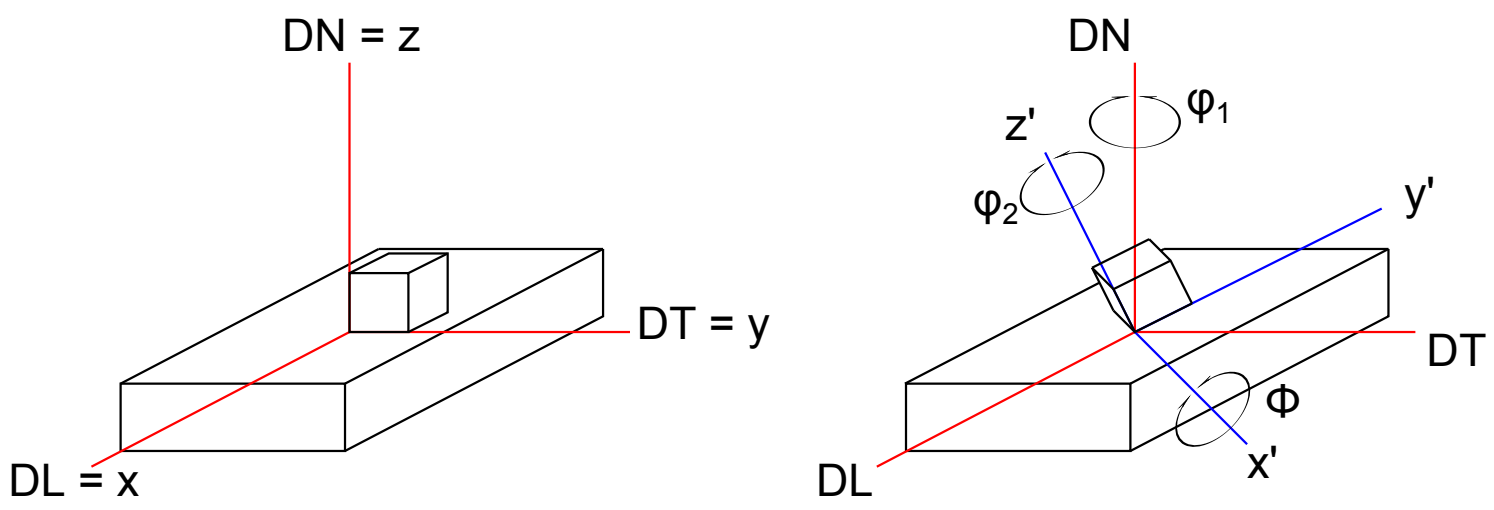

Figura 5.1: Ângulos de Euler utilizados para compor uma função de distribuição de orientação (FDO).

Para cada orientação definida pelos ângulos $\left(\varphi_{1}, \Phi, \varphi_{2}\right)$, a FDO correspondente nada mais é do que a fração volumétrica de grãos que apresentam esta mesma orientação. Normalmente é apresentada em gráficos como o da Fig. 5.2, retirada de Plaut et al. (2009). Neste tipo de imagem, cada quadro corresponde às curvas de nível da FDO em função dos ângulos $\varphi_{1}$ e $\Phi$ para um dado $\varphi_{2}$ fixo.

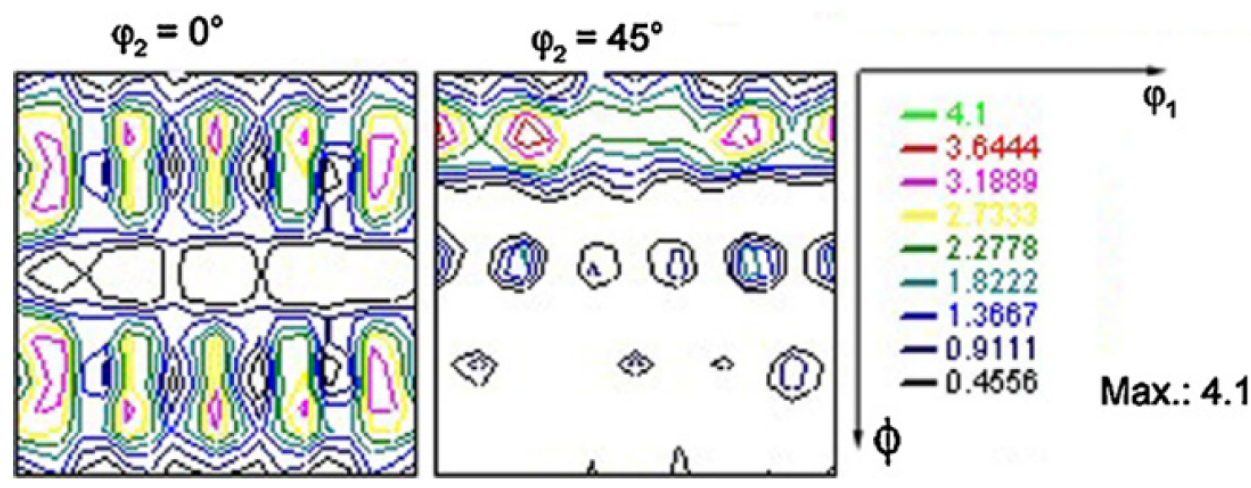

Figura 5.2: FDO para uma amostra de aço SAE 1050 laminado a quente (PLAUT et al., 2009).

Aços com boa conformabilidade normalmente apresentam um número considerável de grãos orientados de maneira que seu plano $\{111\}$ fique paralelo ao plano da chapa (PLAUT et al., 2009). Tal textura é conhecida como fibra $\gamma$. Em termos de ângulos de Euler, isso significa que boa parte dos cristais apresentam $\Phi=55^{\circ}$ e $\varphi_{2}=45^{\circ}$. A Fig. 5.3 mostra aonde, no gráfico de uma FDO, se localiza a orientação correspondente à fibra $\gamma$. Uma outra fibra importante é comum em aços carbono é a fibra $\alpha$, caracterizada pelo plano $\{110\}$ perpendicular à direção de laminação. Esta fibra é geralmente formada durante deformações a frio e tende a ser destruída durante a recristalização deste material. 


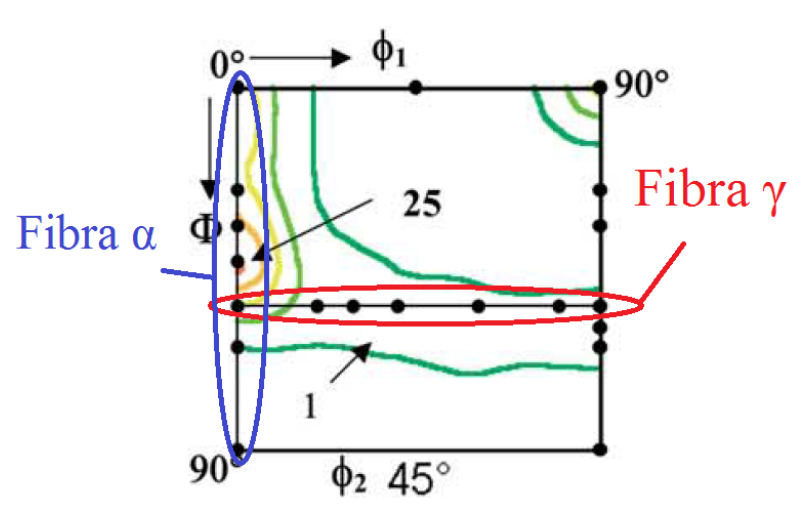

Figura 5.3: FDO para uma amostra de aço médio carbono laminado a quente mostrando o aspecto das fibras $\gamma$ e $\alpha$ no diagrama. Adaptado de Storojeva et al. (2004).

O trabalho de Plaut et al. (2009) faz uma análise da textura encontrada em chapas de aço SAE 1050 laminado a quente e como a imposição de deformações a frio, por meio de reduções na espessura, e o tratamento de recozimento alteram tal textura. Os autores chegam a conclusão que o recozimento não alterou em grande escala a textura do material original, que era fraca. $\mathrm{O}$ material não apresentava a fibra $\gamma$ tradicional, mas uma fibra próxima, chamada na literatura de $\gamma^{\prime}$. Com uma redução na espessura de 50\%, a fibra $\gamma^{\prime}$ se aproximou da fibra $\gamma$, garantindo uma maior estampabilidade ao material. Tal efeito também será avaliado no presente trabalho.

\subsection{Resultados}

A seguir, apresentamos as FDOs para as amostras analisadas. A Fig. 5.4 ilustra os resultados para o aço SAE 1050 esferoidizado e a Fig. 5.5 os resultados para o aço SAE 1050 na condição laminada a quente.

Podemos observar que nenhuma das amostras apresentou uma textura significativa. Também é interessante notar que a deformação não alterou a orientação dos cristais nas amostras laminadas a quente, as quais não apresentam grãos na com a textura da fibra $\gamma\left(0^{\circ}<\phi_{1}<\right.$ $90^{\circ}, \Phi=55^{\circ}, \phi_{2}=45^{\circ}$ ). Para as amostras esferoidizadas não deformadas, há uma fibra $\gamma$ fraca, que tende a diminuir com a deformação. Também vale notar que a fibra $\alpha\left(\phi_{1}=0^{\circ}, 0^{\circ}<\right.$ $\Phi<90^{\circ}, \phi_{2}=45^{\circ}$ ) se apresenta mais forte nas amostras esferoidizadas do que nas amostras laminadas a quente.

De modo a visualizar melhor a evolução das fibras $\alpha$ e $\gamma$, as Figs. 5.6 e 5.7 mostram cortes das FDOs nas fibras correspondentes para as amostras esferoidizadas e laminadas a quente, respectivamente. Também estamos mostrando a fibra $\gamma^{\prime}\left(0^{\circ}<\phi_{1}<90^{\circ}, \Phi=45^{\circ}, \phi_{2}=\right.$ 


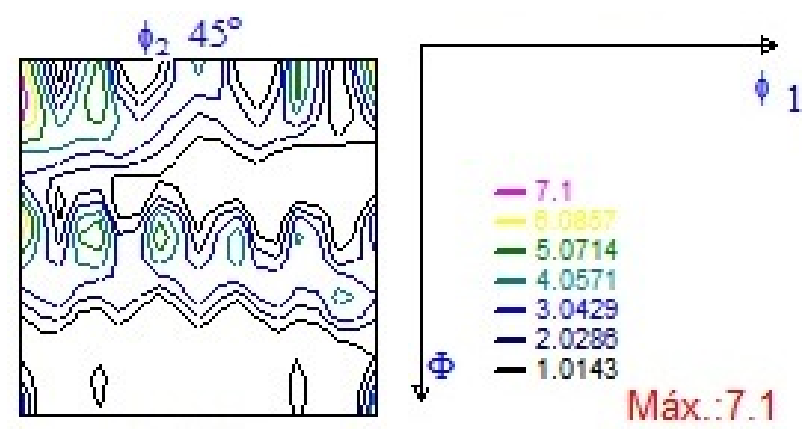

(a)

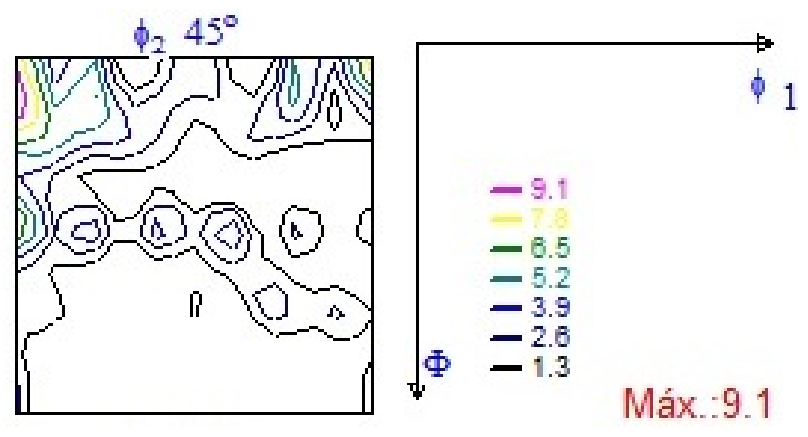

(b)

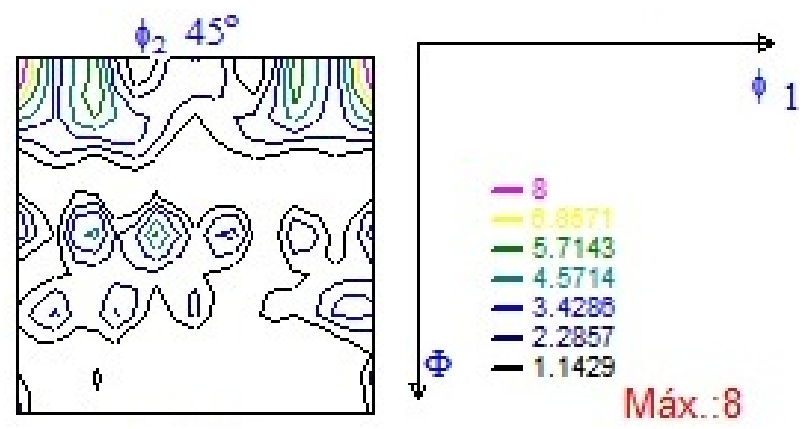

(c)

Figura 5.4: Figuras de distribuição de orientação para o aço SAE 1050 esferoidizado. (a) Amostra não deformada. (b) Amostra deformada a $0^{\circ}$. (c) Amostra deformada a $90^{\circ}$.

$45^{\circ}$ ), que se aproxima da fibra $\gamma$ e está presente em todas as amostras.

Alguns picos de intensidade são encontrados nas linhas das fibras $\gamma^{\prime}$ e $\alpha$ e são representados pelas letras a-f. Os índices de Miller correspondentes a estas orientações com maior densidade são mostradas nas Tabs. 5.1 e 5.2, para as fibras $\gamma^{\prime}$ e $\alpha$, respectivamente. A posição destes picos nas FDO's é mostrada na Fig. 5.8.

É fácil notar que, não importando a microestrutura do material, as orientações com maior intensidade tanto na fibra $\gamma^{\prime}$ quanto na fibra $\alpha$ são as mesmas. Com isso podemos concluir que o tratamento de recozimento para esferoidização da cementita não altera estas texturas de maneira significativa, o que concorda com a análise de Plaut et al. (2009). Além disso, os materiais esferoidizados apresentaram intensidade mais forte em todas as fibras analisadas, o 


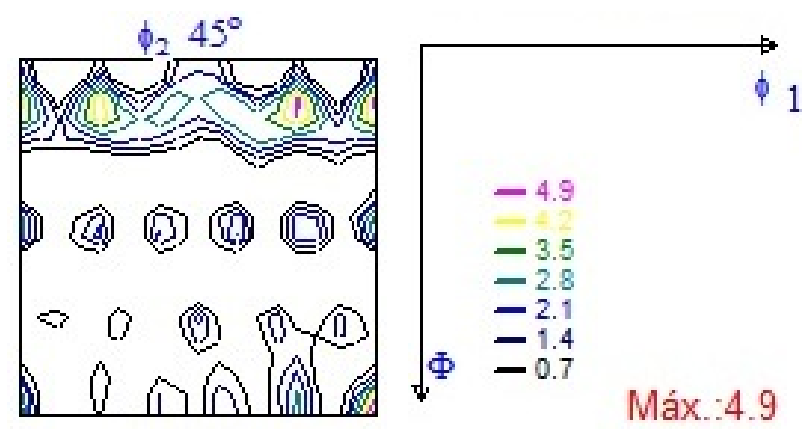

(a)

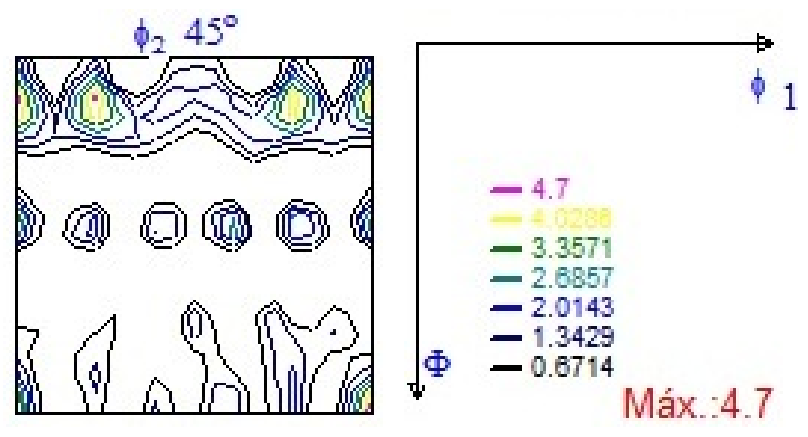

(b)

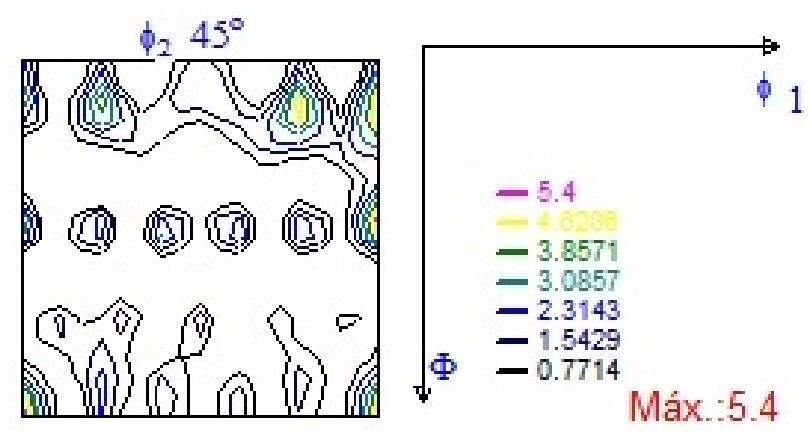

(c)

Figura 5.5: Figuras de distribuição de orientação para o aço SAE 1050 laminado a quente. (a) Amostra não deformada. (b) Amostra deformada a $0^{\circ}$. (c) Amostra deformada a $90^{\circ}$.

que indica que o recozimento intensifica texturas preexistentes.

A exceção se dá na fibra $\gamma$, que não está presente nos materiais laminados a quente, mas aparece, mesmo que de maneira fraca, para o material esferoidizado. A presença dessa fibra está associada a um comportamento menos anisotrópico do material. Ou seja, o material esferoidizado deformado em diferentes direções deve apresentar menor dispersão nas propriedades mecânicas do que o material laminado a quente, o que pode ser confirmado nos ensaios de tração por meio da análise da Tab. 4.4. Essa fibra, porém, é destruída com a deformação, como pode ser visto na Fig. 5.1. Assim, os materiais esferoidizados já deformados devem apresentar maior anisotropia.

Já em relação às fibras $\gamma^{\prime}$ e $\alpha$, percebemos, em ambos os casos, as deformações não 
interferiram nem na posição dos picos nem em seus valores de maneira significativa.

Tabela 5.1: Orientações importantes na fibra $\gamma^{\prime}$.

\begin{tabular}{ccc}
\hline & Ângulos de Euler $\left(\varphi_{1}, \Phi, \varphi_{2}\right)$ & Índices de Miller $\{h k l\}<u v w>$ \\
\hline $\mathrm{a}$ & $\left(0^{\circ}, 45^{\circ}, 45^{\circ}\right)$ & $\{557\}<\overline{1} 10>$ \\
$\mathrm{b}$ & $\left(20^{\circ}, 45^{\circ}, 45^{\circ}\right)$ & $\{557\}<\overline{1017 \overline{5}>}$ \\
$\mathrm{c}$ & $\left(35^{\circ}, 45^{\circ}, 45^{\circ}\right)$ & $\{557\}<\overline{15} 43 \overline{20}>$ \\
$\mathrm{d}$ & $\left(55^{\circ}, 45^{\circ}, 45^{\circ}\right)$ & $\{557\}<07 \overline{5}>$ \\
$\mathrm{e}$ & $\left(70^{\circ}, 45^{\circ}, 45^{\circ}\right)$ & $\{557\}<1435 \overline{35}>$ \\
$\mathrm{f}$ & $\left(90^{\circ}, 45^{\circ}, 45^{\circ}\right)$ & $\{557\}<\overline{24} \overline{2535}>$ \\
\hline
\end{tabular}

Tabela 5.2: Orientações importantes na fibra $\alpha$.

\begin{tabular}{ccc}
\hline & Ângulos de Euler $\left(\varphi_{1}, \Phi, \varphi_{2}\right)$ & Índices de Miller $\{h k l\}<u v w>$ \\
\hline $\mathrm{a}$ & $\left(0^{\circ}, 10^{\circ}, 45^{\circ}\right)$ & $\{119\}<1 \overline{1} 0>$ \\
$\mathrm{b}$ & $\left(0^{\circ}, 40^{\circ}, 45^{\circ}\right)$ & $\{223\}<1 \overline{1} 0>$ \\
$\mathrm{c}$ & $\left(0^{\circ}, 90^{\circ}, 45^{\circ}\right)$ & $\{110\}<1 \overline{1} 0>$ \\
\hline
\end{tabular}

\subsection{Conclusões parciais}

Como conclusão, podemos afirmar que a a orientação cristalográfica nas amostras analisadas não deve influenciar de maneira significativa as propriedades mecânicas, visto que nenhuma textura forte foi encontrada. Deste modo, nenhum efeito de encruamento, variação de rigidez ou influência na fratura pode ser atribuída à textura do material.

A presença da fibra $\gamma$ nas amostras esferoidizadas indicam que estas devem apresentar um comportamento mais isotrópico do que as amostras laminadas a quente, o que pôde ser observado no ensaio de tração apresentados no Cap. 4. Entretanto, na análise das outras fibras $\gamma^{\prime}$ e $\alpha$, a direção da deformação não mudou a orientação dos grãos.

O material esferoidizado se comporta de maneira igual tanto na direção de laminação quanto na direção transversal, ou seja, a variação entre as propriedades mecânicas das amostras deformadas a $0^{\circ} \mathrm{e} 90^{\circ}$ não se mostrou significativa. Já para o material laminado a quente, a ausência da fibra $\gamma$ indica que deve haver uma anisotropia maior, que se mostrou presente da deformação de fratura das amostras deformadas a $0^{\circ} \mathrm{e} 90^{\circ}$. As outras propriedades mecânicas não apresentaram grande variação.

Com isso, podemos justificar que não efetuaremos, no Cap. 6, qualquer simulação do 
ensaio de tração das amostras retiradas na direção transversal à laminação do material, e que todas as propriedades mecânicas, tanto do aço 1050 esferoidizado quanto do aço 1050 laminado a quente, serão tomadas como aquelas na direção de laminação. Tais simulações são assunto do próximo capítulo. 


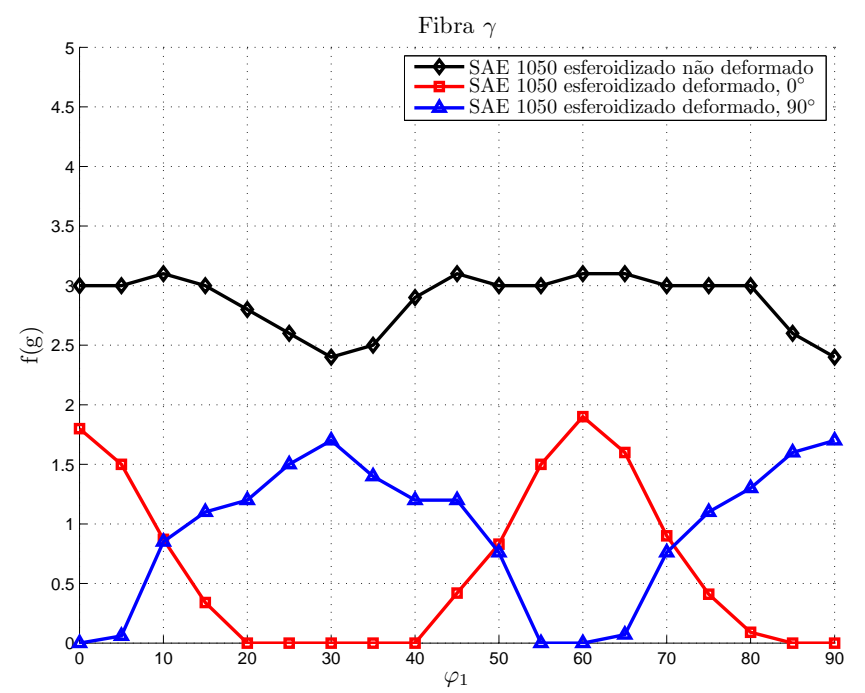

(a)

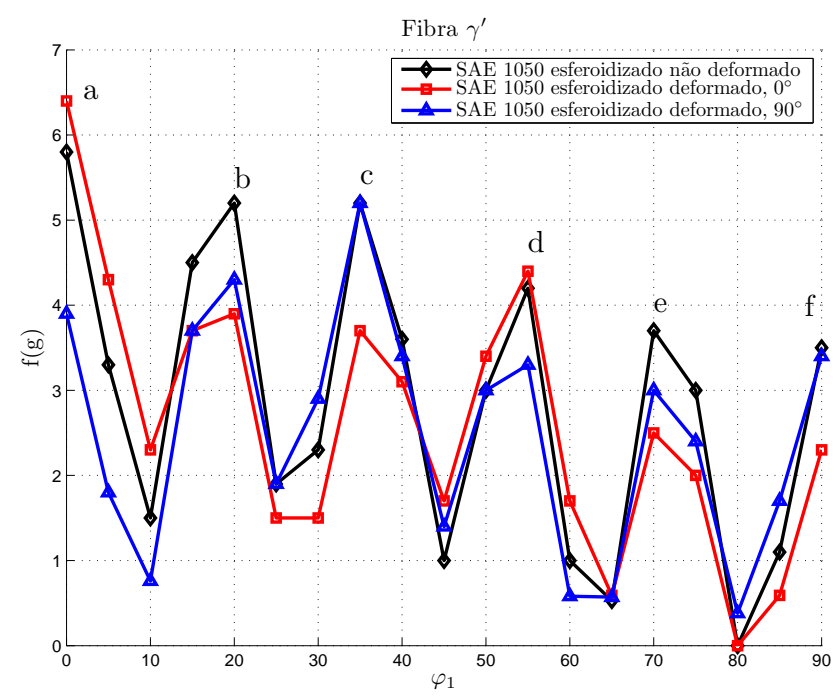

(b)

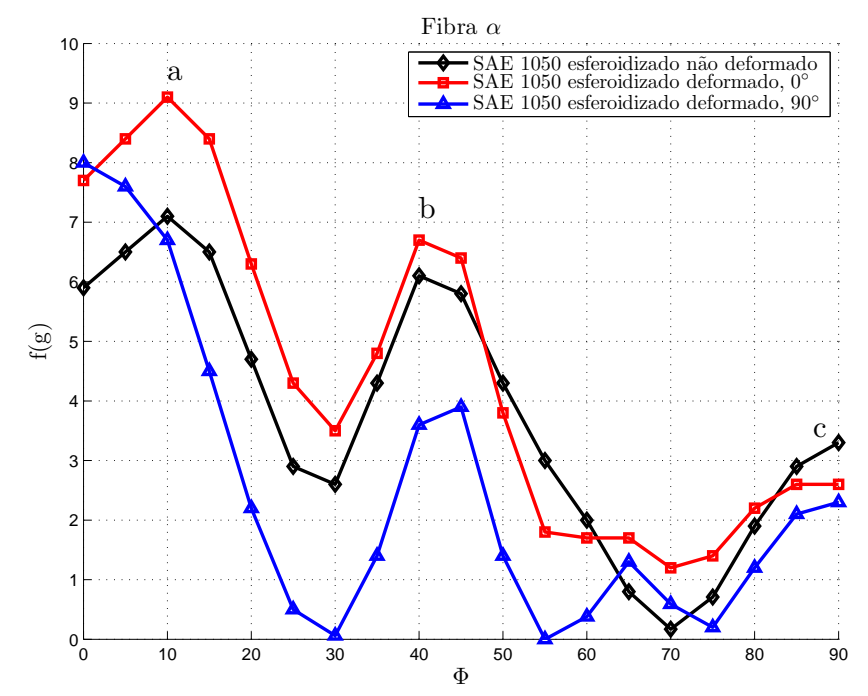

(c)

Figura 5.6: Evolução das fibras (a) $\gamma$, (b) $\gamma^{\prime}$ e (c) $\alpha$ para o aço SAE 1050 esferoidizado quando deformado nas direções de laminação $\left(0^{\circ}\right)$ e transversal $\left(90^{\circ}\right)$. 


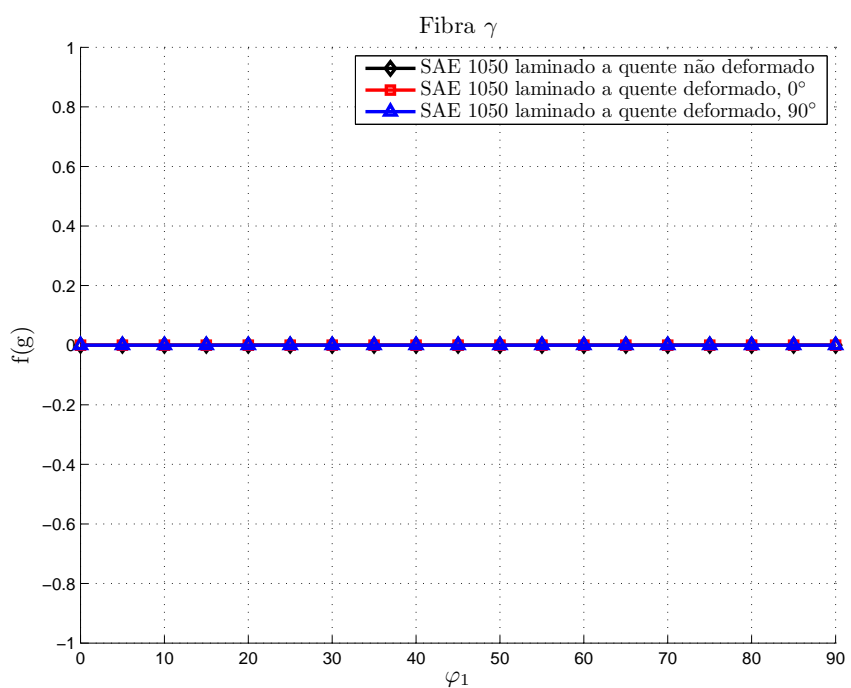

(a)

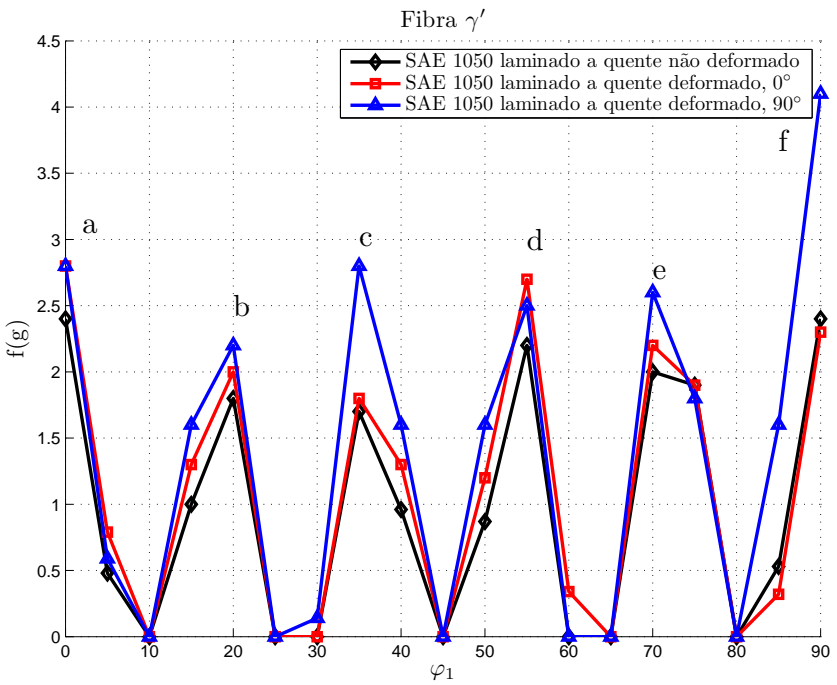

(b)

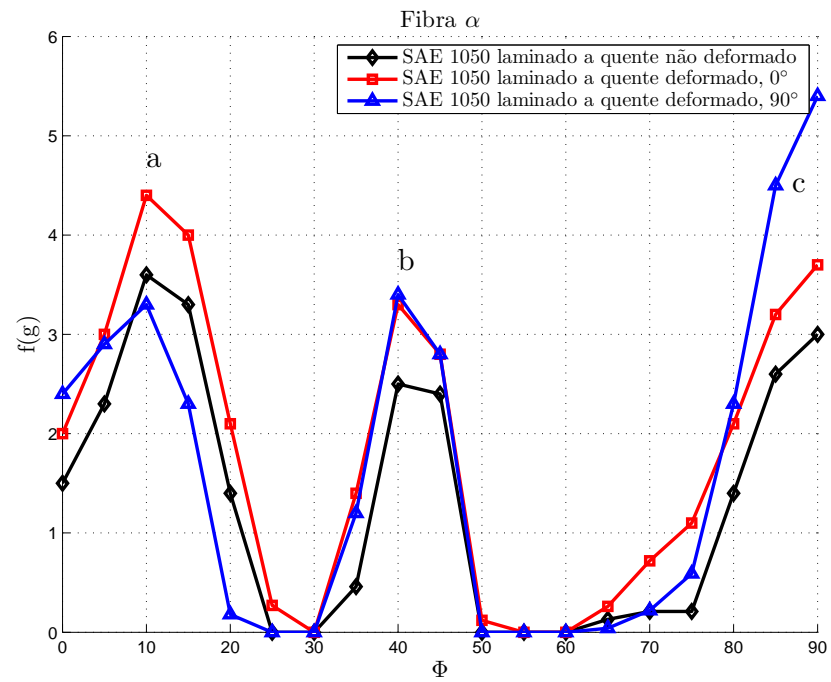

(c)

Figura 5.7: Evolução das fibras (a) $\gamma$, (b) $\gamma^{\prime}$ e (c) $\alpha$ para o aço SAE 1050 laminado a quente quando deformado nas direções de laminação $\left(0^{\circ}\right)$ e transversal $\left(90^{\circ}\right)$. 


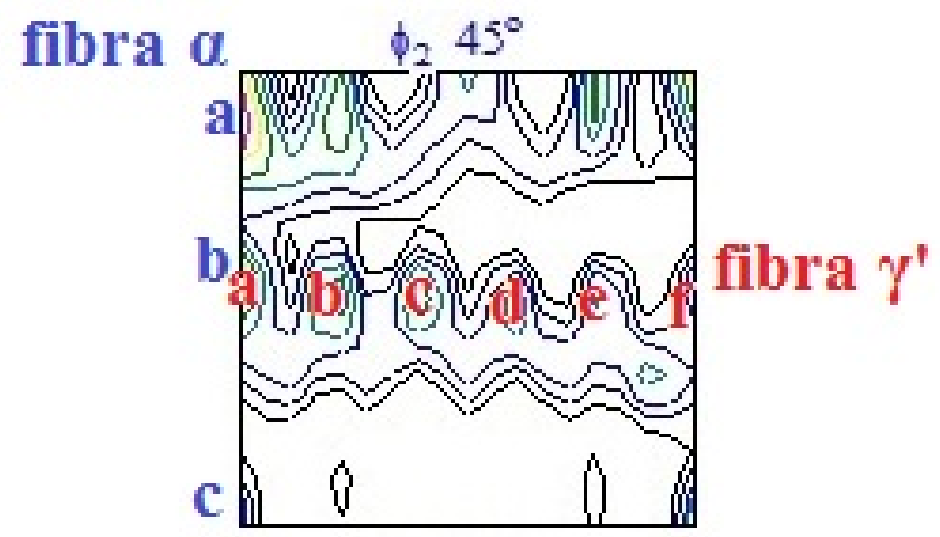

Figura 5.8: Posição dos picos de intensidade correspondentes às fibras $\gamma^{\prime}$, em vermelho, e $\alpha$, em azul. 


\section{SIMULAÇÕES NUMÉRICAS}

\subsection{Revisão da literatura}

Diversos trabalhos utilizaram algoritmos numéricos para tratar a evolução do dano em materiais metálicos para diversos tipos de carregamento. Aqui citaremos alguns destes trabalhos que utilizam o modelo de Lemaitre. Existem diversos outros modelos, como mostrado na Sec. 2.6.

Aboutalebi, Farzin e Poursina (2010) efetuaram ensaios de tração para um aço livre de interstícios - IF, do inglês intestitial free - utilizando a variação da dureza como medida indireta para a evolução do dano. Notar que este tipo de medição não seria adequada para o presente trabalho, visto que, diferentemente dos aços IF, os aços médio carbono estudados nesta dissertação apresentam quantidade considerável de fases duras (cementita), o que gera grande dispersão nos ensaios de dureza. Os autores conseguiram reproduzir a fratura de corpos de prova de ensaios de tração com um furo, como mostrado na Fig. 6.1.

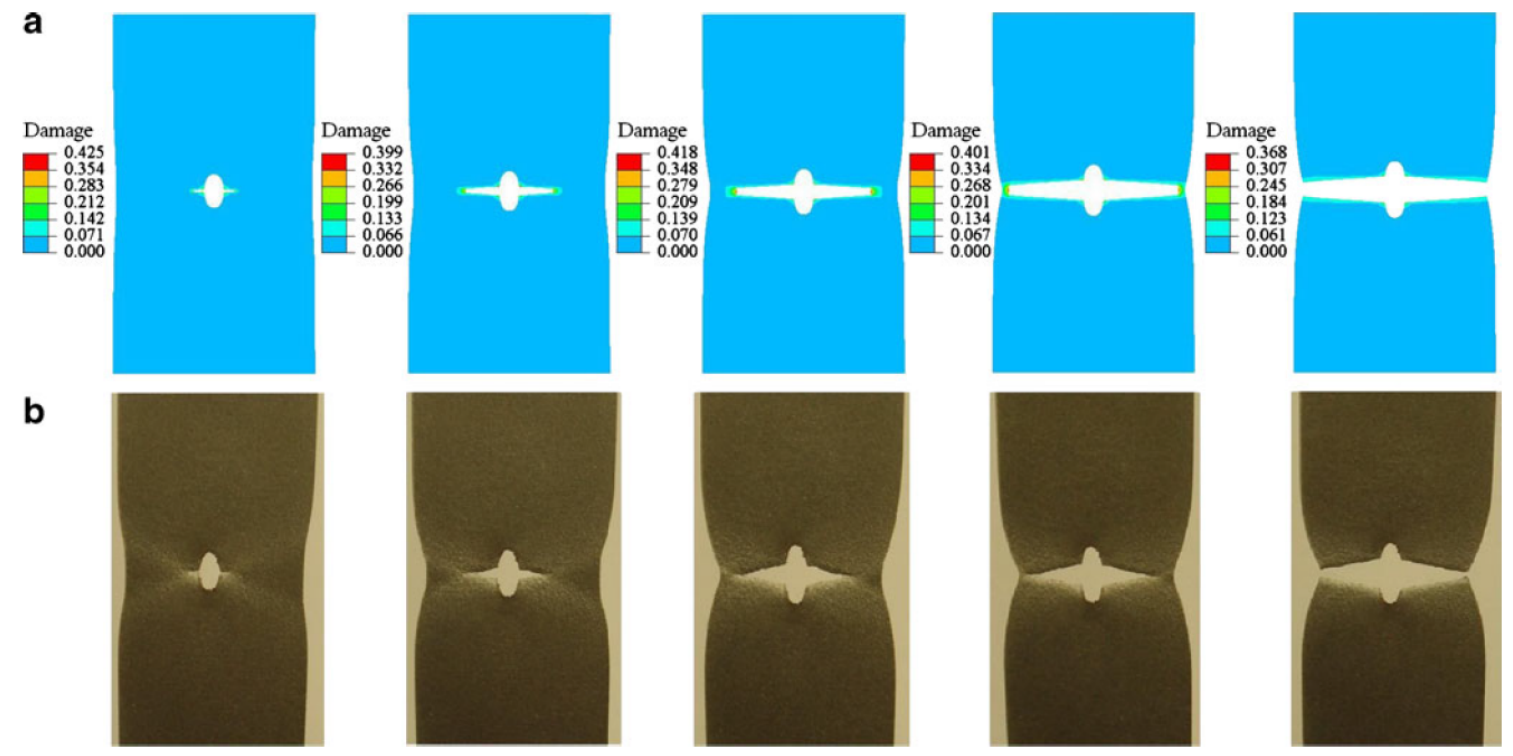

Figura 6.1: Evolução da fratura para um ensaio de tração de corpo de prova com furo. (a) Simulações. (b) Experimentos. (ABOUTALEBI; FARZIN; POURSINA, 2010).

O trabalho de Khelifa, Oudjene e Kennane (2007) efetua um estudo numérico de um 
ensaio de estampagem profunda para a liga de alumínio AA 5754. A Fig. 6.2 mostra uma comparação entre a fratura simulada numericamente e a observada no experimento. Neste trabalho foram considerados efeitos de encruamento cinemático, associados à taxa de deformação, os quais foram desconsiderados na presente dissertação. É interessante notar que é possível estabelecer critérios de deleção de elementos cuja variável de dano excede um valor crítico, simulando a propagação de uma fratura.

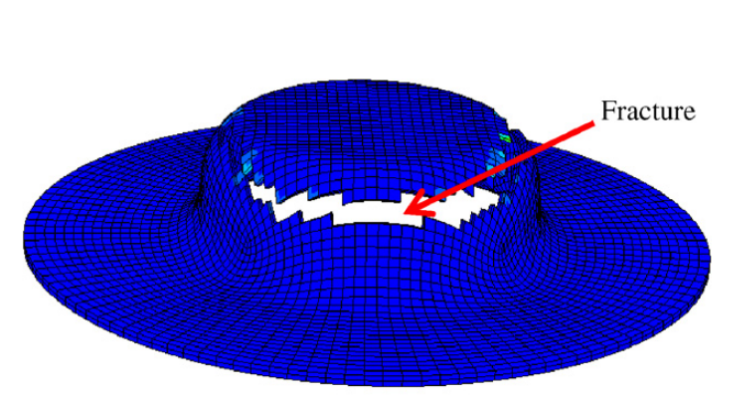

a)

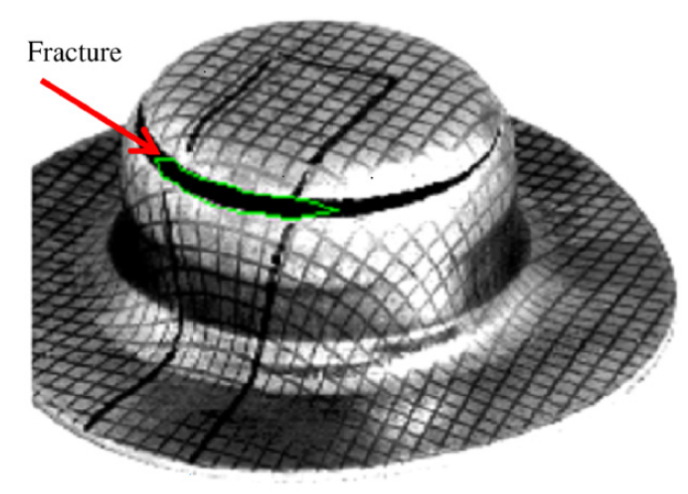

b)

Figura 6.2: Fratura num ensaio de estampagem profunda. (a) Simulação. (b) Experimento. (KHELIFA; OUDJENE; KENNANE, 2007).

Celentano e Chaboche (2007) trataram da caracterização de aços carbono (SAE 1020 e SAE 1045) por meio de ensaios de tração de barras cilíndricas e posterior uso de simulações numéricas para previsão da falha em ensaios de compressão de tubos na direção radial. Uma das maneiras de efetuar uma comparação é por meio do gráfico de força em função do deslocamento, mostrada na Fig. 6.3. Neste caso, utilizaremos as curvas tensão-deformação como critério de comparação.

Uma outra capabilidade importante dos métodos numéricos é possibilitar estudos paramétricos, como o efetuado por Behrens e Just (2002). Os autores estudaram uma operação de forjamento a frio de uma peça "duplo cálice" efetuada em cinco estágios e que apresentava uma falha de fabricação. Eles perceberam que tal defeito ocorria durante o quarto estágio do forjamento e propuseram novas geometrias de matrizes, reduzindo o valor do dano máximo, como mostrado na Fig. 6.4. Tal modificação foi posteriormente testada e o defeito de fabricação foi eliminado.

Vemos que a aplicação numérica do modelo de Lemaitre já apresenta resultados concretos na literatura. A seguir apresentaremos a metodologia empregada no presente trabalho para o estudo numérico dos ensaios de tração. 


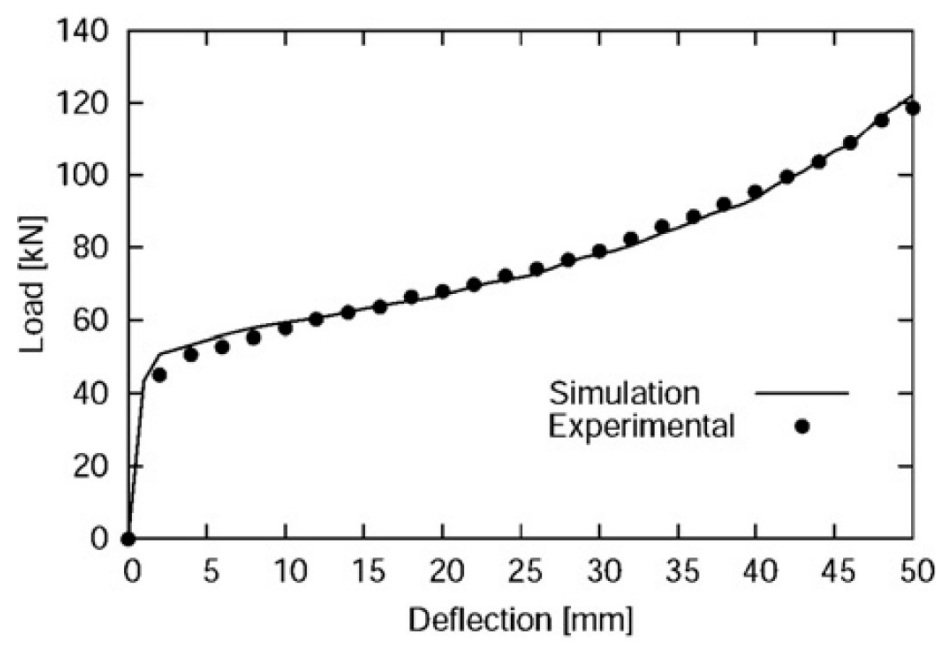

Figura 6.3: Evolução da força no punção em função do deslocamento do mesmo em ensaio de compressão axial de um tubo de aço SAE 1020. (CELENTANO; CHABOCHE, 2007).

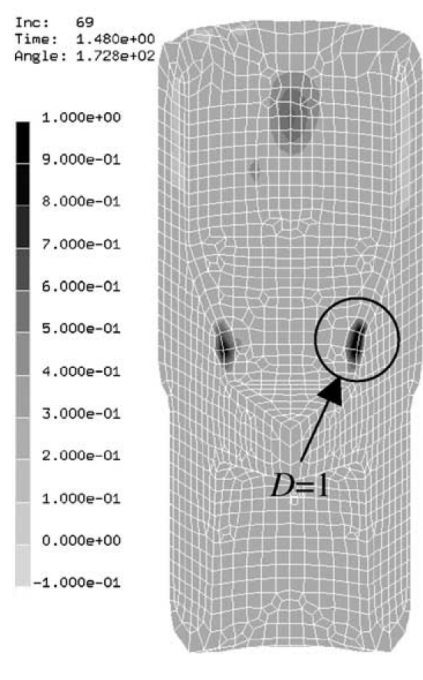

a)

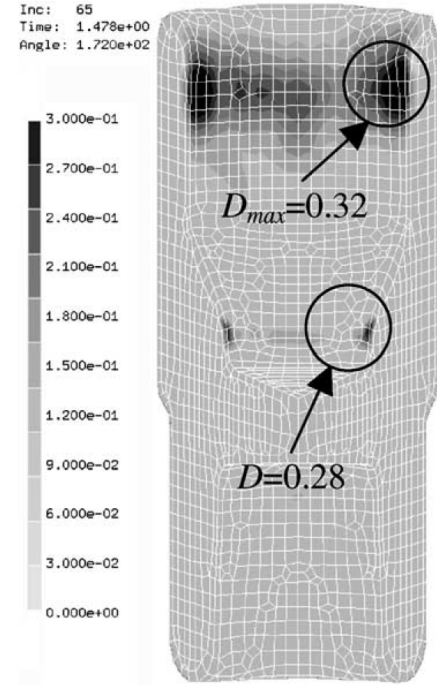

b)

Figura 6.4: Contornos da variável de dano no quarto estágio do forjamento do "duplo cálice". (a) Matrizes com geometrias originais. (b) Matrizes com geometrias modificadas (BEHRENS; JUST, 2002).

\subsection{Metodologia}

O modelo de evolução do dano em materiais dúcteis exige que as equações desta variável sejam acopladas às equações constitutivas do material, como visto no Capítulo 2. Devido à grande complexidade do modelo, a solução é a implementação de um algoritmo numérico para resolução do sistema de equações.

Alguns trabalhos tratam do desenvolvimento de algoritmos implícitos, como de Souza Neto (2002), Mashayekhi et al. (2007) e Teng (2008). Aqui utilizaremos um algoritmo explícito, 
desenvolvido por Lee e Pourboghrat (2005).

Retomando, as hipóteses assumidas para o equacionamento foram as seguintes:

- plasticidade isotrópica;

- efeitos cinemáticos descartados - não há influência da taxa de deformação;

- dano isotrópico;

- material se deforma de maneira quasi-estática;

- deformação totalmente isotérmica.

Assim, as seguintes equações são necessárias:

Lei de Hooke - elasticidade

$$
\boldsymbol{\sigma}=(1-D) \mathbf{A}: \boldsymbol{\varepsilon}
$$

Critério de von Mises para plasticidade

$$
\sigma_{e q}=(1-D) \sigma_{e s c}
$$

\section{Encruamento isotrópico}

$$
\sigma_{e s c}=\sigma_{e s c, 0}+K p^{n}
$$

Evolução do dano dúctil - Lemaitre

$$
\mathrm{d} D=\frac{\sigma_{e q}^{2} R_{v}}{2 E S(1-D)^{2}} \mathrm{~d} p
$$

\section{Dano crítico}

$$
D_{c}=\frac{D_{1 c}}{R_{v}}\left[\frac{\sigma_{u}}{\sigma_{e q}}(1-D)\right]^{2}
$$

As equações foram implementadas no solver comercial Abaqus/Explicit por meio da subrotina VUMAT (SIMULIA, 2010). Detalhes da implementação, baseada no algoritmo desenvolvido por Lee e Pourboghrat (2005) para métodos explícitos, são mostrados no Apêndice D e a rotina completa pode ser encontrada no Apêndice E. Um manual de instruções para montagem e execução das simulações na interface gráfica do Abaqus é mostrado no Apêndice F. 
A Fig. 6.5 esquematiza o funcionamento do algoritmo. No presente trabalho, o critério de plasticidade adotado foi o de von Mises, que considera um material isotrópico. Contudo, o modelo de Lemaitre pode ser acoplado a outros modelos de plasticidade como o de Hill, que considera anisotropia nos materiais, o que foi efetuado no trabalho de Teixeira et al. (2006). A maior diferença deste algoritmo para aqueles implementados nos softwares comerciais para cálculo de tensões e deformações por um método explícito é que, ao adicionar as equações de dano, o cálculo do incremento plástico equivalente $\Delta p$ deixa de ser uma equação de primeiro grau e se torna uma equação de segundo grau.

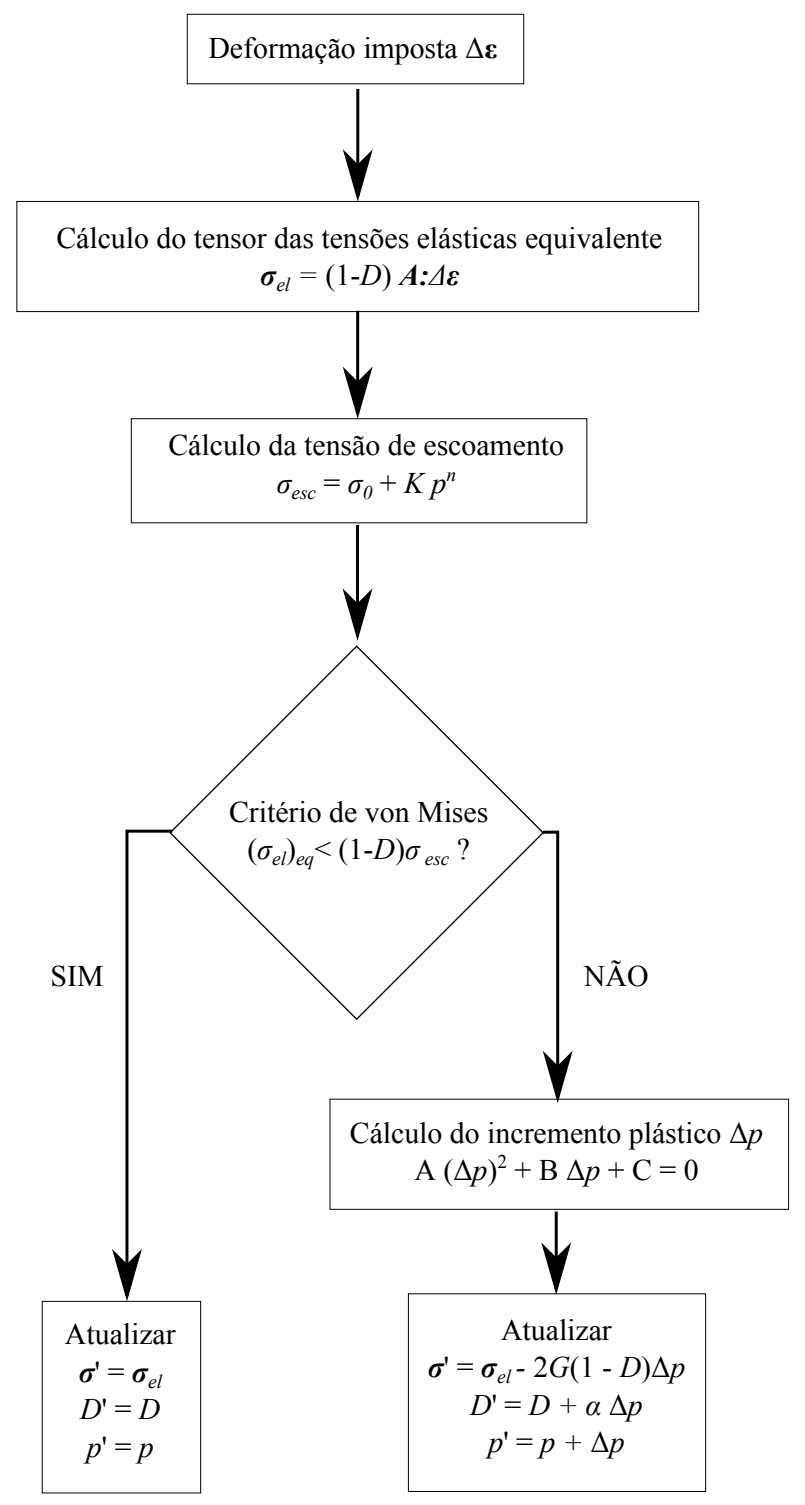

Figura 6.5: Fluxograma da subrotina VUMAT para cálculo do dano com solver explícito. Ver mais detalhes no Apêndice D.

As simulações foram efetuadas utilizando um modelo tridimensional do corpo de prova, com as dimensões mostradas na Fig. 6.6. 


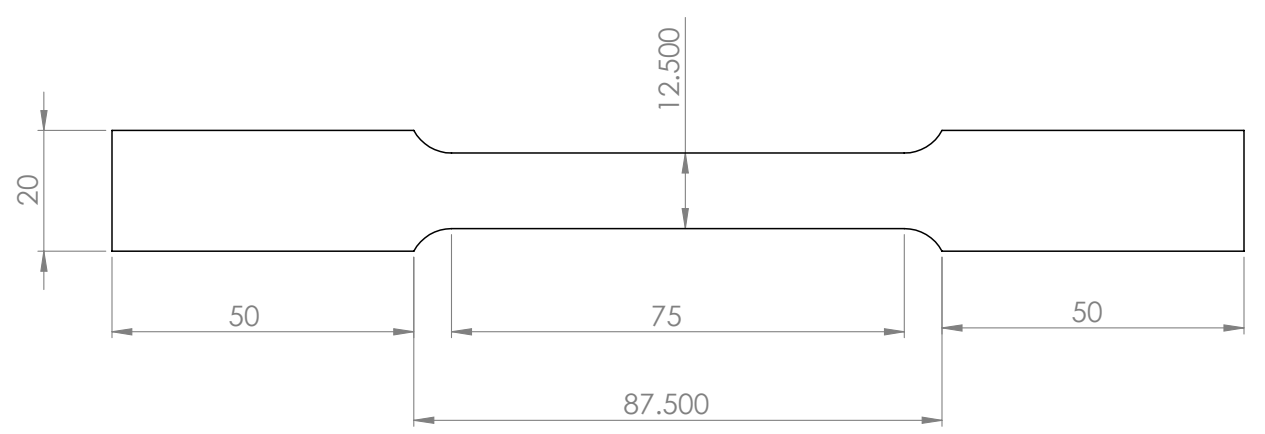

Figura 6.6: Dimensões do corpo de prova utilizado nas simulações numéricas. Espessura é de $1,0 \mathrm{~mm}$.

As seguintes condições de contorno foram impostas:

- restrição de movimento longitudinal, transversal e normal na região da garra esquerda;

- restrição de movimento transversal e normal na região da garra direita;

- deslocamento imposto na região da garra direita, constante em cada passo temporal.

Como critério de falha, em todo elemento cuja variável de dano relativo $D / D_{c}$ excedia o valor de 1, a rigidez do elemento era definida como nula, simulando a fratura do material.

\subsection{Resultados}

Simulações foram efetuadas para os corpos de prova de aço 1050 nas condições esferoidizado e laminado a quente na direção de laminação. Simulações dos corpos de prova na direção transversal de laminação não foram apresentados, visto que a variação nas propriedades mecânicas com relação aos corpos de prova na direção de laminação, não foi significativa o suficiente para podermos afirmar que não se tratam de erros experimentais somente.

A seguir apresentamos os resultados obtidos com as simulações numéricas. Em primeiro lugar, a curva tensão-deformação real é apresentada na Fig. 6.7. Os resultados experimentais são mostrados juntamente com duas curvas numéricas. A primeira, denominada "tensão aparente", é a tensão que conseguimos medir por meio de uma célula de carga e é, na verdade, calculada como:

$$
\sigma_{\text {aparente }}=\frac{\sigma_{\text {verdadeira }}}{1-D}
$$

aonde $\sigma_{\text {verdadeira }}$ é a tensão real verdadeira aplicada e $D$ é o dano acumulado em cada elemento de volume. Esta diferença se dá porque, com a evolução do dano, a área que efetivamente resiste 
ao carregamento mecânico é reduzida. Desta maneira, o material consegue suportar quantidades menores de tensão em cada elemento volumétrico. No entanto, este efeito microscópico não consegue ser capturado pelas medições experimentais, as quais se baseiam na área aparente do corpo de prova. Os resultados numéricos foram obtidos analisando o elemento que primeiro chega a fratura desde o início do ensaio de tração.

Podemos ver que o comportamento mecânico simulado apresenta boa concordância com o resultado medido experimentalmente, mesmo que as curvas numéricas não apresentem a característica de tenderem assintoticamente para um valor de tensão máximo como as curvas experimentais. Isto é devido à escolha da equação de Ludwik para caracterização do comportamento plástico do material. Caso outra equação que considere mais parâmetros fosse utilizada, como a de Voce (VOCE, 1948), as curvas numéricas poderiam se aproximar ainda mais das curvas experimentais.

Os resultados numéricos permitem uma melhor análise da evolução das deformações no material até o momento da fratura. A Fig. 6.8 mostra os contornos de deformação longitudinais no momento da fratura para a simulação do material laminado a quente, na qual fica claro a não homogeneidade de deformações ao longo do comprimento do corpo de prova. Este fenômeno de localização de deformações pôde ser estudado por meio de uma análise dos elementos na linha de simetria da peça, mostrados em vermelho na figura.

Deste modo, tomando as deformações longitudinais e transversais nos elementos ilustrados na Fig. 6.8, podemos montar o caminho de deformação tanto para a liga esferoidizada quanto para a liga laminada a quente. Tal resultado é mostrado na Fig. 6.9(a). Adicionalmente, mostramos a curva $\varepsilon_{1}=-2 \varepsilon_{2}$, que corresponde à condição teórica de tensão puramente uniaxial (BANABIC et al., 2000).

Na Fig. 6.9(b) mostramos, no instante da fratura, o valor da deformação longitudinal local ao longo da linha de simetria do corpo de prova e comparação com os resultados experimentais obtidos. A posição zero corresponde à extremidade próxima à garra e vai crescendo conforme vamos nos aproximando da região da fratura. Notamos que o material esferoidizado apresenta ao longo de todo o comprimento do CP um valor de deformação maior do que o material laminado a quente, o que é consistente com o fato de o último falhar com um alongamento menor.

Também é constatado que até um comprimento de cerca de $5 \mathrm{~mm}$ distante da garra ocorre um crescimento rápido das deformações, seguido por um crescimento em taxa constante até próximo da fratura, aonde a localização das deformações fica evidenciada por um crescimento elevado. Em comparação com as deformações medidas pela marcação de círculos nos 


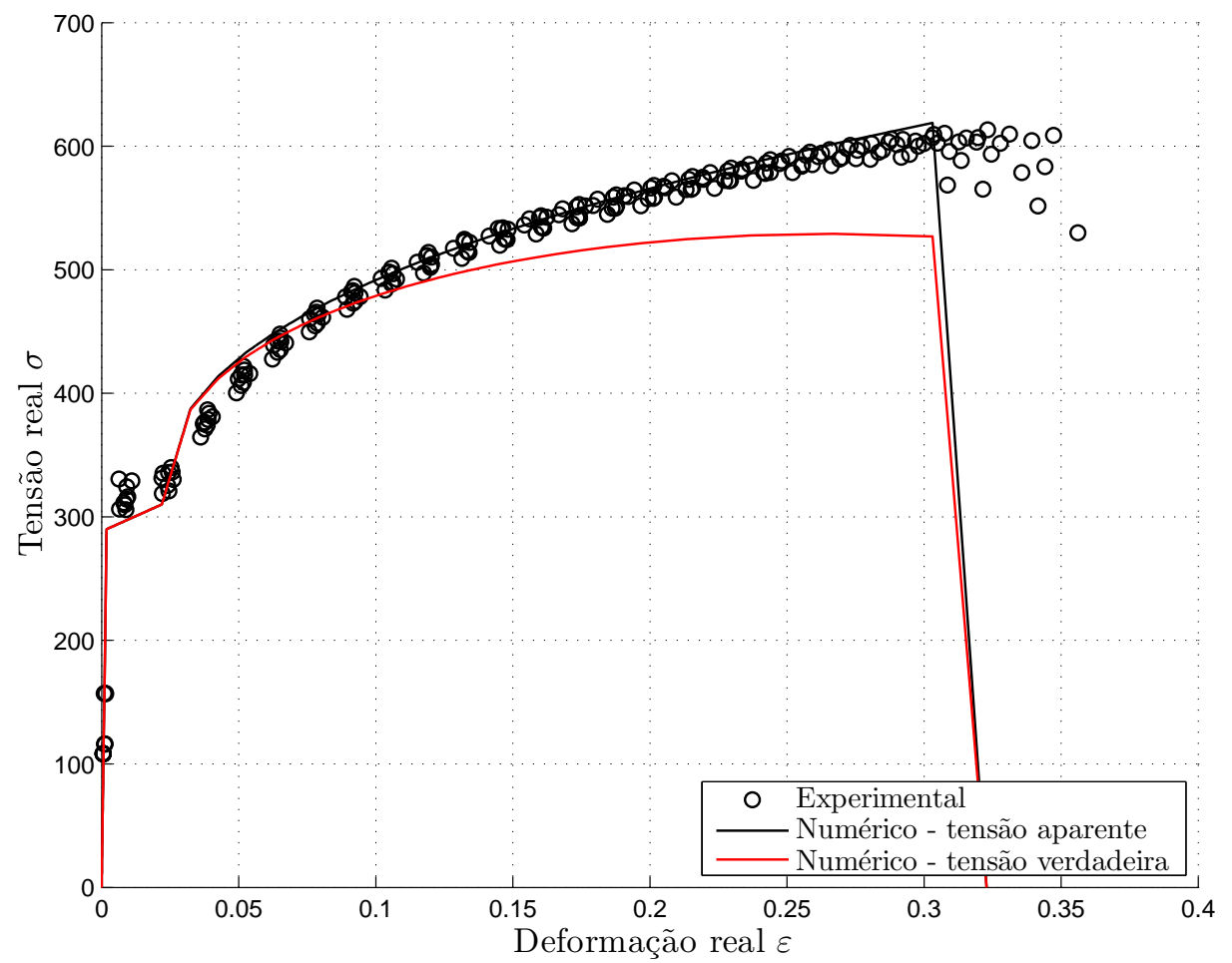

(a)

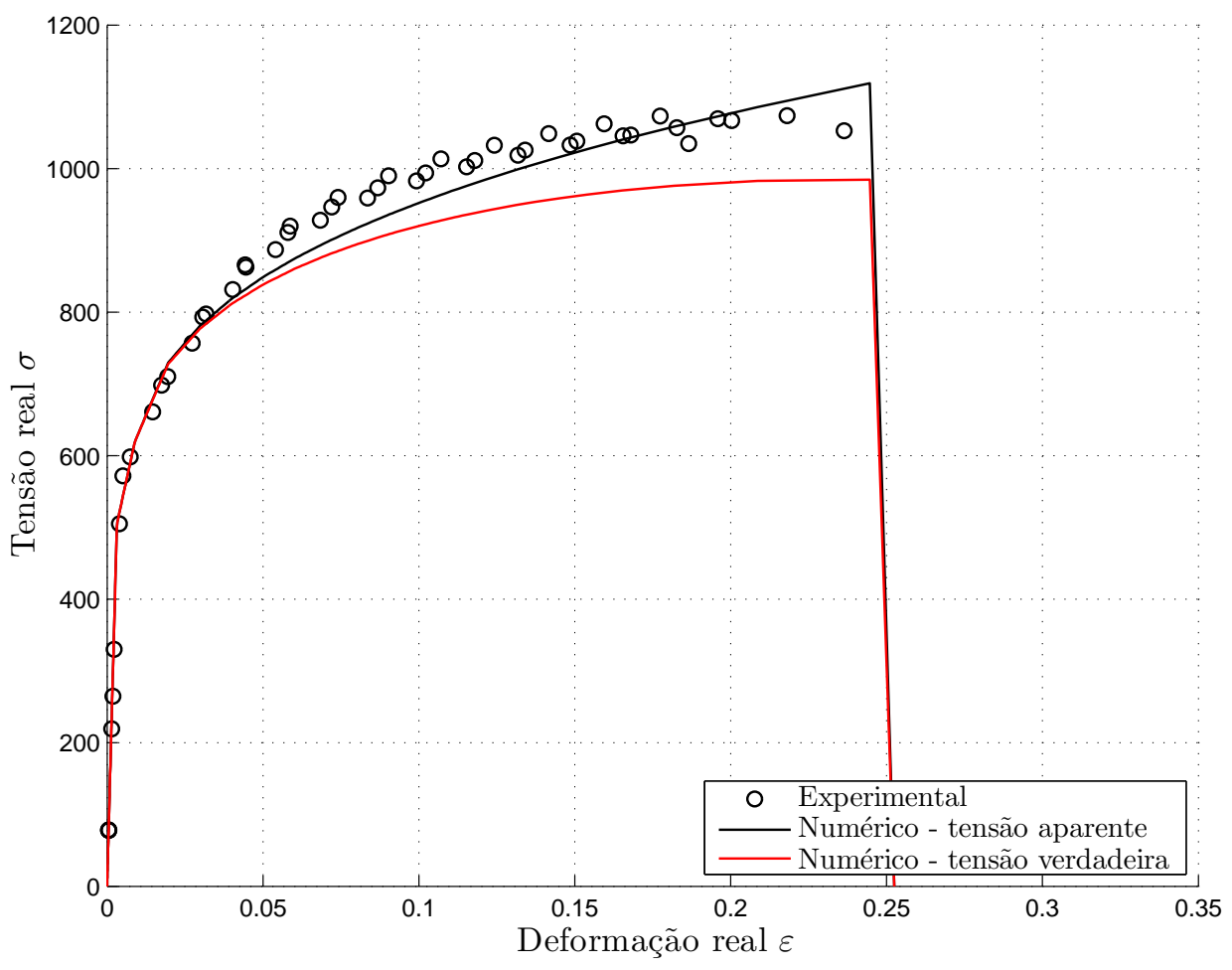

(b)

Figura 6.7: Curva tensão-deformação real para o aço SAE 1050 na direção de laminação. (a) Liga esferoidizada. (b) Liga laminada a quente. 


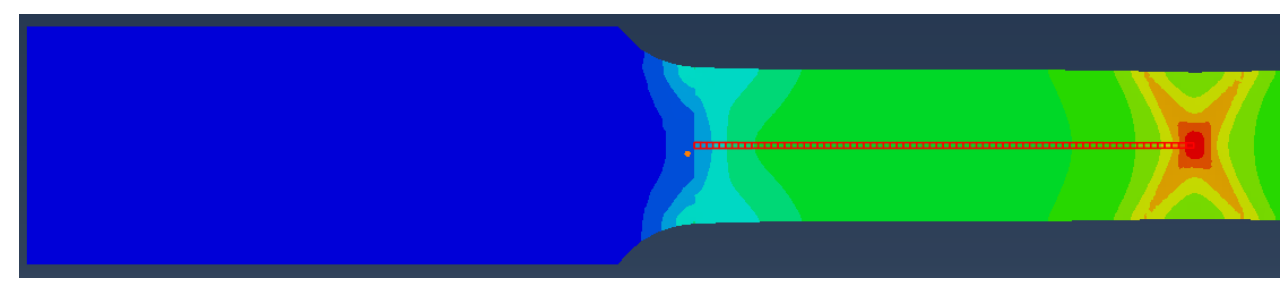

Figura 6.8: Contornos de deformação longitudinal para a simulação corpo de prova laminado a quente no momento da fratura.

corpos de prova experimentais, notamos que, apesar da dispersão decorrente da falta de acurácia das medições experimentais, os valores de deformação longitudinais estão na mesma ordem de grandeza, tanto na região de crescimento homogêneo das deformações, quanto na região de localização.

Os corpos de prova esferoidizados tem um crescimento de deformações menos acentuado na região da localização, indicando que o tratamento térmico de coalescimento da cementita ajuda a diminuir este efeito. Como explicado por Thompson (1987), a localização das deformações está diretamente relacionada com o estágio de coalescimento dos microvazios no processo da fratura dúctil. Portanto, atrasar a localização acaba atrasando o final do processo de fratura dúctil como um todo, aumentando as deformações máximas que podem ser impostas ao material e, portanto, sua ductilidade. Isto também é constatado experimentalmente, visto que os corpos de prova esferoidizados se romperam com uma deformação maior, como pôde ser visto nas curvas tensão-deformação do Cap. 4.

As Figs. 6.10 e 6.11 mostram os contornos de deformação longitudinal, dano acumulado, tensão verdadeira e tensão aparente.

Também a evolução do dano foi comparada com os resultados experimentais e mostrados na Fig. 6.12. Podemos perceber que a evolução do dano utilizando o modelo de Lemaitre nas simulações numéricas segue a mesma tendência dos resultados experimentais e prevê de maneira razoável o momento da fratura do corpo de prova. O resultado numérico foi tomado analisando a evolução do dano no primeiro elemento que atinge o dano crítico.

A evolução do dano não é linear como seria o esperado pelo modelo de Lemaitre. Isto pode ser explicado pelo fator de triaxialidade $R_{v}$, definido como:

$$
R_{v}=\frac{2}{3}(1+\nu)+3(1-2 \nu)\left(\frac{\sigma_{H}}{\sigma_{e q}}\right)^{2}
$$

No modelo de Lemaitre, assumimos que durante o ensaio de tração o material está sujeito a um estado de tensões perfeitamente uniaxial, que corresponde a $R_{v}=1$. No entanto, 


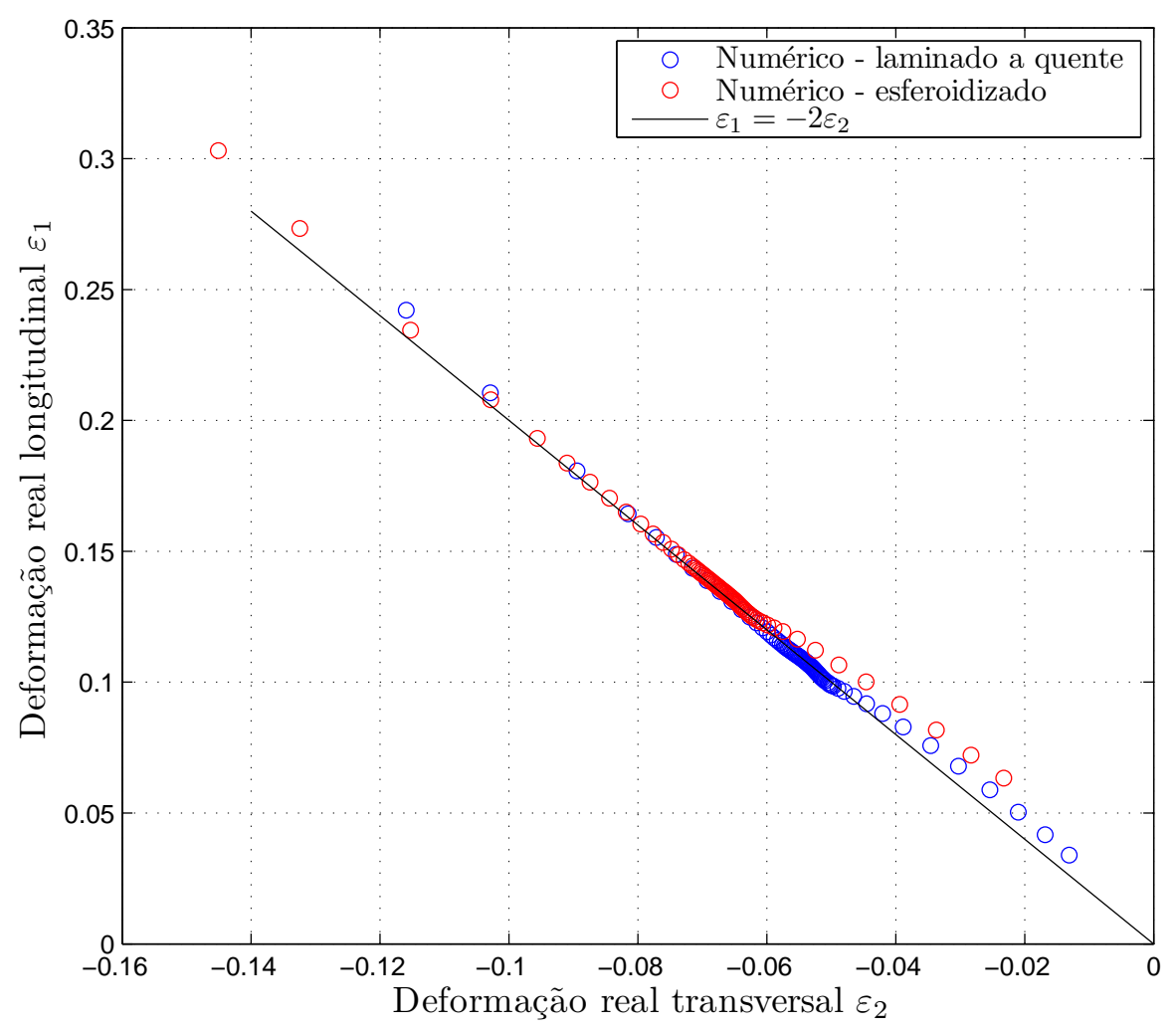

(a)

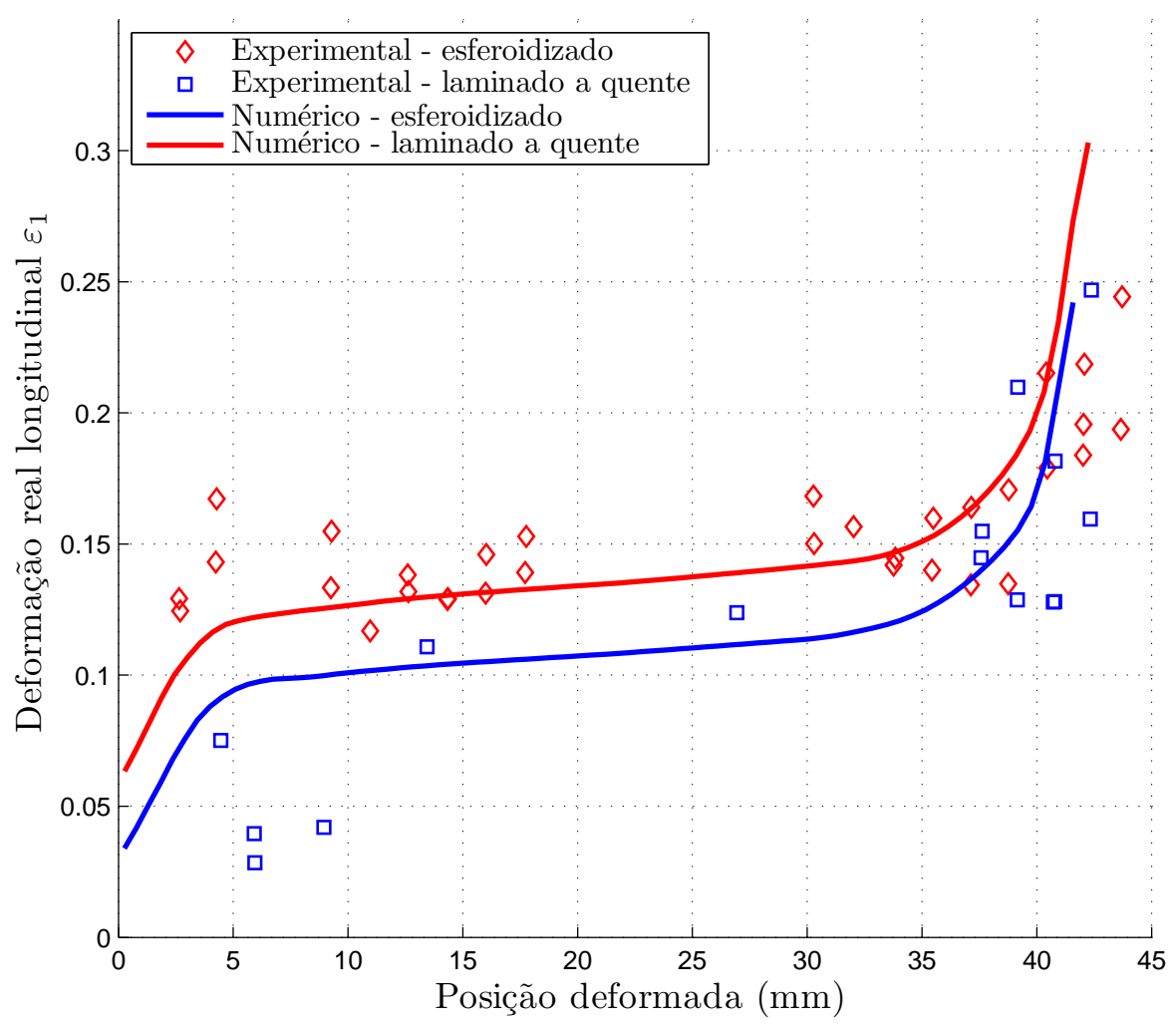

(b)

Figura 6.9: Deformações ao longo da linha de simetria do corpo de prova no momento da fratura. (a) Caminho de deformações longitudinais e transversais. (b) Distribuição das deformações longitudinais em função da posição e comparação com resultados experimentais. 


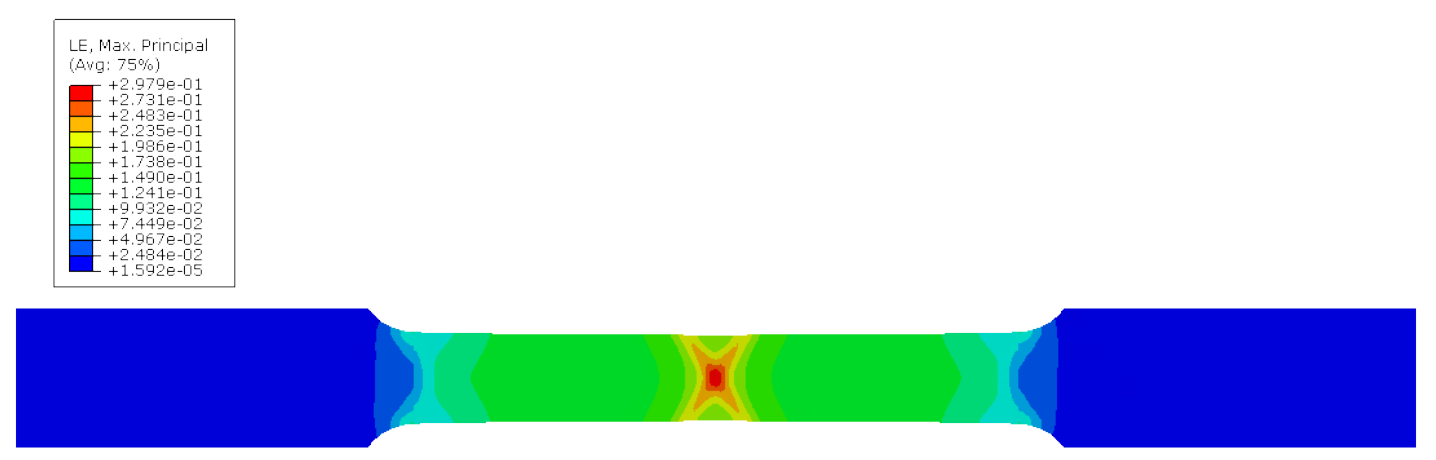

(a)

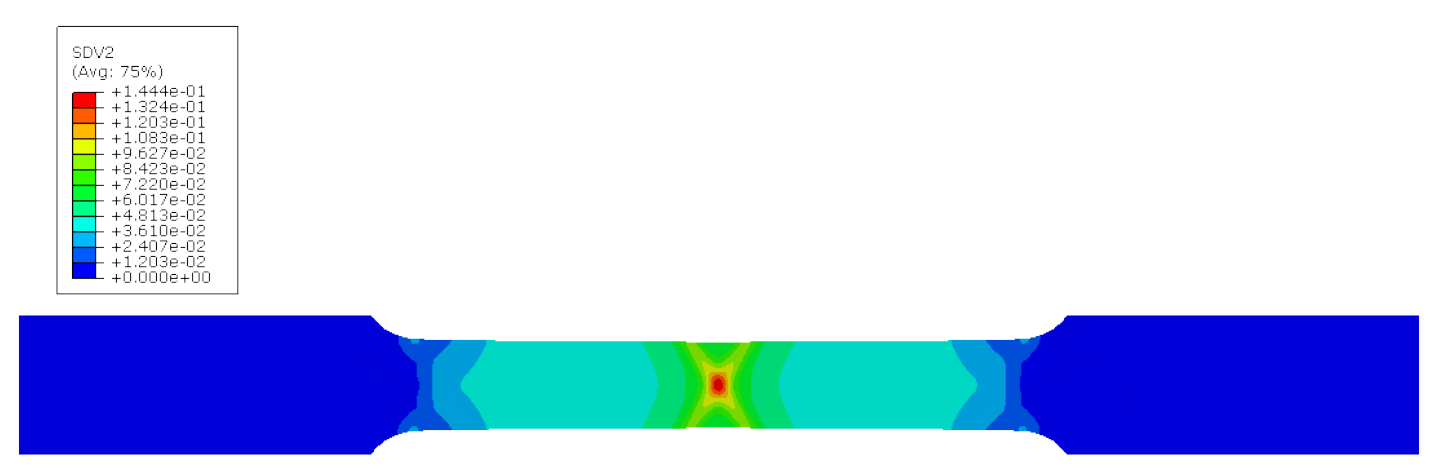

(b)

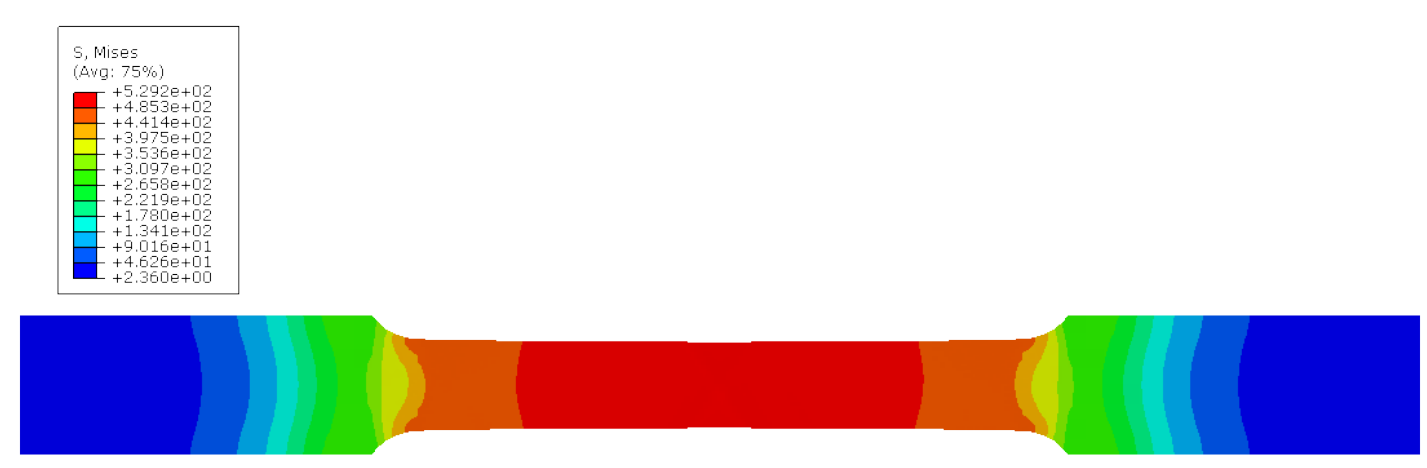

(c)

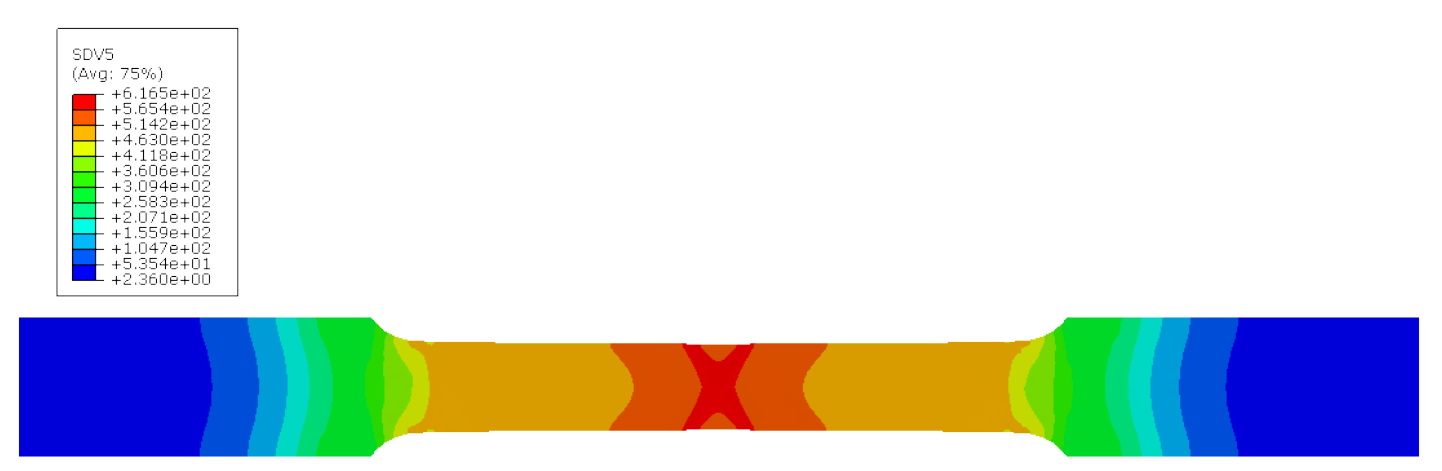

(d)

Figura 6.10: Contornos real para o aço SAE 1050 esferoidizado. (a) Deformação longitudinal. (b) Dano. (c) Tensão verdadeira. (d) Tensão aparente. 


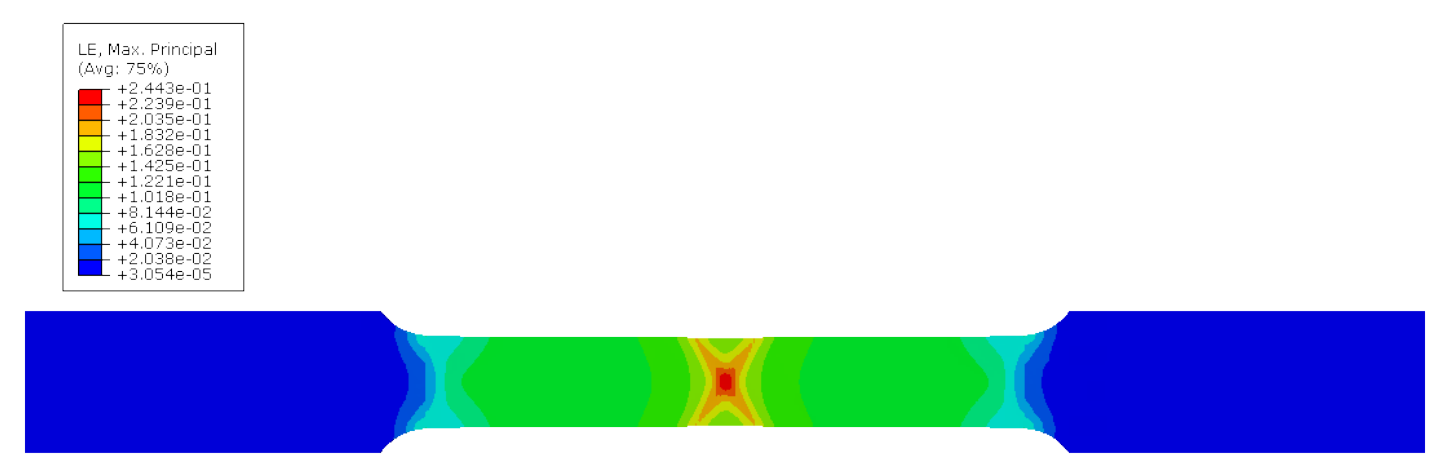

(a)

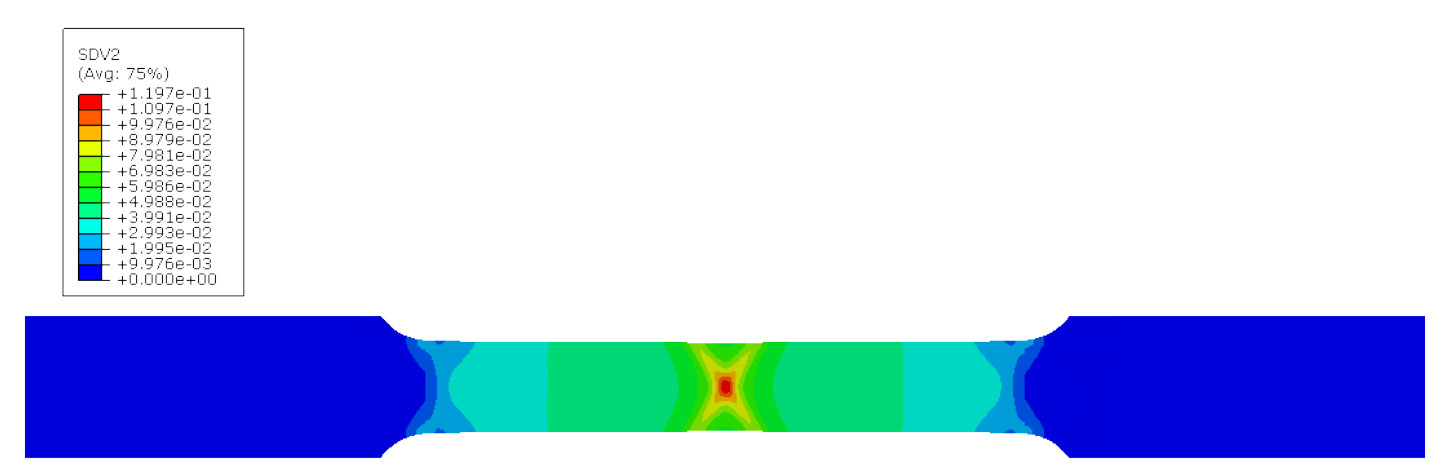

(b)

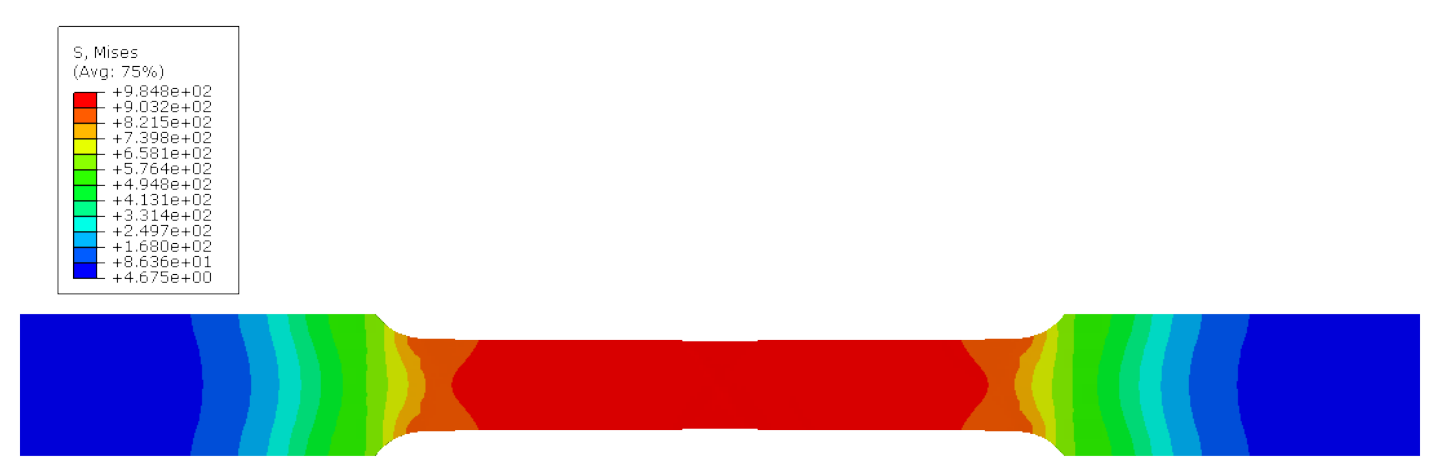

(c)

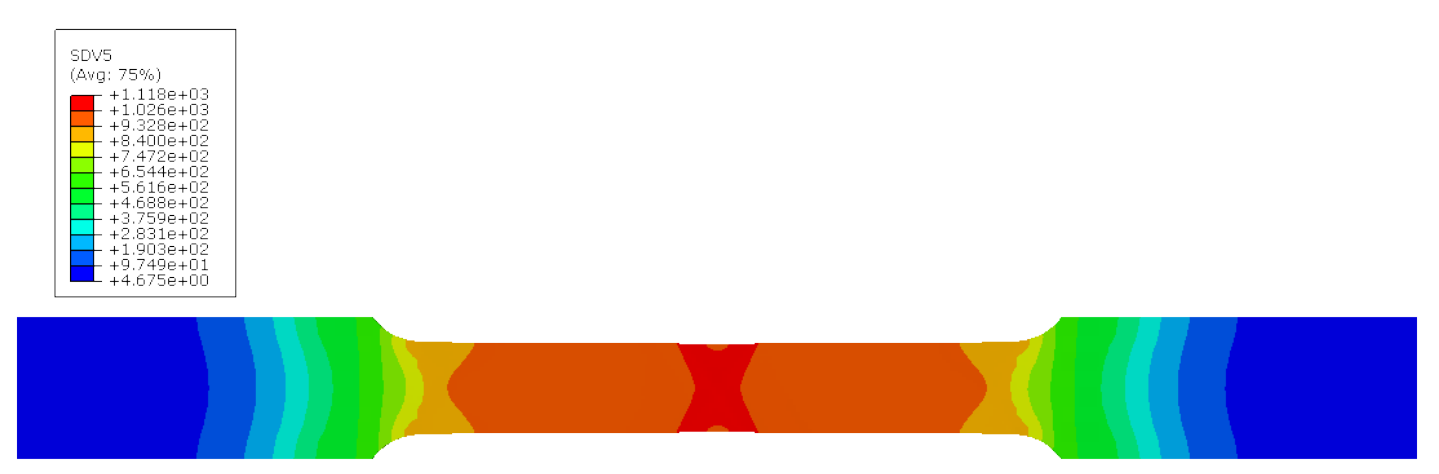

(d)

Figura 6.11: Contornos real para o aço SAE 1050 laminado a quente. (a) Deformação longitudinal. (b) Dano. (c) Tensão verdadeira. (d) Tensão aparente. 
analisando a evolução deste fator, mostrada na Fig. 6.13, notamos que a partir de um certo ponto o estado de tensões deixa de ser perfeitamente uniaxial, fato causado pela localização de deformações e estricção da seção transversal do material.

Contudo, a variação de $R_{v}$ não chega a $8 \%$ o que, embora faça a evolução do dano não ser completamente linear, não chega a invalidar a hipótese de ensaio perfeitamente uniaxial, permitindo a utilização do modelo linear sem grandes prejuízos.

Na Fig. 6.12(a) vemos que na simulação houve a fratura com uma deformação menor do que o medido experimentalmente. Na verdade isto é devido a uma baixa quantidade de steps salvos. Quando o material vai se aproximando da fratura, tanto as deformações quanto o dano começam a crescer muito rapidamente com o tempo, e a quantidade de steps salvos não foi suficiente para capturar o instante exato em que o dano atinge o valor crítico. Isto fica claro quando analisamos, nas Figs. 6.10(b) e 6.11(b), as quais mostrar o último passo antes da fratura, que os valores de dano estão abaixo do dano crítico medido experimentalmente. Aumentar a frequência de salvamento dos passos intermediários da simulação nos trará um resultado melhor, com o custo de aumentar o tempo de simulação.

As figuras 6.14, 6.15, 6.16 e 6.17 mostram, em diferentes estágios da simulação numérica, os contornos de dano e deformação longitudinal para os dois materiais simulados. Nas figuras observa-se que a localização das deformações e do dano só começam a acontecer com cerca de $99 \%$ da simulação concluída. Isso é compatível com o observado experimentalmente, quando só é possível visualizar algum tipo de estricção momentos antes do material se romper.

Nas figuras com os contornos de dano, também adicionamos fotos dos corpos de prova rompidos nos ensaios de tração efetuados. Os corpos de prova não se romperam perfeitamente no centro na espécime, como as simulações numéricas indicam, o que pode ser explicado por imprecisões dimensionais decorrentes do lixamento das amostras e imperfeições na montagem do ensaio. Desalinhamentos no posicionamento da amostra na máquina ou variação da área da seção transversal fazem com que a localização das deformações deixe de ocorrer no centro das amostras. Contudo, podemos perceber, que para o caso esferoidizado, o ângulo de ocorrência da fratura foi bem estimado pela simulação numérica, em torno de $25^{\circ}$. Contudo, para o material laminado a quente, o ângulo de fratura não foi bem capturado, visto que a instabilidade que leva à estricção ocorre na direção espessura, não no plano da chapa, como a simulação indica. Isto, no entanto, não impediu que os resultados numéricos capturassem de maneira satisfatória outros parâmetros importantes, como estado de tensões, deformação máxima e evolução da variável de dano até a fratura. 


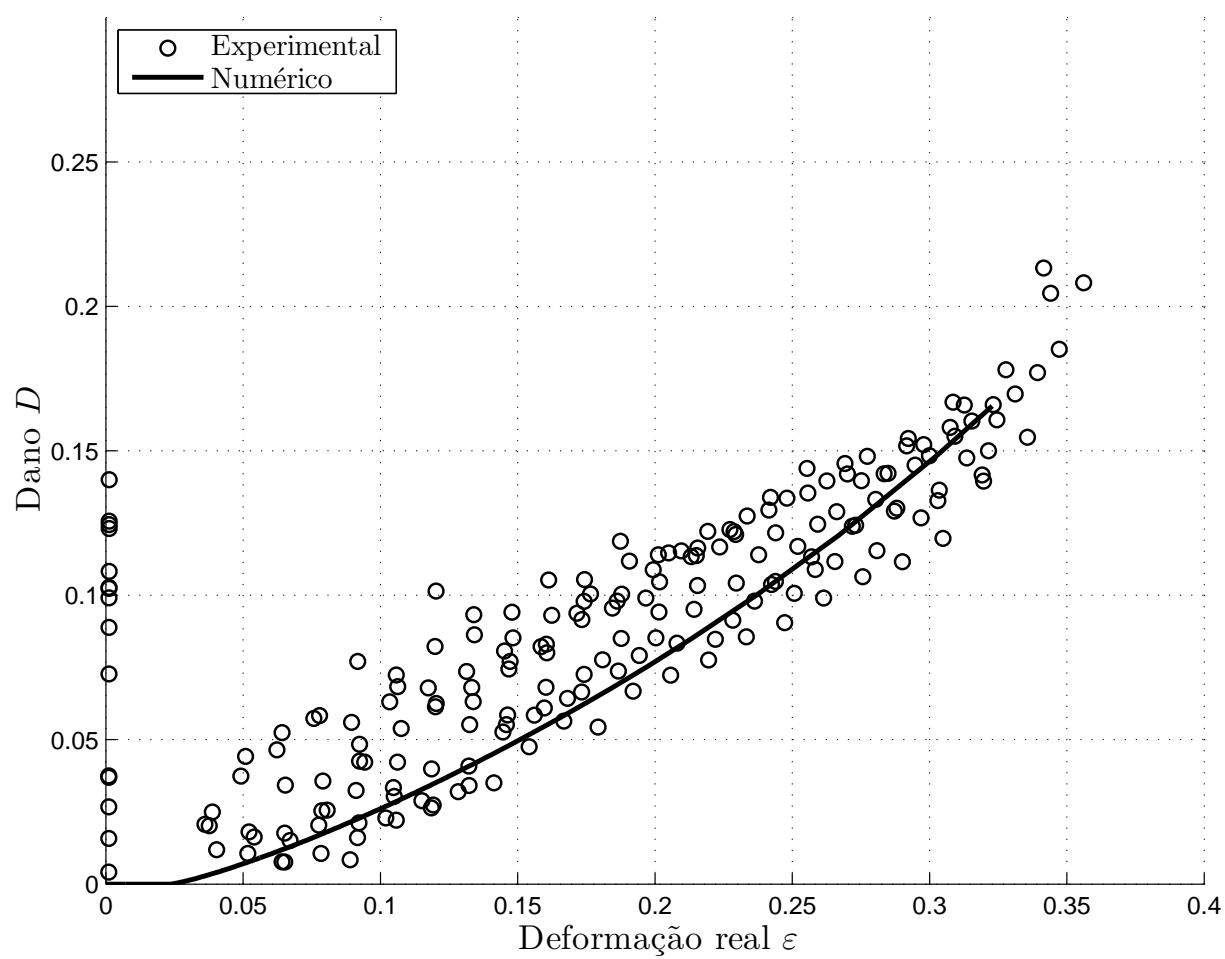

(a)

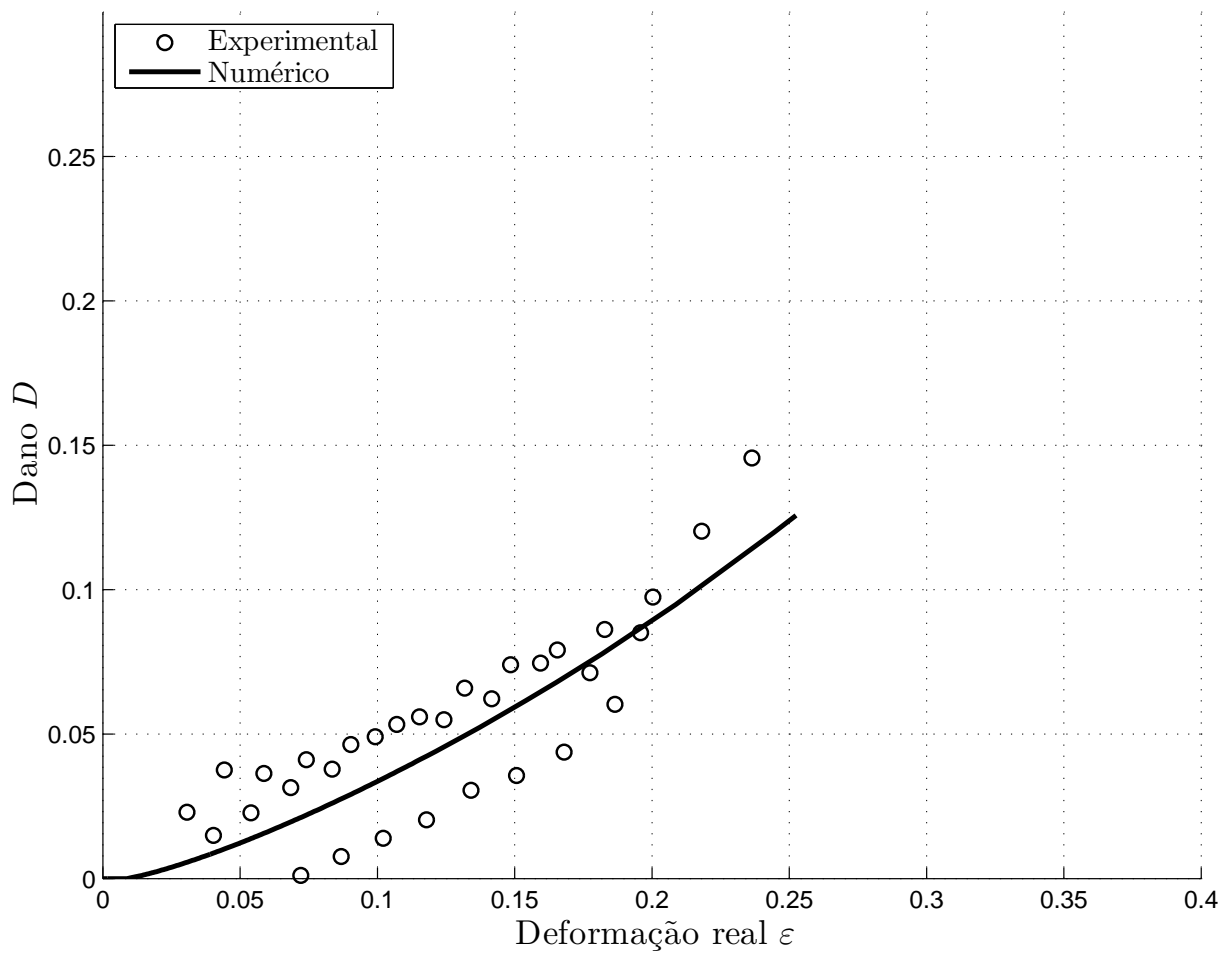

(b)

Figura 6.12: Curva de evolução do dano para o aço SAE 1050 na direção de laminação. (a) Liga esferoidizada. (b) Liga laminada a quente. 


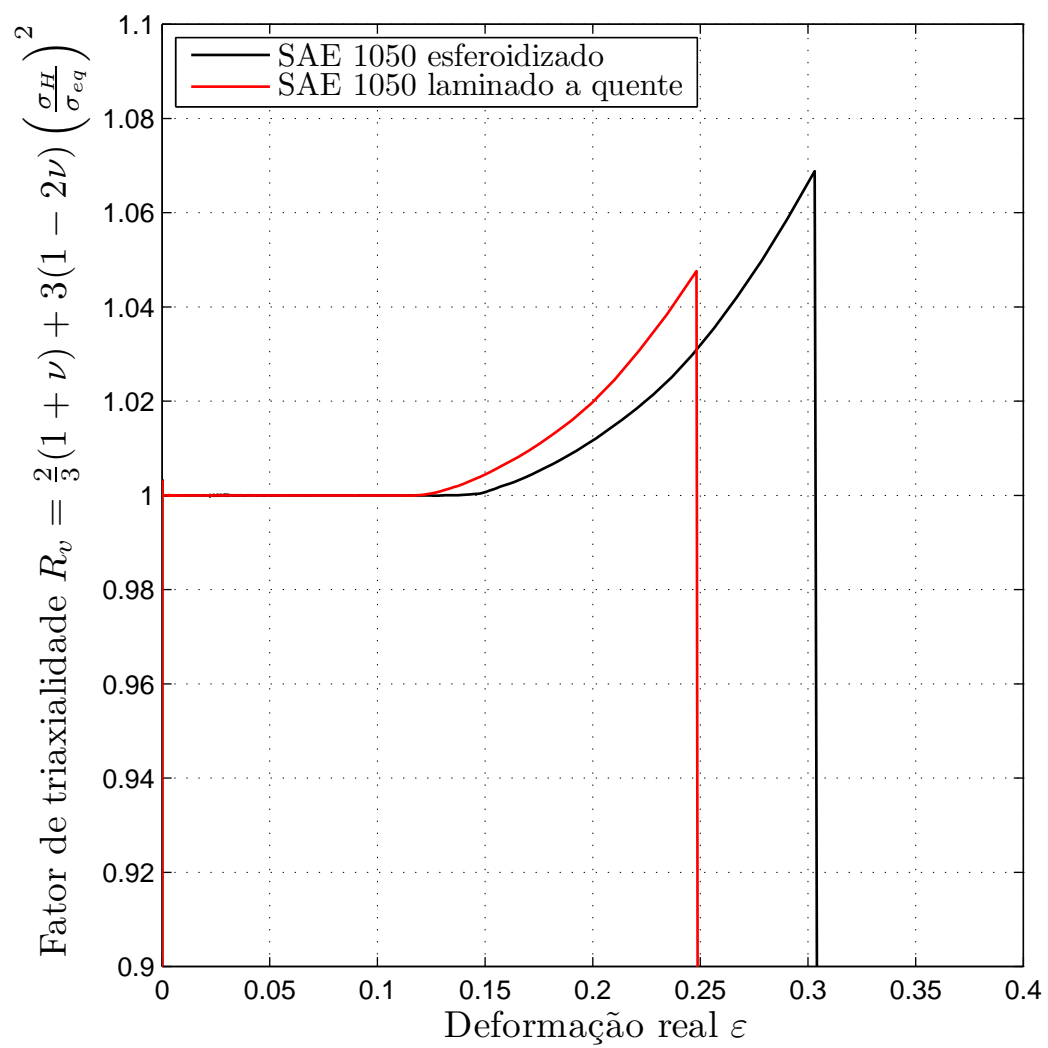

Figura 6.13: Curva de evolução do fator de triaxialidade para o aço SAE 1050 na direção de laminação nas condições esferoidizado e laminado a quente.

\subsection{Comparação com aços da série SAE 10XX}

Também efetuamos simulações para os aços carbono 1020 e 1045, baseando-se nas propriedades encontradas nos trabalhos de Celentano, Tapia e Chaboche (2004) e Celentano e Chaboche (2007). A evolução do dano dessas simulações, juntamente com as dos aços 1050 estudadas neste trabalho, é mostrada na Fig. 6.18.

É interessante notar o efeito do aumento do teor de carbono, que faz o surgimento do dano ocorrer em deformações mais baixas. Isso é coerente, visto que os microvazios tendem a se formar nas interfaces entre a matriz ferrítica e as fases duras (cementita), e a quantidade deste última é proporcional ao teor de carbono do aço. A inclinação da curva também aumenta com a quantidade de carbono presente no material. Ou seja, quanto maior for a quantidade de fases duras no material, mas rápido se dará a criação e crescimento de novos microvazios.

Esta análise é coerente com o resultado encontrado por Le Roy et al. (1981), que estudou a evolução dos vazios por meio de microscopia eletrônica de varredura para diversos aços na condição esferoidizada, mostrados na Fig. 6.19. 


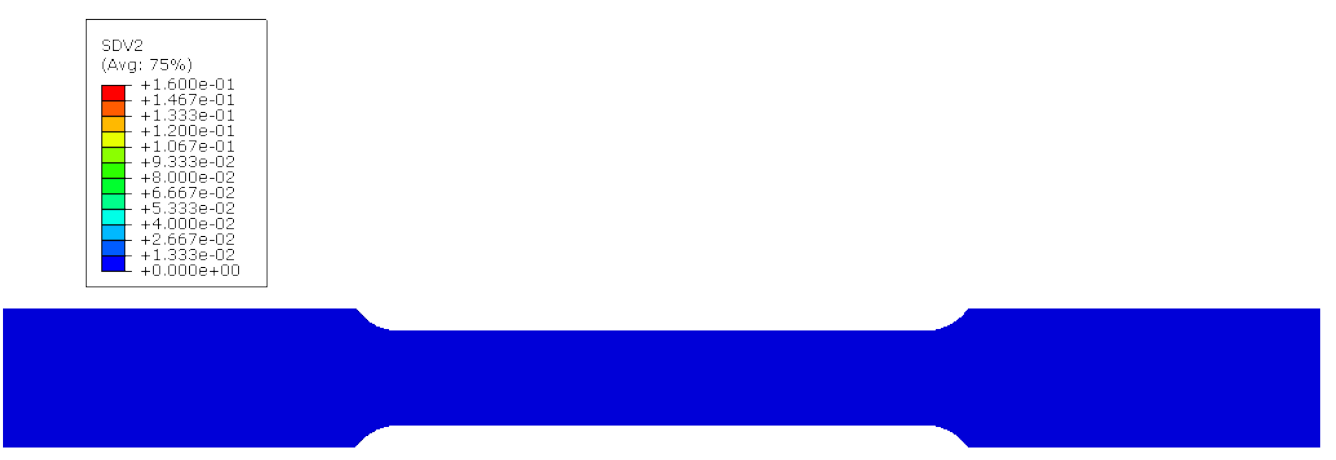

(a)

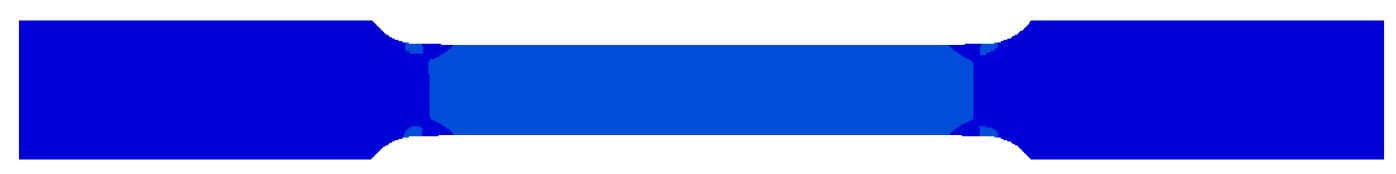

(b)

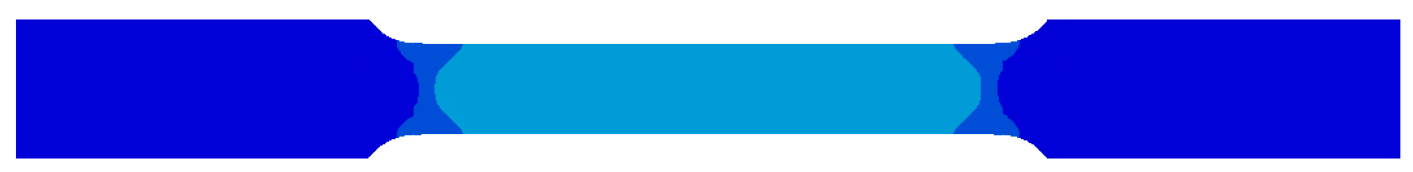

(c)

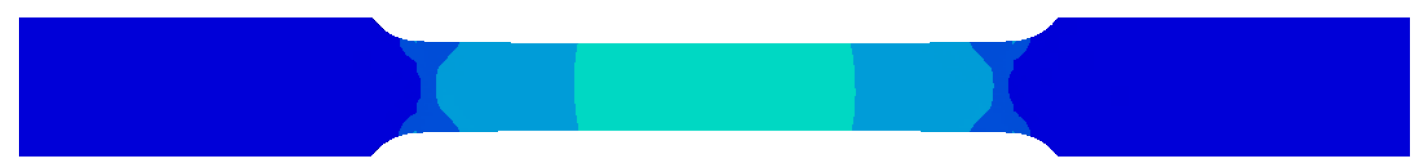

(d)

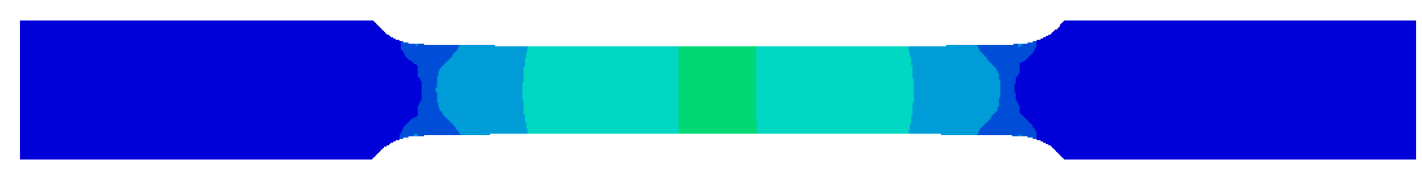

(e)

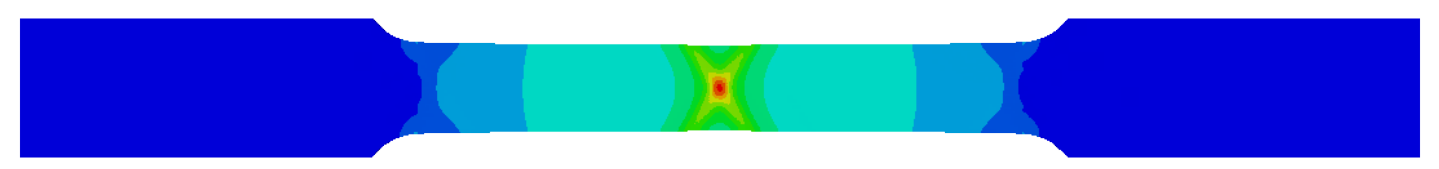

(f)

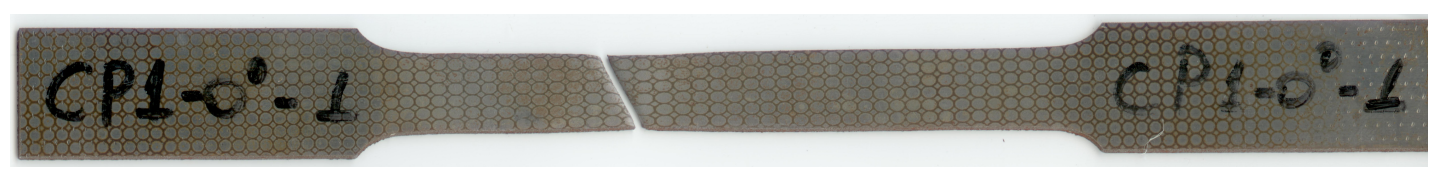

(g)

Figura 6.14: Contornos da variável de dano para o aço SAE 1050 esferoidizado. (a) Início da simulação. (b) $75 \%$. (c) $90 \%$. (d) $95 \%$ (e) $99 \%$. (f) 100\%. (g) Corpo de prova experimental.

Com isso, podemos concluir que a microestrutura do material interfere no valor da quantidade máxima de vazios que o material pode suportar antes da falha, representado pela 


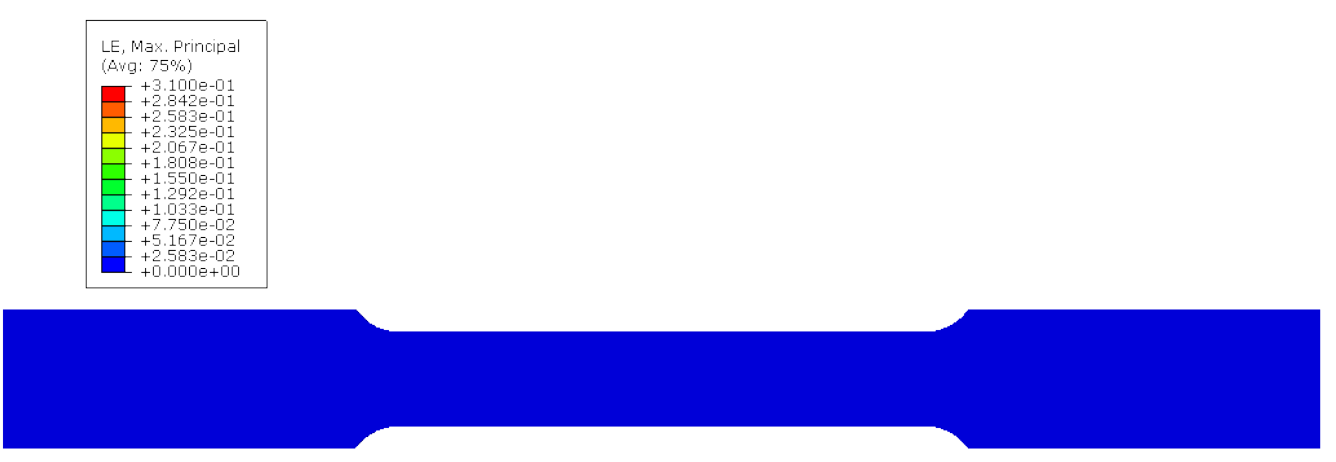

(a)

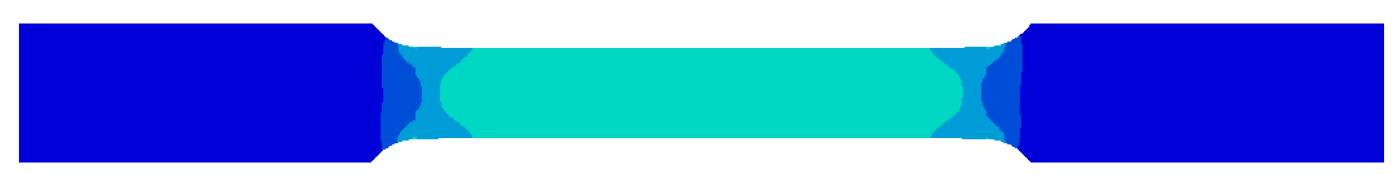

(b)

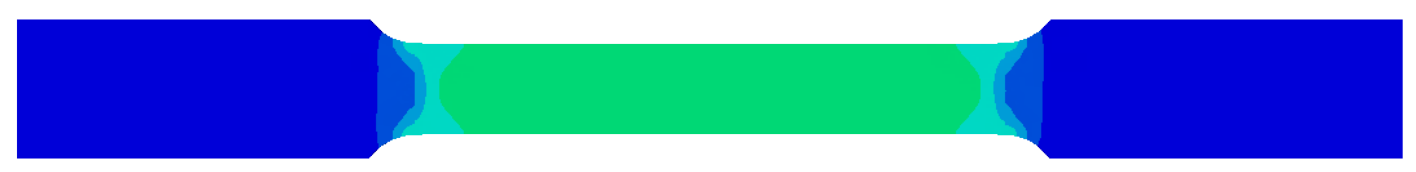

(c)

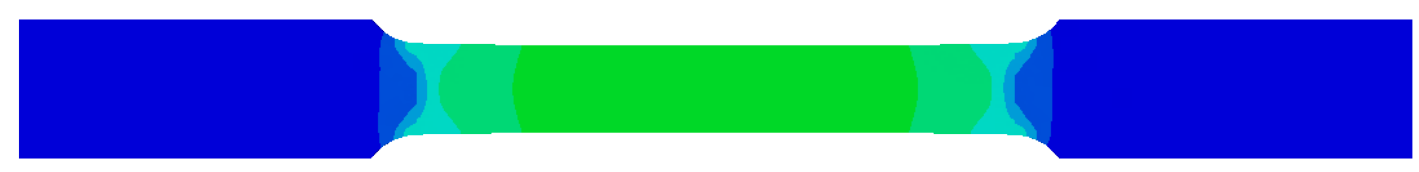

(d)

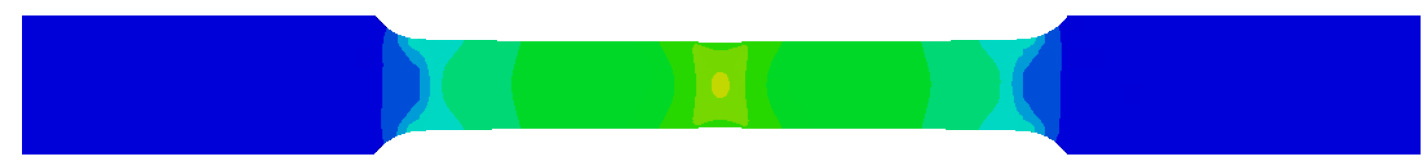

(e)

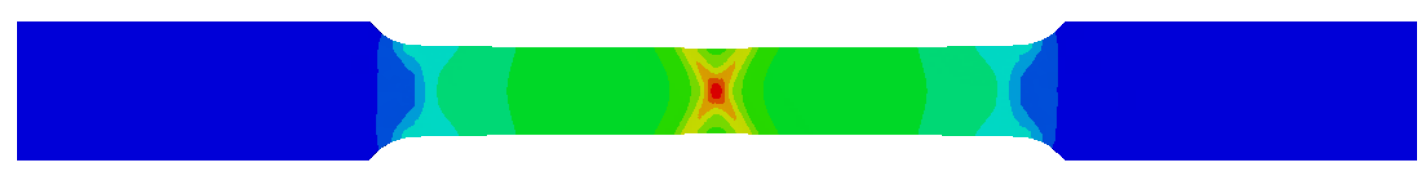

(f)

Figura 6.15: Contornos de deformação longitudinal para o aço SAE 1050 esferoidizado. (a) Início da simulação. (b) $75 \%$. (c) $90 \%$. (d) $95 \%$ (e) $99 \%$. (f) $100 \%$.

mecânica do dano como a variável de dano crítico $D_{c}$. Quanto mais homogênea for tal microestrutura, maior deverá ser o dano crítico. Já a evolução do dano, assim como a deformação limite de início do dano, está relacionada com a quantidade de fases duras, e, portanto, com o teor de carbono, para os aços carbono da série 10XX.

É possível buscar alguma relação empírica para quantificar a variação desses parâmetros com o nível de carbono nestes aços. Para isso, plotamos tanto a deformação crítica para 


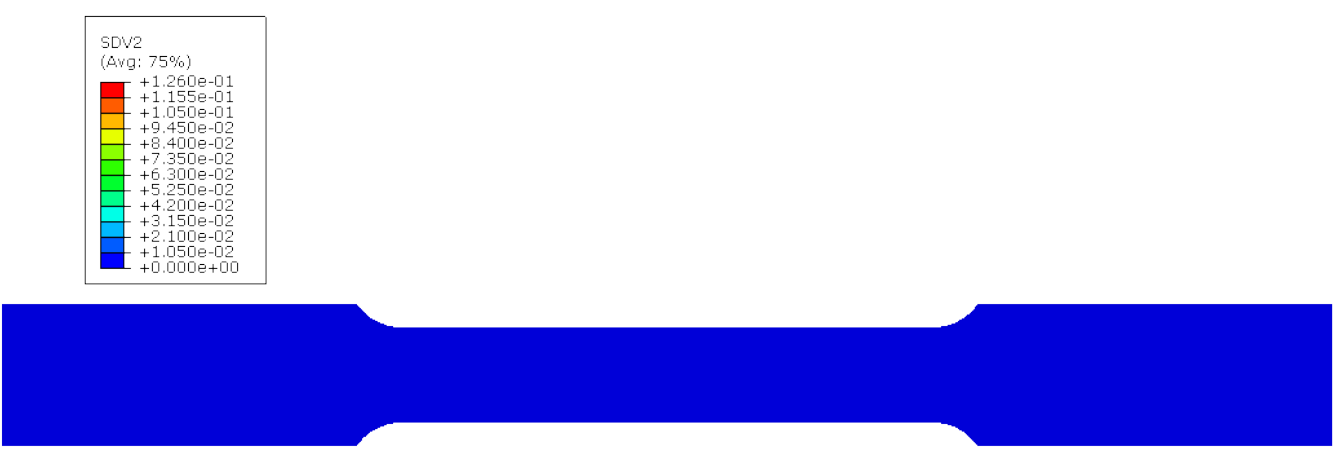

(a)

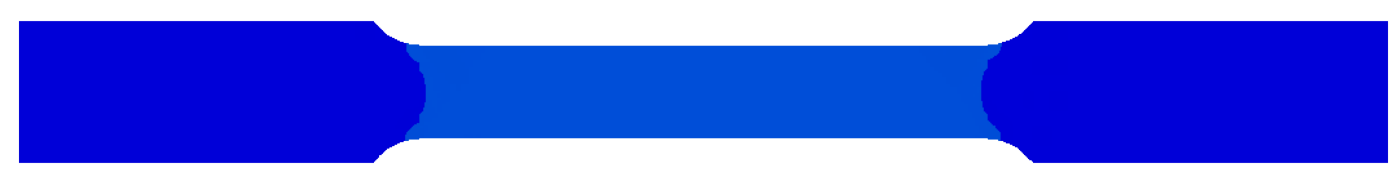

(b)

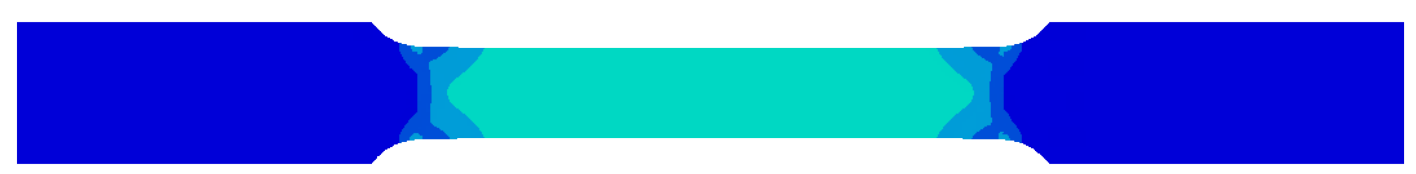

(c)

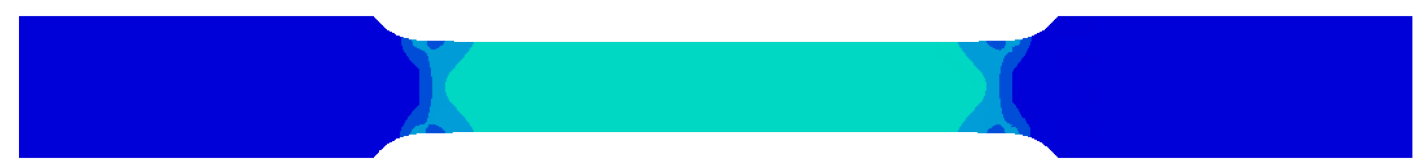

(d)

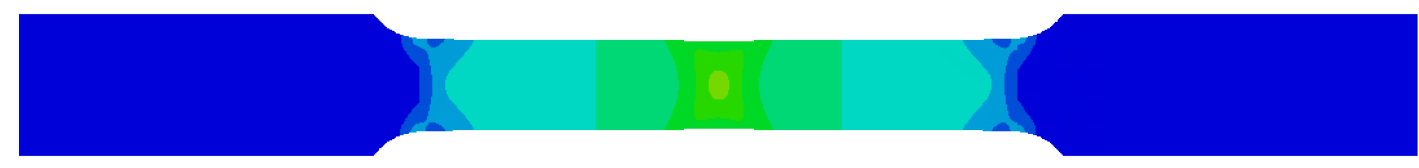

(e)

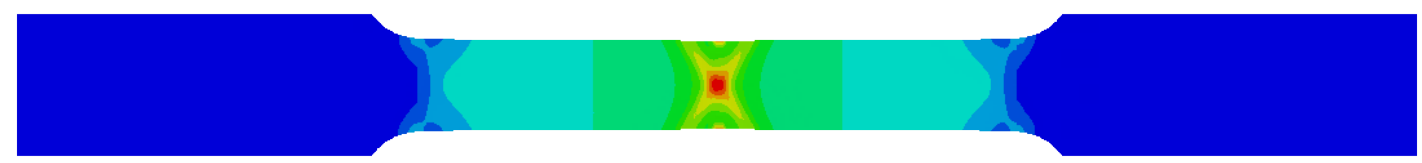

(f)

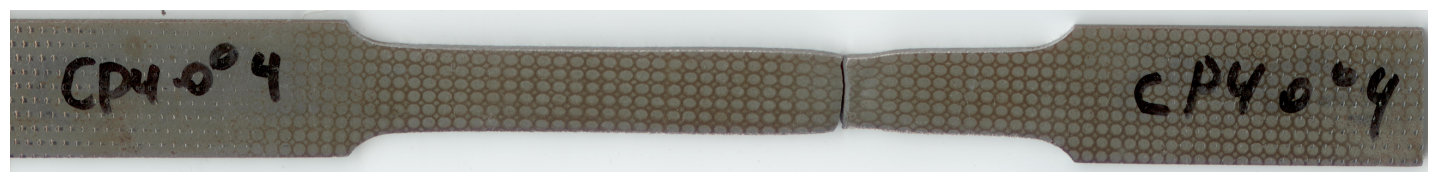

(g)

Figura 6.16: Contornos da variável de dano para o aço SAE 1050 laminado a quente. (a) Início da simulação. (b) $75 \%$. (c) $90 \%$. (d) $95 \%$ (e) $99 \%$. (f) 100\%. (g) Corpo de prova experimental.

início do dano $\varepsilon_{D}$ quanto o parâmetro de resistência ao dano $S$ como funções do nível de car- 


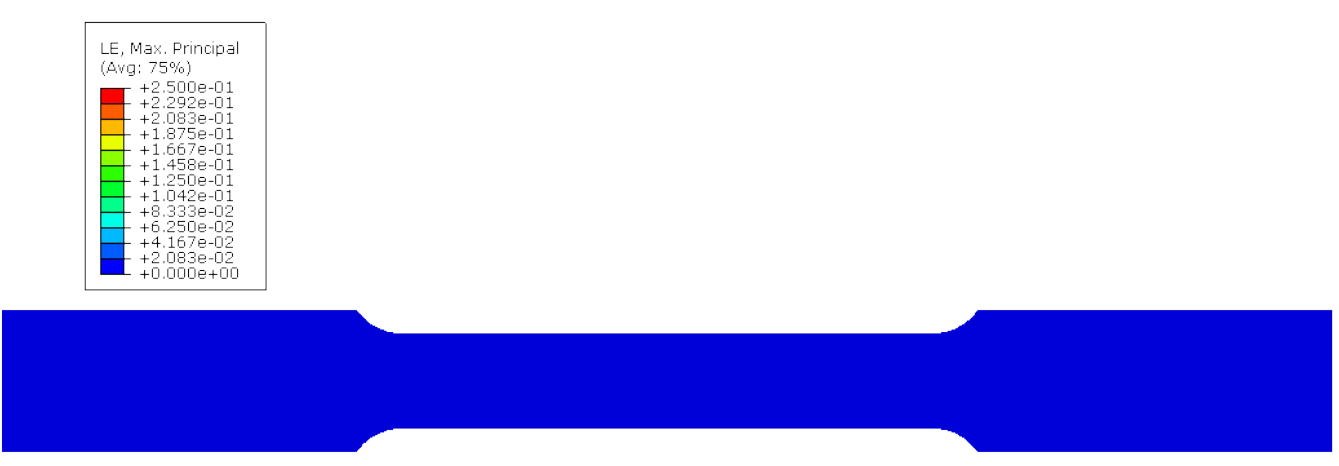

(a)

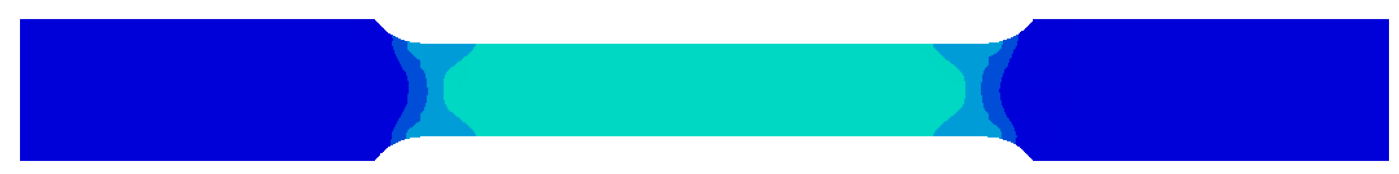

(b)

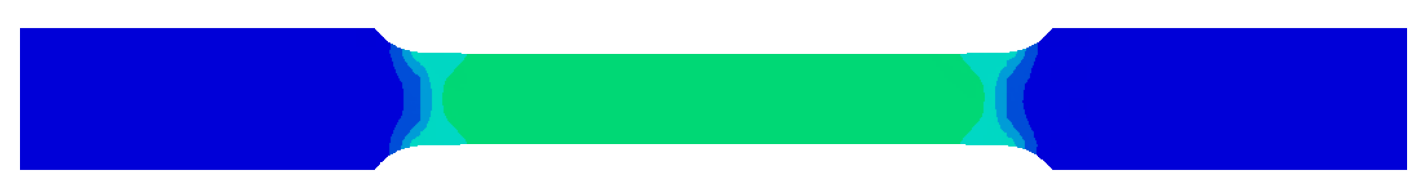

(c)

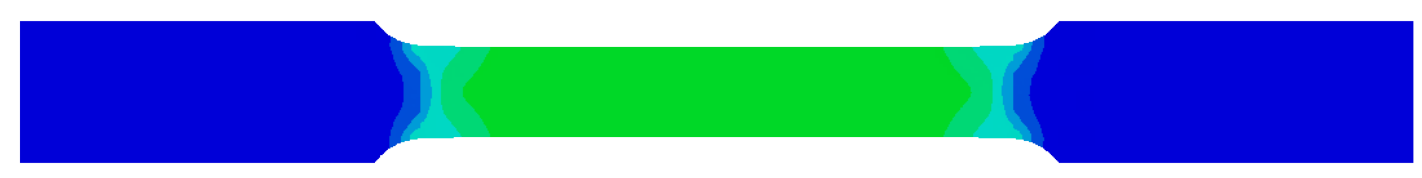

(d)

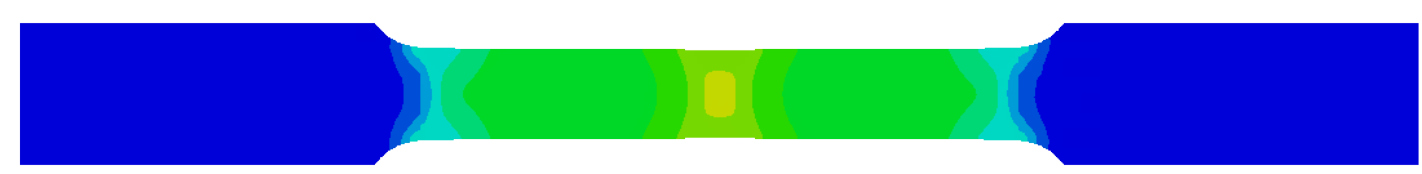

(e)

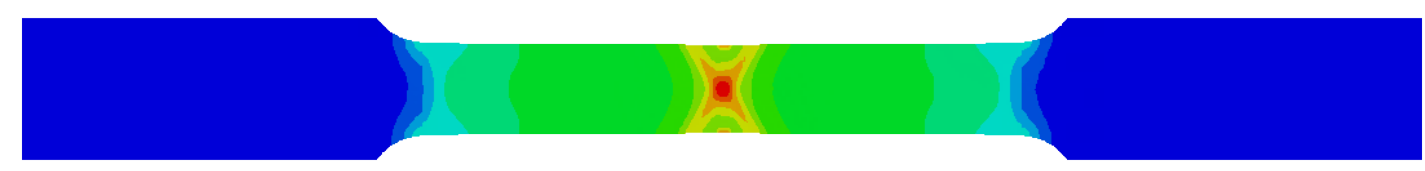

(f)

Figura 6.17: Contornos de deformação longitudinal para o aço SAE 1050 laminado a quente. (a) Início da simulação. (b) $75 \%$. (c) $90 \%$. (d) $95 \%$ (e) $99 \%$. (f) $100 \%$.

bono, como mostrado na Fig. 6.20. Uma regressão do tipo exponencial foi utilizada, do tipo:

$$
y=a x^{b}+c
$$

Os parâmetros identificados, para ambas as variáveis, são mostrados na Tab. 6.1.

Quanto ao dano crítico uniaxial $D_{1 c}$, podemos estimar seu valor por meio da relação 


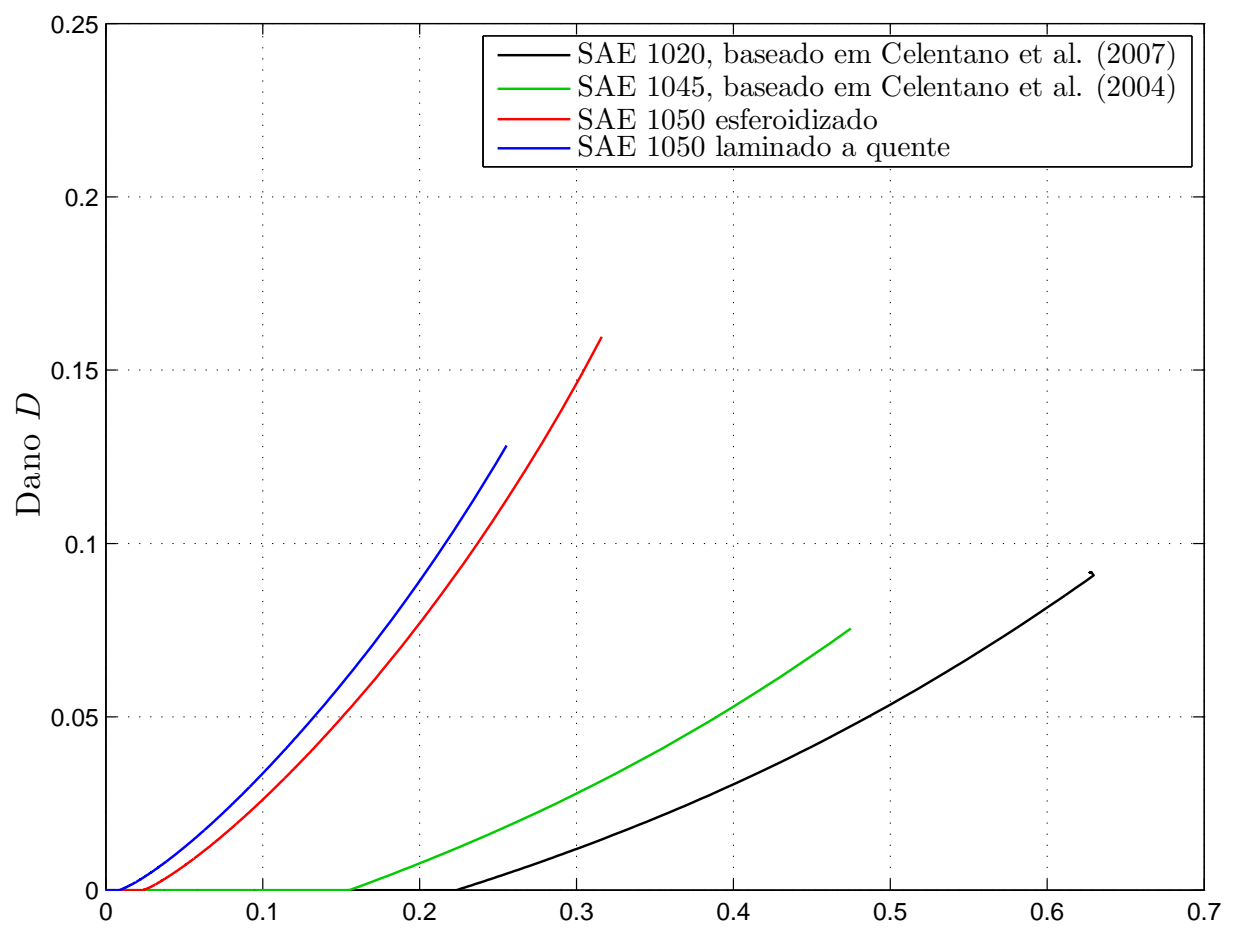

Figura 6.18: Curva de evolução do dano para aços carbono da série 10XX.

Tabela 6.1: Constantes da regressão exponencial das propriedades de evolução do dano com o nível de carbono dos aços da série SAE 10XX.

\begin{tabular}{cccc}
\hline Propriedade & $a$ & $b$ & $c$ \\
\hline Deformação limite para surgimento do dano $\varepsilon_{D}(-)$ & $-252,2$ & 10,3 & 0,22 \\
Parâmetro de resistência ao dano $S(\mathrm{MPa})$ & $-537,2$ & 4,97 & 20,2 \\
\hline
\end{tabular}

proposta por Lemaitre (1996):

$$
D_{1 c}=1-\frac{s_{f}}{s_{u}}
$$

onde $s_{f}$ é a tensão de engenharia na fratura e $s_{u}$ é a limite de resistência de engenharia, dados obtidos por ensaios de tração simples ou listados nos catálogos de fornecedores de matéria prima. Para testar a validade dessa relação, mostramos a Tab. 6.2. Notamos que o erro da estimativa é da ordem de $10 \%$. Tal valor pode ser justificado pela grande dispersão do valor da tensão na fratura do material, visto que é o crescimento das trincas nos estágios avançados da fratura dúctil é um fenômeno afetados por um número grande de fatores, desde tamanho dos precipitados de segunda fase na microestrutura até irregularidades geométricas no corpo de prova decorrentes do processo de manufatura. 


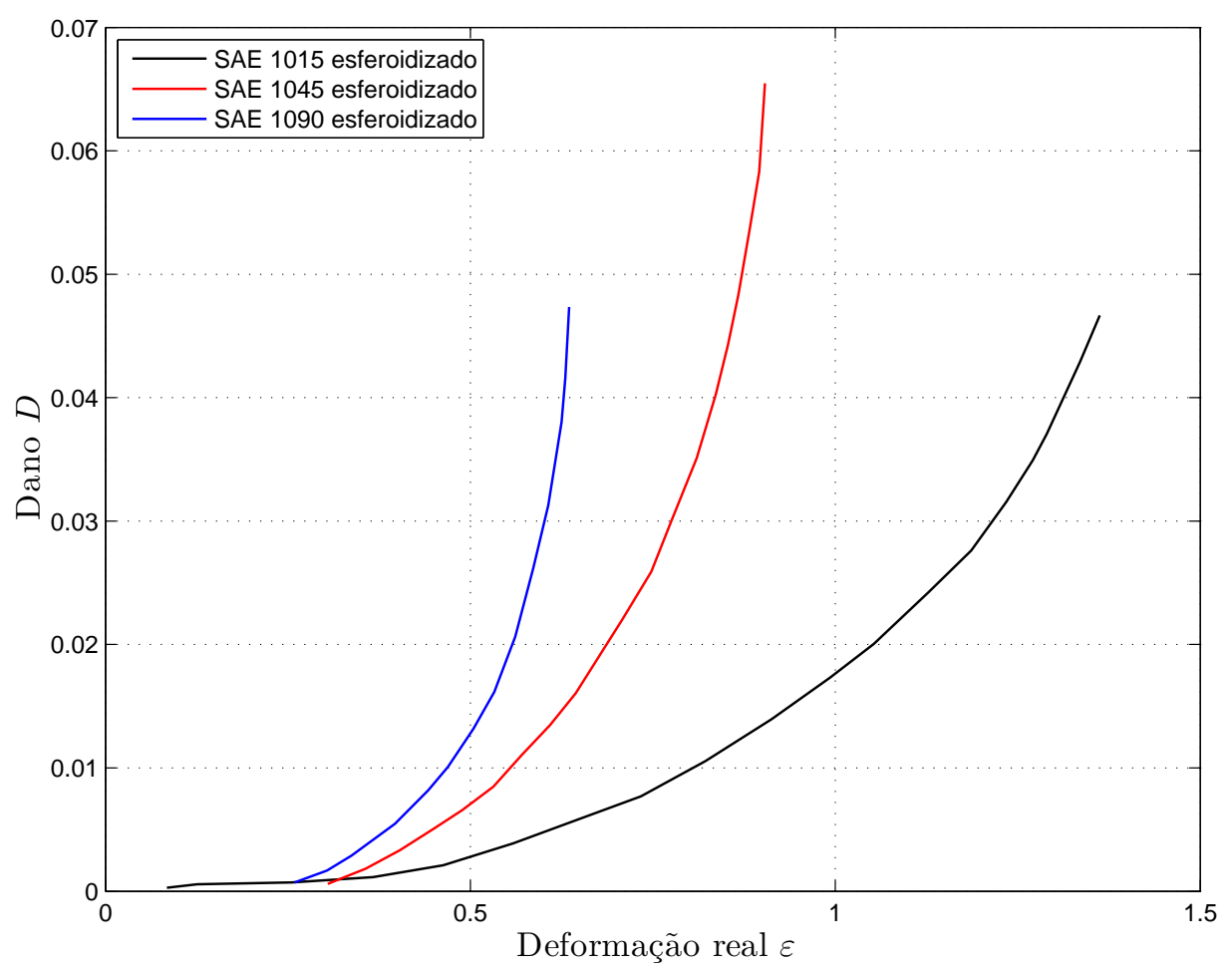

Figura 6.19: Evolução do dano medido diretamente pela fração de vazios para ligas de aço esferoidizadas. Adaptado de Le Roy et al. (1981).

Tabela 6.2: Estimativa do dano crítico uniaxial.

\begin{tabular}{cccccc}
\hline Material & $s_{f}(\mathrm{MPa})$ & $s_{u}(\mathrm{MPa})$ & $D_{1 c}$ estimado & $D_{1 c}$ medido & $\begin{array}{c}\text { Erro da } \\
\text { estimativa }\end{array}$ \\
\hline $\begin{array}{c}\text { SAE 1050 } \\
\text { esferoidizado } \\
\begin{array}{c}\text { SAE 1050 } \\
\text { laminado a quente }\end{array}\end{array}$ & 400 & 480 & 0,17 & 0,19 & $10,5 \%$ \\
\hline
\end{tabular}

\subsection{Conclusões parciais}

A implementação do modelo de evolução de dano proposto por Lemaitre (1996), utilizandose o algoritmo explícito de Lee e Pourboghrat (2005), foi efetuada com sucesso no software Abaqus/Explicit, e pudemos observar que a evolução do dano segundo o modelo corresponde bem àquela medida experimentalmente via variação do módulo de elasticidade.

O modelo de Lemaitre é baseado em uma evolução linear do dano, porém os resultados encontrados numericamente mostram uma pequena não-linearidade. Isto é explicado devido à variação do fator de triaxialidade durante a simulação, como mostrado na Fig. 6.13. 


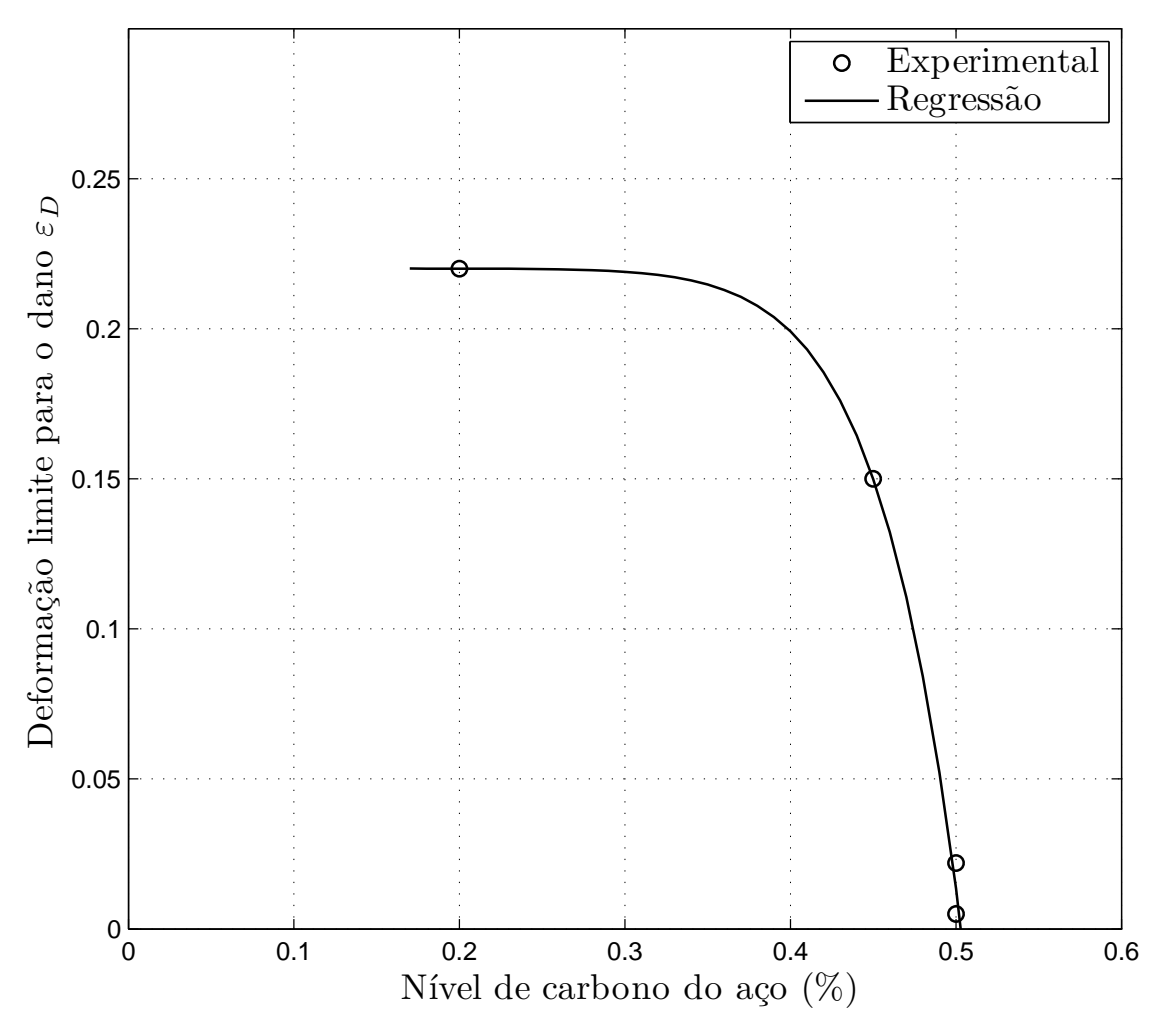

(a)

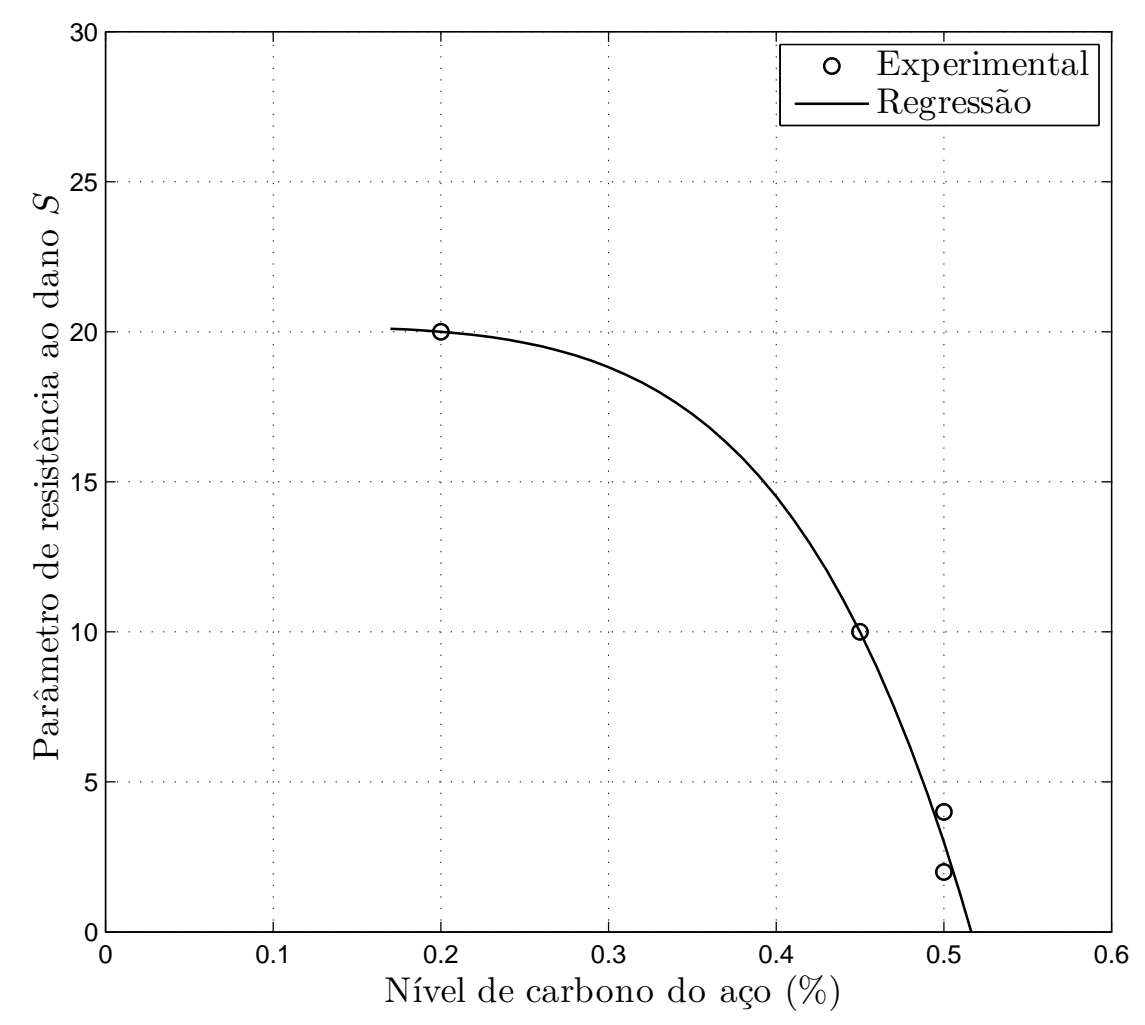

(b)

Figura 6.20: Variação dos parâmetros de evolução do dano com o nível de carbono em aços da série SAE 10XX. (a) Deformação limite para surgimento do dano. (b) Parâmetro de resistência ao dano. 
É possível comparar o aspecto da fratura visualizada experimentalmente e numericamente, mesmo que a teoria da mecânica do dano não descreva a propagação de uma trinca macroscópica. Percebemos que, principalmente para o caso do material esferoidizado, que tinha uma espessura de chapa menor, o modelo numérico conseguiu prever o ângulo de formação da banda de ruptura.

Uma análise das Figs. 6.10(c) e 6.11(c) mostra que, segundo a teoria da mecânica do dano, a localização das deformações na região da fratura não leva a um aumento da tensão verdadeira atuando no material nestes pontos. O que ocorre é a concentração da variável de dano próximo à estricção, que acaba por diminuir a área efetiva da seção transversal resistente, e aumentar o valor da tensão aparente, a qual conseguimos medir de maneira indireta nos ensaios.

Uma comparação entre a evolução do dano para os aços SAE 1050 estudados neste trabalho e os aços SAE 1020 e 1045 encontrados na literatura foi efetuada, e foi constatado que o aumento do teor de carbono diminui a deformação crítica para surgimento do dano e aumenta a taxa de crescimento do dano com a deformação. Isto está relacionado com com a nucleação e crescimento de microcavidades, eventos que ocorrem preferencialmente nas interfaces entre a matriz ferrítica do aço e as partículas duras de segunda fase, cuja quantidade é diretamente proporcional ao nível de carbono. O dano crítico do material parece ser influenciado pela morfologia da microestrutura.

Regressões exponenciais foram propostas para relacionar os parâmetros $S$ e $\varepsilon_{D}$ com o nível de carbono das ligas de aço da série SAE 10XX para níveis de carbono entre 0,20\% e $0,50 \%$. Estas, assim como a relação de Lemaitre para cálculo de $D_{1 c}$, podem ser úteis em fases preliminares de projeto, nas quais busca-se ordens de grandeza das propriedades mecânicas e/ou dimensões, economizando tempo e recursos. No entanto, nas fases de detalhamento, nas quais é necessário um equacionamento mais preciso e confiável, recomenda-se a adoção de uma metodologia de caracterização do material em questão como a aqui apresentada.

No capítulo seguinte, as conclusões finais do trabalho, e discussões pertinentes, serão apresentadas, assim como propostas de trabalhos futuros. 


\section{CONCLUSÕES E COMENTÁRIOS}

Este trabalho se propôs a apresentar a teoria da mecânica do dano como proposta por Lemaitre para análise da fratura dúctil de materiais metálicos e usá-la para estudo da ductilidade de uma liga de aço médio carbono em duas condições de microestrutura.

Corpos de prova de chapas de aços SAE 1050 esferoidizado e laminado a quente, e em duas orientações distintas, foram ensaiados em tração com baixa velocidade de deformação e temperatura ambiente de modo a obter propriedades mecânicas referentes ao modelo de evolução de dano de Lemaitre, sendo estes módulo de elasticidade, tensão de escoamento, curva de escoamento para deformações plásticas, dano crítico uniaxial, deformação limite para surgimento do dano e resistência à evolução do dano. O dano em si foi medido por meio da variação do módulo de elasticidade, calculado em ciclos de carregamento e descarregamento ao longo do ensaio de tração.

Entre as amostras esferoidizadas e laminadas a quente, as diferenças nas propriedades mecânicas encontradas foram as esperadas, isto é, maior deformação de ruptura e menores tensões para a primeira em relação à última. Já para a evolução do dano, apenas o dano crítico variou de maneira significativa, sendo maior para os CP's esferoidizados. Na comparação entre amostras deformadas na direção original de laminação e transversal a essa direção, as diferenças encontradas podem ser atribuídas a dispersão experimental, e não a anisotropia dos materiais.

A evolução da textura na região próxima à fratura dos corpos de prova foi analisada por meio da técnica de difração de raios X. A análise das figuras de distribuição de orientação mostrou que tanto os materiais esferoidizados quanto os laminados a quente apresentaram a fraca intensidade de fibras $\gamma^{\prime}$ e $\alpha$, e tal textura não muda com as direções de deformação estudadas, as quais são paralelo e transversal à direção de laminação original da chapa, nem com as deformações plásticas inerentes aos ensaios de tração realizados. A fibra $\gamma$ aparece apenas nas amostras esferoidizadas, indicando que ela surge durante o tratamento térmico, e é responsável pelo comportamento mais isotrópico destas amostras.

O modelo de dano de Lemaitre foi acoplado a um modelo de elementos finitos para 
cálculo de plasticidade isotrópica do Abaqus/Explicit por meio de uma subrotina VUMAT, apresentada no apêndice do trabalho. Simulações numéricas do ensaio de tração foram efetuadas para os corpos de prova deformados na direção de laminação, nas duas condições de microestrutura, e os resultados foram comparados com os experimentos, mostrando boa concordância. Apresentamos a diferença entre a tensão efetiva, a qual pode-se medir em células de carga nos ensaios experimentais, e a tensão verdadeira atuando no material danificado, a qual se satura quando o dano começa a aparecer. É o acúmulo do dano que faz a tensão efetiva aumentar nos estágios mais avançados da deformação.

A evolução do dano nas simulações não foi linear com a deformação, como seria esperado pelo modelo de Lemaitre. Isso é justificado pelo desvio, a partir de uma deformação de cerca de $10 \%$, do estado de tensões do material, que deixa de ser perfeitamente uniaxial como considerado no modelo.

Embora a mecânica do dano não seja capaz de descrever a formação de trincas macroscópicas e sua propagação nos estágios anteriores à fratura, o uso dessa teoria em conjunto com uma caracterização experimental pode ser uma maneira útil de prever os estágios iniciais do fenômeno da fratura dúctil, o que pode ser importante em processos industriais de manufatura.

Finalmente, uma comparação entre a evolução do dano para os aços SAE 1050 estudados neste trabalho e os aços SAE 1020 e 1045 encontrados na literatura foi efetuada. Notou-se que a deformação limite para início do dano e o parâmetro de resistência ao dano, inversamente proporcional à taxa de crescimento deste com a deformação, diminuíram conforme o nível de carbono das ligas aumentou. Este resultado é esperado, visto que o fenômeno da fratura dúctil tem origem na nucleação e crescimento de microcavidades, eventos que ocorrem preferencialmente nas interfaces entre a matriz ferrítica do aço e as partículas duras de segunda fase, cuja quantidade é diretamente proporcional ao nível de carbono. Já a morfologia da microestrutura, se apresenta cementita esferoidizada ou ferrita-perlita lamelar, tem maior influência no dano crítico do material.

Uma regressão exponencial foi proposta para relacionar tanto o parâmetro de resistência quanto a deformação limite para o dano com o nível de carbono das ligas de aço da série SAE 10XX para níveis de carbono entre 0,20\% e 0,50\%. Tal equação pode ser útil em estágios preliminares de projeto, nas quais simulações são efetuadas para estimar ordens de grandeza de dimensões e propriedades mecânicas. Contudo, para estudos mais precisos, uma metodologia semelhante à utilizada no presente trabalho deve ser adotada para completa caracterização da liga em questão. 


\subsection{Futuros trabalhos}

A seguir, propomos algumas possibilidades de trabalhos que possam ser desenvolvidos como complemento ao presente estudo.

Medição direta da variável de dano: tal feito pode ser obtido por meio do cálculo de fração de vazios efetuados por microscopia eletrônica de varredura. Embora haja na literatura evidência de que o dano medido de maneira direta, por fração de vazios, e indireta, por variação de alguma propriedade mecânica ou elétrica, não podem ser comparados, algum tipo de correlação deve existir e tal tópico carece de estudos.

Caracterização de outras ligas metálicas: pode-se verificar se a relação empírica proposta para os aços da série SAE 10XX se mantém para outros níveis de carbono. Em aços ligados, e outras ligas como alumínio ou titânio, buscar uma correlação entre presença de outras fases e o efeito dos elementos de liga nas propriedades de evolução do dano.

Estudo da evolução do dano em outros modos de carregamento: verificação da validade de aplicação dos parâmetros encontrados no ensaio de tração em outros estados de tensão do material, como torção, cisalhamento, tração planar e compressão. Buscar uma relação empírica entre deformação na fratura e relação de triaxialidade do carregamento.

Estudo de outras variáveis de processo: quantificar o efeito da temperatura e da velocidade de deformação nos parâmetros de evolução do dano. 


\section{REFERÊNCIAS}

ABOUTALEBI, F. H.; FARZIN, M.; POURSINA, M. Numerical simulation and experimental validation of a ductile damage model for DIN 1623 St14 steel. International Journal of Advanced Manufacturing Technology, v. 53, p. 157-165, 2010.

ALVES, M. Measurement of ductile material damage. Mechanics of Structures and Machines, v. 29 , p. 451-476, 2001.

ALVES, M.; YU, J.; JONES, N. On the elastic modulus degradation in continuum damage mechanics. Computers and Structures, v. 76, p. 703-712, 2000.

ASM Handbook - Forming and forging, vol.14. 4a . ed. [S.l.]: ASM International, 1996.

ASM Handbook - Heat treating, vol. 4. 4ª ed. [S.1.]: ASM International, 1996.

ASSOCIAÇÃO BRASILEIRA DE NORMAS TÉCNICAS. NBR 6152: Materiais metálicos Ensaio de tração à temperatura ambiente. 1992.

ASSOCIAÇÃO BRASILEIRA DE NORMAS TÉCNICAS. NBR 6662: Tiras relaminadas de aços-carbono e aços ligados - Especificação. 2008.

BANABIC, D.; BARLAT, F.; CAZACU, O.; KUWABARA, T. Advances in anisotropy and formability. International Journal of Material Forming, v. 3, p. 165-189, 2010.

BANABIC, D.; BUNGE, H.-J.; PÖHLANDT, K. P.; TEKKAYA, A. E. Formabiliry of Metallic Materials. [S.1.]: Springer, 2000.

BAO, Y.; WIERZBICKI, T. On fracture locus in the equivalent strain and stress triaxiality space. International Journal of Mechanical Sciences, v. 46, p. 81-98, 2004.

BEHRENS, A.; JUST, H. Extension of the forming limits in cold and warm forging by the fe based fracture analysis with the integrated damage model of effective stresses. Journal of Materials Processing Technology, v. 125-126, p. 235-241, 2002.

BEHRENS, A.; JUST, H. Theoretical and experimental damage prediction in cold and semi-hot bulk forming of ductile steels. Steel Research International, v. 76, p. 210-218, 2005.

BEHRENS, B. A.; HAGEN, T.; KLASSEN, A.; KNIGGE, J.; MIELKE, J.; PFEIFFER, I. Forging of aluminium components under a superimposed hydrostatic pressure to induce local strain hardening. Advanced Materials Research, v. 137, p. 191-217, 2010.

BENITO, J. A.; MANERO, J. M.; JORBA, J.; ROCA, A. Change of Young's modulus of cold-deformed pure iron in a tensile test. Metallurgical and Materials Transactions A, v. 36A, p. 3317-3324, 2005.

BONORA, N. A nonlinear CDM model for ductile failure. Engineering Fracture Mechanics, v. 58, p. 11-28, 1997. 
BRESSAN, J. D.; WILLIAMS, J. A. The use of a shear instability criterion to predict local necking in sheet metal deformation. International Journal of Mechanical Sciences, v. 25, p. $155-168,1983$.

CALLISTER JR., W. D. Ciência e Engenharia dos Materiais: Uma Introducção. [S.1.]: LTC, 2002.

CELENTANO, D. J.; CHABOCHE, J.-L. Experimental and numerical characterization of damage evolution in steels. International Journal of Plasticity, v. 23, p. 1739-1762, 2007.

CELENTANO, D. J.; TAPIA, P. E.; CHABOCHE, J. L. Experimental and numerical characterization if damage evolution in steels. In: BUSCAGLIA, G.; DARI, E.; ZAMONSKY, O. (Ed.). Mecánica Computacional. Bariloche, Argentina: [s.n.], 2004. XXIII, p. 45-58.

CHABOCHE, J. L. Continuum damage mechanics: present state and future trends. Nuclear Engineering and Design, v. 105, p. 19-33, 1987.

CHABOCHE, J. L. Continuum damage mechanics: Part I - general concepts. Journal of Applied Mechanics, v. 55, p. 55-64, 1988.

CHABOCHE, J. L. Continuum damage mechanics: Part II - damage growth, crack initiation and crack growth. Journal of Applied Mechanics, v. 55, p. 65-72, 1988.

CHANDRAKANTH, S.; PANDEY, P. An isotropic damage model for ductile material. Engineering Fracture Mechanics, v. 50, p. 457-465, 1995.

CHOW, C. L.; WANG, J. An anisotropic theory of continuum damage mechanics for ductile fracture. Engineering Fracture Mechanics, Elsevier, v. 27, p. 547-558, 1987.

COCKROFT, M. G.; LATHAM, D. J. Ductility and the workability of metals. Journal of the Institute of Metals, v. 96, p. 33-39, 1968.

DE SOUZA NETO, E. A. A fast, one-equation integration algorithm for the Lemaitre ductile damage model. Communications in Numerical Methods in Engineering, v. 18, p. 541-554, 2002.

DESMORAT, R.; CANTOURNET, S. Modeling microdefects closure effect with isotropic/anisotropic damage. International Journal of Damage Mechanics, v. 17, p. 65-96, 2008.

DOEGE, E.; BOHNSACK, R. Closed die technologies for hot forging. Journal of Materials Processing Technology, v. 98, p. 165-170, 2000.

FRENCH, I. E.; WEINRICH, P. F. The influence of hydrostatic pressure on the tensile deformation of a spheroidized 0.5\% C steel. Scripta Metallurgica, v. 8, p. 87-90, 1974.

FREUDENTHAL, A. M. The inelastic behavior of engineering materials and structures. $1^{\mathrm{a}}$. ed. [S.1.]: John Wiley \& Sons, 1950.

GARRISON JR., W. M.; MOODY, N. R. Ductile fracture. Journal of Physics and Chemistry of Solids, v. 48, p. 1035-1074, 1987.

GERE, J. M. Mecânica dos materiais. São Paulo: Pioneira Thomson Learning, 2003. 
GRIFFITH, A. A. The phenomena of rupture and flow in solids. Philosophical Transactions of the Royal Society of London, v. 221, p. 163-198, 1920.

GRONOSTAJSKI, Z. The constitutive equations for fem analysis. Journal of Materials Processing Technology, v. 106, p. 40-44, 2000.

GURLAND, J. Observations on the fracture of cementite particles in a spheroidized $1.05 \% \mathrm{C}$ steel deformed at room temperature. Acta Metallurgica, v. 20, p. 735-741, 1972.

GURSON, A. L. Continuum theory of ductile rupture by void nucleation and growth: part I Yield criteria and flow rules for porous ductile media. Journal of Engineering Materials and Technology, v. 99, p. 2-15, 1977.

HARTLEY, C. S.; LEE, J. J.; GARDE, A.; CHUNG, H. M.; KASSNER, T. F. Microstructurebased constitutive relation for dilute alloys of $\alpha$-zirconium. In: Proceedings of the 4th International Conference on Zirconium in the Nuclear Industry. Stratford-upon-Avon, England: [s.n.], 1978.

HENRY, J. On the mode of testing building materials, and an account of the marble used in the extension of the United States Capitol. Proceedings of the American Association for the Advancement of Science, v. 9, p. 102-112, 1855.

HILL, R. On discontinuous plastic states, with special reference to localized necking in thin sheets. Journal of the Mechanics and Physics of Solids, v. 1, p. 19-30, 1952.

HOLlOMON, J. H. Tensile deformation. Transaction of American Institute of Mechanical Engineering, v. 162, p. 268-277, 1945.

IRWIN, G. R. Fracture dynamics. In: FRACTURING OF METALS. American Society For Metals. [S.1.], 1948. p. 147-166.

JESWIET, J.; GEIGER, M.; ENGEL, U.; KLEINER, M.; SCHIKORRA, M.; DUFLOU, J.; NEUGEBAUER, R.; BARIANI, P.; BRUSCHI, S. Metal forming progress since 2000. CIRP Journal of Manufacturing Science and Technology, v. 1, p. 2-17, 2008.

JONES, R. M. Deformation theory of plasticity. Blacksburg: Bull Ridge Publishing, 2009.

KACHANOV, L. M. Time of the rupture process under creep conditions. Izvestia Akademii Nauk SSSR, Otdelenie tekhnicheskich nauk, 1958.

KHELIFA, M.; OUDJENE, M.; KENNANE, A. Fracture in sheet metal forming: Effect of ductile damage evolution. Computers and Structures, v. 85, p. 205-212, 2007.

LANDAU, L. D.; LIFSHITZ, E. M. Theory of Elasticity. Bristol: Pergamon Press, 1964.

LE ROY, G.; EMBURY, J. D.; EDWARDS, G.; ASHBY, M. F. A model of ductile fracture based on the nucleation and growth of voids. Acta Metallurgica, v. 29, p. 1509-1522, 1981.

LEE, S. W.; POURBOGHRAT, F. Finite element simulation of the punchless piercing process with lemaitre damage model. International Journal of Mechanical Sciences, v. 47, p. 1756-1768, 2005.

LEMAITRE, J. How to use damage mechanics. Nuclear Engineering and Design, v. 80, p. 233-245, 1984. 
LEMAITRE, J. A continuous damage mechanics model for ductile fracture. Journal of Engineering Materials and Technology, v. 77, p. 335-344, 1985.

LEMAITRE, J. A Course on Damage Mechanics. 2a . ed. [S.1.]: Springer, 1996.

LI, Y.; LUO, M.; GERLACH, J.; WIERZBICKI, T. Prediction of shear-induced fracture in sheet metal forming. Journal of Materials Processing Technology, v. 210, p. 1858-1869, 2010.

LUDWIK, P. Elements der Technologischen Mechanik. 3ª . ed. Berlin: Springer, 1909.

MALVERN, L. E. Introduction to the mechanics of a continuous medium. New Jersey: Prentice-Hall, 1969.

MASHAYEKHI, M.; ZIAEI-RAD, S.; PARVIZIAN, J.; NIKLEWICZ, J.; HADAVINIA, $\mathrm{H}$. Ductile crack growth based on damage criterion: Experimental and numerical studies. Mechanics of Materials, v. 39, p. 623-636, 2007.

MAUGIN, G. A. The thermodynamics of plasticity and fracture. Cambridge: Cambridge University Press, 1992.

McCLINTOCK, F. A. A criterion for ductile fracture by the growth of holes. Journal of Applied Mechanics, v. 35, p. 363-371, 1968.

MORESTIN, F.; BOIVIN, M. On the necessity of taking into account the variation in the young modulus with plastic strain in elastic-plastic software. Nuclear Engineering and Design, v. 162 , p. 107-116, 1996.

NIAZI, M. S.; WISSELINK, H. H.; MEINDERS, T.; HUéTINK, J. Failure predictions for DP steel cross-die test using anisotropic damage. International Journal of Damage Mechanics, v. 21 , p. $713-754,2012$.

NORRIS JR., D. M.; REAUGH, J. E.; MORAN, B.; QUINONES, D. F. Plastic-strain, mean-stress criterion for ductile fracture. Journal of Engineering Manufacturing Technology, Transactions of ASME, v. 100, p. 279-286, 1977.

OYANE, M.; SATO, T.; OKIMOTO, K.; SHIMA, S. Criteria for ductile fracture and their applications. Journal of Mechanical Working Technology, v. 4, p. 65-81, 1980.

PADILHA, A. F.; SICILIANO JR., F. Encruamento, recristalização, crescimento de grão e textura. $3^{\text {a }}$ ed. ed. [S.1.]: ABM, 2005.

PLAUT, R. L.; PADILHA, A. F.; LIMA, N. B.; HERRERA, C.; FILHO, A. F.; YOSHIMURA, L. H. Medium carbon steel deep drawing: A study on the evolution of mechanical properties, texture and simulations, from cold rolling to the end product. Materials Science and Engineering A, v. 499, p. 337-341, 2009.

RACHA, S. K. R. Damage characterization of four wrought aluminum alloys. Dissertação (Mestrado) - Tenesee Technological University, 2008.

RICE, J. R. The localization of plastic deformation. In: 14th International Congress on Theoretical and Applied Mechanics. [S.1.: s.n.], 1976.

RICE, J. R.; TRACEY, D. M. On the ductile enlargement of voids in triaxial stress fields. Journal of the Mechanics and Physics of Solids, v. 17, p. 201-217, 1969. 
SAH, J. P.; RICHARDSON, G. J.; SELLARS, C. M. Recrystallization during hot deformation of nickel. Journal of the Australian Institute of Metals, v. 14, p. 292-297, 1969.

SAMANTA, S. K. Resistance to dynamic compression of low-carbon steel and alloy steels at elevated temperatures and at high strain-rates. International Journal of Mechanical Sciences, v. 10, p. 613-618, 1968.

SCHWALBE, K.-H. On the influence of microstructure on crack propagation mechanisms and fracture toughness of metallic materials. Engineering Fracture Mechanics, v. 9, p. 795-832, 1977.

SEMIATIN, S. L.; GOETZ, R. L.; SHELL, E. B.; SEETHARAMAN, V.; GHOSH, A. K. Cavitation and failure during hot forging of Ti-6Al-4V. Metallurgical and Materials Transactions A, v. 30, p. 1411-1424, 1999.

SIMULIA. Abaqus 6.10 User Subroutines Reference Manual. [S.1.], 2010.

SOUZA, F. M. Estudo da microestrutura, da textura cristalográfica e da recristalização em chapas obtidas por lingotamento contínuo e semicontínuo da liga de alumínio AA4006. Tese (Doutorado) - Escola Politécnica da Universidade de São Paulo, 2012.

STANDRING, P. A universal classification of manufacturing processes for producing components from solid state metal. In: $14^{a}$ Conferência Internacional de Forjamento Brasil (30 Senafor). [S.1.: s.n.], 2010.

STOROJEVA, L.; PONGE, D.; KASPAR, R.; RAABE, D. Development of microstructure and texture of medium carbon steel during heavy warm deformation. Acta Materialia, v. 52, p. 2209-2220, 2004.

STöREN, S.; RICE, J. R. Localized necking in thin sheets. Journal of the Mechanics and Physics of Solids, v. 23, p. 421-441, 1975.

SWIFT, H. W. Plastic instability under plane stress. Journal of the Mechancis and Physics of Solids, v. 1, p. 1-18, 1952.

TAI, W.; YANG, B. A new damage mechanics criterion for ductile fracture. Engineering Fracture Mechanics, v. 27, p. 371-378, 1987.

TEIXEIRA, P.; SANTOS, A. D.; PIRES, F. M. A.; DE Sá, J. M. A. C. Finite element prediction of ductile fracture in sheet metal forming processes. Journal of Materials Processing Technology, v. 177, p. 278-281, 2006.

TENG, X. Numerical prediction of slant fracture with continuum damage mechanics. Engineering Fracture Mechanics, v. 75, p. 2020-2041, 2008.

THAKKAR, B. K.; PANDEY, P. C. A high-order isotropic continuum damage evolution model. International Journal of Damage Mechanics, v. 16, p. 403-426, 2007.

THOMPSON, A. W. Modeling of local strains in ductile fracture. Metallurgical and Materials Transactions A, v. 18, p. 1877-1886, 1987. 
TIAN, R.; CHAN, S.; TANG, S.; KOPACKZ, A. M.; WANG, J. S.; JOU, H. J.; SIAD, L.; LINGREN, L. E.; OLSON, G. B.; LIU, W. K. A multiresolution continuum simulation of the ductile fracture process. Journal of the Mechanics and Physics of Solids, v. 58, p. 1681-1700, 2010 .

TIE-JUN, W. Unified CDM model and local criterion for ductile fracture: I - unified CDM model for ductile fracture. Engineering Fracture Mechanics, v. 42, p. 177-183, 1992.

TIE-JUN, W. Unified CDM model and local criterion for ductile fracture: II - ductile fracture local criterion based on the CDM model. Engineering Fracture Mechanics, v. 42, p. 185-193, 1992. ISSN 00137944.

TIMOSHENKO, S.; GOODIER, J. N. Theory of elasticity. New York: McGraw-Hill Book Company, 1951.

TIPPER, C. F. The fracture of metals. Metallurgia, v. 39, p. 133-137, 1949.

TVEGAARD, V.; HUTCHINSON, J. W. Two mechanisms of ductile fracture: void by void growth versus multiple void interaction. International Journal of Solids and Structures, v. 39, p. 3581-3597, 2002.

VAZ JR., M.; DE SANTI JR., N.; DE SOUZA NETO, E. A. Numerical prediction of ductile failure onset under tensile and compressive stress states. International Journal of Damage Mechanics, v. 19, p. 175-795, 2010.

VOCE, E. The relationship between stress and strain for homogeneous deformation. Journal of the Institute of Metals, v. 74, p. 537-562, 1948.

VOLK, W.; HORA, P. New algorithm for a robust user-independent evaluation of beginning instability for the experimental flc determination. International Journal of Material Forming, v. 4, p. 339-346, 2011.

WILSDORF, H. G. F. The ductile fracture of metals: A microstructural viewpoint. Materials Science and Engineering, v. 59, p. 1-39, 1983. 


\section{APÊNDICE A - CONTRAÇÃO TENSORIAL DE SEGUNDA ORDEM}

Dado dois tensores de segunda ordem A e B, a contração de segunda ordem, indicada por A : B é o produto interno destes tensores, definido como:

$\mathbf{A}: \mathbf{B}=\left[\begin{array}{lll}a_{11} & a_{12} & a_{13} \\ a_{21} & a_{22} & a_{23} \\ a_{31} & a_{32} & a_{33}\end{array}\right]:\left[\begin{array}{lll}b_{11} & b_{12} & b_{13} \\ b_{21} & b_{22} & b_{23} \\ b_{31} & b_{32} & b_{33}\end{array}\right]=a_{11} b_{11}+a_{12} b_{12}+\ldots+a_{i j} b_{i j}+\ldots+a_{33} b_{33}$

que resulta em um escalar $c$.

É interessante notar que o traço de um tensor pode ser escrito como a contração de segunda ordem com a matriz identidade I de mesma ordem do tensor. Ou seja:

$$
\operatorname{tr}(\mathbf{A})=\mathbf{A}: \mathbf{I}=a_{11}+a_{22}+a_{33}
$$

Na notação de Einstein, a operação A : B pode ser escrita como:

$$
c=\mathbf{A}: \mathbf{B}=\sum_{i=1}^{3} \sum_{j=1}^{3} a_{i j} b_{i j}
$$

No caso de A ser um tensor de quarta ordem, como o tensor de rigidez da lei de Hooke generalizada, a contração de segunda ordem pode ser escrita como:

$$
c_{i j}=\mathbf{A}: \mathbf{B}=\sum_{k=1}^{3} \sum_{l=1}^{3} a_{i j k l} b_{k l}
$$

que resulta num tensor $\mathbf{C}$ de segunda ordem com componentes $c_{i j}$ 


\section{APÊNDICE B - DEDUÇÃO DA EXPRESSÃO DA TAXA DE DISSIPAÇÃO DA ENERGIA DE DEFORMAÇÃO}

Da teoria clássica da elasticidade (LANDAU; LIFSHITZ, 1964), combinada com o conceito de tensão efetiva de Leimaitre $\tilde{\boldsymbol{\sigma}}(1-D)=\boldsymbol{\sigma}$, podemos escrever a lei de Hooke da seguinte maneira:

$$
\varepsilon^{e}=\frac{1+\nu}{E} \frac{\boldsymbol{\sigma}^{D}}{1-D}+\frac{1-2 \nu}{E} \frac{\sigma_{H}}{1-D} \mathbf{I}
$$

onde I é a matriz identidade de ordem $3, \sigma_{H}$ é a tensão hidrostática e $\sigma^{D}$ é o tensor deviatório das tensões, definidos como:

$$
\begin{gathered}
\sigma_{H}=\frac{1}{3} \boldsymbol{\sigma}: \mathbf{I} \\
\boldsymbol{\sigma}^{D}=\boldsymbol{\sigma}-\sigma_{H} \mathbf{I}
\end{gathered}
$$

Da definição do trabalho de deformação elástico $\mathrm{d} W^{e}=\boldsymbol{\sigma}$ : $\mathrm{d} \varepsilon^{e}$, e separando a tensão em suas componentes deviatória e hidrostática:

$$
W^{e}=\int\left(\boldsymbol{\sigma}^{D}+\sigma_{H} \mathbf{I}\right):\left(\frac{1+\nu}{E} \frac{\mathrm{d} \boldsymbol{\sigma}^{D}}{1-D}+\frac{1-2 \nu}{E} \frac{\mathrm{d} \sigma_{H}}{1-D} \mathbf{I}\right)
$$

Assim, aplicando a propriedade distributiva na Eq. (B.3), obtemos:

$$
W^{e}=\frac{1+\nu}{E(1-D)} \int\left(\boldsymbol{\sigma}^{D}: \mathrm{d} \boldsymbol{\sigma}^{D}+\sigma_{H} \mathbf{I}: \mathrm{d} \boldsymbol{\sigma}^{D}\right)+\frac{1-2 \nu}{E(1-D)} \int\left(\boldsymbol{\sigma}^{D}: \mathbf{I} \mathrm{d} \sigma_{H}+\mathbf{I}: \mathbf{I} \sigma_{H} \mathrm{~d} \sigma_{H}\right)
$$

Efetuando as integrações:

$$
\begin{gathered}
\int\left(\boldsymbol{\sigma}^{D}: \mathrm{d} \boldsymbol{\sigma}^{D}+\sigma_{H} \mathbf{I}: \mathrm{d} \boldsymbol{\sigma}^{D}\right)=\frac{\boldsymbol{\sigma}^{D}: \boldsymbol{\sigma}^{D}}{2}+\sigma_{H} \boldsymbol{\sigma}^{D}: \mathbf{I} \\
\int\left(\boldsymbol{\sigma}^{D}: \mathbf{I} \mathrm{d} \sigma_{H}+\mathbf{I}: \mathbf{I} \sigma_{H} \mathrm{~d} \sigma_{H}\right)=\sigma_{H} \boldsymbol{\sigma}^{D}: \mathbf{I}+\mathbf{I}: \mathbf{I} \frac{\sigma_{H}^{2}}{2}
\end{gathered}
$$

Sabendo o resultado do produto interno $\mathbf{I}: \mathbf{I}=3$, demonstra-se que, como consequên- 
cia de sua definição, a parte deviatória de um tensor tem traço nulo, ou seja:

$$
\operatorname{tr}\left(\boldsymbol{\sigma}^{D}\right)=\boldsymbol{\sigma}^{D}: \mathbf{I}=\left(\boldsymbol{\sigma}-\sigma_{H} \mathbf{I}\right): \mathbf{I}=\boldsymbol{\sigma}: \mathbf{I}-\frac{1}{3}(\boldsymbol{\sigma}: \mathbf{I})(\mathbf{I}: \mathbf{I})=\boldsymbol{\sigma}: \mathbf{I}-\boldsymbol{\sigma}: \mathbf{I}=0
$$

Isto posto, o trabalho elástico pode ser escrito como:

$$
W^{e}=\frac{1+\nu}{E(1-D)} \frac{\boldsymbol{\sigma}^{D}: \boldsymbol{\sigma}^{D}}{2}+\frac{3(1-2 \nu)}{E(1-D)} \frac{\sigma_{H}^{2}}{2}
$$

Utilizando a definição da tensão equivalente de von Mises $\sigma_{e q}=\sqrt{(3 / 2) \boldsymbol{\sigma}^{D}: \boldsymbol{\sigma}^{D}} \mathrm{e}$ reordenando os termos, pode-se obter:

$$
W^{e}=\frac{2}{3} \frac{1+\nu}{2 E(1-D)} \sigma_{e q}^{2}+\frac{3(1-2 \nu)}{2 E(1-D)} \sigma_{H}^{2}
$$

e, finalmente:

$$
W^{e}=\frac{\sigma_{e q}^{2}}{2 E(1-D)}\left[\frac{2}{3}(1+\nu)+3(1-2 \nu)\left(\frac{\sigma_{H}}{\sigma_{e q}}\right)^{2}\right]
$$

Sabemos, pela Eq. (2.29b):

$$
-Y=\frac{W^{e}}{1-D}
$$

Logo, a taxa de dissipação da energia de deformação pode ser escrita como:

$$
-Y=\frac{\sigma_{e q}^{2}}{2 E(1-D)^{2}}\left[\frac{2}{3}(1+\nu)+3(1-2 \nu)\left(\frac{\sigma_{H}}{\sigma_{e q}}\right)^{2}\right]
$$




\section{APÊNDICE C - POTENCIAL DE DISSIPAÇÃO}

A função potencial de dissipação para o caso de elasto-plasticidade isotrópica do critério de von Mises é definida como (MAUGIN, 1992):

$$
f=\frac{\sigma_{e q}-R}{1-D}-\sigma_{0}
$$

onde $\sigma_{e q}=\sqrt{(3 / 2) \boldsymbol{\sigma}^{D}: \boldsymbol{\sigma}^{D}}$ é a tensão equivalente de von Mises, $\sigma_{0}$ é a tensão de escoamento inicial do material e $R=R(p)$ é o encruamento isotrópico, com $p$ sendo a deformação plástica acumulada.

Lemaitre (1996) afirma que deve haver um termo, desacoplado dos demais, que indique a contribuição do dano na dissipação, ou seja:

$$
F=\frac{\sigma_{e q}-R}{1-D}-\sigma_{0}+\phi(Y, D)
$$

Assim, a evolução do dano será dada pela seguinte equação:

$$
\dot{D}=-\frac{\partial F}{\partial Y} \dot{\lambda}=-\frac{\partial \phi}{\partial Y} \dot{\lambda}
$$

onde $\dot{\lambda}$ é um multiplicador plástico. Para determiná-lo, tomemos a evolução da deformação plástica, ou seja:

$$
\dot{\boldsymbol{\varepsilon}}^{p}=\frac{\partial F}{\partial \boldsymbol{\sigma}} \dot{\lambda}=\frac{\partial}{\partial \boldsymbol{\sigma}}\left(\frac{\sqrt{\frac{3}{2} \boldsymbol{\sigma}^{D}: \boldsymbol{\sigma}^{D}}}{1-D}\right) \dot{\lambda}=\frac{1}{2} \frac{\frac{3}{2} 2 \boldsymbol{\sigma}^{D}}{\sqrt{\frac{3}{2} \boldsymbol{\sigma}^{D}: \boldsymbol{\sigma}^{D}}} \frac{\dot{\lambda}}{1-D}=\frac{3}{2} \frac{\boldsymbol{\sigma}^{D}}{\sigma_{e q}} \frac{\dot{\lambda}}{1-D}
$$

Agora, combinemos a equação anterior com a definição da deformação plástica acumulada $p$ :

$$
\dot{p}=\sqrt{\frac{2}{3} \dot{\varepsilon}^{p}: \dot{\varepsilon}^{p}}
$$


Assim, pode-se escrever:

$$
\dot{p}=\sqrt{\frac{2}{3}} \frac{3}{2} \frac{\dot{\lambda}}{\sigma_{e q}(1-D)} \sqrt{\boldsymbol{\sigma}^{D}: \boldsymbol{\sigma}^{D}}=\frac{\dot{\lambda}}{1-D} \frac{\sqrt{\frac{3}{2} \boldsymbol{\sigma}^{D}: \boldsymbol{\sigma}^{D}}}{\sigma_{e q}}=\frac{\dot{\lambda}}{1-D}
$$

Para calcularmos analiticamente o valor do multiplicador plástico $\dot{\lambda}$, vamos considerar a condição de plasticidade de von Mises. Segundo esta condição, quando o material se plastifica, a função potencial $f$ deve ser permanentemente nula, ou seja:

$$
\begin{gathered}
f=\frac{\sigma_{e q}-R(p)}{1-D}-\sigma_{0}=0 \\
\dot{f}=0
\end{gathered}
$$

Desenvolvendo a Eq. (C.7b), obtemos:

$$
\dot{f}=\frac{\partial f}{\partial \boldsymbol{\sigma}}: \dot{\boldsymbol{\sigma}}+\frac{\partial f}{\partial D} \dot{D}+\frac{\partial f}{\partial R} \dot{R}=0
$$

Vamos calcular termo a termo:

$$
\begin{gathered}
\frac{\partial f}{\partial \boldsymbol{\sigma}}=\frac{3}{2} \frac{\boldsymbol{\sigma}^{D}}{\sigma_{e q}} \frac{1}{1-D} \\
\frac{\partial f}{\partial D}=\left(\sigma_{e q}-R\right) \frac{\partial}{\partial D}\left(\frac{1}{1-D}\right)=\frac{\sigma_{e q}-R}{(1-D)^{2}} \\
\frac{\partial f}{\partial R}=\frac{1}{(1-D)} \frac{\partial(-R)}{\partial R}=\frac{-1}{(1-D)}
\end{gathered}
$$

Substituindo $\dot{D}$ e $\dot{R}$ por:

$$
\begin{gathered}
\dot{D}=-\frac{\partial \phi}{\partial Y} \dot{\lambda} \\
\dot{R}=\frac{\partial R}{\partial p} \dot{p}=\frac{\partial R}{\partial p} \frac{\dot{\lambda}}{(1-D)}
\end{gathered}
$$

obtém-se:

$$
\frac{3}{2} \frac{\boldsymbol{\sigma}^{D}}{\sigma_{e q}}: \frac{\dot{\boldsymbol{\sigma}}}{1-D}-\frac{\sigma_{e q}-R}{(1-D)^{2}} \frac{\partial \phi}{\partial Y} \dot{\lambda}-\frac{\partial R}{\partial p} \frac{\dot{\lambda}}{(1-D)^{2}}=0
$$

o que, substituindo $\sigma_{0}=\left(\sigma_{e q}-R\right) /(1-D)$, resulta em:

$$
\dot{\lambda}=\frac{3}{2}\left(\frac{\boldsymbol{\sigma}^{D}: \dot{\boldsymbol{\sigma}}}{\sigma_{e q}}\right) \frac{(1-D)}{\frac{\partial \phi}{\partial Y} \sigma_{0}(1-D)+\frac{\partial R}{\partial p}}
$$




\section{APÊNDICE D - FORMULAÇÃO ACOPLADA DAS EQUAÇÕES DE EVOLUÇÃO DO DANO PELO MÉTODO DOS ELEMENTOS FINITOS}

Como visto no capítulo 2, o equacionamento obtido por Lemaitre para a evolução do dano acumulado em um elemento sólido qualquer depende de, e também altera, o tensor das tensões deste elemento. Sendo assim, deve-se resolver os problemas da plasticidade e do dano de maneira acoplada, de modo a obter a resposta do material a determinado carregamento. $\mathrm{O}$ equacionamento aqui apresentado pode ser encontrado em Lemaitre (1996).

Como hipótese, assumiremos que o encruamento do material se dá de maneira isotrópica e sem dependência da taxa de deformação ao qual é submetido. O critério de plasticidade de von Mises acoplado com o dano diz que o regime plástico no material acontece quando:

$$
f=\frac{\sigma_{e q}}{1-D}-\sigma_{e s c}\left(\varepsilon^{p}\right)=0
$$

onde $\sigma_{e q}$ é a tensão equivalente de von Mises e $\sigma_{e s c}\left(\varepsilon^{p}\right)$ é a tensão de escoamento dependente da deformação plástica, dada pela equação de Ludwig:

$$
\sigma_{e s c}\left(\varepsilon^{p}\right)=\sigma_{e s c, 0}+K\left(\varepsilon^{p}\right)^{n}
$$

Caso a condição de plasticidade seja satisfeita, o problema passa a ser determinar qual é a parcela do incremento de deformação total que corresponde ao incremento de deformação plástica em cada ponto. A parcela elástica da tensão é dada pela lei de Hooke generalizada:

$$
\sigma_{i j}=(1-D)\left(\Lambda \delta_{i j} \varepsilon_{k k}^{e}+2 G \varepsilon_{i j}^{e}\right)
$$

onde $\delta_{i j}$ é a função delta de Dirac, $\Lambda=\frac{E \nu}{(1+\nu)(1-2 \nu)}$ e $G=\frac{E}{2(1+\nu)}$ são as constantes de Lamé e 
os índices $i j$ se referem à notação de Einstein.

O incremento plástico é dado por:

$$
\dot{\varepsilon}_{i j}^{p}=\frac{\partial f}{\partial \sigma_{i j}} \dot{\lambda}=\frac{3}{2} \frac{\sigma_{i j}^{D}}{\sigma_{e q}} \frac{\dot{\lambda}}{1-D}
$$

com $\dot{\lambda}$ sendo o multiplicador plástico associado à função $f$ e $\sigma_{i j}^{D}$ é o tensor deviatório das tensões, definido como:

$$
\sigma_{i j}^{D}=\sigma_{i j}-\frac{1}{3} \delta_{i j} \sigma_{k k}
$$

Podemos mostrar, partindo da definição da deformação plástica acumulada $p$ :

$$
\dot{p}=\sqrt{\frac{2}{3} \dot{\varepsilon}_{i j}^{p} \dot{\varepsilon}_{i j}^{p}}
$$

em conjunto com a Eq. (D.4) que $\dot{p}=\frac{\dot{\lambda}}{1-D}$. Assim, a Eq. (D.4) se torna:

$$
\dot{\varepsilon}_{i j}^{p}=\frac{3}{2} \frac{\sigma_{i j}^{D}}{\sigma_{e q}} \dot{p}
$$

A evolução do dano no material é dada pela Eq. (2.44):

$$
\dot{D}=\frac{\sigma_{e q}^{2} R_{v} \dot{p}}{2 E S(1-D)^{2}} \mathrm{H}\left(p-p_{D}\right)
$$

Resolvendo essas equações de modo a encontrar a deformação plástica acumulada correta, conseguimos obter os incrementos desejados. A seguir é apresentado o algoritmo implementado na subrotina VUMAT para utilização com o software Abaqus/Explicit.

\section{D.1 Algoritmo numérico}

O algoritmo utilizado é baseado no trabalho desenvolvido por Lee e Pourboghrat (2005) e utiliza a discretização de Euler explícita. Os índices $t$ dizem respeito ao passo de tempo anterior e $t+\Delta t$ ao passo de tempo atual.

Primeiramente, calculamos a parcela do tensor das tensões correspondente ao incremento elástico. Para isso, consideramos que $\Delta \varepsilon_{i j}=\Delta \varepsilon_{i j}^{e}$, ou seja, toda deformação do passo de tempo é elástica.

$$
\sigma_{i j}^{\text {teste }}=\sigma_{i j, t}+\left(1-D_{t}\right)\left(\Lambda \delta_{i j} \Delta \varepsilon_{i j}+2 G \Delta \varepsilon_{i j}\right)
$$


É efetuada a verificação da Eq. (D.1) utilizando-se o tensor $\sigma_{i j}^{\text {teste }}$. Caso $f<0$, então as grandezas são atualizadas da seguinte maneira:

$$
\begin{gathered}
\sigma_{i j, t+\Delta t}=\sigma_{i j}^{t e s t e} \\
p_{t+\Delta t}=p_{t} \\
D_{t+\Delta t}=D_{t}
\end{gathered}
$$

Caso contrário, para manter a consistência $(f=0)$, devemos corrigir a parte deviatória do tensor das tensões. Tal correção é feita da seguinte maneira:

$$
\sigma_{i j, t+\Delta t}^{D}=\sigma_{i j}^{t e s t e}+c_{0}
$$

onde $c_{0}$ é a correção. Como a condição $f=0$ deve ser satisfeita, temos que:

$$
\sigma_{i j, t+\Delta t}^{D}=\sigma_{i j, t}^{D}+2 G\left(1-D_{t}\right)\left(\Delta \varepsilon_{i j}^{e}\right)
$$

Igualando Eq. (D.13) e Eq. (D.14), utilizando a Eq. (D.9) e sabendo que $\Delta \varepsilon_{i j}=\Delta \varepsilon_{i j}^{e}+\Delta \varepsilon_{i j}^{p}$, temos:

$$
c_{0}=-2 G(1-D) \Delta \varepsilon_{i j}^{p}=-2 G(1-D) \frac{3}{2}\left[\frac{\sigma_{i j}^{D}}{\sigma_{e q}}\right]^{\text {teste }} \Delta p
$$

A relação $\left[\frac{\sigma_{i j}^{D}}{\sigma_{e q}}\right]$ dá as direções normais à superfície de escoamento no campo das tensões. Lee e Pourboghrat (2005) afirmam que:

$$
\left[\frac{\sigma_{i j}^{D}}{\sigma_{e q}}\right]^{t e s t e}=\left[\frac{\sigma_{i j}^{D}}{\sigma_{e q}}\right]^{t+\Delta t}=q_{i j}
$$

De Eq. (D.1), tiramos que:

$$
\sigma_{e q, t+\Delta t}=\left(1-D_{t+\Delta t}\right) \sigma_{e s c, t+\Delta t}
$$

Multiplicando ambos os lados da equação pelo tensor $\sigma_{i j, t+\Delta t}^{D}$ e remanejando os termos, obtemos:

$$
\sigma_{i j, t+\Delta t}^{D}=\left(1-D_{t+\Delta t}\right) \sigma_{e s c, t+\Delta t}\left[\frac{\sigma_{i j}^{D}}{\sigma_{e q}}\right]^{t+\Delta t}=\left(1-D_{t+\Delta t}\right)\left(\sigma_{e s c, t+\Delta t}\right) q_{i j}
$$

Utilizando-se a dicretização explícita de Euler, temos que:

$$
D_{t+\Delta t}=D_{t}+\frac{\partial D}{\partial p} \Delta p=D_{t}+\alpha_{t} \Delta p
$$


e, utilizando a Eq. (D.8):

$$
\alpha_{t}=\frac{\sigma_{e q, t}^{2} R_{v}}{2 E S\left(1-D_{t}\right)^{2}}
$$

quando a deformação plástica acumulada $p$ for maior que um valor mínimo $p_{D}$. Caso contrário, $\alpha$ tem valor nulo, ou seja, o dano tem incremento nulo.

Também obtemos:

$$
\sigma_{e s c, t+\Delta t}=\sigma_{e s c, t}+\frac{\partial \sigma_{e s c}}{\partial p} \Delta p=\sigma_{e s c, t}+h_{t} \Delta p
$$

e, utilizando a Eq. (D.2):

$$
h_{t}=K n p_{t}^{(n-1)}
$$

Igualando as equações Eq. (D.13) e Eq. (D.18), obtemos uma equação quadrática para calcular o incremento da deformação plástica acumulada $\Delta p$ :

$$
A(\Delta p)^{2}+B(\Delta p)+C=0
$$

com:

$$
\begin{gathered}
A=\alpha_{t} h_{t} \\
B=\alpha_{t} \sigma_{e s c, t}-\left(1-D_{t}\right)\left(h_{t}+3 G\right) \\
C=\sigma_{e q}^{t e s t e}-\sigma_{e s c, t}\left(1-D_{t}\right)
\end{gathered}
$$

O incremento $\Delta p$ é tomado como a menor raiz positiva da Eq. (D.23). Assim, atualizamos as grandezas da seguinte maneira:

$$
\begin{gathered}
\sigma_{i j, t+\Delta t}=\sigma_{i j}^{t e s t e}-2 G\left(1-D_{t}\right) \Delta p \\
p_{t+\Delta t}=p_{t}+\Delta p \\
D_{t+\Delta t}=D_{t}+\alpha_{t} \Delta p
\end{gathered}
$$




\section{APÊNDICE E - SUBROTINA VUMAT PARA CÁLCULO DA EVOLUÇÃO DO DANO UTILIZANDO O ABAQUS/EXPLICIT}

SUBROUTINE VUMAT (

C Read only -

1 NBLOCK, NDIR, NSHR, NSTATEV, NFIELDV, NPROPS, LANNEAL,

2 Steptime, totaltime, Dt, CMNAME, COORDMP, CHARLENGTH,

3 PROPS, DENSITY, STRAININC, RELSPININC,

4 TEMPOLD, STRETCHOLD, DEFGRADOLD, FIELDOLD,

5 STRESSOLD, STATEOLD, ENERINTERNOLD, ENERINELASOLD,

6 TEMPNEW, STRETCHNEW, DEFGRADNEW, FIELDNEW,

C Write only -

7 STRESSNEW, STATENEW， ENERINTERNNEW， ENERINELASNEW)

C

INCLUDE 'VABA_PARAM.INC'

C

DIMENSION PROPS (NPROPS), DENSITY(NBLOCK), COORDMP (NBLOCK),

1 CHARLENGTH (NBLOCK), STRAININC (NBLOCK, NDIR+NSHR),

2 RELSPININC (NBLOCK, NSHR), TEMPOLD (NBLOCK),

3 STRETCHOLD (NBLOCK, NDIR+NSHR), DEFGRADOLD (NBLOCK, NDIR+NSHR+NSHR),

4 FIELDOLD (NBLOCK, NFIELDV), STRESSOLD (NBLOCK, NDIR+NSHR),

5 STATEOLD (NBLOCK, NSTATEV), ENERINTERNOLD (NBLOCK),

6 ENERINELASOLD (NBLOCK), TEMPNEW (NBLOCK),

7 STRETCHNEW (NBLOCK, NDIR+NSHR), DEFGRADNEW (NBLOCK, NDIR+NSHR+NSHR),

8 FIELDNEW (NBLOCK, NFIELDV), STRESSNEW (NBLOCK, NDIR+NSHR),

9 STATENEW(NBLOCK, NSTATEV), ENERINTERNNEW(NBLOCK),

1 ENERINELASNEW (NBLOCK)

C

CHARACTER $* 8$ CMNAME

DIMENSION flOw(NDIR+NSHR), strial (NDIR+NSHR) 


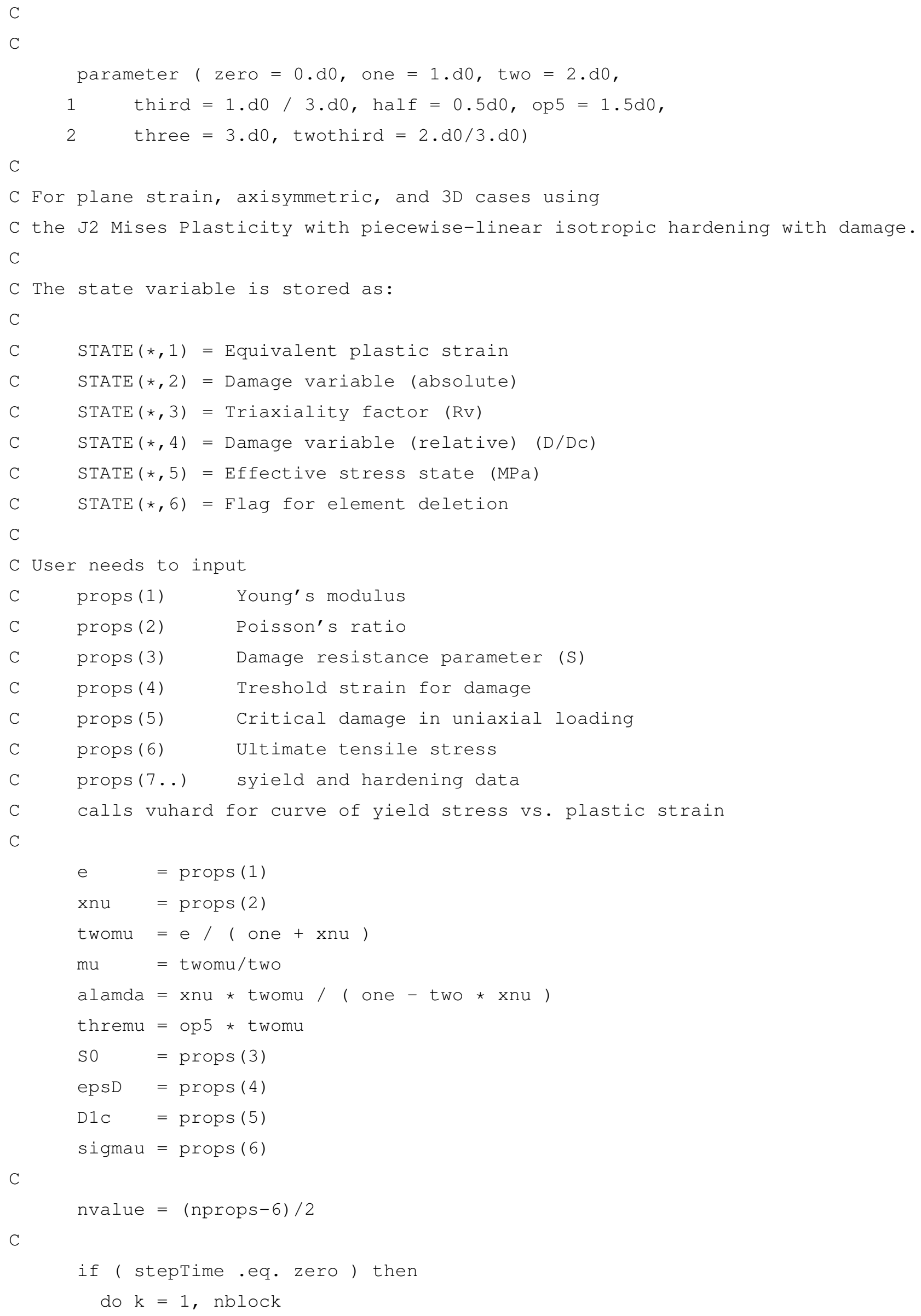




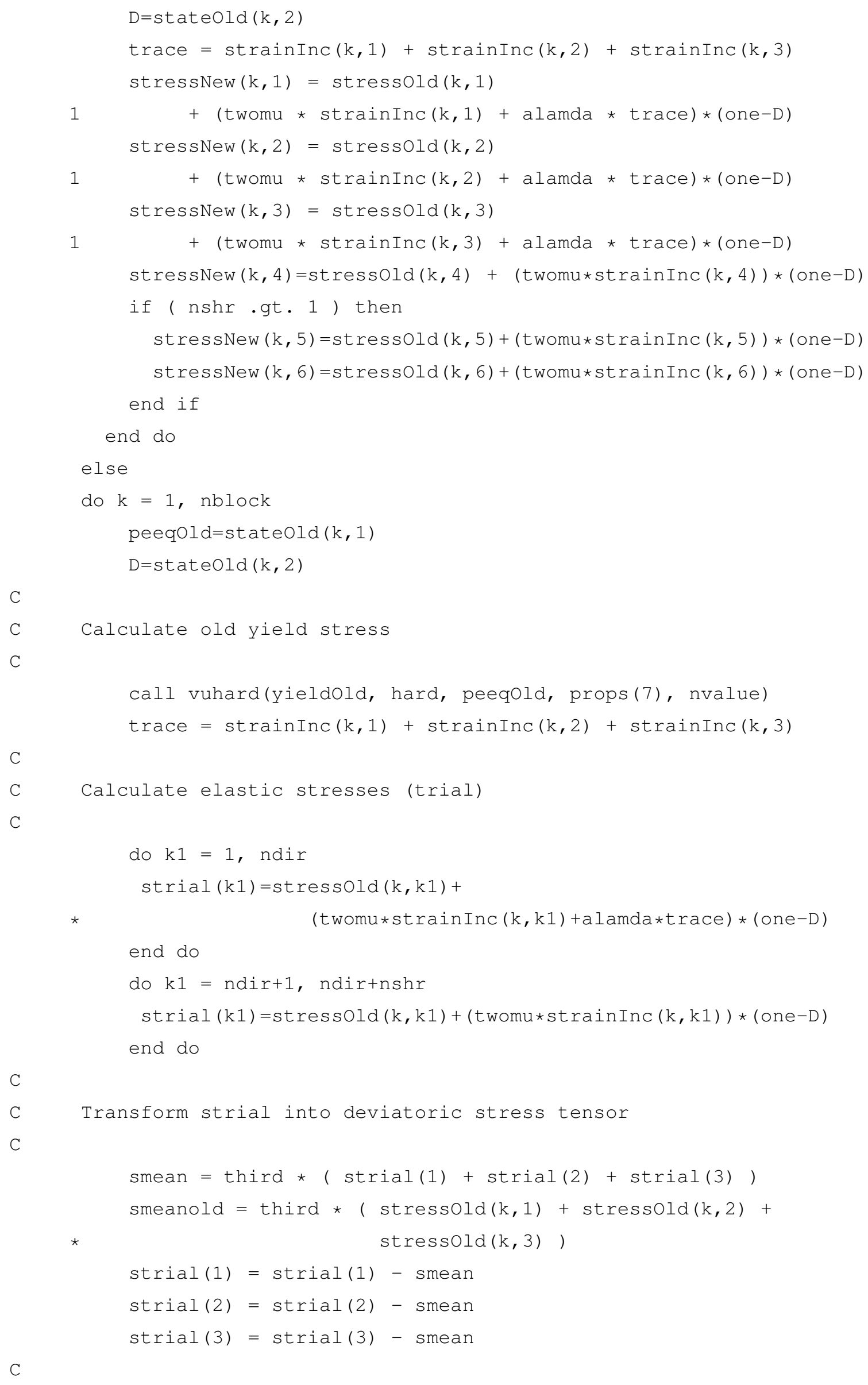




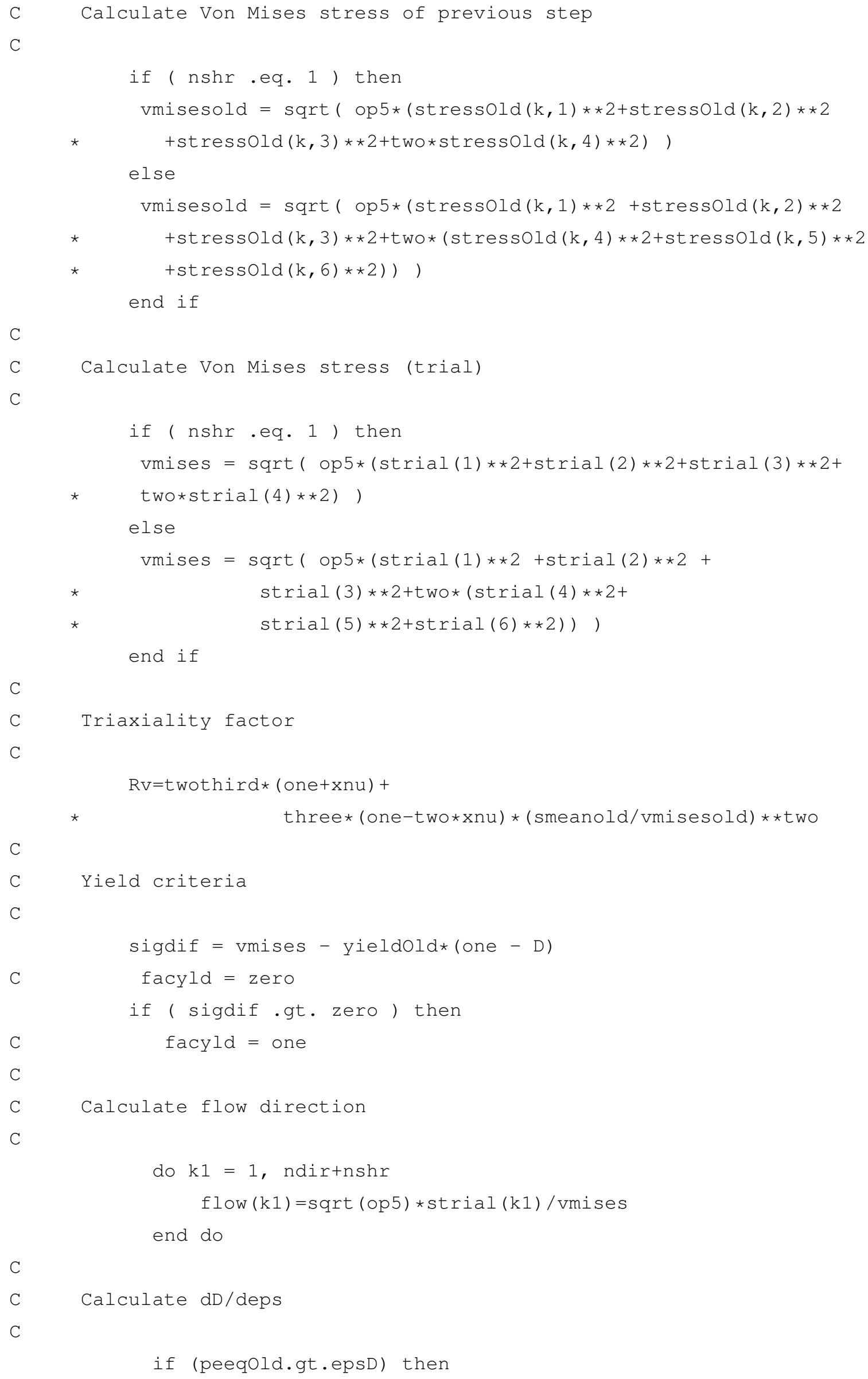




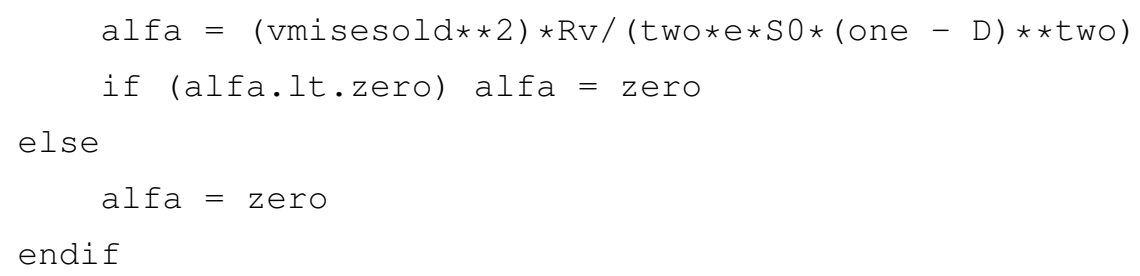




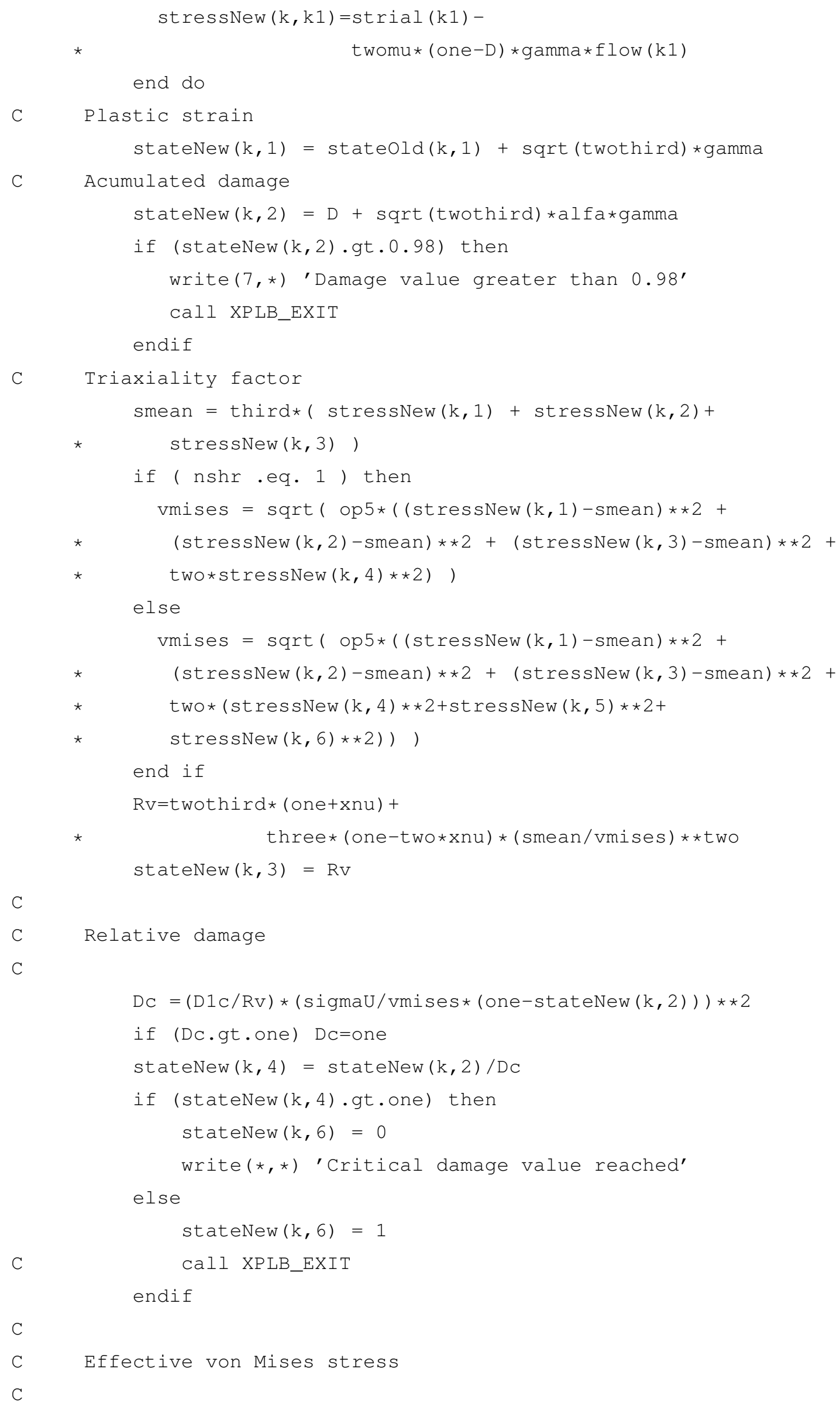




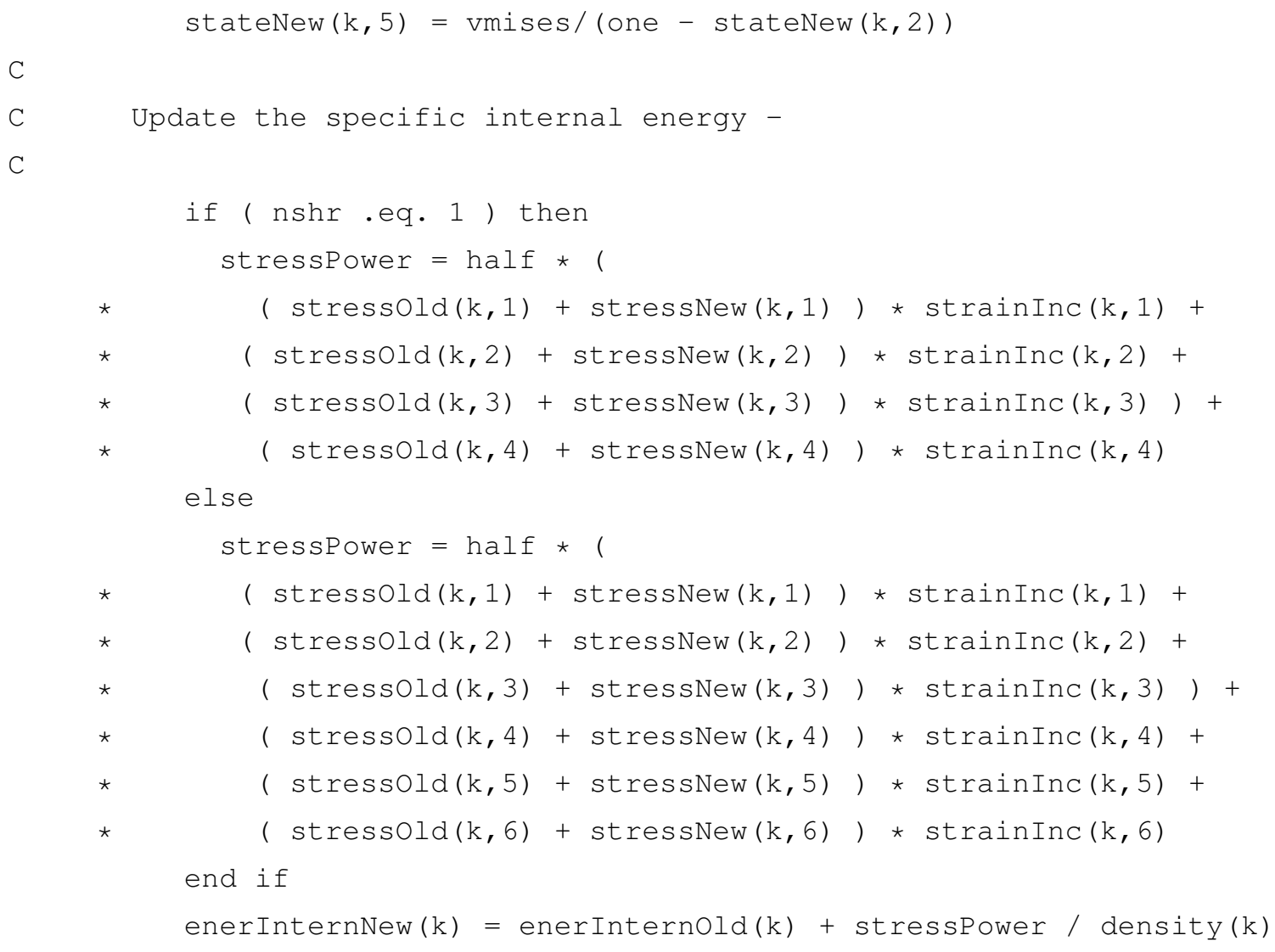

C

C

C

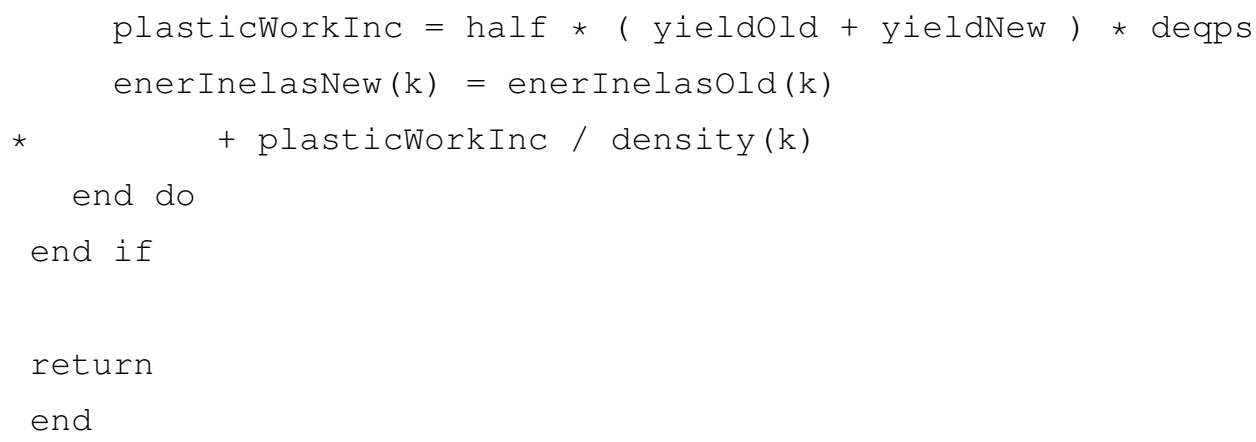


C

if (nvalue.gt.1) then

do $k 1=1$, nvalue-1

eqpl $1=$ table $(2, \mathrm{k} 1+1)$

if (eqplas.lt.eqpll) then

eqpl $0=$ table $(2, k 1)$

C

C

C

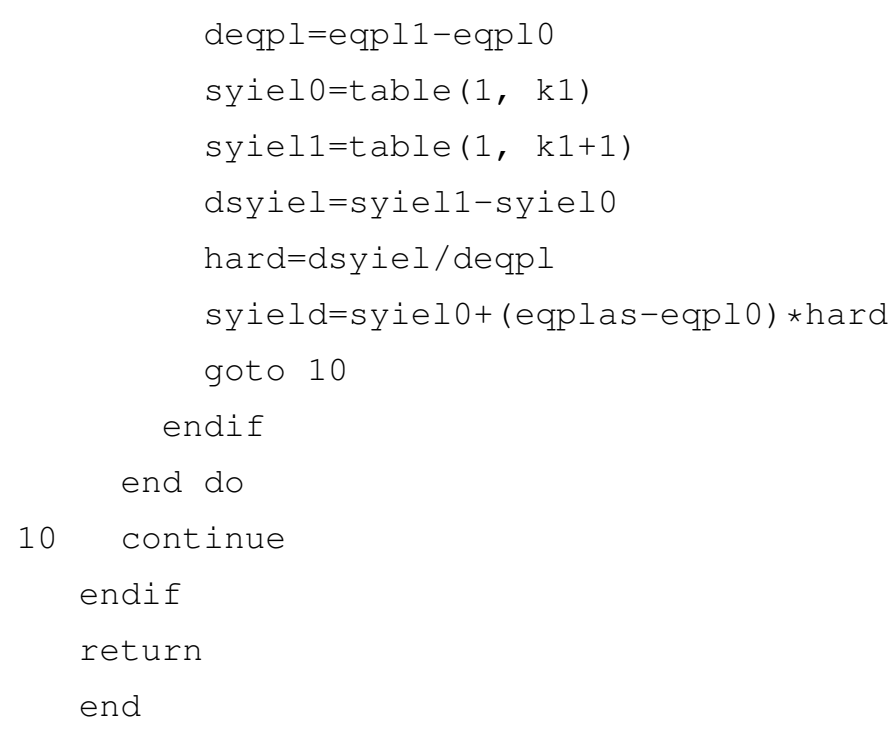




\section{APÊNDICE F - MANUAL PARA USO DA SUBROTINA VUMAT NO ABAQUS/EXPLICIT}

Nesta seção mostramos como utilizar a subrotina VUMAT com o software Abaqus e o passo a passo da montagem do caso para simulação do ensaio de tração com o modelo de dano acoplado ao estudo de tensões e deformações do material.

Em primeiro lugar, o Intel Visual Fortran Compiler, versão 11 ou superior, deve estar instalado.

Importar o modelo do corpo de prova: o modelo pode ser desenhado em qualquer software do tipo CAD e deve ser exportado no formato IGES (extensão .igs).

Criação da malha: a malha é criada por meio do comando seed edges, definindo o tamanho médio dos elementos finitos. Para a região de teste, uma dimensão de $0,5 \mathrm{~mm}$ foi utilizada. Para a região das garras, utilizamos 2,5 mm. A malha nestas duas regiões é estruturada. Na região do raio de curvatura utilizamos malha não estruturada para acomodar a diferença de dimensões do elemento. A malha é extrudada, com dois elementos na direção da espessura.

Definição do material: na definição do modelo do material devemos indicar o valor da densidade. Além disso, para correto uso da subrotina VUMAT, as variáveis definidas pelo usuário devem ser indicadas, por meio do comando General -> Depvar. No nosso modelo, são utilizadas 6 variáveis definidas pelo usuário, as quais são, respectivamente, deformação plástica acumulada $p$, variável de dano absoluta $D$, fator de triaxialidade $R_{v}$, variável de dano relativa $D / D_{c}$, tensão de von Mises efetiva $\sigma_{e q} /(1-D)$ e finalmente o flag de indicação se o dano no material excedeu o valor crítico. A sexta variável também é indicada como a que controla a deleção dos elementos. Esta variável tem valor inicial 1 e quando a relação $D>D_{c}$ é satisfeita, ela tem valor determinado como zero, indicando que a rigidez do elemento deve ser definida como nula pelo solver, simulando a fratura do material. As propriedades mecânicas são definidas por meio da aba General->User material. Nossa rotina VUMAT pede que as propriedades mecânicas sejam inseridas na seguinte sequência: módulo de Young $E$, coeficiente de Poisson $\nu$, parâmetro de resistência ao dano $S$, deformação limite para início de dano $\varepsilon_{D}$, dano crítico unidimensional $D_{1 c}$, tensão limite de resistência $\sigma_{u}$, curva de escoamento $\sigma_{e s c}\left(\varepsilon_{1}^{p}\right), \varepsilon_{1}^{p}, \sigma_{e s c}\left(\varepsilon_{2}^{p}\right), \varepsilon_{2}^{p}, \sigma_{e s c}\left(\varepsilon_{3}^{p}\right), \varepsilon_{3}^{p}, \ldots$

Definição da montagem: é preciso definir uma montagem com todos as peças que serão analisadas. Como nossa simulação só terá o corpo de prova, apenas tal modelo deve ser adicionado à montagem.

Definição da seção: a seção definirá o tipo de elemento utilizado pelo solver. No caso, optamos por elementos sólidos e homogêneos (isotrópicos). Também neste passo associamos o material definido anteriormente 
ao modelo do corpo de prova.

Definição dos resultados a serem armazenados: neste passo são definidos quais variáveis deverão ser salvas para posterior pós-processamento. Além das tradicionais variáveis de tensão, deslocamentos, forças, energias e deformações, devemos assinalar a opção $S D V$, que corresponde às variáveis definidas pelo usuário na subrotina VUMAT.

Definição do step: aqui definimos que a análise será feita por um método dinâmico e explícito. As opções sobre o incremento temporal podem ser deixadas no default, que considera um incremento automático de modo a garantir estabilidade e convergência do método numérico.

Definição das condições de contorno: aqui definimos que as condições que simularão a máquina de ensaio. A garra esquerda será engastada, ou seja, os deslocamentos serão restringidos em todas as direções. A garra direita terá deslocamentos transversal e normal restringidos, enquanto que o deslocamento longitudinal é colocado com um valor final de $20 \mathrm{~mm}$, com uma curva de carregamento linear, definida na opção amplitude.

Definição do job: neste passo editamos as definições do job. Aqui indicamos que usaremos a subrotina VUMAT nas simulação. Isso é feito na aba General-> user subroutine file, no qual o arquivo .for com as instruções na linguagem Fortran deve ser selecionado.

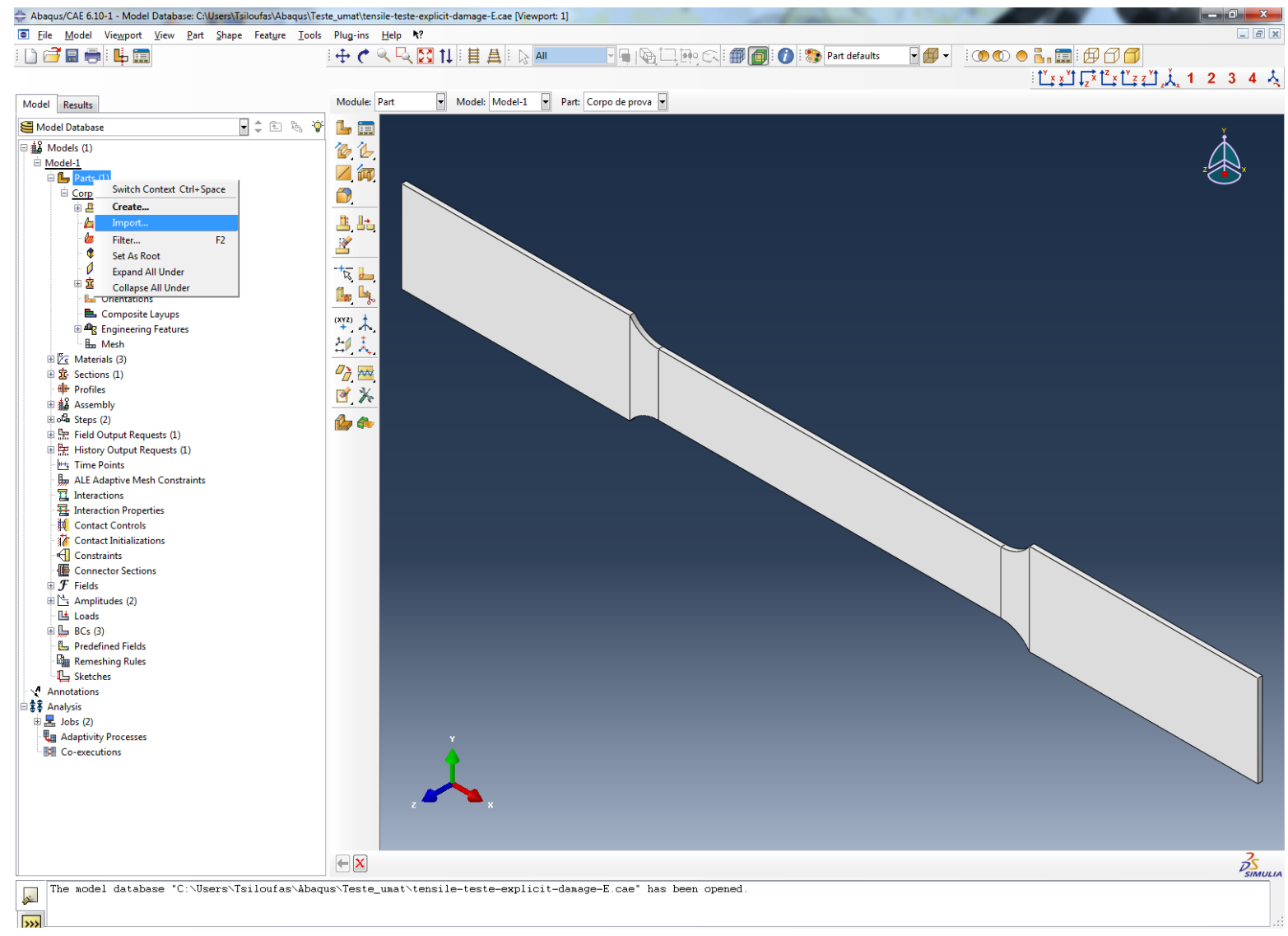

Figura F.1: Importando modelo IGES. 


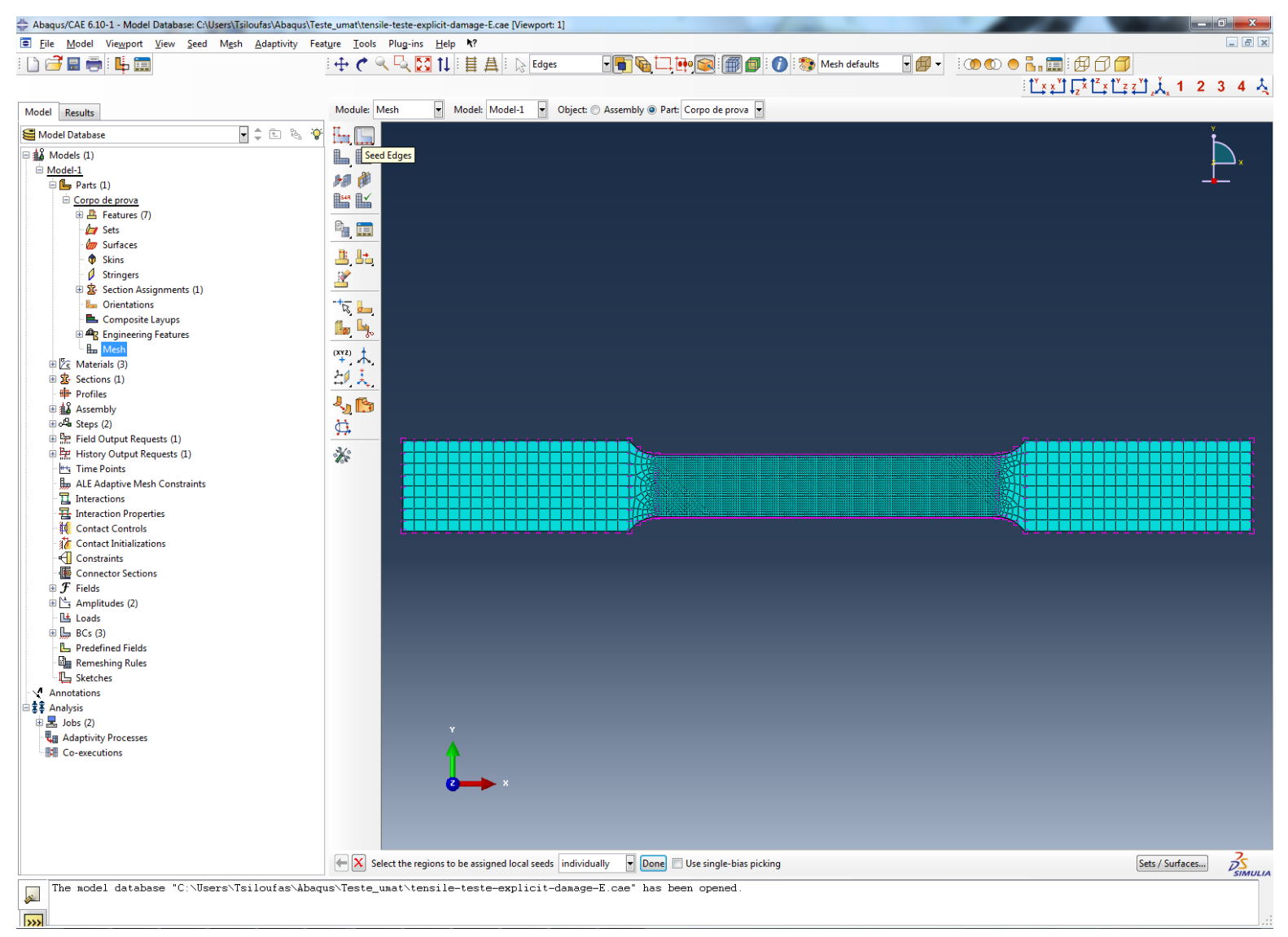

Figura F.2: Criação da malha. 


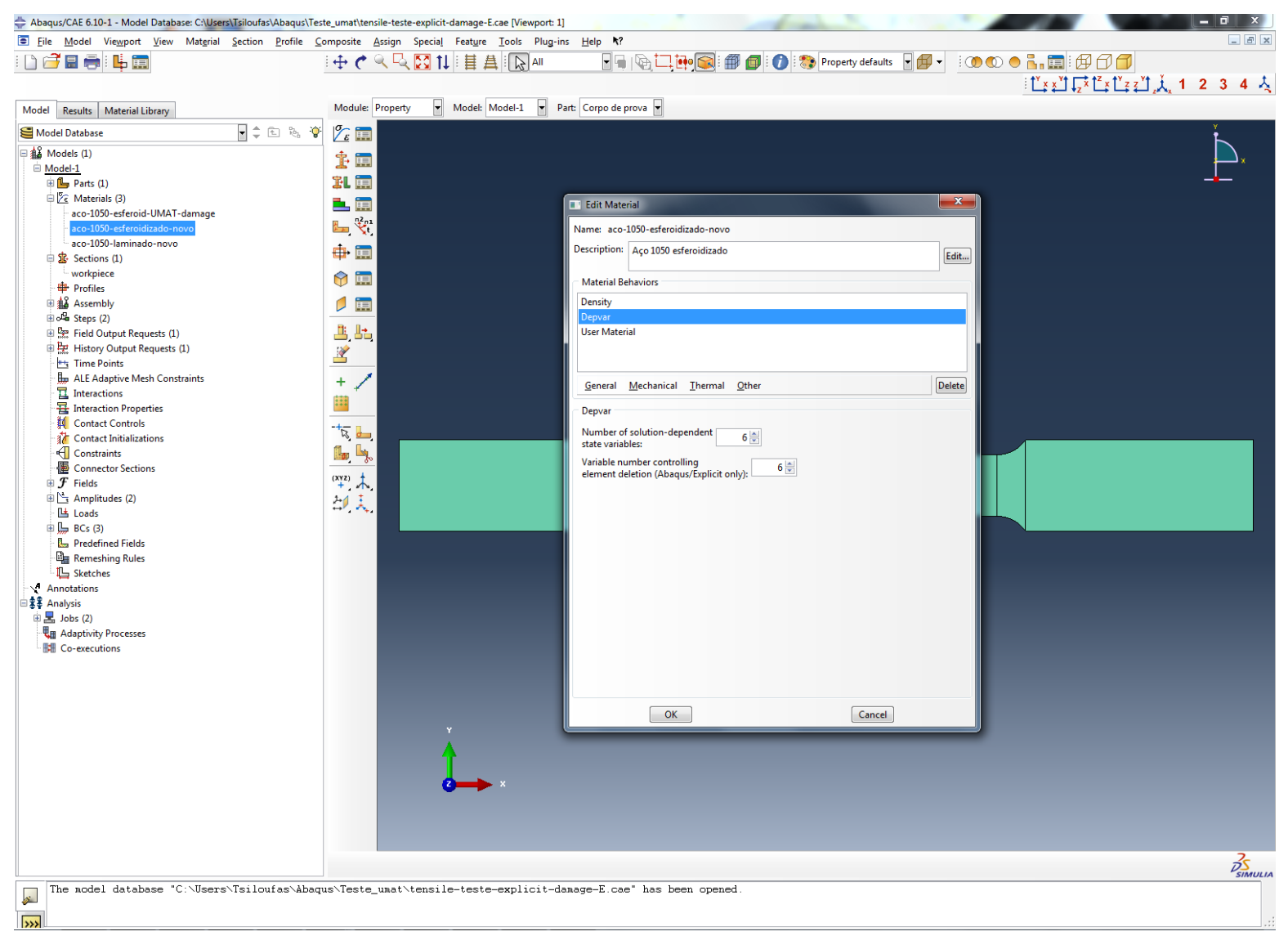

Figura F.3: Definição do modelo de material - variáveis definidas pelo usuário. 


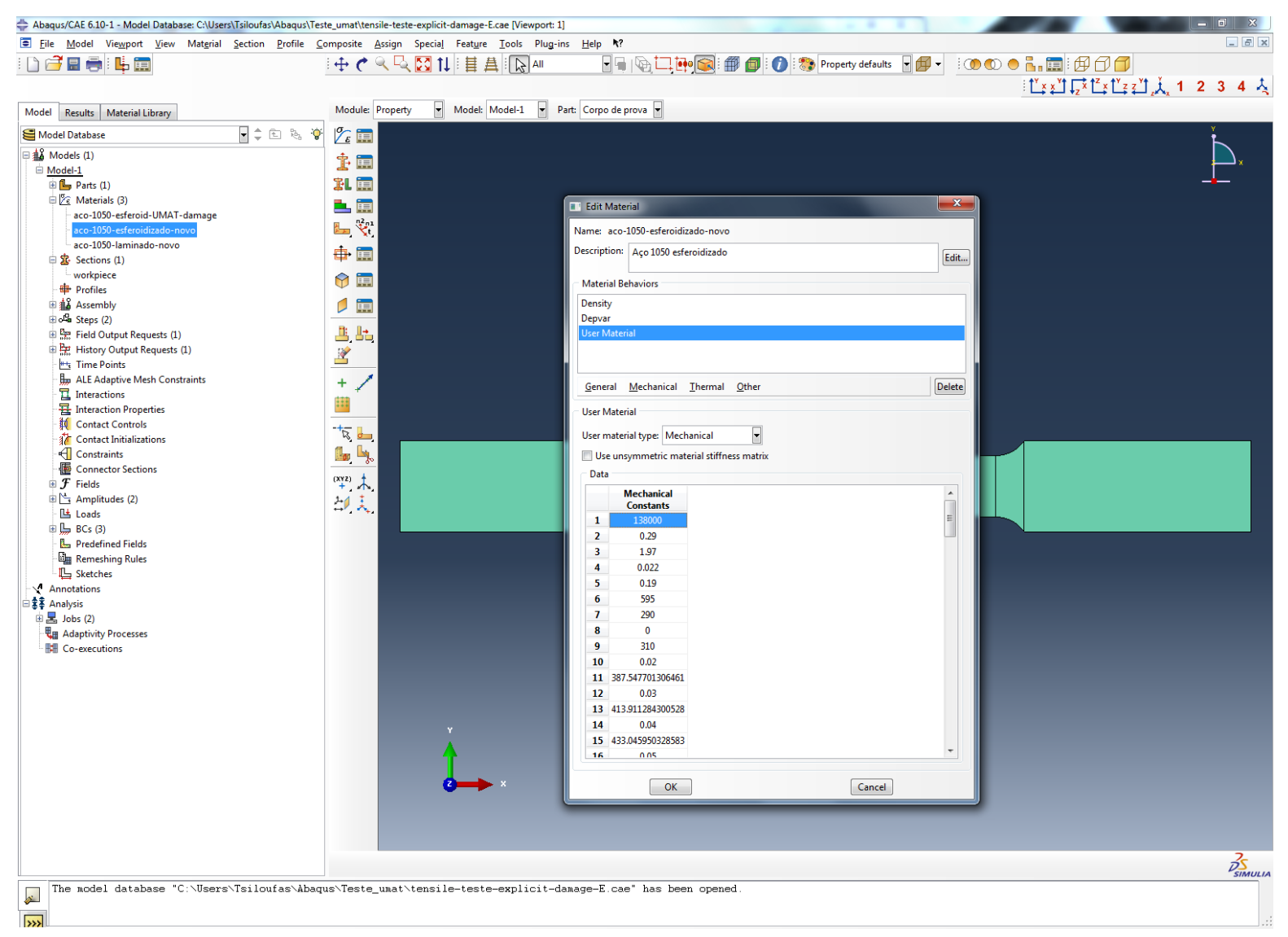

Figura F.4: Definição do modelo de material - propriedades mecânicas. 


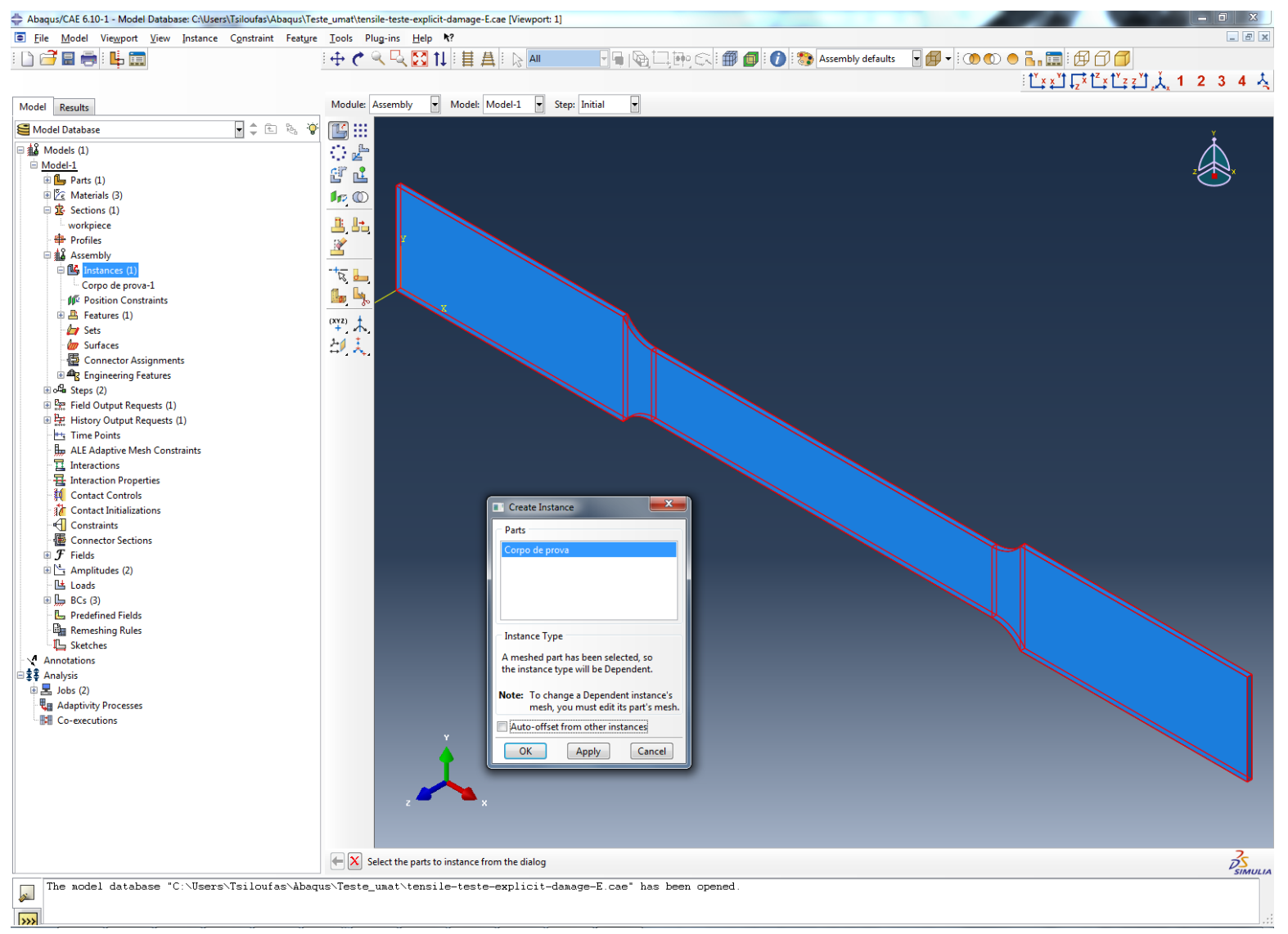

Figura F.5: Definição da montagem. 


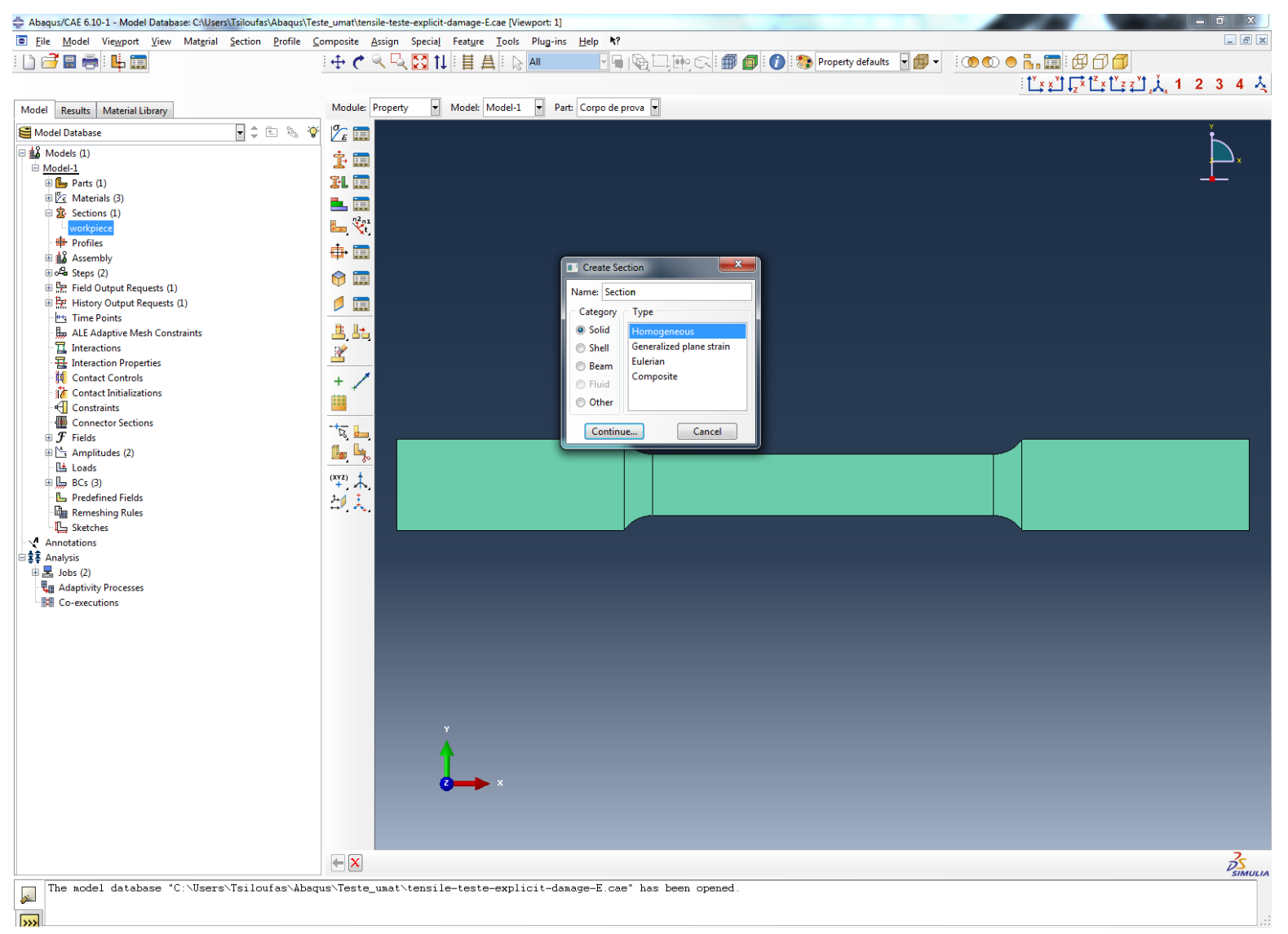

Figura F.6: Definição da seção - tipo de elemento. 


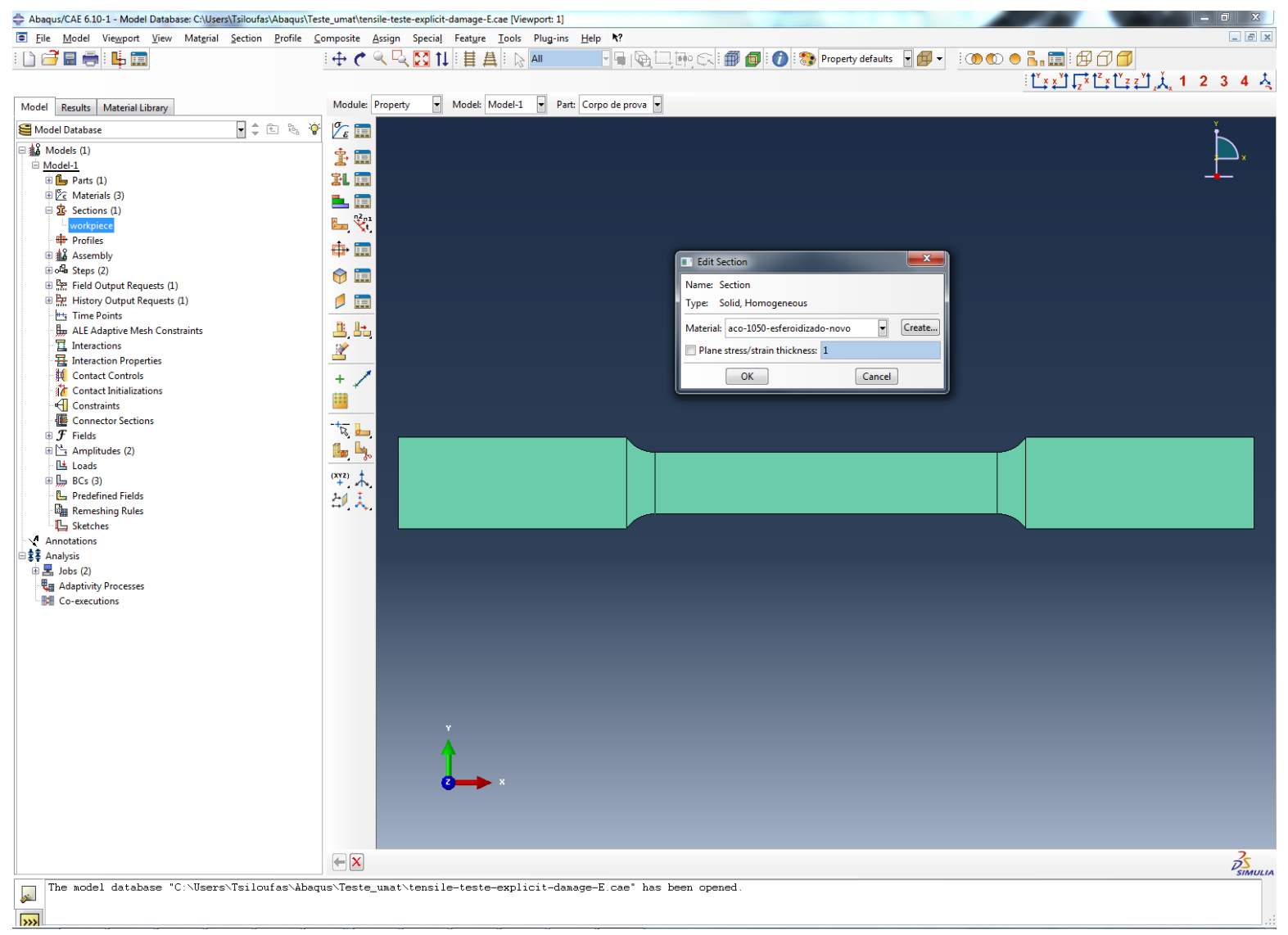

Figura F.7: Definição da seção - associar material ao modelo. 


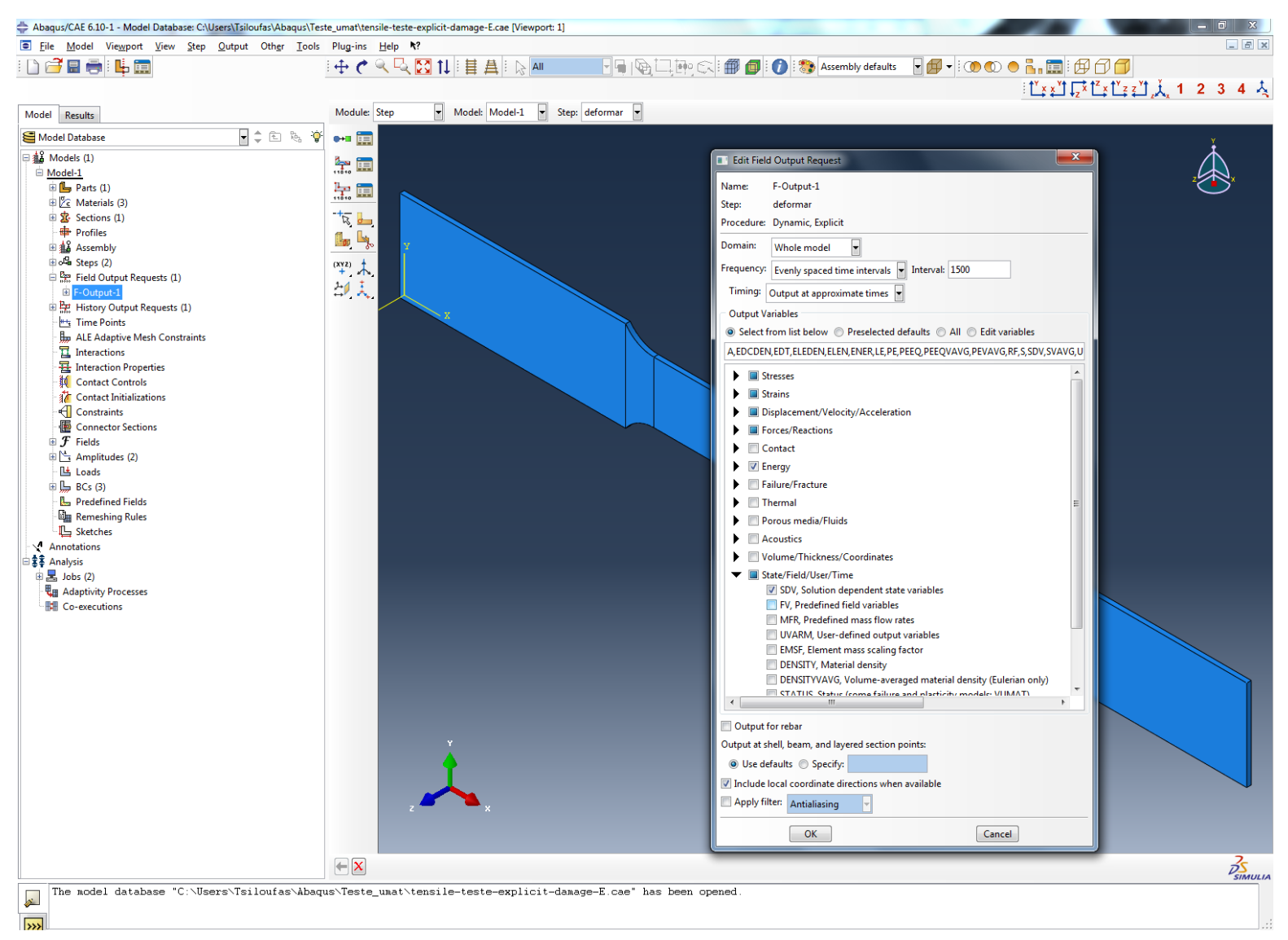

Figura F.8: Definição dos resultados a serem salvos. 


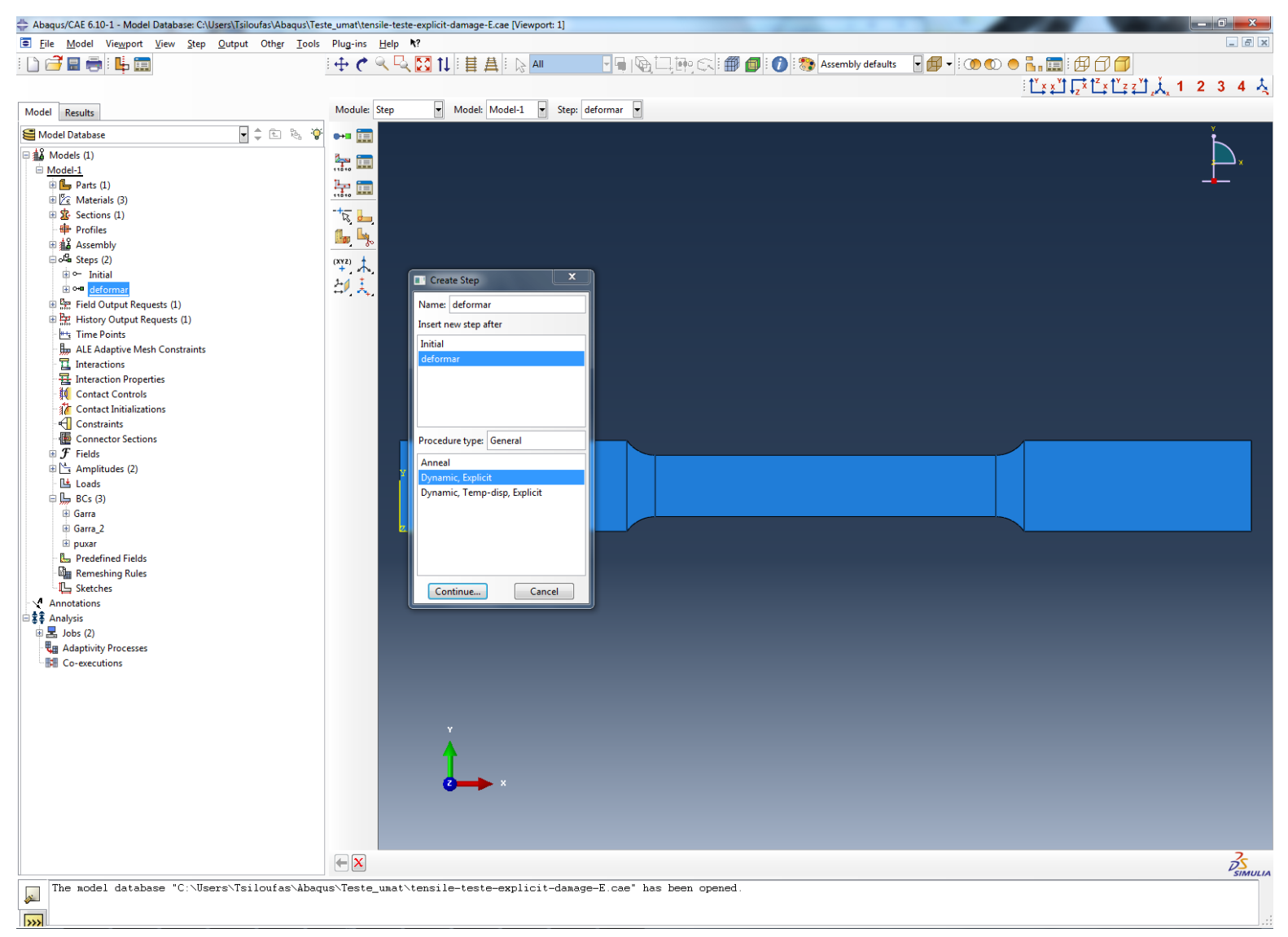

Figura F.9: Definição do step. 


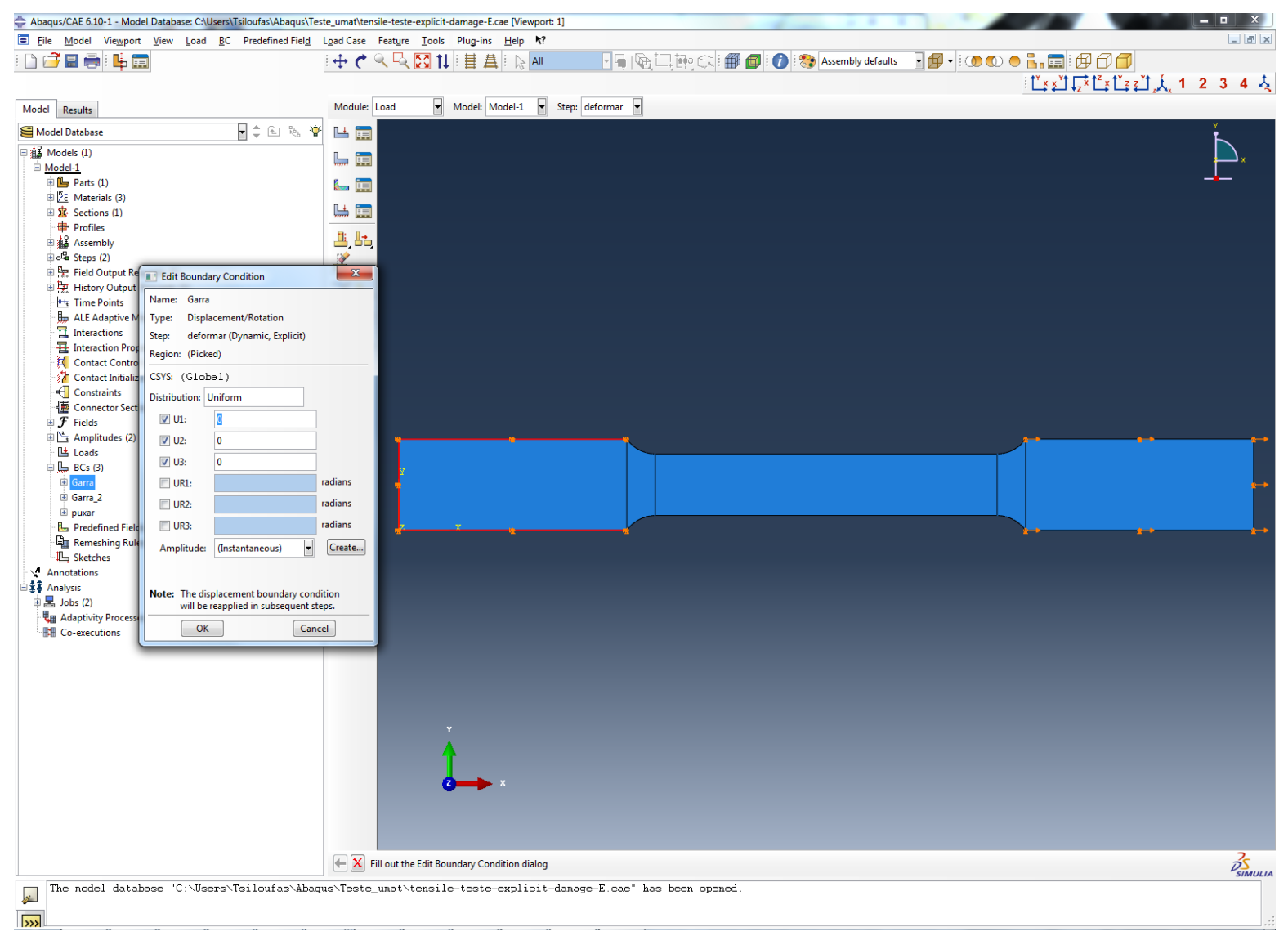

Figura F.10: Definição da condição de contorno na garra esquerda. 


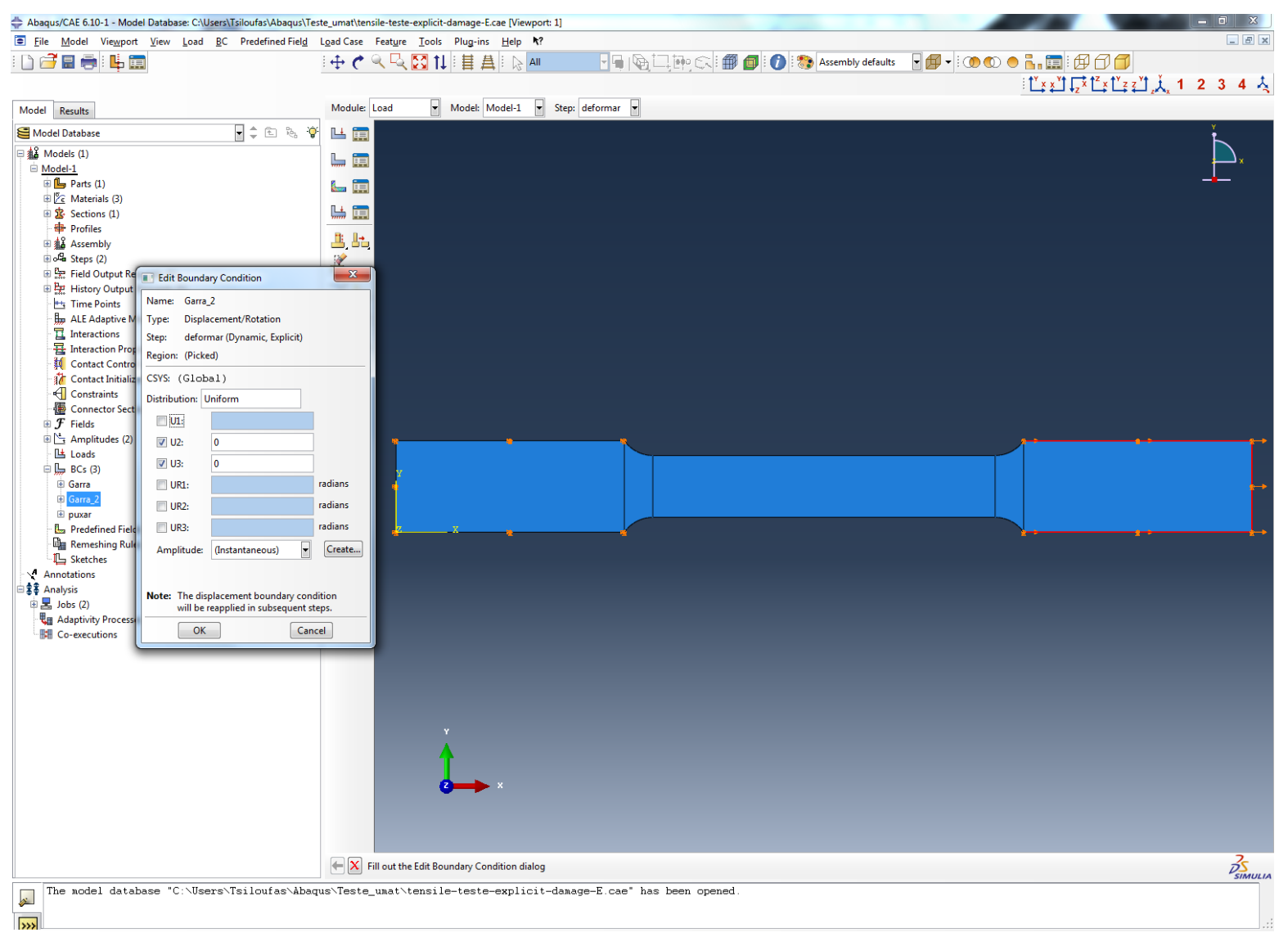

Figura F.11: Definição da condição de contorno na garra direita. 


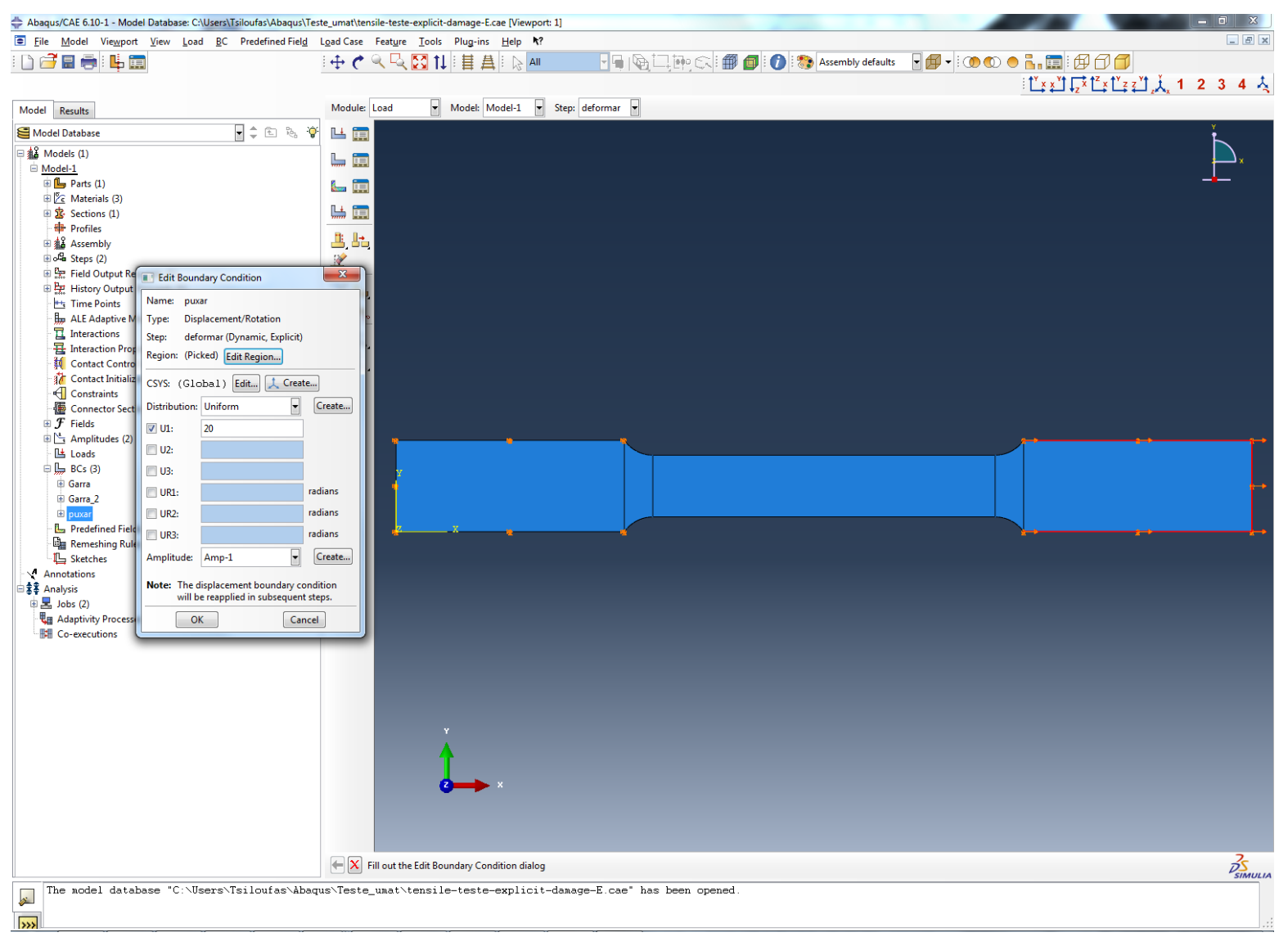

Figura F.12: Definição do deslocamento imposto à garra direita. 


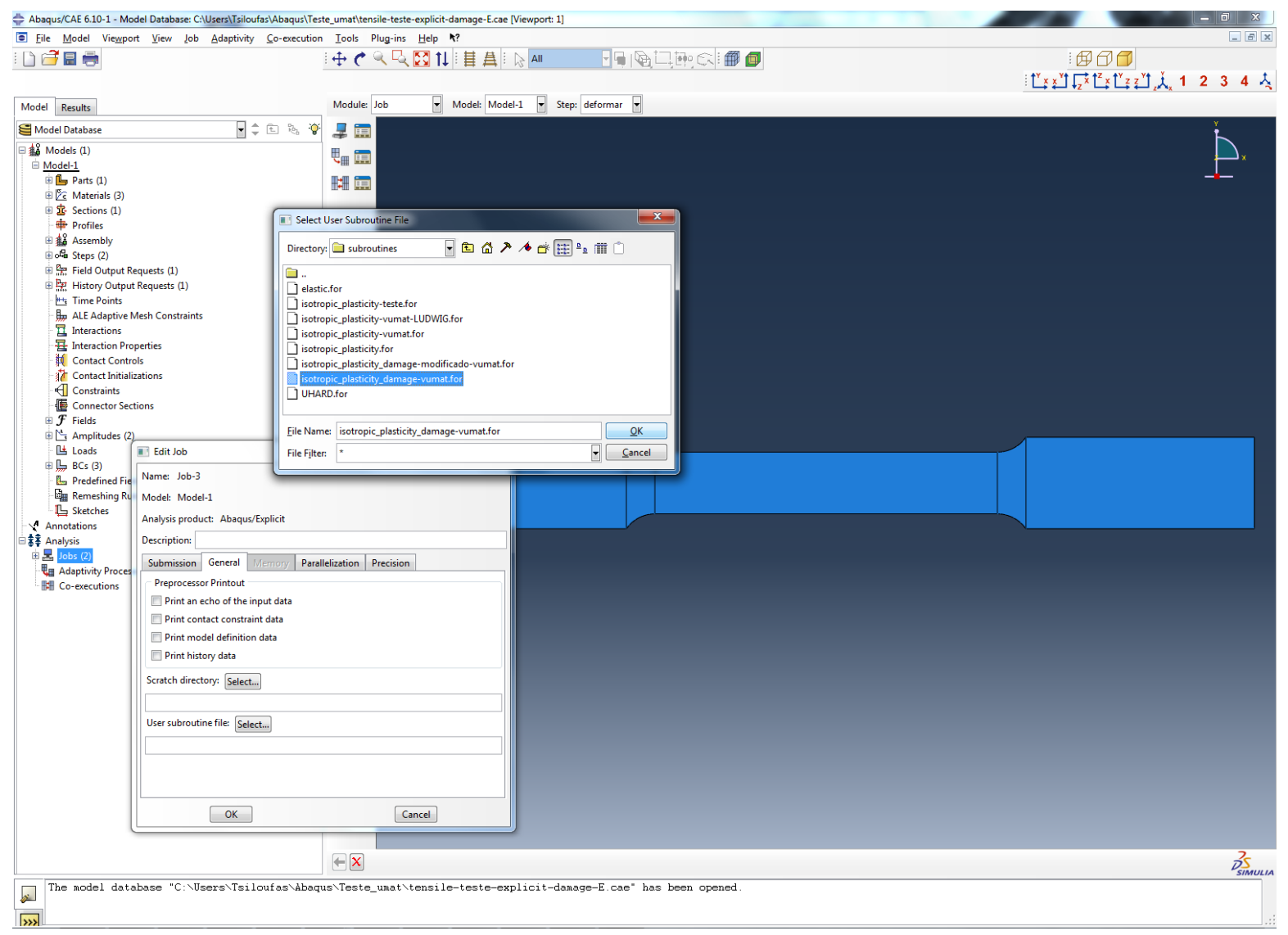

Figura F.13: Definição do job, com indicação do uso da subrotina VUMAT. 


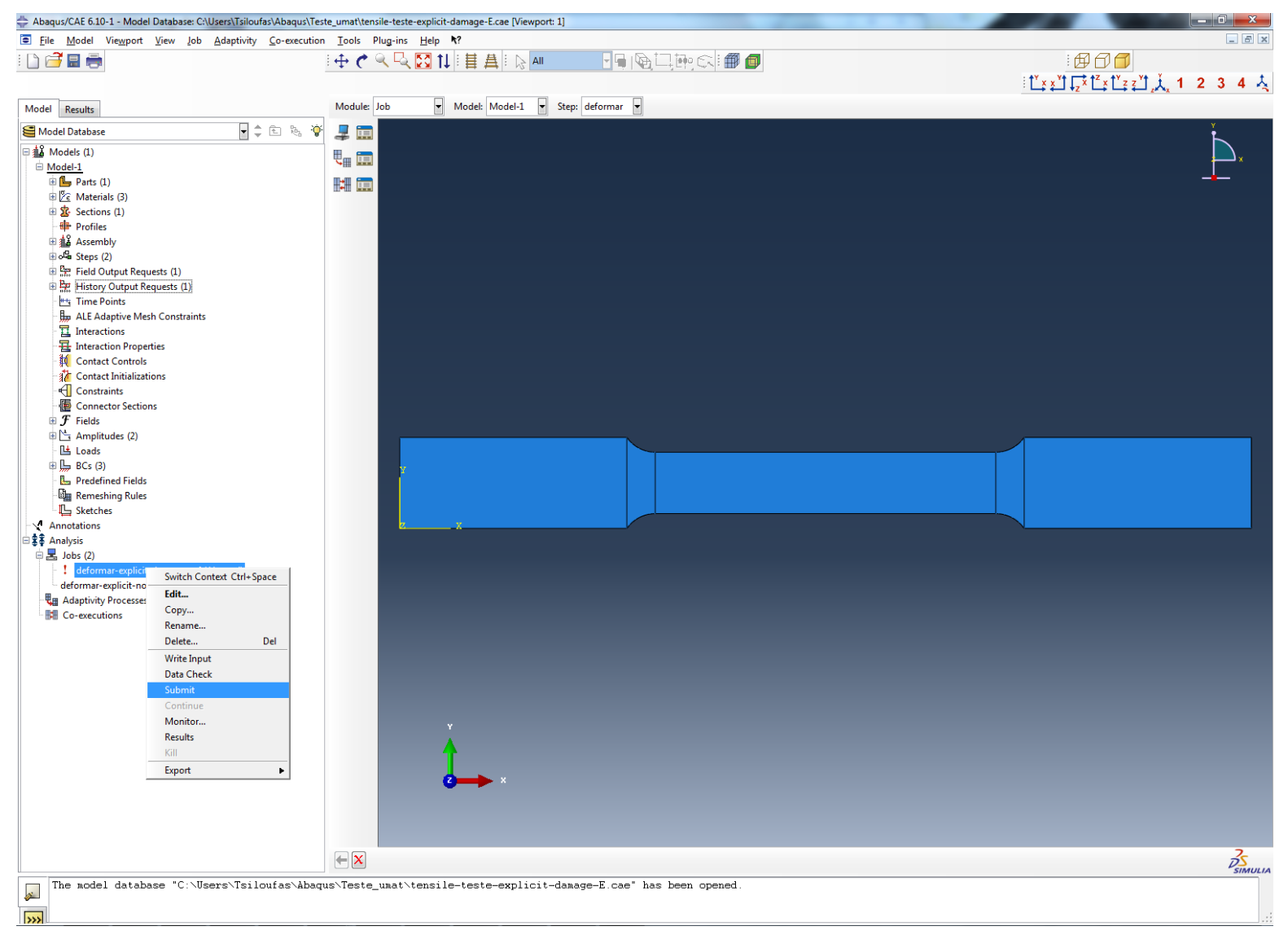

Figura F.14: Submetendo o caso para simulação. 